\title{
SMALL GROUP READ ALOUD WITH \\ NONFICTION AND FICTION LITERATURE \\ IN PRESCHOOL
}

\begin{abstract}
A Dissertation
Presented to

the Faculty of the Graduate School

at the University of Missouri-Columbia

In Partial Fulfillment

of the Requirements for the Degree

Doctor of Philosophy

by

ARIEL ROBINSON

Dr. Carol Gilles, Dissertation Supervisor
\end{abstract}

July 2018 
The undersigned, appointed by the dean of the Graduate School, have examined the dissertation entitled

\section{SMALL GROUP READ ALOUD WITH NONFICTION AND FICTION LITERATURE IN PRESCHOOL}

presented by Ariel Robinson, a candidate for the degree of doctor of philosophy, and hereby certify that, in their opinion, it is worthy of acceptance.

Professor Carol Gilles

Professor Jill Ostrow

Professor Tony Castro

Professor Louis Manfra 


\section{ACKNOWLEDGEMENTS}

Thank you to my advisor, Dr. Carol Gilles, for your dedication in guiding me through my program and dissertation. Thank you for your persistence in critiquing countless drafts and for always taking the time to sort through ideas with me. Your passion for literacy education is evident throughout your work as a teacher and scholar. It was a privilege to be your graduate assistant and to help you edit manuscripts by some of the most brilliant scholars in our field for Literacy Research: Theory, Method, and Practice. If I ever say, “It's just a few Oxford commas," please ignore me because it's not true!

I also extend my gratitude to my doctoral committee. Thank you for dedicating your careers to bettering the lives of children and youth through excellent teaching and research. Dr. Jill Ostrow, thank you for your quick work and honest feedback that brought my dissertation into sharper focus and for acting as my second reader. Dr. Tony Castro, you exude enthusiasm and can write faster on a whiteboard than any other human I have ever witnessed. Thank you for teaching me so much about case study methodology and for helping me with revisions. Dr. Louis Manfra, I fully appreciate your support for my study and your expertise with young children.

Thank you to my friends and colleagues. I am grateful for your friendship and support along the way. Selena Van Horn, you are brilliant. Thank you for your insight and mentoring. Dawn Castagno-Dysart, I am grateful that your encouragement is only a text away. Thank you to Mary Ratchford Douglass for being an intrepid world traveler who is always ready for adventure. To my fellow graduate students in the fishbowl, each of you is an inspiration to pursue excellence. To my friends Donna Sue, Alyce, Dean, and 
Nancy, thank you for bearing with me as I have forfeited countless bike rides, canoe trips, and concerts because I was studying.

Thank you to the teachers in my study for welcoming me into your classroom. I appreciate your willingness to show me how you nurture young children's literacy development. I celebrate your effort in providing a wonderful education for the children in your care. Thank you to children in my study for teaching me how you think and learn. May you all grow up to be talented readers and writers. It is my hope that this dissertation honors each of you.

I extend special gratitude to my family. I did not take this journey alone with you beside me. Thank you to my husband, Christian, for always being proud of me and for believing I am the smartest person you know. Do you remember when you told the financial aid staff you would be willing to sell your truck to pay for my education? I am also deeply grateful to my son, Hans and daughter, Rosie. You have grown up watching your mother go through school and I hope I have inspired you to dream big and work hard. We have come a long way from the days of me taping math formulas to the kitchen walls to memorize while I scrubbed the dishes. Thank you for your abiding patience as I have been in school for more than half your lives. 


\section{TABLE OF CONTENTS}

ACKNOWLEDGEMENTS................................................................

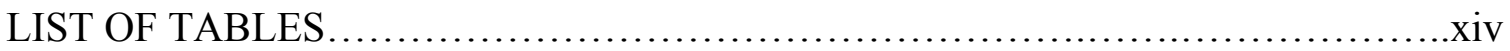

LIST OF FIGURES..............................................................

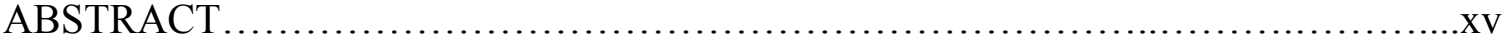

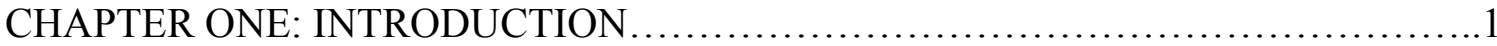

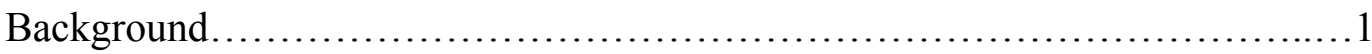

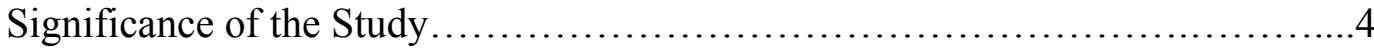

Read Aloud With Fiction and Nonfiction Literature......................4

Small Group Teaching and Learning in Preschool........................8

Scaffolding Children's Meaning Making Strategies......................11

Theoretical Underpinnings............................................... 12

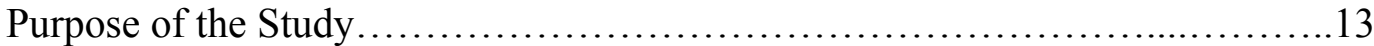

The Research Questions.................................................14

Methodological Procedures.................................................. 14

Ethical Considerations.......................................................... 15

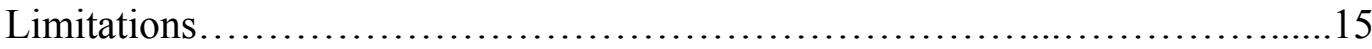

Provisions for Trustworthiness...............................................

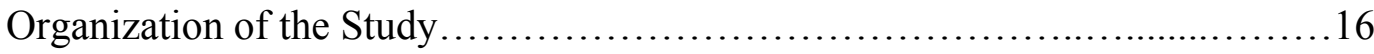

CHAPTER TWO: REVIEW OF THE LITERATURE $\ldots \ldots \ldots \ldots \ldots \ldots \ldots \ldots \ldots \ldots \ldots \ldots$

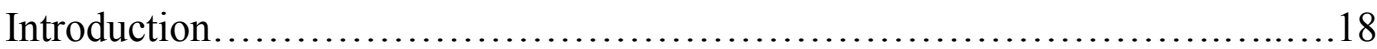

Vygotsky's Sociocultural Theory of Development.............................18

Language and Literacy Development..................................19 
Development in the Preschool Years..............................20

The Development of Scientific and Spontaneous Concepts..............21

Scaffolding in the Zone of Proximal Development.....................22

Planned Supports in the Classroom.........................24

Interactional Scaffolding................................24

Scaffolding in Preschool Classrooms.........................26

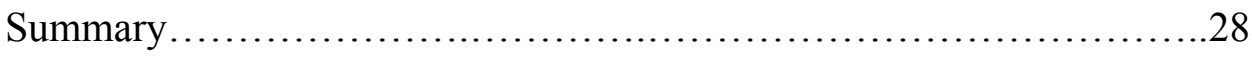

Rosenblatt's Transactional Theory of Reader Response.......................28

Efferent and Aesthetic Stances...................................29

The Efferent-Aesthetic Continuum........................30

Evocation and Reflection..........................................31

Reader Response in Early Childhood..............................31

Response to Picturebooks........................................32

Response to Fictional and Nonfiction Literature......................33

Response to Fictional Literature...........................35

Response to Nonfiction Literature.........................36

Summary......................................................

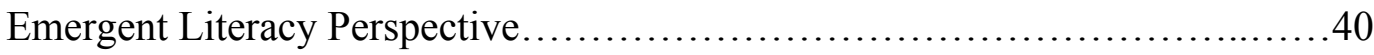

Emergent Literacy Assessment..................................41

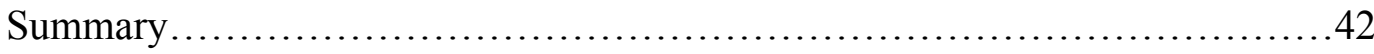

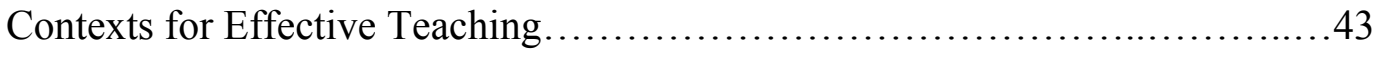

A Framework for Effective Teaching.............................43

Emotional, Organizational, and Instructional Supports...............45 
Talk in the Classroom............................................. 47

Differentiated Instruction.............................................49

Interactive Reading ................................................. 50

Children's Language Development..................................52

Children's Meaning Making...............................................52

Interactive Reading With Fiction and Nonfiction Literature...............55

Interactive Reading in Preschool......................................58

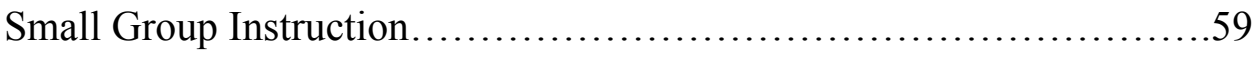

Small Group Interactive Reading..............................62

Small Groups in Preschool......................................64

Small Group Language and Literacy Instruction.................65

Small Group Instruction Across the Curriculum..................67

Social Learning Opportunities...............................68

Multiple Ages in Early Childhood Classrooms...........................68

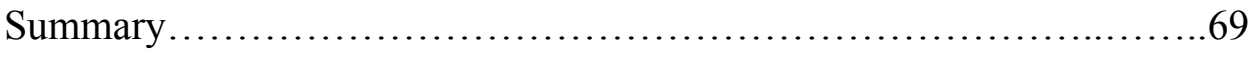

Summary of Chapter Two.................................................. 71

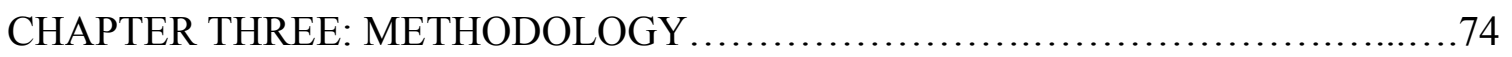

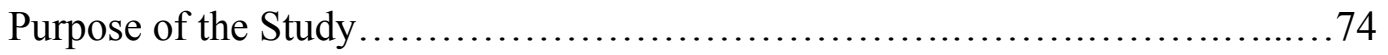

Research Questions..................................................... 74

Methodological Frameworks................................................ 75

Social Constructivism............................................. 75

Instrumental Case Study ........................................ 76

Constant-Comparative Analysis.....................................77 


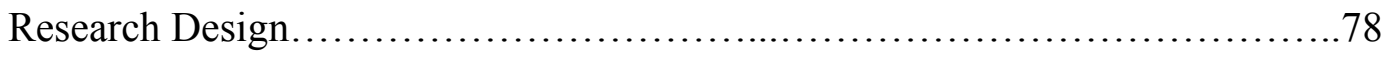

Considerations for Child Study ...................................... 78

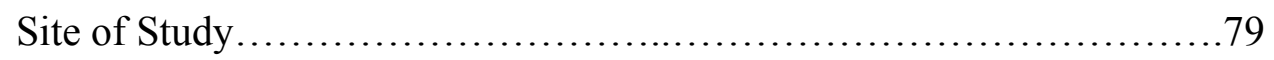

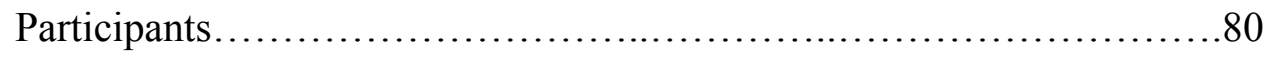

Classroom Environment................................................ 80

Researcher Role................................................. 81

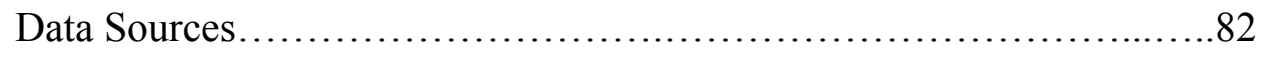

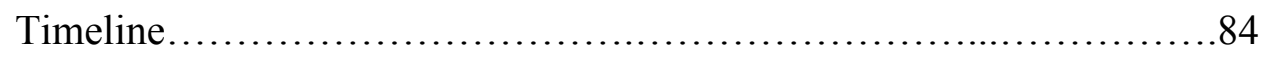

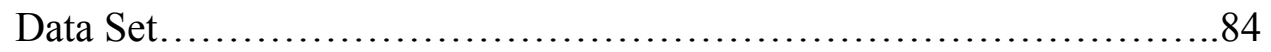

Read Aloud Books.............................................. 85

Teacher Interviews......................................... 85

Observation of Small Group Reading Sessions...................86

Observation of Teacher Planning Sessions........................87

Collection of Teacher-Created Artifacts.......................87

Child Interviews............................................ 87

Logs: Analytic Memos and Reflections.........................88

Data Analysis................................................... 88

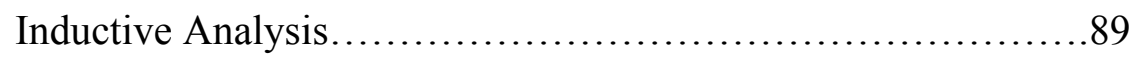

Data Triangulation............................................... 91

Theory Triangulation............................................. 91

Ethics and Positionality ................................................ 92

Research in Early Childhood Classrooms...............................92

Consent to Conduct Research.........................................93 
Positionality. 94

Provisions for Trustworthiness......................................94

Limitations........................................................ 96

Summary of Chapter Three......................................................

CHAPTER FOUR: RESEARCH FINDINGS........................................99

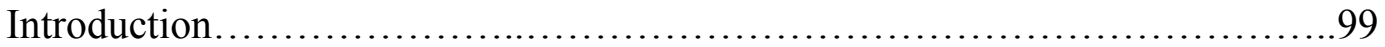

Section I: The Classroom Context.............................................100

The Teachers....................................................

The Children........................................................... 102

The Families............................................................. 104

The Curriculum.................................................... 104

Teachers Designed Curriculum................................105

Teachers Chose Books and Activities....................107

Teachers Planned Small Group Reading and Response..107

Section II: Small Group Read Aloud With Fictional and

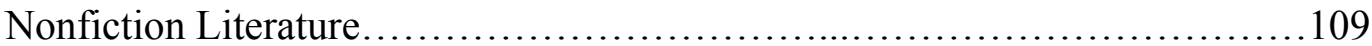

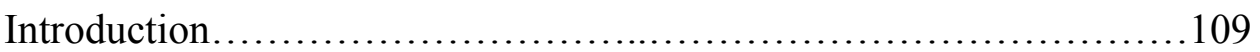

Small Group Read Aloud With Fictional Literature.......................109

Small Group Read Aloud With Dewey: There's a Cat in the

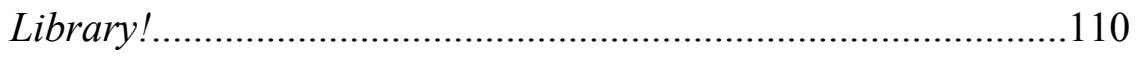

Analysis..............................................116

Kailee Scaffolded Children's Meaning Making of the Text in Different Ways.....................116 
Children Were Becoming Strategic Readers by Integrating Information From Pictures and Their

Background Knowledge.

Children Moved Along the Efferent-Aesthetic Continuum to Make Sense of New Information in the Text......................................118

Small Group Read Aloud With Lucy's Picture.................119

Analysis

Kailee Utilized Various Teaching Moves That

Scaffolded Children's Meaning Making....

Kailee Supported Children's Aesthetic Stances.. 124

Older Children Served as Peer Models for Their

Younger Classmates

Small Group Read Aloud With Nonfiction Literature..................125

Small Group Read Aloud With Patterns at the Museum..........125

Analysis.

Kailee Scaffolded Children's Interpretations of

Patterns.

Older Children Served as Peer Models for Their

Younger Classmates

Kailee and the Children Took a Predominantly

Efferent Stance Toward the Text

Small Group Read Aloud With One Tiny Turtle. 
Analysis

Becky Utilized Various Talk Moves to Scaffold

Children's Comprehension

Children Shifted Along the Efferent-Aesthetic

Continuum.................................. 138

Integration of Episodic Analyses With Interview Data..................139

Introduction............................................. 140

Teachers' Strategies for Both Fictional and Nonfiction Texts....140

Teachers' Strategies Unique to Fictional and Nonfiction Texts..142

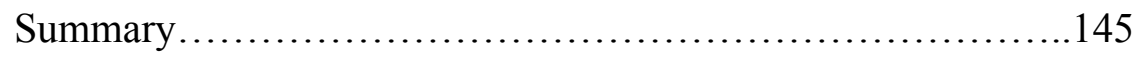

Children's Reading Strategies............................. 146

Older Children Served as Peer Models for Younger Children....149

There Were Differences Between Teachers and Children's

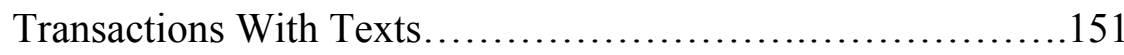

Section III: Scaffolding and Modeling Strategies With Nonfiction Literature...155

Introduction............................................... 155

Reading I: A Listen to World Music..............................157

Analysis.................................................163

Scaffolding Techniques With Both Children.............163

Scaffolding for Individual Children..................167

Michael.....................................167

Lucy....................................168

Modeling Reading Strategies.........................171 
Summary 173

Reading II: A Listen to World Music....................................173

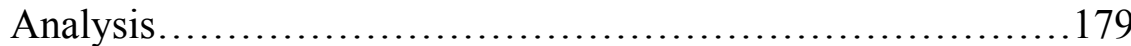

Scaffolding for Both Children.........................180

Becky Encouraged Peer Tutoring.......................182

Scaffolding for Individual Children.....................183

Thanom..........................................183

Amelia.......................................... 184

Summary....................................................

Integration of Episodic Analyses With Interview Data...................187

Introduction.............................................. 187

Becky's Scaffolding of Strategies Across Both Reading

Episodes................................................... 187

Becky's Modeling of Strategies Across Both Reading

Episodes..................................................190

Becky Scaffolded a Limited Repertoire of Strategies for the

Younger Children

Becky Scaffolded a Wider Range of Strategies for the Older

Children

Summary 196

Summary of Chapter Four. .196

CHAPTER FIVE: PURPOSE, SUMMARY OF PROCEDURES, ANALYSIS OF FINDINGS, IMPLICATIONS, AND FINAL REFLECTION. 


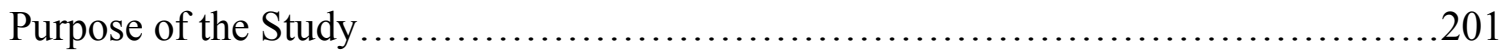

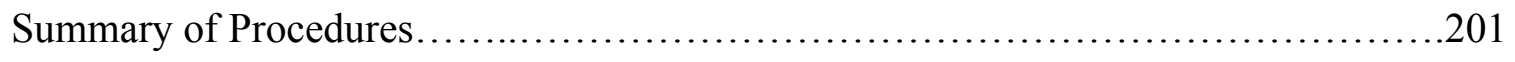

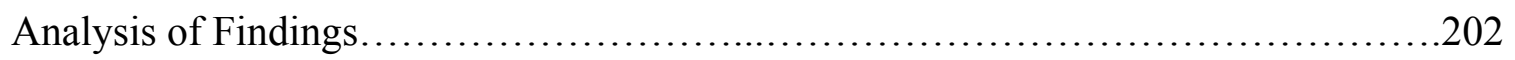

Sociocultural Analysis of Findings.......................................204

Transactional Reader Response Analysis of Findings...........................206

Emergent Literacy Analysis of Findings....................................208

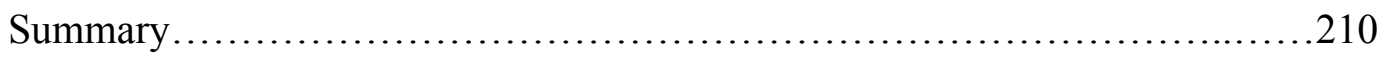

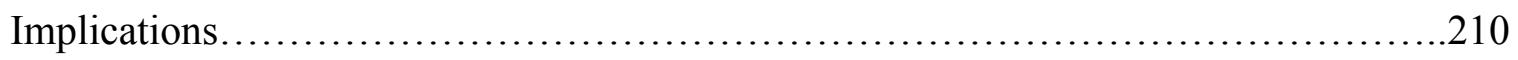

Implications for Future Research......................................210

Read Aloud of Fiction and Nonfiction Texts With

Different Populations...........................................210

Repeated Readings of Nonfiction Literature..........................211

Large Versus Small Group Reading.................................211

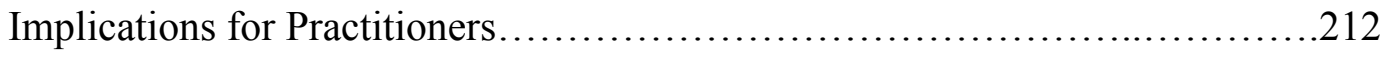

Implications for Preschool Teachers.................................212

Choose Fictional and Nonfiction Literature for the

Preschool Classroom........................................212

Read Nonfiction With Preschoolers...........................214

Differentiate Instruction for Younger and Older Preschoolers...215

Read on the Efferent-Aesthetic Continuum....................216

Implications for Preschool Administrators.............................216

Implications for Early Childhood Teacher Education Faculty ....................216

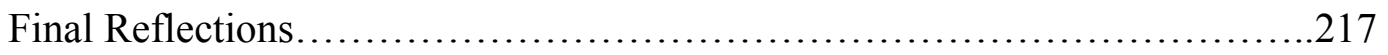



A. Letter of Support From the Laboratory School
B. Parent Informed Consent Letter
C. Classroom Configuration
D. Teacher Read Aloud Books and Activities
E. Data Sources Table
F. Sample of Teacher Interview Protocols
G. Sample of Weekly Lesson Plans
H. Daily Schedule

I. List of A Priori Child Interview Questions

J. Sample of Coded Log: Analytic Memo and Reflection

K. Sample of Coded Teacher Interview

L. Sample of Coded Read Aloud Session

M. The Creative Curriculum ${ }^{\mathrm{TM}}$ Overview

N. Types of Scaffolding That Occurred During Read Aloud Sessions 


\section{LIST OF TABLES}

Table 1: Research Questions and Data Sources............................................................83

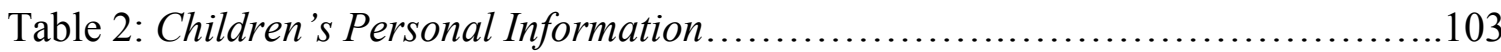

Table 3: Teachers' and Children's Reading Strategies.............................203

\section{LIST OF FIGURES}

Figure 1. Grace laughs at Dewey's antics...................................... 113

Figure 2. Julia and Alexandra inspect the illustrations........................... 122

Figure 3. Willow points to a color pattern as Kailee and Michael observe .............127

Figure 4. Tommy points to a window while Kailee and Alexandra observe...............129

Figure 5. Lucy makes the sign for turtle while Becky reads.........................135

Figure 6. Ava points to a seashell on the last page of the story......................137

Figure 7. Becky shows Lucy and Michael the book title.............................. 158

Figure 8. Amelia points to the mariachi band while Thanom observes..................178 


\author{
SMALL GROUP READ ALOUD WITH \\ NONFICTION AND FICTION LITERATURE \\ IN PRESCHOOL \\ Ariel Robinson \\ Dr. Carol Gilles, Dissertation Supervisor
}

\begin{abstract}
The purpose of this study was to investigate teacher's roles and children's responses during small group read aloud with fiction and nonfiction literature in one preschool classroom. This instrumental case study draws from three theoretical orientations: sociocultural theory, reader response theory, and the emergent literacy perspective. Two preschool teachers and 19 children were video and audio recorded as they participated in small group read aloud events that occurred during choice time in their classroom twice per day. Transcripts of interviews and small group read aloud sessions were analyzed. Analysis included open coding, axial coding, and constantcomparative techniques to reach data saturation.

Research findings suggest that teachers employed similar and different scaffolding and modeling strategies when reading fictional and nonfiction literature, differentiated instruction for younger and older children, as well as responded aesthetically to fictional stories and efferently to nonfiction texts. Children utilized a range of meaning making strategies and responded both aesthetically and efferently to both types of text. Older children served as peer models for their younger classmates.

This study has several implications. Future research should investigate read aloud with fiction and nonfiction literature with different populations of teachers and children,
\end{abstract}


repeated readings of nonfiction literature, and large versus small group read aloud in preschool. Implications for preschool teachers include careful selection of fiction and nonfiction literature, employing additional reading strategies for nonfiction, differentiating instruction for younger and older preschoolers, and reading across the efferent-aesthetic continuum with both types of text. Preschool administrators should make reading instruction with fiction and nonfiction texts a priority. Early childhood teacher education faculty can support preservice teachers' capacities to read fiction and nonfiction literature with children.

Keywords: Sociocultural theory, transactional theory, emergent literacy, read aloud, small groups, nonfiction, fiction, preschool 


\section{CHAPTER ONE: INTRODUCTION}

\section{Background}

Reading books aloud to young children has long been a cherished activity for me. I value read aloud because it is a social event in which children and teachers come together to explore wonderful stories and adventures. It expands children's worlds as they encounter things, ideas, places, people, and happenings that extend beyond their immediate experiences. Books help children learn about their social worlds: family life,

friendships, going to school, life's bittersweet moments, as well as things that exist only in the imagination. Huck (1990/1998) articulates how great books "take you out of yourself and return you to yourself - a changed self' (p. 4). Literature helps us to understand what it is to be human, to realize connections among people, develop social imagination, and vicariously participate in the experiences of others.

As a preschool teacher, I reflected on my own attitudes toward reading different texts to my young students. When reading fictional stories, I felt confident and enthusiastic. I read with expression, offered my own commentary, and encouraged children to think deeply about characters' feelings and perspectives as well as critically evaluate their actions. Children related to characters and took up dramatic enactments. They offered their own insights and connected story events to their personal experiences. They appeared to relish these readings and often asked to me to reread stories featuring their most beloved characters.

As a preschool teacher, I regularly read aloud to groups of children. When I read aloud to the whole class, it was difficult to manage the large group if I permitted children to talk while I was reading. Individual children sometimes made tangential comments or 
told long personal stories. It was impossible to answer everyone's questions or give them a chance to speak. Other children's attention seemed to wane since they were expected to sit silently and listen. Only children sitting close to the book could see the pictures.

As a component of our curriculum, my co-teachers and I read aloud to small groups of preschoolers every day. This grouping structure was more manageable than large group. Small group read aloud was interactive as children huddled close; they frequently pointed to pictures, asked questions, and commented on pictures or story events. Each child had the chance to participate in the conversations that regularly took place at these times. I knew that small group read aloud was an important part of the curriculum because we explored many topics in our stories that are important to young children such as family, friendship, pets, school, seasons, holidays, and celebrations. Our conversations touched on loss and sadness, hurt feelings, good and bad choices, and other struggles young children might experience.

While I loved reading fictional literature aloud, I rarely chose to read nonfiction with my young students. I did not know how to keep children interested and engaged in meaningful dialogue around these texts. Many of the nonfiction texts in my classroom contained long passages; they were "wordy." It seemed like my young listeners' attention would wander after a few pages and we were unable to persevere through an entire book. I felt less sure about the best ways to read these texts with my young students. Would children notice if I didn't read every word? After all, wasn't I supposed to be drawing children's attention to print and modeling speech-print matching? Which parts of the text should I read and which can I omit? Is it okay for teachers to "read the pictures" just like children? Clearly, I had more questions than answers. 
Although I rarely read nonfiction literature aloud, my co-teachers and I made these texts available to our young students. We knew that nonfiction literature contains interesting content so we stocked them in the classroom library and placed them throughout the room. Children often chose nonfiction to share with friends and I noticed their excitement as they responded enthusiastically to the pictures. Although I was uncomfortable reading most nonfiction aloud, I knew children were capable of engaging with these texts and some children seemed to prefer them. Not only were children captivated by the pictures, I knew that informational materials were important sources of new vocabulary and content.

As a component of my doctoral coursework, I conducted a class project in which I read a fictional story and nonfiction book with one preschooler, a five-year-old girl, and wrote a report on the similarities and differences between the two readings. She chose a familiar fictional text and read the pictures to tell the story. As we read the nonfiction book, she immediately began to point to photographs, ask questions, and enthusiastically share personal connections to the topic. I could barely read the words on the page because she interjected constantly and blocked the words with her hand as she pointed to the photographs. From this experience, I realized that reading fiction and nonfiction with her required different techniques and that it was possible for young children to become highly engaged during read aloud with nonfiction literature.

Later, I conducted a pilot study in which I examined how a preschool teacher designed curriculum during one unit of study (forest animals) and read nonfiction books with small groups of four-and five-year-old children. The teacher engaged children by asking about their background experiences with the book topic and welcomed their 
participation as conversational partners. Similar to my prior experience, nonfiction books elicited elaborative dialogue as children frequently commented, pointed to pictures, and shared their personal experiences.

\section{Significance of the Study}

\section{Read Aloud With Fiction and Nonfiction Literature}

Reading aloud to children is one of the most widely embraced and enduring teaching practices, especially in early childhood education. Read aloud is generally viewed among early childhood educators as essential for fostering young children's literacy development. In fact, some reading experts claim that reading aloud to children, especially preschoolers, is "The single most important activity for building the knowledge required for eventual success in reading" (Anderson, Hiebert, Scott, \& Wilkinson, 1985, p. 23). These scholars also claim that the benefits of reading aloud to preschoolers "are greatest when the child is an active participant, engaging in discussions about stories, learning to identify letters and words, and talking about the meanings of words" (p. 23). Children are enabled to become active participants when adults adopt an interactive reading style (Blewitt \& Langan, 2016; Milburn, Girolametto, Weitzman, \& Greenberg, 2014). Interactive read aloud is a complex event in which adults use voice and other modes, such as facial expressions and gesture, to interpret text and facilitate children's responses (May, 2011). It serves as a context for co-constructing meaning through dialogue and multimodal response and as a means of building upon and extending, children's knowledge (Adomat 2009, 2010; Wiseman, 2011).

The practice of reading interactively with young children has strong support from the body of literature (Beck \& McKeown, 2001; Fisher, Flood, Lapp, \& Frey, 2004; 
Freebody \& Luke, 2003; Kimmel \& Segel, 1988; Klesius \& Griffith, 1996; Meyer, Wardrop, Stahl, \& Linn, 1994; Morrow, 2003; Richardson, 2000; Trelease, 1979). However, most studies have focused nearly exclusively on the reading of fiction as opposed to other types of children's literature, such as nonfiction (see Duke, 2003; Heisey \& Kucan, 2010; Maloch, 2008; Mantzicopoulos \& Patrick, 2010; Moschovaki \& Meadows, 2005; Pappas, 2006; Pentimonti, Zucker, Justice, \& Kaderavek, 2010; PollardDurodola et al., 2011; Price, Bradley, \& Smith, 2012; Price, van Kleek, \& Huberty, 2009; Smolkin \& Donovan, 2001; Torr \& Clugston, 1999; Tower, 2002; Webster, 2009 for exceptions). Some reasons for this discrepancy might be that fictional texts are prevalent in many early learning environments and early childhood teachers overwhelmingly prefer fiction to read aloud to their young students (Duke, 2000; Hindman, Connor, Jewkes, \& Morrison, 2008; Yopp \& Yopp, 2006, 2012). Scholars have found that some early childhood teachers are reluctant to read nonfiction books to their young students; teachers have expressed limited familiarity with informational materials and concern students are disengaged (Pentimonti et al., 2010). Price et al. (2012) reported teachers conveyed less enjoyment and confidence when reading nonfiction texts compared to fictional books.

Nearly 20 years ago, Duke (2000) investigated the scarcity of nonfiction texts in 20 first grade classrooms over 79 school days and found that only 3.6 minutes per day were spent interacting with written informational texts (nonfiction). Moreover, classrooms contained minimal informational environmental print: an average of $2.6 \%$ of texts displayed on the walls and an average of $9.8 \%$ of texts in classroom libraries. Duke (2000) also reported fewer nonfiction texts in classrooms with predominantly low-income children. Since there were more children enrolled in those classes, there were far fewer 
informational materials per child. Duke (2000) noted students seemed engaged with the few nonfiction books from which to choose during sustained silent reading (SSR), suggesting that children read these texts when they were available.

Subsequent studies are consistent with Duke's finding that nonfiction is underrepresented in early childhood classrooms. Preschool teachers also choose fiction for read aloud much more often than nonfiction (Hindman et al., 2008; Yopp \& Yopp, 2006; 2012). Yopp and Yopp (2006) found preschoolers have far less exposure to nonfiction than fictional literature. In a two-part study, they documented $8 \%$ of the books read aloud in preschool classrooms and $7 \%$ of the books read aloud to kindergarteners at home were informational. These researchers concluded nonfiction texts were scarce at home and school for the children they studied. Pentimonti et al. (2010), who sought to replicate Yopp and Yopp's (2006) study, reported that the preschool teachers they observed read nonfiction texts (expository and mixed) aloud about $17 \%$ of the time. Pentimonti, Zucker, and Justice (2011) reported 14\% of texts read aloud in preschools serving mostly lowincome children were nonfiction (mixed and informational/non-narrative). Yopp and Yopp (2012) documented 9\% of texts read aloud by preschool through third grade teachers were nonfiction (mixed and informational/non-narrative). They found no statistically significant difference among grade levels. After 600 hours of observations in 55 kindergarten classrooms, Wright (2014) documented that kindergarten teachers spent $83 \%$ of read aloud time reading fiction (17\% nonfiction). Almost $60 \%(58.5 \%)$ of the teachers in the study did not read any nonfiction aloud. These studies suggest the situation has not improved since Duke's (2000) investigation nearly 20 years ago. Fiction continues to dominate the landscape of early childhood classrooms. 
Fictional stories help children learn about human nature to better understand themselves and others. Fiction, which is "not intended to be a literally true depiction of reality" (Hopkins \& Skolnick Weisberg, 2016, p. 50), enables children to draw from their social experiences as they analyze characters and story events. Loizou and colleagues (2011) indicate, "Stories are essential for the emotional, cognitive, and social development of children as well as their literacy development" (p. 73). Stories lend themselves to inferring as children interpret characters' feelings and perspectives based on the written text and illustrations, relate to characters' mental states and emotions, as well as consider changes characters undergo (Torr \& Clugston, 1999; Wiseman, 2011). Children might empathize with a character in familiar scenarios or experience vicariously situations different from their own experiences. They can apply these understandings and skills to future literacy learning as they encounter more complex characters, detailed settings, and complex plot lines, which require more proficient inferring to make sense of the text.

Pappas (1991) indicates children need exposure to a range of texts and that the exclusive reading of fictional stories is inadequate for their literacy development. Nonfiction literature, which is "intended to depict only the truth about something that actually happened" (Hopkins \& Skolnick Weisberg, 2016, p. 50), offers rich and exciting opportunities for young children to expand their knowledge of their physical and social worlds as they learn about their immediate environments and explore new topics (Duke, 2000). Nonfiction literature provides important sources of knowledge children might not learn from fictional texts (Duke, 2000; Richgels, 2002).

Young children often have far more experience with fictional stories than nonfiction, which could negatively impact their school performance because the ability to 
successfully engage with nonfiction texts is central to school achievement (Duke, 2000). Increased content knowledge is linked to better reading comprehension (Duke \& Block, 2012). Kraemer, McCabe, and Sinatra (2012) indicate nonfiction texts have the potential to support children's comprehension and future learning. They found children who listened to informational reading scored higher on nonfiction text comprehension assessments than children who listened only to fictional stories. Duke (2000) speculated students' low achievement in content area reading might be attributed to a lack of experience with nonfiction literature and called for increased attention to informational reading in early childhood classrooms.

This lack of experience might lead to what Daniels (1990) termed the "expository gap" (p. 107). This gap widens as children progress through school and are expected to read and produce nonfiction texts proficiently. Sanacore and Palumbo (2009) suggest the lack of exposure to nonfiction during the early school years leads to the "fourth grade slump" (Chall, 1983), in which some students begin to struggle with content area reading in the upper elementary grades. Some researchers indicate increased immersion in nonfiction reading with a focus on content learning and comprehension in early childhood education might help alleviate the fourth grade slump (Hirsch, 2003; Kraemer et al., 2012; Sanacore \& Palumbo, 2009). Some scholars claim the ability to read and write nonfiction texts is key to success in school and work (Hirsch, 2003; Venezky, 2000).

\section{Small Group Teaching and Learning in Preschool}

Small groups are an ideal setting for teaching and learning in preschool (Blewitt \& Langan, 2016; Piasta \& Wagner, 2010; Pollard-Durodola et al., 2016; Roberts \& Neal, 2004; Sin Goh, Yamauchi, \& Ratliffe, 2012; Tompkins, Zucker, Justice, \& Binici, 2013). 
They enable children to have close proximity and frequent interactions with their teacher (Girolametto, Hoaken, Weitzman, \& van Lieshout, 2000). Young children also have the chance to participate in social learning in which they exchange ideas, collectively solve problems, share materials, and engage in conversations with their peers (Morrow, 2007; Morrow \& Smith, 1990; Schreiber \& Valle, 2013; Wasik, 2008). When children are in multi-age and mixed ability small groups, younger children have the chance to observe their slightly older peers who can serve as models and might be operating in their zone of proximal development (Wasik, 2008). Meanwhile, older peers might assume leadership roles.

Preschool teachers can utilize effective strategies in small groups through instructional conversations (Collins, 2010; Sin Goh et al., 2012). This strategy entails teaching through dialogue and avoiding the Initiation-Response-Evaluation (I-R-E) pattern in which the teacher initiates responses from students and follows with an evaluation of students' replies (Cazden, 2001; Mehan, 1979). In instructional conversations, teachers engage children in genuine discussions about the text through elaborative dialogue (Girolametto \& Weitzman; 2002; Tompkins et al., 2013).

Scholars have found that small group contexts are beneficial for supporting learning in many areas of the preschool curriculum (Klein, Starkey, \& Wakeley, 2004, Martins, Salvador, Albuquerque, \& Silva, 2016; Morrow, 2007; Piasta \& Wagner, 2010; Pollard-Durodola et al., 2016; Ramani, 2012; Roberts \& Neal, 2004). Small groups are an appropriate setting for language and literacy instruction in preschool (Martins et al., 2016; Piasta \& Wagner, 2010; Roberts \& Neal, 2004). Teaching and learning in this setting has been found to be effective for alphabetic learning (Piasta \& Wagner, 2010), English 
language listening comprehension (Roberts \& Neal, 2004), invented spelling, (Martins et al., 2016), and letter and word recognition (Connor, Morrison, \& Slominski, 2006).

Small groups are also beneficial for students from special populations, such as supporting the language and literacy development of emergent bilingual preschoolers (Magruder, Hayslip, Espinoza, \& Matera, 2013) and children with special needs. Urlacher, Wolery, and Ledford (2016) found that preschoolers with disabilities named more sight words and labeled items used during small group activities whereas Aldemir and Gursel (2014) documented how young children with disabilities learned from peers in small groups. Ledford and Wolery (2015) found that preschoolers with disabilities practiced social skills by sharing materials more in small groups than other times of the day.

While small group teaching and learning has been found to be an appropriate setting for instruction across the preschool curriculum, little is known about small group interactive read aloud and the exchanges among teachers and children that take place in this grouping structure. Studies that inquire into small groups as a context for assessment are also scarce. In this inquiry, I examine the affordances of small groups for teacherlearner interactions as teachers read fiction and nonfiction literature and support children's meaning making as well as responses to literature across the efferent-aesthetic continuum.

\section{Scaffolding Children's Meaning Making Strategies}

Interactional scaffolding is the responsive supports a more knowledgeable individual provides to a learner during teaching and learning (Athanases \& de Oliveira, 2014; Reynolds, 2017). van de Pol, Volman, and Beishuizen (2010), describe three common characteristics of interactional scaffolding: contingency, fading, and transfer of 
responsibility. Scaffolding supports must be contingent and responsive to children's needs, the teacher gradually withdraws supports as learners demonstrate competence, and learners become increasingly independent. Scaffolding is an effective teaching technique when teachers are sensitive and responsive to preschoolers' learning and developmental needs (Hsin \& Hsin-Kai, 2011). Preschool teachers can utilize a range of scaffolding strategies to support their young students' learning (Zurek, Torquati, \& Acar, 2014). These strategies include activating children's prior knowledge, recalling previous experiences, eliciting inferences and predictions, and prompting children to attend to certain objects in their environments. Teachers successfully use contextualizing (bridging the unfamiliar to the familiar) and de-contextualizing (distancing, generalizing) strategies to help children make connections between their experiences and the larger world. Preschool teachers can scaffold children's responses by questioning and commenting, and by offering feedback and elaborating on children's ideas during instructional conversations. Scaffolding also takes place when teachers assume active roles through coparticipation and collaboration as they work with children on joint tasks (Zurek et al., 2014).

While scaffolding is an effective teaching strategy in preschool, few studies address the role of scaffolding in supporting preschoolers' meaning making during small group read aloud. Studies of scaffolding in preschool tend to focus on targeted skills-based instruction such as counting, letter recognition, phonemic awareness training, as well as vocabulary acquisition. In this study, I examine the complexities in the interactions between teachers and learners as teachers support children's meaning making strategies.

\section{Theoretical Underpinnings}


This study draws from multiple theories that address different developmental processes and constructs. Vygotsky's (1930/1978) sociocultural theory of child development emphasizes the social and cultural influences on learning and cognitive development. According to Vygotsky's (1930/1978) notion of the zone of proximal development (ZPD), instruction is most effective when new skills are introduced that are just beyond a child's ability to complete independently. With scaffolding, the child is able to learn these skills, which would have otherwise been out of reach. Sociocultural theory provides a lens for studying the nature of teaching and learning that occurred through interactions during small group read aloud.

Rosenblatt's (1978) transactional theory of reader response alleges that many factors affect readers' interpretations of texts. These include readers' cultures, personal histories and experiences, beliefs and values, and internal states. Readers also respond along the efferent-aesthetic continuum as they encounter different ideas in the text (Rosenblatt, 1998). When readers take an aesthetic stance, they turn inward toward their own feelings. They take on perspectives of people and characters. Readers respond efferently when they seek information to gain knowledge. Efferent responses do not evoke strong feelings like aesthetic responses. Rosenblatt's transactional theory of reader response enables me to gain insight into the types of responses teachers and children display as they read together in small groups.

The emergent literacy perspective also informed this inquiry. From this view, children begin to develop language and literacy long before they are able to speak, read, and write conventionally (Teale, 1986; Whitehurst \& Lonigan, 1998). Moreover, these early developments provide the essential foundation for later language and literacy 
learning. In our culture, emergent literacy entails a range of developments in oral language use, vocabulary development, alphabetic knowledge, book-handling skills, as well as meaning making strategies when interacting with literature. Emergent writing includes ascribing meaning to drawings, letters, and other marks, and writing for different purposes. The children in my study are in the emergent phase of language and literacy development. From this perspective, the language and literacy behaviors the children in my study, who are aged two-and-half to five years, are meaningful and vital to their development.

\section{Purpose of the Study}

This study emerged from my lingering questions during my time as a preschool teacher and it serves several purposes. The first purpose was to develop a deeper understanding of the responses among preschoolers, aged two-and-a-half to five years, and their teachers as they read fiction and nonfiction together in small groups. I aimed to learn about the strategies preschool teachers used to engage their young students with fiction and nonfiction and how they modeled and scaffolded meaning making strategies. I also sought to discover the stances preschool teachers and children took as they read fiction and nonfiction literature. I analyzed their talk and other modes of response (e.g., gesture, emotion) to gain insight into their meaning making processes.

\section{The Research Questions}

The purpose of this inquiry was to investigate the strategies preschool teachers employed when reading fictional and nonfiction literature with small groups of preschoolers ages two-and-a-half to five years, as well as the stances teachers and children took when reading both types of text. The following broad research question guided this 
inquiry: What are teachers' roles and children's responses during small group read aloud with fiction and nonfiction texts for children ages two-and-a-half to five years old in one preschool classroom? For a deeper exploration of this question, the following sub-questions were investigated:

1. How do children respond during small group read aloud?

2. How do teachers use modeling and scaffolding during small group read aloud to elicit children's responses?

\section{Methodological Procedures}

This qualitative study was based on a few methodological paradigms and traditions including a social constructivist or interpretivist orientation (Denzin \& Lincoln, 2011) and instrumental case study methodology (Stake, 1995). I collected data in one multi-age preschool classroom, four to five days per week, for six weeks. Participants included two teachers and 19 children ages two-and-a-half to five years. Data collection procedures were consistent with qualitative methodology and comprised interviews, observations, and photographs of teacher and child-created artifacts. In this instrumental case study (Stake, 1995), the teachers and children who participated in small group read aloud were the bounded system. Data analysis consisted of constant-comparative methods (Glaser \& Strauss, 1967; Saldaña, 2016; White \& Marsh, 2006).

\section{Ethical Considerations}

I obtained Institutional Review Board (IRB) and school administrative approval to conduct research at the site. Two classroom teachers and the parents of 19 children in one preschool classroom gave signed consent to participate. Since the children were very young, I obtained their verbal assent. Researching young children requires sensitivity to 
children's immediate needs, maintaining confidentiality, and using extreme caution to avoid coercion (Castle, 2012; Mertler, 2009). Conducting research in a space where individuals are living their everyday lives also carries a unique set of ethical considerations. As an observer-participant (Leavy, 2017; Merriam, 2009), it was essential that I adopt an ethic of care and respect. I interacted in a warm and professional matter, remained as unobtrusive as possible, and withheld evaluation of all participants.

\section{Limitations}

I acknowledge the limitations of this study, which are common in qualitative research. Since I was the research instrument, data collection, analysis, and reporting were subject to my personal biases. Reliability, validity, and generalizability were not established due to the purposive sampling (Bogdan \& Biklen, 1998; Lavrakas, 2008) of a small number of participants. I did not conduct member checking as a means to ensure I had accurately represented participants' views and experiences. However, I summarized their statements during interviews to verify their intents.

\section{Provisions for Trustworthiness}

Throughout the research and reporting processes, I addressed the four criteria for establishing trustworthiness (Lincoln \& Guba, 1985): credibility, dependability, confirmability, and transferability. I established credibility through "persistent observation" (p. 30), utilizing multiple data collection methods, and triangulation of data. I addressed dependability by engaging in a deep and thorough investigation and describing my research processes and findings in detail. I established confirmability by using participants' words and actions. In regard to transferability, findings were reported in 
sufficient detail so that others who read this research report might apply the findings to similar contexts.

\section{Organization of the Study}

In adhering to the traditional protocol, this dissertation is divided into five chapters. Chapter One provides an introduction to the study and an overview of research processes. Chapter Two comprises a review of the extant literature relating to key theoretical orientations and various contexts for effective teaching. Chapter Three provides an overview of the research methodology that includes the purpose of the study, research questions, methodological frameworks, a description of the research design, a discussion of ethics, provisions for trustworthiness, and limitations.

Chapter Four comprises the findings of the study. The chapter begins with the research questions and an in-depth context for the study including the teachers, children, families, and curriculum. In the next section, I examine read aloud episodes with two fictional stories and two nonfiction books to discover how teachers scaffolded and modeled reading strategies with fiction and nonfiction texts, as well as teachers' and children's responses to both types of text. In the subsequent section, I investigate one teacher's modeling and scaffolding of children's meaning making in two read aloud episodes with the same nonfiction book.

Chapter Five provides an overview of the entire research enterprise including a statement of purpose; summary of procedures; analysis of findings; analyses through the lenses of sociocultural theory, transactional theory, and emergent literacy; as well as implications for research, practitioners, and early childhood teacher education faculty. Chapter Five concludes with my final reflection on the project. 


\section{CHAPTER TWO: REVIEW OF THE LITERATURE \\ Introduction}

This study draws from multiple theoretical perspectives: Vygotsky’s sociocultural theory of development, Rosenblatt's transactional theory of reader response, and the emergent literacy perspective. The literature review concludes with an exploration of various classroom contexts for effective teaching. All theoretical perspectives foreground the influences of social interactions and culture on children's early literacy learning and development.

\section{Vygotsky's Sociocultural Theory of Development}

What the child can do in cooperation today he can do alone tomorrow --L. S. Vygotsky (1986, p. 188)

According to Vygotsky, children progress through critical periods in which their cognitive functions transform (Mahn, 2003; Vygotsky, 1930/1978). As they develop, children gain increased control of their attention and memory and are able to use more abstract reasoning rather than simply relying on sensory perception alone to make sense of their worlds. Vygotsky indicated children's development of mental functions relating to perception, memory, and concept formation appears twice: first in the social environment (interpsychologically, between people) and then internally (intrapsychologically, within the child) (Vygotsky, 1981, 1986). Vygotsky (1981) explained, “Any function in the child's cultural development appears twice, or on two planes. First, it appears on the social plane, and then on the psychological plane" (p. 163). He believed social interactions drive development and described a "social situation of development" (Vygotsky, 1998, p. 198) in which children's social environment and development are bidirectional. Social 
experiences influence children's growth and children's development shapes their social interactions and experiences.

\section{Language and Literacy Development}

One central tenet of sociocultural theory is that learning and development are mediated during social interaction through the use of tools, with language being the most important tool (Vygotsky, 1981, 1986). Language is the primary tool that propels cognitive development; children are first exposed to language in their social environments and internalize it (Karpov, 2003). Cognitive functions such as attention, memory, and imagination are transformed through the internalization of language (Bodrova \& Leong, 2003). Kozulin (2003) explains that children appropriate psychological tools, the "symbolic artifacts" (p. 15) from their environments. These artifacts, such as language and other symbols convey culturally specific meaning (Kozulin, 2003). From this perspective, children's social and cultural environments have such strong influences that children's development and understandings of their worlds are specific to their social experiences and the larger culture.

Literacy is understood to be a shared communicative practice reflecting the culture in which it occurs. Literacy encompasses oral language, decoding and encoding (reading and writing), and the use of other cultural tools and symbols in multiple modalities (Gee, 2012). Literacy involves various uses of texts. Wells (1990) offers a comprehensive definition of text as "any artifact that is constructed as a representation of meaning using a conventional symbolic system" (p. 378). Text might include language (in various forms, oral, written, sign), icons, nonverbal cues, and any other symbols used to convey meaning. In other words, humans use texts (a variety cultural tools) to communicate to ourselves 
and to others (Barton \& Hamilton, 2000). Children's literacy develops through experiences with texts in their social environments.

Bakhtin extended the role of language in learning and development to literary texts (Bakhtin, 1990; Holquist, 1990). To Bakhtin (1990), literary texts are a form of knowledge that serve as tools in which one individual's knowledge and thinking are communicated to others. In that process, there is the potential for furthering their audience's thinking and learning. Literature is also a means for transmitting culture as authors put forth ideas that are culturally significant. In these ways, literary texts produce and reproduce culture.

\section{Development in the Preschool Years}

The preschool years, encompassing ages three through seven, are marked by increased intellectual capabilities (Bodrova \& Leong, 2003). In early childhood, children begin to use language to make sense of their worlds; they realize words have meaning, especially in reference to concrete objects (Vygotsky, 1986). They make meaning through verbal thinking as thought and language become inextricable (Vygotsky, 1998).

Preschoolers' mental functions become qualitatively more advanced than those of younger children who make meaning primarily through nonverbal perception; their psychological development moves toward abstraction. For example, preschoolers become increasingly adept at referencing items and events not found in the immediate environment, recognizing emotions, and making inferences. Intellectual development shifts from biological to sociohistorical; learning and development are not driven by biological maturation but by social processes.

Preschoolers become increasingly capable of mutual understanding (Vygotsky, 1986). They benefit from activities involving joint attention and collaboration. They often 
enjoy learning in dyads or small groups in which they can exchange ideas and work together. The nature of preschool children's play evolves as it becomes more socially oriented and they increasingly use their imaginations in pretense play. Young children often role-play during which they assume identities and co-construct narratives of actual and imagined events.

During the preschool years, children become more proficient in language and literacy through social interaction and as they gain experience with cultural artifacts (such as books, toys, technology, and other objects in their environments). In addition to developing cognitive and linguistic skills, young children develop early literacy skills. They begin to demonstrate book-handling skills and concepts of print, tell stories, create art, and imitate writing for real-world purposes. Children develop literacy through interaction, dialogue, and other shared experiences. They benefit from language and literacy experiences in collaboration with more knowledgeable others (Dodici, Draper, \& Peterson, 2003; McGee \& Richgels, 2012; Morrow, 2007). Development occurs through apprenticeship and guided participation in joint activities in which children are afforded the opportunity to imitate more competent others in the context of literacy activities (Rogoff, 1995).

\section{The Development of Scientific and Spontaneous Concepts}

Vygotsky (1986) differentiated between children's development of scientific and spontaneous concepts and indicated that children develop these concepts differently. Scientific concepts are those that children develop only through interactions with more knowledgeable or competent others. Vygotsky explained, "The scientific concepts evolve under the conditions of systematic cooperation between the child and the teacher. 
Development and maturation of the child's higher mental functions are products of this cooperation" (1986, p. 148). Vygotsky (1986) indicated that development of scientific concepts occurs first through initial exposure during interaction, in what he described as “the systematicity of instruction and cooperation" (1986, p. 148). In other words, children first develop scientific concepts through interactions in the social environment when a more knowledgeable or competent other introduces them to words and ideas, "initial verbal definition," (Vygotsky, 1986, p. 148), mediated primarily through language. When children are introduced to the word, it is just the beginning of understanding. They then reason about the meanings of those words and ideas to develop fuller, more complex understandings. At last, they can then use those new understandings to expand toward new conceptualizations that spontaneously originate within each child (spontaneous concepts) as opposed to conceptualizations emerging from the interaction between them and more knowledgeable others. Forman and Cazden (1985) point out that the more knowledgeable other might be a peer. When children interact with peers (including younger peers), they can learn from each other rather than always learning from an adult or much older individual.

\section{Scaffolding in the Zone of Proximal Development}

Vygotsky indicated, "the only good kind of instruction is that which marches ahead of development and leads it" (1986, p. 188). To Vygotsky, learning is optimal and children develop cognitively when interacting with more advanced others in their zone of proximal development (ZPD). A child's ZPD is the discrepancy between actual development and the level of development the child is capable of achieving through guidance from a more knowledgeable other (Vygotsky, 1986). The ZPD is the discrepancy 
between the learner's independent and potential functioning (Vygotsky, 1986; Wells, 1999). Learners grow toward their potential through guidance and/or in collaboration with more experienced others (Holquist, 1990; Vygotsky, 1986). Holquist (1990) indicated this difference "may be traversed $[\ldots]$ through the pedagogical activity of the parts in a dialogic simultaneity relating to each other in time" (p. 83). This guidance occurs primarily through language since language serves as the primary tool for thinking and expressing thought.

This support, "scaffolding" (Wood, Bruner, \& Ross, 1976), is embedded in social interactions. Although Vygotsky never used the term "scaffolding," it has become associated with sociocultural theory because it emphasizes the teacher-learner relationship in which learning occurs through interaction with more knowledgeable others; this interaction between expert and novice is the mechanism that drives learning and development (Belland, 2014; Cazden, 1979; Gibbons, 2002; Pea, 2004).

According to van de Pol et al. (2010), no single definition of scaffolding exists. However, they describe common characteristics among various definitions. One essential characteristic is contingency: Scaffolding supports must be responsive to children's needs. Another key characteristic is fading, the gradual withdrawal of support as learners gain competence. A third characteristic of scaffolding is transfer of responsibility in which learners become accountable for demonstrating competencies as they are expected to accomplish tasks independently.

Planned supports in the classroom. Scaffolding has various meanings as scholars emphasize different aspects of learner support (Hammond \& Gibbons, 2005; Reynolds, 2017). Some researchers study nonhuman scaffolds such as technological devices (e.g., 
computer-mediated learning; Graesser et al., 2000; La Joie, 2005; Pea, 2004; Reiser, 2004) and the environment-as-scaffold such as Sharpe's (2001) conception of "designed-in" (p. 33) supports that underscore the importance of instructional design. These preplanned supports include the ways teachers create environments conducive to learning. In designing instruction, teachers plan and implement curriculum by formulating goals and objectives, creating lessons, and selecting materials and activities. They also consider student interests, prior experiences, and previous learning to design instruction that is appropriate and relevant (Athanases \& de Oliveira, 2014). Teachers also provide supports by preparing the learning environment and determining how they will manage time, materials, and classroom space, as well as grouping students (e.g., whole class, small groups, partners, independent work; Applebee \& Langer, 1983; Maloch, 2002). Hammond and Gibbons (2005) argue that these designed-in features provide the context in which interactional scaffolding occurs.

Interactional scaffolding. Reynolds (2017) describes interactional scaffolding as the responsive supports a more knowledgeable individual provides to a learner. Interactional scaffolding requires the teacher to remain flexible and sensitive to students' responses to instruction (Hammond \& Gibbons, 2005). "Point of need" (Sharpe, 2001, p. 33) scaffolds are contingent on interaction with students. Athanases and de Oliveira (2014) describe how interactional scaffolding happens in-the-moment during classroom discourse, highlighting the dynamic and reciprocal nature of the process. Interactional scaffolding encapsulates the many forms of support that occur during the ongoing communication between the teacher and learners; various scholars focus on the different aspects of interactional scaffolding (Reynolds, 2017). Some highlight the effectiveness of 
scaffolding in guiding students' reasoning (Brush \& Saye, 2002), metacognition (Azevedo \& Hadwin, 2005), direct teaching of comprehension strategies (Clark \& Graves, 2005; Maloch, 2008), how understanding is negotiated through dialogue (Gibbons, 2003; Maloch, 2002; Mercer, 1994), the contingency of support in response to students' understandings (Gibbons, 2002; Maloch, 2008; van Lier, 1996; Wells, 1986), and the impacts of varying levels of supports on student learning (Mariani, 1997; Pentimonti et al., 2017). Teachers' use of scaffolding techniques, such as questioning (Ioney \& Carter, 2007), gesture (Cole, 2006), and specific support strategies such as prompting children to generalize (to the real world), reason (explain why), predict, co-participation (thinking and working together), reducing choices (of correct answers), and eliciting (by having a child recall information just heard) (Pentimonti et al., 2017) also impact learning.

Scaffolding can also take place during assessment. Macrine and Sabbatino (2008) explored how continuous dialogue between the teacher and learner allowed for flexible support during assessment tasks while La Joie (2005) describes in-the-moment decisions teachers made to adjust feedback according to the learner's level of performance during dynamic assessment. Shepard (2005) offers insight into how scaffolding works during formative assessment as the teacher elicits and builds on students' prior knowledge, gives feedback, and guides students in self-assessment.

Scaffolding in preschool classrooms. Teachers' scaffolding can support preschoolers' learning in a variety of content areas (e.g., language arts, math, science) (Butts, Hofman, \& Anderson, 1993; Hsin \& Hsin-Kai, 2011; Zurek et al., 2014). Teachers can provide designed-in supports (Sharpe, 2001) through intentional planning and implementation of the curriculum; careful selection of books, activities, and materials; and 
learning structures (i.e., whole class, small group, partners, individual). Hsin and Hsin-Kai (2011) found that scaffolding preschoolers' (four and five year olds) learning is effective if it is contingent on individual children's learning and developmental needs. They suggest that younger preschoolers might benefit from more intensive scaffolding as they are constructing foundational knowledge about the world around them.

During their two-year study (74 observations) among 144 preschoolers (ages three to five), Zurek et al. (2014) documented how preschool teachers successfully used a range of interactional scaffolding strategies to support children's learning about the natural world as they designed and implemented an environmental education curriculum. These strategies included activating children's prior knowledge, eliciting children's inferences and predictions, prompting children to attend to certain objects in their surroundings and the attributes of those objects, giving clues (hints), using gestures, as well as addressing and clarifying children's misconceptions. Teachers used both contextualizing (bridging the unfamiliar to the familiar) and de-contextualizing (distancing, generalizing) strategies to help children make connections between the new and the known. They elicited children's responses by questioning and commenting and also offered feedback and elaborated on children's contributions. Teachers took active roles through co-participation and collaboration by thinking aloud and working with children on joint tasks.

Zurek et al. (2014) noted that scaffolding for preschoolers can be frequent and complex as teachers' levels of support are contingent on children's learning. They also found that teachers offered affective scaffolding support to help manage children's frustration as well as maintain their interest and promote shared understandings and collaboration during social learning activities. These researchers concluded that 
scaffolding is an effective teaching strategy for preschoolers and that teachers should adjust their supports to assist young children's learning.

Researchers have found that certain contexts are especially conducive to scaffolding in preschool. Butts et al. (1993) indicate that learning content via hands-on exploration and instructional dialogue with the teacher are most effective. Tarim (2015) found that children learned more in small groups than they did individually, suggesting that small group learning is ideal. Not only do children have the opportunity to learn from each other, teachers were able to scaffold individual children's learning effectively in small groups.

While Vygotsky's sociocultural theory and related ideas (i.e., ZPD, scaffolding) are widely applied in education, they are not without criticism. Green and Piel (2010) indicate that nearly all assessments of children's functioning in the ZPD are conducted through pretests, instruction, and posttests. Since Vygotsky was not a stage theorist, it is impossible to conclude that improvements in children's performance are a result of exposure to interventions or that actual cognitive development has taken place. Another critique is that Vygotsky's theory is vague; he did not live long enough to refine his ideas (Green \& Piel, 2010). Nevertheless, his work continues to be useful in describing transactions between learners and more experienced others as well as the role of language in learning and development.

\section{Summary}

From a sociocultural perspective, children's learning and development occur through social interactions that are mediated primarily through language. During the preschool years (ages three to seven), language becomes the primary tool that drives 
cognitive development. Preschool-aged children become more adept at using language for a variety of purposes such as play, social interaction, and learning. Based on Vygotsky's notion of the zone of proximal development (ZPD), learning occurs as the result of interactions with more knowledgeable others; children develop scientific concepts through these interactions and then develop spontaneous concepts based on existing conceptual knowledge. My study draws from sociocultural theory as I examine the interactional scaffolding among preschool teachers and children as they read both fiction and nonfiction literature together.

\section{Rosenblatt's Transactional Theory of Reader Response}

According to Rosenblatt's transactional theory, reading is an active process in which meaning is made in the transaction between the reader and text $(1938 / 1983 ; 1978)$. Through transaction, a work is created in the mind of the reader. A "new synthesis" (1938/1983, p. 112) emerges as the reader brings meaning to the marks on the page. Meaning does not exist solely in the text or the reader's mind but is generated in the transaction between the two, which Rosenblatt called the "poem" (Rosenblatt, 1978). To Rosenblatt, a literary work "gains its significance from the ways in which the minds and emotions of particular readers respond to the verbal stimuli offered by the text" (1938/1983, p. 28). Readers draw connections between words, ideas, and concepts introduced in the text and bring their own personalities, memories, values, strongly held beliefs, "present needs and preoccupations" (1938/1983, p. 30), and physical and mental states to the reading event. In addition, readers draw upon their reservoirs of past experiences to make meaning. 
Rosenblatt (1938/1983) believed reading literary works broadens individuals' understandings and offers opportunities to move outside personal experiences, including one's culture. Literature serves as a vehicle for developing the capacity to "think rationally within an emotionally colored context" (Rosenblatt, 1938/1983, p. 226), to develop the intellectual tools needed to reason through emotionally charged situations. Rosenblatt (1938/1983) believed readers' vicarious participation through literature was key to gaining insights into the lives of people who were different than their own in regard to culture, history, social position, and other aspects.

\section{Efferent and Aesthetic Stances}

According to Rosenblatt (1998), texts can be read efferently and aesthetically. Efferent reading is derived from the Latin effere, meaning "to take away" (Rosenblatt, 1938/1983; 1978). Efferent reading is more impersonal, abstract, and analytical (1998); the reader extracts the public (shared) meaning of a text (Rosenblatt, 1993). When readers read efferently, they read to follow directions, find a solution to a problem, determine action to be undertaken, or take away new knowledge to be retained after the reading event (Rosenblatt, 1978).

Rosenblatt described the aesthetic stance, when readers seek "cognitive coherence with a pervasive affective quality" $(1998$, p. 894). The term "aesthetic" is derived from the Greek aisthitikos ( $\alpha \iota \sigma \theta \eta \tau \imath \kappa o ́ \varsigma)$ meaning "to perceive, sense, feel” (1998). Aesthetic reading is private; it involves turning inward toward one's own experiences and feelings (Rosenblatt, 1978; 1993). When readers read aesthetically, they connect with the text both intellectually and emotionally, and evoke a "poem" (1978). To Rosenblatt, a poem is not a thing; it "is an active process lived through during the relationship between a reader and a 
text" (1978, pp. 20-21). Aesthetic reading is participatory, a lived through experience. An individual might be reading aesthetically when getting lost in a novel or savoring the beauty of imagery conveyed through words.

The efferent-aesthetic continuum. Efferent and aesthetic stances lay at polar ends of a continuum and any text can be read efferently or aesthetically (Rosenblatt, 1978). The text offers a range of potential responses and readers decide how to approach the cognitive and emotional demands of the text (1978). Readers choose, either consciously or unconsciously, which stance to take according to their purpose for reading. Rosenblatt indicated, "competent reading requires the ability to handle both cognitive and affective aspects in a continuous process of choice, synthesis and organization” (1998, pp. 897898).

While readers typically choose a predominant stance, they can and should be able to alter stances throughout the reading event (Rosenblatt, 1978). Readers shift attention according to interests, memories, and experience as they encounter new ideas while progressing through the text (1978). Ideally, they negotiate responses to the text and takes a flexible stance on the efferent-aesthetic continuum.

\section{Evocation and Reflection}

Rosenblatt viewed reading as a creative and constructive activity in which readers respond continuously, even after the reading event. She described readers' preliminary responses as "evocations", their initial thoughts and feelings that unfold as they read. In Rosenblatt's own words, evocation is “emerging meaning - that part of the stream of thought that is felt to be linked to the text" (1998, p. 887). When the reader evokes a "poem" (Rosenblatt, 1978), it is a creative process, a synthesis of responses. Rosenblatt 
(1998) believed readers' responses do not stop with evocation. They actively make meaning by responding to the text and then reflect on those initial responses (Tyson, 2006). Therefore, it is essential readers have opportunities to reflect on their evocations, reason through immediate responses, and continually evaluate their interpretations (Rosenblatt, 1998). Rosenblatt (1938/1983) also indicated that response can occur through social interactions as a group of readers negotiates ideas in the text to move toward deeper understanding.

\section{Reader Response in Early Childhood}

Hungerford (1993) indicated that reader response could look different among younger children than with older readers. Young children respond to being read to by engaging in dialogue about characters, story events or places, and connecting them to their own lives. They might respond creatively through art, dictate their own stories, and through dramatic play (Hungerford, 1993). Preschoolers engage in intensive dramatic play in response to fictional stories that involve roleplaying in fantasy worlds. Like Hungerford, Arizpe and Styles (2016) found that young children engage in artistic response as they create artwork based on story characters, as well as artifacts to use as props in their dramatic play.

\section{Response to Picturebooks}

Picturebooks tell stories through multiple sign systems (Martinez \& Harmon, 2012; Sipe, 2008). Serafini (2014) describes picturebooks as "multimodal ensembles" (p.

11) that combine the elements of visual features (art, photographs, diagrams, maps), design (layout, font, color), and written language. These "blended structures" (Serafini, 2014, p. 17) encompass different genres and literary styles (e.g., wordless, postmodern, 
graphic novels, informational). Picturebooks tell stories or convey information using each element in varying degrees and in unique configurations (Serafini, 2014; Sipe, 2008). Words "convey temporal information" (Martinez \& Harmon, 2012, p. 324) and "images best convey spatial information" (p. 324). Arizpe and Styles (2016) indicated that pictures and words present information differently and work in conjunction to tell stories, so children must negotiate the interplay all of these elements when making meaning. Sipe (2008) emphasized how readers need to attend to all parts and features of picturebooks and that adults and children can discuss the decisions authors and illustrators make to convey information.

In picturebooks for young children, illustrations and photographs convey information about events, characters, setting, and mood. In their study of 486 children (ages four to eleven), Arizpe and Styles (2016) found that children as young as four were adept at analyzing the visual features of picturebooks and could hold conversations about the pictures. Children reported that pictures were more interesting than words. They noticed the atmosphere the illustrator created through design elements such as color and line, as well as depictions of objects. Children were able to infer characters' feelings conveyed through both pictures and words. Arizpe and Styles (2016) suggested that pictures might conjure emotions by bringing forth memories as they discovered that children engaged in thoughtful conversations about the feelings the pictures evoked.

Arizpe and Styles (2016) concluded that children as young as four are capable of interpreting and analyzing text, as well as responding through multiple modalities (such as language, art, and play). The linguistic, design, and visual features of picturebooks required children to integrate information from all elements to make meaning. Children 
arrived at sophisticated meanings through "careful looking" (p. 180) at pictures. Arizpe and Styles (2016) concluded that children had rich learning experiences because they were deeply engaged in the worthwhile pursuit of meaning making during picturebook reading.

\section{Response to Fictional and Nonfiction Literature}

Diverse texts give children opportunities to think in different ways (Kamberelis, 1999). Bruner (1986) argued that there are two modes of thought—paradigmatic and narrative - each with a distinct purpose. The purpose of thinking in the paradigmatic (or logico-scientific) mode is to study something empirically, such as the ways mathematicians or scientists study to describe or explain phenomena. The goal is to "transcend the particular by higher and higher reaching for abstraction" (Bruner, 1986, p. 13). Bruner (1986) indicates that the narrative mode "deals in human or human-like intention and action vicissitudes and consequences that mark their course. It strives to put its timeless miracles into the particulars of experience and to locate the experience in time and place" (p. 13). Narratives are centered upon "concern for the human condition" (p. 14). When reading narratives, the reader must navigate two landscapes simultaneously. The landscape of action is concerned with characters and events (plot) within a story's setting(s). It is visible and explicit. The landscape of consciousness lies in characters' inner worlds and relates to "what those involved in the action know, think, or feel, or do not know, think, or feel" (p. 14), which must often be inferred by the reader.

Torr and Clugston (1999) discuss how these distinct ways of ordering experience can be found among types children's literature; these different ways of knowing can be expressed narratively (through stories) and scientifically (through information-gathering). Kress (1994) points out the language of narratives (stories) and non-narrative nonfiction 
differs. Narratives tend to be written in past tense whereas nonfiction makes use of timeless present tense verbs. Kress (1994) writes, "a formal distinction between forms of knowledge: that which is presented in the present tense is fact plus knowledge; that which is presented in the past tense is fiction plus knowledge" (p. 103). Shine and Roser (1999) suggest that young children respond to assorted texts differently because they offer children diverse opportunities for interpretation as they read for different purposes.

Harste, Woodward, and Burke (1984) found in their groundbreaking and award winning ethnographic study of 67 three to six-year-olds that young children produced pretend readings that differed according to the type of text and contained genre-specific language. That is, children reproduced specific linguistic features of texts. Pappas (1993) found kindergarteners' pretend readings of fiction and nonfiction increasingly approximated the linguistic characteristics of these types of texts with each repeated reading. Duke and Kays (1998) found kindergarteners displayed increased use of linguistic features typical of nonfiction texts in their pretend readings with exposure over time. Purcell-Gates (1988) found children in the primary grades produced pretend readings that contained linguistic features of fairy tales having been exposed to that genre. For example, they used formulaic openings (e.g., "Once upon a time," "There once was") and attributive adjectives (“a beautiful princess"), and spoke in past tense, which is typical of narratives. Loizou, Kyriakides, and Hadjicharalambous (2011) also found children produced formulaic language in telling fairy tales and other narratives.

Response to fictional literature. According to Smidt (2012), fictional stories are bound by rules. They are told from the perspective of a narrator, typically in past tense. The setting provides a sense of time, place, and social context to form a cohesive whole. 
Stories have characters with their own thoughts and feelings whose behaviors propel the action forward. Narratives unfold across time in a logical sequence with a clear beginning, middle, and end. Children gain an awareness of these unwritten rules as they become more familiar with stories.

When reading stories, readers navigate the dual landscape of action and perception by making sense of events and by inferring characters' perceptions as events unfold (i.e., what characters know, feel, have experienced, etc.). Children might take an aesthetic stance to empathize with a character in familiar scenarios or experience vicariously situations different from their own. They can apply these approaches to stories in future literacy learning as they encounter more multifaceted characters, detailed settings, and complex plot lines, which require more proficient inferring to make sense of the text.

Young children's knowledge of text type develops as they gain an understanding of text structure. Children can learn to link causes with effects, problems and solutions, and following the sequence of events that play out across the pages of fictional stories (Kamberelis, 1999). They use reasoning skills to problem solve and ask critical questions about characters' motives, feelings, and actions (Wiseman, 2011). Through talk, young children can analyze literary elements such as characters, setting, and plot, as well as predict story events (Shine \& Roser, 1999; Torr \& Clugston, 1999). Exposure to stories helps young children learn to recognize and grapple with a central problem and reason through solutions (Torr \& Clugston, 1999).

Smidt (2012) explains children learn to narrate, to become story makers through exposure to narratives. Children's lives are filled with stories, including their own; they structure "their own thoughts, feelings and experiences into little stories or 
protonarratives" (p. 39). When telling stories, children draw upon their understandings of story language so that their narratives are not told in their everyday language. They begin to imitate the language they find in texts. Bus (2003) writes, "When children begin to reproduce facets of the story, then the phrasings of their emergent readings become more similar to the original text $[\ldots]$ their emergent readings included nouns, verbs, and whole phrases derived from the focal book" (p. 10). Smidt (2012) claims children go beyond imitating story language, they transform it by infusing their own language as well as language from poetry, lullabies, and songs as they tell their own stories.

Response to nonfiction literature. Young children are naturally curious about the world. They love to learn about real things through hands-on exploration, talk, and by engaging with books and other texts. Children do not learn to read and then read to learn; they do both from a young age (Duke, 2003; Smith, 1978). Duke (2000) affirms children can manage the complexities of nonfiction from an early age. Young children are capable of understanding textual and graphic features, text structures, content, and specialized vocabulary (Donovan \& Smolkin, 2002; Duke \& Bennett-Armistead, 2003). Teachers can use read aloud as a time for exposing children to these aspects of nonfiction texts (Heisey \& Kucan, 2010). During read aloud, teachers can introduce common features such as the title, table of contents, headings, index, and glossary and how each helps to organize the text. Teachers can provide direct instruction for interpreting graphic features such as tables, graphs, charts, diagrams, maps, sidebars, and photographs with captions, which contain information in a non-narrative format. Calo (2011) discovered how one primary grade teacher explicitly taught children how text and graphic features work. In this study, the teacher taught her students how captions help tell the story by explaining what is 
happening in the pictures. Pappas (2006) noted nonfiction also give children exposure to labels - individual words or phrases that name objects, features, or processes (similar to captions). Webster (2009) discovered how one teacher guided children through the process of looking back (i.e., rereading, reviewing pictures) to locate facts.

Nonfiction literature presents abundant opportunities for young children to develop content knowledge and vocabulary (Duke \& Block, 2012; Reese \& Harris, 1997). Ideas and concepts children encounter can deepen their understanding of familiar content and ignite their interest in various topics. It is essential to connect vocabulary instruction to content learning. Duke (2013) recommends creating a "lexically curious environment" (p. 42) in which teachers and children explore words and their meanings together. Young children who have been exposed to nonfiction demonstrate increased use of technical or academic vocabulary (Duke \& Kays, 1998). Webster (2009) found interactive read-alouds expanded content knowledge and enlarged related vocabulary among first graders. Wright (2014) found that kindergarten teachers explained more vocabulary words per minute during nonfiction read aloud than any other time of day. Pollard-Durodola et al. (2011) describe how one preschool teacher introduced content vocabulary during read-aloud. The teacher offered content-specific definitions in familiar terms and conducted repeated readings throughout a thematic unit. Through this approach, the teacher built a solid foundation of content and related vocabulary into the curriculum. Brassell (2006) reported how one teacher supported students' science vocabulary through explicit vocabulary study in which students learned new science words, analyzed word parts (e.g., affixes, bases), and categorized semantically similar words. Wright (2014) concluded that young children 
are capable of learning academic vocabulary and that capitalizing on the potential for teaching vocabulary during nonfiction reading should start in the preschool classroom.

In addition to content-specific vocabulary, nonfiction often contains generic nouns and timeless verbs (Duke, 2000). Generic nouns refer to broad categories (e.g., "owls," "the woods," "a squirrel"). Timeless verbs are stated in the present tense (e.g., "bears hibernate in the winter") (Pappas, 1993). Young children's use of these linguistic features can increase through experiences with nonfiction (Pappas, 1993; Tower, 2002). Duke and Kays (1998) documented children's recurrent use of generic nouns and timeless verbs during pretend readings of nonfiction books. In addition, their talk frequently related to the topic. Mantzicopoulos and Patrick (2010) found young children used many words from the text when retelling. These studies provide evidence children can understand and appropriate text-specific words and linguistic features.

Young children use many strategies to comprehend nonfiction literature. Tower (2002) found they rely heavily on pictures to make meaning; pictures prompted extended talk among young children as they identified objects, discussed events depicted in pictures, as well as connected objects in pictures to their background knowledge. They related their own experiences (i.e., made personal connections) to pictures and events (Moschovaki \& Meadows, 2005; Tower, 2002). Young children also used their knowledge base and experiences to make sense of unfamiliar content encountered in nonfiction (Tower, 2002; Webster, 2009). Mantzicopoulos and Patrick (2010) discovered children commented and made connections beyond textual ideas, suggesting they drew from their prior knowledge and linked it to new information.

\section{Summary}


Rosenblatt's transactional theory proposes that meaning is created during the transaction between the reader and the text. Readers also take stances on the efferentaesthetic continuum as they read; their stances can shift across the continuum according to their reading purposes. Readers' initial responses can evolve through reflection upon their own evocations as well as other readers' responses after a reading event. Young children are capable of constructing meaning when reading both fiction and nonfiction picturebooks. Response can be active and social as children respond aesthetically and efferently, through dialogue, expressive arts, dramatic play, and by creating artifacts that serve as material representations of their knowledge.

Rosenblatt's transactional theory, as well as young children's responses to fictional and nonfiction picturebooks, are important to my study since I examined teachers' and children's responses along the efferent-aesthetic continuum with both types of text.

\section{Emergent Literacy Perspective}

Emergent literacy refers to young children's interactions with text that lay the foundation for conventional reading and writing. Owocki (2001) identifies key principles of children's literacy development from the emergent literacy perspective:

- "Literacy develops as a social and cultural practice" (p. 6) and is embedded in socially and culturally relevant interactions with text (reading a newspaper, writing a note, texting);

- "Literacy develops through hypothesis testing" (p. 7). Children constantly revise their thinking and knowledge about the ways text functions through socially mediated literacy experiences; 
- "Literacy develops idiosyncratically" (p. 8) Children have unique paths of literacy development shaped by personal characteristics, social experiences, and cultural influences;

- "Literacy concepts develop simultaneously" (p. 9) as children come to understand the relationship between function and form. Functions pertain to the ways text is used whereas form relates to the shapes and structures of text (how a greeting card, text message, street sign works).

From the emergent literacy perspective, young children's oral language and knowledge of print develop over time through social interactions and as they gain experience with the literacy materials found in their surroundings (Teale, 1986). The interests, understandings, and behaviors young children display are valued aspects of literacy development and viewed as essential precursors to conventional reading and writing (Whitehurst \& Lonigan, 1998). Language and literacy understandings begin in infancy and continue as children develop language that more closely resembles that of older users and they independently draw upon a repertoire of strategies to read and write. For many children, more conventional language and literacy behaviors occur during the elementary years, marking the end of the emergent literacy period.

Children actively learn through social interactions and direct experiences with people and objects in their environments (Vygotsky, 1981). Teale (1986) indicates young children's literacy development occurs in three ways: through their interactions with adults (or more knowledgeable others), independent explorations of literacy-related materials, and their observations of others (models). This perspective emphasizes the 
importance of more experienced others modeling literacy behaviors (especially for real world purposes) and involving children with printed materials.

Sometimes, the focus is not literacy itself but reading and writing as a function of life (for practical purposes) (Teale, 1986). Children observe adults reading and writing for practical purposes (e.g., reading books, newspapers, and other materials; filling out applications; running errands; conducting internet searches, reading a menu). Children's first literacy behaviors are often those relevant to life such as pretending to read a book, scribbling a shopping list, drawing signs, filling out forms, counting money, or signing their name. Through these activities, children learn reading and writing have real world applications.

\section{Emergent Literacy Assessment}

Owocki (2001) indicates that literacy assessment in early childhood should be multifaceted and occur within the context of everyday classroom life. Observations should happen during authentic literacy experiences taking place for real world purposes (e.g., reading, drawing, writing) and when using literacy related tools (e.g., books, writing instruments, technology). Teachers need to use a variety of assessment methods to construct a comprehensive literacy profile (e.g., collection of work samples, observation of book handling and other emerging reading behaviors, meaning-making strategies) as well as children's dispositions (preferences, attitudes, understandings about the uses of

literacy materials). McGee and Richgels (2014) recommend that teachers ask both literal (stated in the text) and inferential (not directly stated) questions to assess children's meaning making during read aloud. 
Owocki and Goodman (2002) emphasize the practice of "kidwatching", "a collection of techniques for gathering and reflecting on data" based on observation of students during learning activities (p. 2) and "making professionally informed teaching decisions based on the data they collect" (p. 3). Unlike obtrusive assessments, which require the teacher to stop teaching to administer a test, quiz, or interview (Heflebower, Hoegh, \& Warrick, 2014), kidwatching often takes place without children's awareness because it naturally occurs as part of instruction. Kidwatching as a form of literacy assessment includes observation and documentation of children's literacy behaviors and knowledge construction, social interactions and language, and responses to interactions with more advanced others (i.e., adults, peers) in children's ZPD.

\section{Summary}

From an emergent literacy perspective, young children's literacy development unfolds through various experiences with texts, long before they are capable of conventional reading and writing. Their literacy development is influenced by social experiences and the texts in their environments as they observe and imitate the ways more knowledgeable others use texts. During the emergent literacy phase, young children interpret pictures, participate in read aloud, and rely heavily on oral language to respond to texts. They also respond through dramatic play and by creating artifacts (e.g., emergent writing, drawing, art pieces).

The emergent literacy perspective is important to my inquiry because the children I studied do not yet read and write conventionally. This perspective informed my observations as I attended to teachers' actions as they read and conversed with their young 
students, as well as the language and literacy behaviors children displayed that are characteristic of this phase of development.

\section{Contexts for Effective Teaching}

\section{A Framework for Effective Teaching}

Bransford, Darling-Hammond, and LePage (2005) outline a three-part framework for effective teaching for teachers of children and youth. Accomplished teachers possess comprehensive knowledge of their students' learning and developmental processes, subject matter and curricular goals, and pedagogical knowledge. First, teachers' knowledge of learners and their development in social contexts entail a general understanding of child development as well as knowledge about the development of individual children. It encompasses an understanding of children's development across domains (i.e., cognitive, linguistic, social, emotional, fine motor, gross motor, etc.) and the role of teaching in supporting each child's learning and development. This allows them to teach to individual children's strengths, needs, experiences, and interests (Bransford et al., 2005).

Second, competent teachers' knowledge of subject matter and curricular goals enables them to design curriculum that addresses a variety of factors: goals and standards to be met, children's learning needs and interests, as well as resources and constraints (e.g., personnel, budgetary, materials, time, space, etc.). Teachers must be well versed in subject matter content and expected outcomes. Then, they can design curriculum that is purposeful in meeting educational goals and that is meaningful and relevant to children (Bransford et al., 2005). 
Finally, capable teachers possess pedagogical knowledge: both general teaching and content area pedagogies, as well as knowledge about working with diverse learners, conducting an array of assessments, and implementing practical classroom management techniques (Bransford et al., 2005). Effective teachers have extensive subject matter knowledge and an understanding of how learners conceptualize (and misconceptualize) particular content. They have the ability to flexibly utilize a repertoire of teaching strategies appropriate for their students and the content. They can also differentiate instruction to meet the individual needs of diverse learners. Effective teachers employ a variety of assessment measures to capture students' learning and development that are informative for guiding instruction. They manage time, space, materials, groups, and individual children. Their use of classroom space is well planned so there is a logical configuration for optimal traffic flow and elimination of blind spots. Materials are organized and easily accessible. Effective teachers establish routines to reduce chaos, disruptions, and transition times. At the same time, they foster a classroom community built on positive interactions and productive collaboration so that all students' needs are met.

\section{Emotional, Organizational, and Instructional Supports}

Howes et al. (2008) indicate that effective teaching involves sensitive interactions around instructional content in which teachers meet children's learning and emotional needs. Curby, Rimm-Kaufman, and Cameron Ponitz (2009) delineate three types of classroom supports that reinforce student's success: emotional, organizational, and instructional supports. Emotional support refers to teachers' dispositions and actions that "foster positive classroom climate, attend sensitively to individual student needs, and 
emphasize student interests and autonomy" (p. 913). In a quantitative study of 147 kindergarteners and first graders over a two-year period, Curby et al. (2009) documented that children made greater gains in three areas: word reading, phonological awareness, and math skills when they had emotionally supportive teachers. Curby, Brock, and Hamre (2009) examined data collected from two previous multi-state studies that included a total of 2,938 preschoolers. They discovered that children in emotionally supportive classrooms made more academic achievement gains and displayed more social competence than children whose teachers were inconsistent in their emotional support. In a multi-state study of 2,800 preschoolers (some three and mostly four-year-olds), Howes et al. (2008) studied the relationship between language and literacy growth and development of social skills with the quality of relationships with their teachers. They concluded that children made the most gains when they had sensitive and responsive teachers and when their interactions with teachers focused on their skill development.

Mashburn et al. (2008) examined three measures of quality (ECERS-R [Harms, Clifford, \& Cryer, 1998], NIEER report [Barnett, Hustedt, Robin, \& Schulman, 2004, 2005], and teachers' emotional and instructional supports) among 2,439 preschoolers in 671 preschools in 11 states. The ECERS-R (Harms, Clifford, \& Cryer, 1998) addresses aspects of the learning environment in subscales relating to "space and furnishings, personal care routines, language-reasoning, activities, interactions, program structure, parents and staff" (para. 1). The NIEER report (Barnett et al., 2004, 2005) examines several dimensions of early childhood care and education: level of teacher education and professional development, class size and teacher-child ratio, comprehensiveness of the curriculum, if one or more meals are served every day, vision/hearing/health screening 
and referral services, and family support services such as "parent-teacher conferences, home visits, parenting support and training, referral to social services, and information related to nutrition" (Mashburn et al., 2008, p. 734). Mashburn et al. (2008) concluded that of all the measures they studied, the quality of teacher-child interactions had the most consistent and strongest associations with children's development.

While several studies point to emotional support as key to children's growth, researchers discovered it is often paired with other types of support (e.g., organizational and instructional). Organizational support refers to "proactive management of the classroom that ensures productive use of time and materials and supports student attention and behavior" (Curby et al., 2009, p. 913). Wilson, Pianta, and Stuhlman (2007) studied the relationship between classroom climate and social skills of 946 first graders and found that children were better socially adjusted when they received consistent emotional support from their teachers (i.e., teachers were positive and sensitive) and structural support (proactive classroom management, teachers allowed autonomy). Organizational support also refers to the features and uses of areas in the classroom. For example, Magruder et al. (2013) describe aspects of the classroom that contribute to the quality of the learning environment in supporting the language and literacy development of emergent bilingual Spanish-speaking preschoolers. Specifically, they recommend colorful displays and inviting furnishings and spaces. Objects should be labeled in English and children's home languages. Books and materials should be in easy reach and should be representative of children's cultures.

Finally, instructional support “involves teachers' encouragement of higher order thinking as students learn new concepts, provision of constructive and specific feedback, 
and stimulation of children's use of language" (Curby et al., 2009, p. 914). Hamre and Pianta (2005) studied the effects of strong emotional and instructional support on the academic achievement of 910 five and six year olds. They operationalize instructional support as explicit teaching, intensive scaffolding, guided practice, productive classroom time, and teachers' constructive feedback. They found that children who received strong emotional and instructional support had higher achievement. Stipek and Byler (2004) conducted a study with 234 four to seven year-olds and their teachers in which they examined the nature of teaching and social climate. They found that teachers who were warm, responsive, attentive, and sensitive to children adopted more constructivist, childcentered teaching practices. They were open to inquiry and allowed their students more autonomy because they viewed their students as capable. Teachers who adopted a more didactic (controlling) style were more likely to regard their students as less capable and more in need of retention.

\section{Talk in the Classroom}

The acts of teaching and learning are mediated primarily through language (Vygotsky, 1930/1978). Since language is the primary means of communication in a classroom, the nature of the talk that occurs in this setting is important. Barnes (1975/1992) first drew attention to the role of talk in teaching and learning by examining different types of classroom discourse and indicated that language within a classroom is both a "pattern of expectations" and a "means of learning" (p. 31). Teachers use language to establish norms in a classroom community relating to power (i.e., who possesses power, how it is shared) as well as interactions and relationships (among teachers and children). 
Mercer (2000) indicates that teachers can create a classroom climate conducive to collaboration by encouraging students to engage in "interthinking", the "joint, coordinated intellectual activity which people regularly accomplish using language" (p. 16).

Essentially, interthinking is the collective thinking that occurs during "exploratory talk" (Barnes, 2008). Exploratory talk is marked by hesitations, rephrasing, tentativeness, and changes in direction as speakers conceive and respond to new ideas. It occurs when group members actively construct meaning together as they engage in learning tasks (Pantaleo, 2007). As group members use exploratory talk to participate in interthinking, they can arrive at "collective intersubjectivity." In classroom contexts, this is characterized by shared meanings among learners and mutual understandings of learning tasks (Johnston, 2003).

In productive classroom talk, teachers moved beyond the Initiation-ResponseEvaluation (I-R-E) response pattern (Cazden, 2001; Mehan, 1979) in which teachers ask a question to elicit a short response, students reply, and teachers quickly evaluate the answer (van der Veen, de Mey, van Kruistum, \& van Oers, 2016). Instead, teachers ask students to expand on their ideas, deepen their reasoning (by asking why), listen to one another, and think together (e.g., by agreeing/disagreeing, building on another's ideas), and use metacommunication to reflect on the quality of their communication (i.e., clarity of message, use of conversational ground rules). These researchers found that students steered conversations in unexpected directions as they asked questions and shared ideas. At the same time, productive classroom talk is conducive to richer conversations and deeper learning (Mercer, 2000). It makes visible students' meaning-making processes.

\section{Differentiated Instruction}


Differentiated instruction entails teachers modifying some aspect of their teaching for individual children (Tomlinson \& Imbeau, 2010). Teachers differentiate instruction in response to children's unique patterns of development and differences in their experiences, needs, strengths, and interests (McAfee \& Leong, 2002). Differentiated instruction occurs as teachers modify content, vary teaching techniques, use different instructional materials, assess different behaviors, and group children for specific purposes. It also includes teachers having flexible expectations of the skills children demonstrate and the products they produce. Teachers effectively differentiate when they know children's current proximity to knowledge and skills. In other words, when they teach and assess in children's ZPD.

Differentiated instruction in early childhood classrooms should be based on a variety of factors (Boat, Dinnebiel, \& Bae, 2010). Teachers must get to know their children well and base decisions informed by observation (kidwatching) and assessment so that they can differentiate instruction according to children's needs and capabilities. This will allow teachers to hold appropriate expectations of children. Boat et al. (2010) also recommend teaching to young children's interests to pique their curiosity and maintain their engagement during learning tasks. Specific supports during teaching and learning can include giving children an appropriate amount of time to process information and respond, as well as providing addition signals such as gesture and reminders. Finally, teachers can explicitly model desired behaviors and perform the task with a child (such as hand-over-hand).

\section{Interactive Reading}


Teachers have the opportunity to expose children to different types of text during read aloud, in which the teacher reads to a single child or group of children. It often involves gathering in a space with the teacher at the front and center of the children, reading in a voice that everyone can hear, and showing children the pictures. Reading aloud to children is an effective instructional technique that is well supported in the research literature (Kimmel \& Segel, 1988; Klesius, \& Griffith, 1996; Morrow, 2003; Richardson, 2000; Trelease, 1979). However, experts also indicate that reading should be interactive since reading aloud to young children without responding to the text has few implications for developing language, literacy, and content knowledge (Beck \& McKeown, 2001; Freebody \& Luke, 2003; Meyer, Wardrop, Stahl, \& Linn, 1994).

Educational experts who write about research-based teaching practices recommend that teachers use think aloud techniques during interactive reading to make their responses available to the group as they model comprehension strategies (Harvey \& Goudvis, 2007; Keene \& Zimmerman, 1997). They think aloud by sharing ideas, making connections, asking questions, as well as making inferences and predictions. Frequent verbal exchanges during interactive reading also enable teachers to scaffold and assess children's uses of meaning-making strategies (Chambers, 2011; Hall, 2013; Hargrave \& Senechal, 2000; McGee \& Schickedanz, 2007; Wiseman, 2011; Wolf, Carey, \& Mieras, 1996). Interactive reading is an ideal time for reflection and discussion as teachers and children take aesthetic and efferent stances to ideas in the text (Rosenblatt, 1978) and continue to refine their initial evocations (Rosenblatt, 1998).

Wiseman (2011) indicated interactive read aloud provides opportunities for openended response in which meaning is co-constructed through dialogue, 
There are compelling reasons to approach reading instruction as an active transaction of establishing connections between children's lives and experiences with making sense of literature by encouraging children to build on their knowledge and extend their story interpretations through conversation surrounding the text (p. 437).

Klesius and Griffith (1996) describe key aspects of interactive reading: these events are informal and conversational, occur in small groups, teacher and child-initiated episodes are balanced, and meaning is negotiated through social interaction and the exchange of ideas. Adults provide scaffolded opportunities for children to use higher order cognitive skills such as critical thinking, problem solving, and inferring. Sipe (2008) explored teachers' role during interactive reading as fellow wonderer, speculator, and interpreter as they model responses. Fisher et al. (2004) outlined essential components of effective teacher-guided interactive reading:

- Texts are appropriate to students' interests and matched to their developmental, emotional, and social needs;

- Teachers establish a clear purpose;

- They preview and practice readings;

- Teachers model fluent and expressive reading;

- They stop periodically to invite dialogue; and

- $\quad$ They tie reading to independent literacy activities (e.g., writing, dramatic play).

These actions help ensure that teachers are prepared and they can maximize the benefits of read aloud time. 
Children's language development. Interactive reading supports young children's oral language skills as they gain experience in articulating their thoughts (Dickinson \& Smith, 1994) and their vocabulary development as they are exposed to novel words in context (Zucker, Cabell, Justice, Pentimonti, \& Kaderavek, 2013). Farrant and Zubrick (2012) found joint parent-child book reading increased young children's vocabulary development and concluded, "there is convergent evidence indicating that parent-child book reading plays a causal role in children's vocabulary development" (p. 357). Elley (1989) found teachers' scaffolding and elaboration of targeted words during shared reading correlates with greater vocabulary gains than when teachers offered no explanation. Suggate, Lenhard, Neudecker, and Schneider (2013) found children learned more vocabulary in social contexts (story telling and shared reading) than when reading to themselves. These scholars concluded, "it is often the conversation around a book that leads to language learning" (p. 565) and attributed the largest vocabulary gains to the social interactions characteristic of interactive reading.

Children's meaning making. Interactive reading techniques can support young children's comprehension, the ability to make meaning from text (Durkin, 1978), as they learn to actively use meaning making strategies (Fisher et al., 2004; Fountas \& Pinnell, 2006; Hoyt, 2007; McGee \& Schickedanz, 2007; Smolkin \& Donovan, 2002; Tompkins, 2009). Danis, Bernard, and Leproux (2000) found adults could support children's abilities to think abstractly in the context of shared storybook reading as children often adjust the level of abstraction to match that of adults. Mulyani (2011) concurred that adults can model higher-order thinking through talk. They can move the dialogue to higher levels of abstraction by posing inferential questions that elicit more cognitively challenging 
responses associated with inferring (Zucker, Justice, Piasta, \& Kaderavek, 2010).

Tompkins, Guo, and Justice (2012) found children's inferences significantly related to comprehension.

Harvey and Goudvis (2007) state that reading is thinking, and the goal of reading is to actively construct meaning. Morrow (2007) recommends that preschool teachers model and scaffold the meaning making strategies they want children to develop. Teachers can help children understand the actions strategic readers take by thinking aloud as they read (Keene \& Zimmerman, 1997). Thinking aloud is a way to introduce children to metacognition as it draws attention to the thinking process (Dorl, 2007). Harvey and Goudvis (2007) advise teachers to "peel back the layers of their thinking" (p. 45) to reveal their thought processes. Dorl (2007) indicates the process of thinking aloud with young children involves combining language with visual cues such as gestures and props. As preschool teachers use think aloud along with other modes of communication, their meaning making processes become more concrete for children (Morrow, 2007). McGee and Richgels (2014) recommend preschool teachers model their own meaning making and scaffold young children's by sharing their personal connections and inferring characters' thoughts and feelings as they read aloud.

Harvey and Goudvis (2007) indicate that children naturally connect ideas in texts to their own lives. They are able to determine how events in stories and facts about everyday objects relate to their personal experiences. Intertextual connections occur when readers construct meaning as they engage with one text by referencing another familiar text (Kristeva, 1980). As children gain exposure to a variety of texts, they can establish intertextual connections by noticing similarities across texts, which can include other 
media besides books. Readers make connections to the larger world when they relate ideas in the text to their general world knowledge (Keene \& Zimmerman, 1997). As children's knowledge of the larger world increases, they begin to formulate connections between texts and the real world that extend beyond their personal experiences.

When inferring, the reader goes beyond the literal meaning of a text to draw conclusions "after considering what is read in relation to one's beliefs, knowledge, and experience" (Keene \& Zimmerman, 1997, p. 153). Inferring is an act of imagination as the reader considers possible meanings while in continuous dialogue with the text. As readers progress through the text, they encounter new ideas, which compel new inferences. Since readers access their distinct knowledge and experiences, inferences are unique to the individual (Keene \& Zimmerman, 1997). Oakhill, Cain, and Bryant (2003) found that children (ages seven to nine) are unlikely to spontaneously generate inferences. Dougherty Stahl (2014) recommends that teachers model inferring for young children by thinking aloud. Kendeou, Bohn-Gettler, White, and van den Broek (2008) found that, with adult support, preschoolers as young as age four can generate inferences during reading. Tompkins et al. (2012) conducted a study in which they examined the inferring abilities of 42 four and five-year olds as the children narrated wordless picturebooks. The researchers discovered children could infer characters' actions and mental states (i.e., thoughts, feelings) from the pictures. Kendeou et al. (2008) discovered that young children's inferring abilities were highly related to comprehension, which makes inferring a vital reading skill. Prediction is a type of inference in which readers draw from their schema as well as clues in the text to infer what will happen as they continue reading (Keene \& 
Zimmerman, 1997). The ongoing cycle of predicting and confirming (or disconfirming) propels the reading forward.

Interactive reading with fictional and nonfiction literature. The kind of text influences the nature and quality of talk that occurs during interactive reading. Moschovaki and Meadows (2005) observed a "book effect" in which nonfiction literature elicited more prediction, analysis, and reasoning than fiction. Preschoolers confirmed (or disconfirmed) their predictions and formulated new hypotheses based on events. They analyzed text structures, such as compare/contrast and cause/effect. Torr and Clugston (1999) compared the type and frequency of questions adults (teachers and mothers) asked preschoolers during interactive readings of fiction and nonfiction books (in dyads). They found questions differed according to the type of text. Adults asked more questions that required children to label aspects of the story relating to characters, setting, and plot (i.e., who, what, when, where questions) when reading fiction and questions requiring an explanation (i.e., why, how) with nonfiction. These authors suggest the different questioning techniques are due to the different forms of knowledge between these types of text. Hasan (1992) indicates "why" questions tend to elicit reasoning because children must legitimize or offer evidence for their claims. Torr and Clugston (1999) assert questions that require reasoning play an important role in the construction of knowledge. They concluded the transactions surrounding fiction and nonfiction reading place different cognitive demands on children and there were differences in the questioning and reasoning patterns between adults and preschoolers across types of text.

In their study of 20 teachers reading one fiction and one nonfiction picturebook to their whole classes (10-24 children) of preschoolers (ages three to five), Price et al. (2012) 
found nonfiction read aloud sessions lasted longer than reading fiction due to more frequent interactions and extended talk turns. These researchers documented more teacher talk during nonfiction than fiction readings (they purposely omitted hybrid texts). They did not analyze children's talk. They found teachers drew children's attention to pictures and labels and offered more descriptions, comments, and questions. Teachers supported children's comprehension by connecting text ideas to real world examples. They found similarities and differences in teachers' talk across types of text. Teachers were consistent in their tendencies to talk more or less, they focused more on content, and less on print and book conventions. One unexpected finding was teachers used similar rates of predicting, explaining, and defining across types of text, which contradicts findings by Moschovaki and Meadows (2005) and Torr and Clugston (1999).

Zucker et al. (2010) reported nonfiction generated more inferential talk among preschoolers and their teachers, suggesting these texts are appropriate choices for moving the dialogue to higher levels of abstraction. Price et al. (2009) found nonfiction elicited more cognitively demanding talk (e.g., predictions, reasoning, explanations) among preschoolers and parents. They interacted longer, engaged in more talk turns, and each utterance was for a longer duration. Parents used a more diverse vocabulary, gave increased feedback, and provided more acknowledgements with nonfiction than fiction.

Torr and Clugston (1999) also found children used the technical vocabulary (i.e., discipline-specific terminology not used in everyday life) to which they were exposed. Not only did adults and children use many words from the text in their discourse, they used technical vocabulary beyond specific terms found in the readings. In other words, interactive reading activities appeared to invite participants to include related technical 
vocabulary in their talk. Adults also asked for definitions and defined and elaborated on technical terms. For example, adults asked children what certain words meant as well as offered a definition or description. Torr and Clugston (1999) concluded nonfiction reading afforded participants the opportunity to use language as a tool for reasoning, learning genre-specific language, and acquiring technical vocabulary. They also noted nonfiction appealed to young children's sense of wonder as they expressed curiosity about topics explored in their informational readings.

Price et al. (2012) found teachers read fiction and nonfiction literature differently. Teachers tended to read all of the text in fiction but significantly less in nonfiction books. During nonfiction read aloud sessions, teachers drew children's attention to pictures and labels as well as offered descriptions and text-to-life connections. Nonfiction readings took longer, likely due to increased teacher and child interactions. These researchers noted teachers worked harder for a longer duration with nonfiction than with fiction. They indicated important areas of future research are to inquire about the reasons teachers read nonfiction texts infrequently, ways to support teachers' increased use of nonfiction, the differential effects of type of text on children's learning, and how children's talk influences dialogue during interactive reading.

The literature on preschool teachers' read aloud practices is mixed. While some preschool teachers are intentional in their read aloud practices, Damber (2015) found that some use it primarily as a classroom management tool (e.g., during transitions, as a timefiller, requiring children to be passive listeners) rather than a purposeful instructional activity. Preschool teachers often lacked purpose in text selection and reading procedures. Moreover, extended talk involving the text was not routine; teachers did not encourage 
response. Damber (2015) also noted read aloud had low-priority status and was frequently cancelled for events deemed more important.

Interactive reading in preschool. Interactive reading is an important component of the preschool curriculum. Sipe (2008) offers advice for ways to make this event especially successful. First of all, it should be highly structured, occurring at certain times, in particular spaces, and as part of established routines. These help make it a regular part of classroom life. Sipe (2008) indicates teachers should encourage all types of response and remain receptive to the variety of response styles children display. Children should have plenty of opportunities to talk throughout and after the reading as way of constructing meaning together. Sipe (2008) also encourages teachers and children to exploit all parts of the book (e.g., peritextual elements, visuals, etc.) as a way of exploring the unique affordances of individual texts.

Preschool teachers' interactive reading also supports other emergent literacy skills. Justice, Kaderavek, Fan, Safka, and Hunt (2009) conducted a study of 23 preschool teachers, 106 preschoolers (59 boys, 47 girls) for 120 sessions (four times per week over a 30-week period) on the effects of teachers' print referencing on children's print knowledge. Print referencing can be conceptualized as the readers" "deliberate integration of verbal and nonverbal behaviors into their reading interactions to elicit children's increased attention to print" (p. 76). Teachers in the print referencing condition received professional development and an instructional manual on print-referencing techniques prior to the study. Preschoolers whose teachers used print-referencing techniques during interactive reading demonstrated more print knowledge (i.e., concepts of print, alphabetic knowledge, name-writing ability) than children whose teachers did not use print- 
referencing techniques. That is, they gained more knowledge of print organization and directionality, the functions of print, alphabetic knowledge, and expressing meaning through writing (Justice et al., 2009). This is important because print knowledge is associated with increased literacy development (Hovland, Gapp, \& Theis, 2011; Joffe, 2009; Justice \& Ezell, 2004; Lovelace \& Stewart, 2007). As research shows, there is a strong rationale for adults using interactive reading techniques when reading with young children.

\section{Small Group Instruction}

Several scholars recommend that teachers incorporate small group instruction into their practice (Cooper, MacGregor, Smith, \& Robinson, 2000; Magruder et al., 2013; Milburn et al., 2014; Pianta et al., 2014; Piasta \& Wagner, 2010; Roberts \& Neal, 2004; Wasik, 2008; Yamauchi, Im, \& Mark, 2013). In this structure, a teacher and a handful of students engage in teaching and learning for a specific purpose (Morrow, 2007; Wasik, 2008). Small groups are distinct from learning centers. In small groups, the teacher plays an active role by planning activities, developing clear objectives, and often using more direct instruction. In centers, children take the lead in exploration while the teacher assumes a more passive role (often as an observer) (Wasik, 2008).

Wyatt and Chapman-DeSousa (2017) indicate small group instruction is "actually a different kind of pedagogical practice, which brings new ways of thinking about time, space, and interactions" (p. 69). Their study explored 14 early childhood special education, kindergarten, first grade, and second grade teachers' transitions from teaching exclusively in whole groups to incorporating small groups as the primary setting for instruction. Teachers shared their challenges and new conceptualizations of teaching after 
adopting this structure. Wyatt and Chapman-DeSousa (2017) found that teachers made adjustments to time management and goals, as well as classroom management. Teachers learned they could not cover as much material because students were more engaged in discussions. This led them to adopt the strategy of teaching fewer concepts but exploring them more deeply. They also felt they had lost control of the rest of the class and had to grapple with the management of students working independently. Their new approach was to provide activities that were continuous and familiar (e.g., reading, writing, computer work) rather than introducing new work that required direct instruction.

As the teachers in Wyatt and Chapman-DeSousa's (2017) study shifted from whole class to small groups, they experienced a move toward "teaching as interaction" (p. 66) and turned away from their role as expert toward facilitator, co-participant, and collaborator. They found themselves using inclusive language, such as "we". These teachers discovered that small group settings gave them closer proximity to their students and were conducive to formative assessment; they learned to listen and question as well as scaffold students' thinking as opposed to just asking questions.

These teachers also noticed changes in their students. Children who had been more reticent became much more talkative. This is consistent with van Kleek's (2008) statement that verbal exchanges tend to decrease as group size increases. Students gained confidence and took more risks with ideas as they engaged in meaningful and authentic discussions. One teacher enhanced the quality of conversations by moving toward "discourse-oriented" (p. 68) talk embedded with vocabulary and content. Some students only wanted to talk to the teacher, motivating teachers to discover ways to facilitate dialogue among children. Another issue was that some students seemed to maintain familiar roles of teacher-as- 
expert and student-as-novice, leading teachers to find ways to position students as experts.

Teaching and learning in small group contexts can be helpful to teachers and beneficial to children because it is conducive to high quality teaching and strategy instruction (Dougherty Stahl, 2014). Small group instruction allows teachers to attend to, and observe, individual children; differentiate instruction; scaffold learning; conduct assessments (e.g., questioning, probing for more information, observing); and deliver appropriate feedback (Morrow, 2007; Wasik, 2008). This gives teachers more opportunities to notice when children share their knowledge, to identify children's skills (Morrow, 2007; Pianta et al., 2014), and build on children's prior knowledge (Yamauchi et al., 2013). If the group is larger, it impedes the teacher's capability to individualize instruction and facilitate interaction (Morrow, 1997). Teachers also have better classroom management in small groups as opposed to whole class contexts; they spend less time and energy managing children and more time teaching content (Logue, 2006).

This structure is associated with increased interaction between teachers and students (Cooper et al., 2000; Hindman et al., 2008; Morrow, 2007). Children enjoy more frequent and higher quality interactions with their teacher in small groups, which is important because quality of teacher-child interactions impacts children's academic and social development (Curby et al., 2009). Turnbull, Anthony, Justice, and Bowles (2009) examined teachers' language stimulation techniques in 14 classrooms (14 teachers, 14 assistants) with 197 preschoolers and coded 5,017 utterances. They discovered teachers' language stimulation occurred most frequently in small groups. Girolametto, Hoaken, Weitzman, and van Lieshout (2000) conducted a study with 40 preschoolers (ages 32-52 months) and found that teachers addressed up to three quarters of children's utterances 
during activities; they attributed this high frequency of response to the small group size. In a study with 26 teachers and 104 toddlers and preschoolers, Girolametto and Weitzman (2002) found teachers asked many questions during small group activities to facilitate conversations. In their study of 39 preschool teachers working with small groups (up to six children) of children (ages 3-5 years), Tompkins et al. (2013) also noted a high amount of teacher questioning during small group activity time. Moreover, teachers asked many inferential questions, requiring children to use reasoning skills to think more abstractly. As teachers raised the level of abstraction in their talk (moving away from the here-and-now), children also raised the level of abstraction in their talk.

Small group interactive reading. Small groups provide an ideal setting for shared book reading (Wasik, 2008). It affords children close proximity to the teacher and the book, allowing each child to hear the teacher and see the book better. It provides a context for teaching specific emergent literacy skills. In small groups, each child has more opportunities to comment and ask questions and for the teacher to respond, making it ideal for social interaction and social learning (Morrow, 2007; Morrow \& Smith, 1990; Schreiber \& Valle, 2013; Wasik, 2008). Teachers can facilitate elaborative conversations around ideas in the text, which maximizes learning and engagement (Cochran-Smith, 1984, Pollard-Durodola et al., 2016). Pantaleo (2007) studied the interthinking, exploratory talk, and collective intersubjectivity within small groups of first graders as they collaboratively reasoned through their understandings of characters and story events after hearing fictional stories read aloud. During these conversations, a supportive adult facilitated generative dialogue by posing open-ended questions, requesting elaboration, 
and urging children to interpret visual elements to elicit deeper thinking. The adult also described, explained, and provided clarification to enrich children's understandings.

In a study of interactive reading among 76 preschoolers (ages 44-69 months) and their teachers, Milburn et al., (2014) found small groups to be an appropriate context for elaborative conversations around texts. Teachers used several interactive strategies, such as summarizing, imitation, expansions, acknowledgements, and open questions (without a simple yes/no answers) to facilitate multiple conversational turns. They also embedded vocabulary in their discussions. In Blewitt and Langan's (2016) study of 40 preschoolers (ages 42-49 months), children learned more targeted vocabulary words when teachers used a high degree of extratextual talk. Teachers asked children to point to illustrations of targeted words and responded to children, resulting in higher word learning than children whose teachers did not use this strategy. They concluded that highly engaging interactive conversations using and novel words during shared book reading is an effective way to teach new vocabulary.

Morrow and Smith (1990) found teachers read differently according to grouping (i.e., one-on-one, small group, and whole class structures). Teachers gave few negative responses in one-on-one and small groups, offered more praise in small groups than large groups, and made more classroom management comments in whole group settings (which were also more formal). In one-on-one situations, the teacher and child were more likely to maintain their respective roles and power positions. In small groups, the boundaries between expert and novice were indistinct as children took part in active discussions. Children's retellings from small group readings also yielded the highest comprehension (via retelling) scores. 
Small groups in preschool. Small groups are an ideal setting for intensive teaching in preschool (Blewitt \& Langan, 2016; Piasta \& Wagner, 2010; Pollard-Durodola et al., 2016; Roberts \& Neal, 2004; Sin Goh et al., 2012; Tompkins et al., 2013). Teachers and children have more opportunities for social interaction, exchanging ideas, exploring concepts, observing each other, and collaboration. Wasik (2008) offers guidelines for small group instruction in preschool. First of all, groups should not exceed five children. Morrow and Smith (1990) recommend 3-4 children for small group read aloud for high engagement. Instruction should be intentional and organized so there is "careful coordination among the activity, instruction, and needs of participants" (Wasik, 2008, p. 517) to maximize learning opportunities. The teacher's learning goals should determine group size so that tasks stay manageable (Wasik, 2008). In their study involving 73 preschoolers, Schlechter, Rosenkranz, Fees, and Dzewaltowski (2017) found that children exhibited increased physical activity in small groups than large groups, likely due to higher participation. This high level of activity might be more difficult for teachers to manage in large groups. Small groups are also flexible. Teachers can assemble children for specific purposes and explore different content to address their curricular goals. Children can be grouped according to similar interests and to work on specific skills (Morrow, 2007) or heterogeneously to provide opportunities for children to learn from more knowledgeable peers (Wasik, 2008).

Small group language and literacy instruction. Small groups provide an ideal setting for young children's language and literacy development. This is important because adult-child conversations are essential for young children's language development (Zimmerman et al., 2009). Piasta and Wagner (2010) conducted a meta-analysis of 63 
studies of young children's alphabet learning along five dimensions: "letter knowledge, letter sound knowledge, letter name fluency, letter sound fluency, and letter writing" (p. 10). They found that small group instruction was more effective for developing children's alphabetic knowledge than one-on-one tutoring. Jones and Henriksen (2013) conducted action research with first graders in small groups (three to six children) to target specific literacy skills (reading and writing initial and final word sounds, reading and writing vowel digraphs, building fluency, decoding multisyllabic words and building vocabulary, monitoring comprehension and fix-up strategies, comprehension, asking/answering questions). Children flexibly moved among groups according to their assessed strengths and needs. These researchers concluded that implementing small groups targeting specific skills was an effective teaching method. Beaulieu-Jones and Proctor (2016) noticed teachers successfully facilitated quiet students' capabilities as conversational leaders in a small group of second graders participating in literature discussions.

Small groups are ideal for teaching specific emergent literacy skills with preschoolers. In a 10 -month study involving 100 preschoolers, 12 teachers, two administrators, 30 assistants, and 15 volunteers, Sin Goh et al., (2012) explored the efficacy of instructional conversations (i.e., teaching through dialogue) in small groups. Instructional conversations are characterized by "a coherent focus, being interesting and engaging, having a high level of participation by all without being dominated by anyone, and resulting in new levels of understanding of the topic" (p. 306). Teachers found instructional conversations in small groups to be dialogic in nature with abundant verbal and nonverbal exchanges. They reported that it was an excellent context for scaffolding 
and assessment, supporting children's academic and social development, as well as building close personal relationships with children.

In a study involving 33 preschoolers, Roberts and Neal (2004) documented that explicit English language instruction in small groups supported children's linguistic development and English language listening comprehension. Martins et al. (2016) conducted a study with 160 five-year-old preschoolers and found that children who participated in small groups aimed at fostering invented spelling skills had more growth in this area than children who did not participate. Connor et al. (2006) investigated the effects of whole class versus individual and small group instruction among 156 preschoolers and their teachers and found that children made greater gains in 'letter and word recognition in individual or small groups than children in whole group instruction. Hindman et al. (2008) found that preschoolers participated infrequently in conversations about the readings when listening to read aloud in large groups.

Small group interactions not only support language and literacy development for native English speakers but children who are emergent bilinguals (Magruder et al., 2013). In a study involving 80 four and five year old emergent bilingual Spanish-speaking children participating in small group read aloud (two to three children per group), Collins (2010) discovered that teachers' "rich explanation" (para. 51), with multiple exposures and explicit descriptions, increased children's understandings of new words in stories.

Small group instruction across the curriculum. There are few studies on the effectiveness of teaching content besides language arts (e.g., math, science, social studies) in small groups but extant research indicates small group instruction is an effective means for exploring topics in-depth and for teaching content (Katz \& Chard, 2001). Buli- 
Holmberg and Jeyaprathaban (2016) studied various grouping structures with 83 students with special needs across 24 schools in grades one through ten during different areas of content instruction (i.e., math, science, social studies, etc.). They found that small groups were inclusive settings in which teachers differentiated for students with special needs while allowing them to observe typically developing peers. Youdale (2010) found small group math instruction in first grade to be an effective way to target counting and number identification skills.

Small groups are effective for content area learning in preschool. Klein et al. (2004) found that preschoolers learned counting, addition, seriation, shapes, and patterns more in teacher-guided small groups than in math centers or computer-assisted learning. In their study of 105 preschool children (ages 39-68 months) and their teachers, Ramani (2012) examined the ways teachers facilitated math learning games in small groups (2-3 children per group). Teachers gave feedback, modeled, and adjusted their scaffolding as children explored counting, number identification, number comparison, and using the number line. Moreover, researchers noted that children were highly engaged. PollardDurodola et al. (2016) conducted an 18-week study involving 42 preschool teachers and 252 children during which teachers read social studies and science texts in small groups (5-6 children). Children scored significantly higher in both receptive and expressive vocabularies having participated in small group interactive reading with rich contentrelated discussions.

Social learning opportunities. In small groups, children can learn from peers through observation as well as negotiate ideas to problem-solve collectively (Martins et al., 2016; Schreiber \& Valle, 2013). Studies point toward opportunities for preschoolers 
with disabilities to learn from peers in small groups. Urlacher et al. (2016) found that preschoolers with disabilities named more sight words and labeled items used during activities whereas Aldemir and Gursel (2014) documented how 4 to 6 year olds with disabilities learned from peers in small groups (e.g., recognizing concepts, such as shapes, size, amount, inside/outside, identifying numbers/math symbols). Ledford and Wolery (2015) found that preschoolers with disabilities practiced social skills by sharing materials more in small groups. Tarim (2009) found that children learn more in small groups than in large groups as children learned from each other, displayed high participation, better listening, cooperation, and sharing. They often engaged in "happy talk" (p. 327), characterized by frequent social interactions and positive statements toward each other.

\section{Multiple Ages in Early Childhood Classrooms}

Research has found there are benefits of multiple ages in early childhood classrooms because children typically remain in the same room for a few years, enabling them to form long-term relationships with their teachers and peers in their classroom community with fewer transitions (Edwards, Blaise, \& Hammer, 2009; Whaley \& Kantor, 1992). Advocates of multi-age classrooms claim that younger children benefit from observations and interactions with older children based on Vygotsky's (1930/1978) notion of learning in the zone of proximal development (ZPD), in which children learn through interactions with more advanced peers who may be functioning in their ZPD (McAfee \& Leong, 2002), as well as Bandura's social learning theory (1986), which posits that individuals learn through observation and imitation. Whaley and Kantor (1992) suggest that multi-age educational settings feel like "life together" (p. 370) in more "family-like" (p. 370) groupings that closely resemble the mixed ages of children in families. Edwards 
et al. (2009) contend that learning is bi-directional as children in multi-age settings can learn from peers of different ages; not just younger children learning from older children.

While there are advantages to multi-aged classes, there are also challenges. Children develop at different rates (McAfee \& Leong, 2002), so there will naturally be a range of developmental levels within any group of young children. Since there is a broad span of ages within a classroom, there is a wide spread in developmental levels and each child has individual needs, interests, and experiences (McAfee \& Leong, 2002). Moller, Forbes-Jones, and Hightower (2008) found that among 806 preschoolers from 70 classrooms, the wider age distribution among children did not enhance development across several domains. It is therefore essential that teachers differentiate instruction to address the developmental range of children in their classrooms and to remain sensitive to individual children's needs.

\section{Summary}

This section examines various contexts for effective teaching such as teachers' knowledge of student learning and development, curricular content and goals, and pedagogical knowledge. Effective teachers offer appropriate emotional, organizational, and instructional supports that work in conjunction to provide social and physical environments in which students can thrive. For some students, appropriate supports include differentiated instruction as teachers modify aspects of their instruction for individual learners. During exploratory talk, group members think together to refine ideas and arrive at shared meanings.

One important element of effective literacy instruction is interactive read aloud. This reading is event is conversational as adults share their thinking and elicit children's 
responses. This instructional technique supports children's oral language and vocabulary development as children gain experience with using language to communicate and are exposed to novel words in context. Adults can also support children's meaning making capabilities during interactive reading as the model and scaffold strategies and support children's use of these strategies.

Small group instruction is supported by research because it allows for frequent interactions among teachers and children. Children can receive individual attention from their teachers and interact with peers in this intimate setting. Moreover, teachers can deliver intensive instruction and carefully observe children for assessment purposes.

Finally, multiple ages in early childhood classrooms present advantages and challenges. Some researchers claim that children's interactions with peers of different ages is natural and family-like, allowing children to learn from peers of different ages and developmental levels. Since there is a range, teachers must differentiate instruction to target individual children's ZPD.

The three-part framework for effective teaching delineates the types of knowledge skilled teachers possess and how they made curricular decisions based on that knowledge. The three broad categories of classroom supports provided insight into the material and interactional aspects of teaching that are associated with positive outcomes for children. The scholarship on talk in the classroom, differentiated instruction, interactive reading, and small group instruction informed my understanding of the teaching and learning processes that occurred during small group read aloud. The literature on multiple ages in the classroom made me more aware of the potential benefits and caveats of younger and older preschoolers learning together. 


\section{Summary of Chapter Two}

My study builds on theoretical underpinnings and perspectives that are supported by a large body of research. Vygotsky's sociocultural theory is widely applied in educational research to understand how social interactions and experiences with cultural artifacts drive children's learning and development. My study draws from Rosenblatt's transactional theory, which has broad applications in educational settings because it serves as a lens for understanding readers' responses to literature. The emergent literacy perspective has garnered wide support as it recognizes that young children develop language and literacy through social interactions, observation and imitation, and exploration of materials. These early experiences lay the foundation for later reading and writing. The literature on contexts for effective teaching informed my understandings of the decisions teachers made, teaching practices, and classroom supports that were evident as the teachers in my study designed and implemented curriculum.

The scholarship on shared reading, reader response, and young children's literacy development is diverse. Several studies examine reader response and literacy development with older populations such as school-age children (kindergarten and older). Predictive studies establish links between young children's skills and later reading ability/academic achievement in elementary school and beyond. Other studies explore shared reading and reader response with special populations such as emergent bilinguals, children in foreign countries, those with specific language impairments, hearing loss, disabilities or who are developmentally delayed, low income, or deemed at risk.

Studies with preschoolers typically examine limited responses to fictional picturebooks that include talk, drawing, writing, and dramatic play. Some studies inquire 
into preschoolers' responses to repeated readings or targeted skill instruction such as phonological and phonemic awareness, letter knowledge, print referencing, vocabulary development, or book-handling skills. Others focus on preschoolers' responses to certain topics, subject matter content, or genres (e.g., math texts, wordless picturebooks, genderthemed books, multicultural literature). Most studies exclusively use fictional texts. Others explore little known aspects of emergent reading such as eye movement or young children's uses of technological devices. Some evaluate particular curricula or programs such as Head Start.

Another body of literature pertaining to shared reading with preschoolers focuses on the adult reader (usually a teacher or parent). Many studies that investigate teachers' read aloud practices take place during large group time. Others inquire into read aloud in teacher-child or parent-child dyads. Some do not include adults and look exclusively at young children's readings of picturebooks. There are few studies that examine preschoolers' response and shared reading in small groups.

My study is distinct in several ways. There has been little exploration of the uses of nonfiction texts in preschool or the similarities and differences between read aloud with fiction and nonfiction literature in preschool. The research on young children's responses to nonfiction is limited. The few studies that compare adults' reading techniques with fiction and nonfiction took place in large groups or dyads, not small groups. Moreover, some studies only analyze teachers' utterances. The scope of my study is unique as it examines teachers' reading with both types of text. I inquire into teacher and children's modes of communication rather than exclusively focusing on teachers' talk. 


\section{CHAPTER THREE: METHODOLOGY \\ Purpose of the Study}

One purpose of this instrumental case study was to investigate how preschool teachers model reading strategies and scaffold children's meaning making with fiction and nonfiction literature with small groups of children, ages two-and-a-half to five years, during choice time in the mornings and afternoons. Another purpose was to investigate teachers' and children's responses to fictional stories and nonfiction books.

\section{Research Questions}

This study explored preschool teachers' read aloud practices and children's responses with fiction and nonfiction texts in small groups. My original questions included the following research question and sub-questions: What are teachers' roles and children's responses during small group read aloud and response activities to fiction and nonfiction texts in one preschool classroom?

- What past and current professional experiences have teachers had with high quality fiction and nonfiction texts?

- How do teachers design curriculum to offer children opportunities to respond?

- What instructional strategies do teachers use during read alouds to elicit children's responses?

- How do children respond during read alouds?

- What instructional strategies do teacher use during response activities to elicit children's responses?

- How do children respond during planned and spontaneous activities after read aloud? 
As I gathered and analyzed data, I discovered that some questions were less salient and others could be combined. I revised my questions to bring them into sharper focus. My final main question and sub-questions were: What are teachers' roles and children's responses during small group read aloud with fiction and nonfiction texts for children ages two-and-a-half to five years old in one preschool classroom?

1. How do children respond during read aloud?

2. How do teachers use modeling and scaffolding during small group read aloud to support children's meaning making?

These questions guided my inquiry into teachers' modeling of reading strategies and scaffolding of children's meaning making, as well as teachers' and children's responses to fiction and nonfiction literature that took place in small groups. The design was flexible as data were analyzed and new understandings emerged. I made necessary adjustments to my research questions as I observed small group read aloud sessions and analyzed the data.

\section{Methodological Frameworks}

To answer these research questions, I drew from different ontological, epistemological, and methodological paradigms and traditions: social constructivism (Denzin \& Lincoln, 2011), instrumental case study (Stake, 1995), and constantcomparative analysis (Glaser \& Strauss, 1967).

\section{Social Constructivism}

From a social constructivist or interpretivist orientation (Denzin \& Lincoln, 2011), I hold the ontological belief (i.e., beliefs about the nature of reality) that individuals construct their own meanings through their lived experiences. Therefore, there are multiple realities. This interpretive framework emphasizes the social construction of 
reality; reality is formed primarily through social interactions as well as cultural and historical contexts in which individuals live their lives (Creswell, 2013; Leavy, 2017). Working from this orientation, I believe that the realities individuals construct are subjective to their unique experiences, and I strive to interpret the meanings participants hold about the phenomena under investigation (Creswell, 2013; Leavy, 2017). In regard to axiology (i.e., the role of values), I acknowledge that my own subjective reality and biases influence my interpretation of others' lived experiences (Creswell, 2013). Nevertheless, I seek to preserve and represent participants' unique realities. While it is impossible to objectively capture others' subjective realities, they can be interpreted with care and sensitivity.

A social constructivist or interpretivist orientation was best suited for my study as I sought to interpret the meanings two preschool teachers have constructed about their lived experiences of reading aloud fiction and nonfiction literature with children in small groups. I also sought to understand the meanings children formed about their experiences of participating in small group read aloud events.

\section{Instrumental Case Study}

I utilized instrumental case study methodology since the goal was to seek a general understanding of phenomena through the study of a particular case (Stake, 1995). Stake described a case as "a specific, a complex, functioning thing" (p. 2), an entity with clear boundaries. Qualitative case study is interpretive; it involves careful observation to describe the nuances and intricacies of the case. It is also holistic; the goal is to gain a deeper understanding by capturing the complexities of a case to construct a comprehensive picture. Qualitative case study involves extended involvement at the site of 
inquiry to collect and analyze an array of data. It is often written to draw readers in and develop readers" "vicarious experiences" (Stake, 1995, p. 63) by offering "thick description" (Geertz, 1973) of the particularities of the case. It often includes vignettes and personal accounts (Van Maanan, 1988) as well as detailed descriptions of physical spaces, social interactions, and artifacts. In Chapter Four, I describe a smaller set of read aloud episodes in-depth to provide "thick description" (Geertz, 1973) of these events.

In this study, the case is the small group read aloud of fiction and nonfiction among teachers and children ages two-and-a-half to five years old that occurred in the mornings and afternoons during choice time in one preschool classroom. These events included one of the two classroom teachers and different children each day and took place in different areas of the classroom, depending on the topic of the book and related response activity. The case does not include the teacher and children who did not participate at that time, other times in the school day, nor activities in other areas of the classroom.

\section{Constant-Comparative Analysis}

I utilized constant-comparative techniques to analyze data (Glaser \& Strauss, 1967, Strauss \& Corbin, 1998). I conducted open coding, categorization, and abstracted themes (Leavy, 2017). The unit of analysis was the utterance, specific expressions of meaning that vary in length, content, and complexity (Zhang \& Wildemuth, 2005). They are categorically distinct and whole; they cannot be reduced any further (Krippendorff, 2004).

\section{Research Design}

\section{Considerations for Child Study}


Shaw, Louca-Mai, and Davey (2011) state that conducting research with children is important because it is an opportunity to investigate children's perspectives and lived experiences. They conclude, "Children and young people are social actors with a unique perspective and insight into their own reality" (p. 4). They suggest that researchers consider children's perspectives and experiences with the phenomena under investigation; children's voices and perspectives should be retained and not altered by adults' interpretations. Shaw et al. (2011) indicate that research with very young children (under age 5) needs to include certain components. First, adults who have close relationships with children (e.g., teachers, families) play important roles. They serve as gatekeepers who can explain the research process in the plainest language possible so that children have better understandings of their parts in a study. These adults are also important for helping children feel comfortable and in obtaining child assent. A child's assent is an agreement to participate that is signaled verbally (saying yes or no), behaviorally (level of participation, responding by marking or coloring), or emotionally (appearing excited, anxious) given in response to the researcher's request for the child to participate (Dockett, Einarsdottir, \& Perry, 2012). In this study, the classroom teachers briefly explained to children that I wanted to learn how they read with their teachers and I would be using a camera and voice recorder.

Next, Shaw et al. (2011) indicate that multiple data collection methods are crucial and must involve adults (e.g., teachers, families) who can supplement and contextualize data children give to provide a more complex account of events. In this study, I collected data from the teachers and children as they read together, as well as interview data from 
the teachers in which they discussed their perspectives and experiences with reading to children.

Finally, researchers can take certain actions during data collection with very young children to help ensure it is a positive experience for everyone. To address power imbalances, they can create a relaxed atmosphere and stay sensitive to children's signals that they do not want to participate. They should be warm and friendly, dress informally yet appropriately, and avoid formal seating such as behind a desk (researchers can share space with children, yet be unobtrusive). Researchers should also reassure children they are not being tested; there are no right or wrong answers. Questions and comments need to be short and simple. Adults should also listen carefully to ensure they are attending to children's meanings. Since young children have short attention spans, data should be collected in multiple brief sessions over time rather than fewer long sessions. In this study, my interview questions with children were extremely brief and conversational. Since child assent is ongoing, I asked children if I could ask them a few questions and when I sensed that children were not going to supply additional information, I ended the exchange.

\section{Site of Study}

The study took place at a laboratory school on a large midwestern university campus. The school serves approximately 75 young children and their families in a fullday, 12-month program. This school has four classrooms: one infant/toddler and three mixed-age preschool rooms. The laboratory school serves as a site for research and partners with different colleges on campus and community organizations to provide comprehensive services and programs for children and families. 
Teachers held bachelor's degrees or higher and participated in ongoing professional development. They mentored preservice teachers in child development and early education programs. Teachers modeled exemplary instructional practices and designed curriculum based on early learning standards. They implemented thematic units derived from children's interests and to expose them to new content.

\section{Participants}

Purposive sampling was used to study specific individuals engaged in certain activities at a particular site (Bogdan \& Biklen, 1998; Lavrakas, 2008). The major site of this study was one preschool classroom with two full time teachers. Both teachers were white females who had been teaching over 20 years each. The lead teacher earned a bachelor's degree in elementary education and a master's degree in early childhood special education. The assistant teacher earned a bachelor's degree in child development. There were 20 children ranging from two-and-a half to five years old in the class; 19 participated in the study. This group of children was culturally and linguistically diverse. Several children (4) were from different cultures and spoke other languages and one child had been diagnosed with Down's syndrome (see Table 1). In a multi-age room, children typically spend more than one year learning together and with their teachers. This allows them to form lasting social bonds that likely contribute to a strong sense of community.

\section{Classroom Environment}

The teachers fostered active learning in a variety of ways. Children enjoyed extended periods of uninterrupted exploration and play each day. There was a balance of teacher-led and child-initiated activities (i.e., pre-planned and spontaneous) and a range of grouping structures (e.g., large/whole, small, one-on-one). Children had plenty of 
opportunities for social interaction and to use various learning materials in different areas of the room. Many of their activities were open-ended, which enabled children to direct their play and activity. The classroom environment was sectioned into different areas that include dramatic play, blocks/construction, puzzles/games, art, writing, science, math, library, technology, and a sensory table (Appendix C). In addition, outdoor spaces included a park-like setting and learning garden. Children regularly took walking field trips to a nearby pond and other welcoming spaces on campus.

I chose this site because teachers strove to create a literacy-rich environment and regularly read nonfiction with their young students. Reading and writing materials were placed throughout the classroom so children could incorporate literacy activities into their play. Teachers rotated materials regularly to maintain children's interests and to provide exposure to a variety of materials. Teachers read to children multiple times per day in different grouping structures. Twice a day, they read aloud to the whole class, then read twice interactively in small groups, and one-on-one sporadically. Small group readings were immediately followed by activities such as cooking, writing, and art, etc.

\section{Researcher Role}

I had overlapping roles depending on the data collection procedure. As the research instrument, I conducted face-to-face interviews with each teacher individually. While in the classroom, I was an observer participant (Leavy, 2017; Merriam, 2009), a passive observer in the classroom. Dyson and Genishi (2005) describe this role as a "regular, nonjudgmental, attentive classroom participant" (p. 52). Corsaro (2003) suggests researchers take a reactive stance and usually speak only when spoken to. The exception 
was when I briefly asked children a few questions (informal child interviews) about their work after they participated in the readings.

Children quickly became accustomed to, and were generally uninterested in, my presence in the classroom. Occasionally, a teacher reminded a child to ignore the audio recorder. Once in a while, children scribbled on my notepad with my pencil or performed in front of my camera. One child requested that I audio and video record her reading some books. She spontaneously held the audio recorder to her mouth as she read aloud while I video recorded her. Consistent with Dyson and Genishi’s (2005) recommendation, I answered her questions or responded to her comments. At times, she asked me a question about the book and I answered her; when she was finished reading, I thanked her.

In addition to being the interviewer and observer participant, I also helped supply books for the classroom throughout the study. When I asked the teachers how I could support them during the study, they disclosed that they invest substantial time and energy into gathering books. During their planning sessions, they requested that I bring both fiction and nonfiction books on topics relating to each unit of study. The books were placed in the different areas of the classroom and children's bookshelves. A few of the books I supplied were included in the study (see Children's Literature references and Appendix D).

\section{Data Sources}

When classroom researchers use a wide variety of data collection methods, they are able to gather data from different sources that paint a more complete portrait of classroom life. Using different methods and collecting multiple forms of data contribute to triangulation, which provides corroborating evidence to support findings and gives 
validity to the work (Creswell, 2013; Denzin, 1984). In qualitative studies, researchers collect data primarily through observation, interviewing, and reviewing artifacts (Leavy, 2017; Merriam, 1998; Stake, 1995). Useful data serve as representations of the phenomena under investigation. The data I found most useful were the types often created by early childhood teachers and young children (Castle, 2012).

Table 1

Research Questions and Data Sources

\begin{tabular}{|c|c|}
\hline Research Question & Data Source \\
\hline $\begin{array}{l}\text { What are teachers' roles and children's } \\
\text { responses during small group read aloud } \\
\text { with fiction and nonfiction texts for } \\
\text { children ages two-and-a-half to five years } \\
\text { old in one preschool classroom? }\end{array}$ & $\begin{array}{l}\text { Observations of read aloud } \\
\text { episodes, teacher interviews, child } \\
\text { interviews, analytic memos }\end{array}$ \\
\hline $\begin{array}{l}\text { - How do children respond during } \\
\text { read aloud? }\end{array}$ & $\begin{array}{l}\text { - Observations of read aloud, teacher } \\
\text { interviews, child interviews }\end{array}$ \\
\hline $\begin{array}{l}\text { How do teachers use modeling and } \\
\text { scaffolding during small group read } \\
\text { aloud to support children's meaning } \\
\text { making? }\end{array}$ & $\begin{array}{l}\text { - Observations of read aloud, teacher } \\
\text { interviews, child interviews }\end{array}$ \\
\hline
\end{tabular}

In this study, data collection procedures included:

- Teacher interviews, audio recordings

- Observation, audio/video recordings of small group reading

- Observation of teacher planning sessions, my planning notes

- Collection of teacher-created artifacts (i.e., lesson plans), photocopies

- Collection of child-created artifacts (e.g., writing samples, artwork, etc.), photographs

- Child interviews, audio/video recordings

- Analytic memos and reflections, double entry journal 


\section{Timeline}

This study took place for six weeks so I could observe teacher planning and instruction during multiple units of study (curriculum design and implementation cycles). I observed small group readings and responsive activities four to five days per week (depending on class schedule); conducted teacher interviews before, midpoint, and at the conclusion of the study; conducted child interviews intermittently; collected child-created artifacts continuously; and observed three teacher planning sessions before I began observations, then every two weeks. The Data Sources table (Appendix E) outlines types of data collected each week.

\section{Data Set}

Over the six-week period, I conducted six teacher interviews (three per teacher) six group interviews of children, three individual child interviews, 28 observations of small group reading and response activities, wrote 28 analytic memos and reflections, conducted three observations of teacher planning sessions, photographed about 12 child-created artifacts, and collected six weekly curriculum plans as well as one daily schedule. I omitted eight of the reading because they either involved a teacher reading to a single child or the texts were songbooks. These lacked a cohesive story with developed characters. I also omitted all response activities and focused exclusively on the read aloud events. I coded 20 reading sessions with 10 fiction and 10 nonfiction books. The balance in fiction and nonfiction was important so that I could draw from sufficient examples of teachers' actions and children's responses with both types of text. A teacher read a few texts twice, to different small groups. The final data set included read aloud episodes with two fictional stories and three nonfiction books (one nonfiction text was read twice). The 
findings from these read aloud sessions are representative of the findings from the larger data set. I narrowed my focus to these particular reading sessions to closely examine teachers' modeling and scaffolding strategies as well teachers' and children's responses.

Read aloud books. Books came from a variety of sources. In addition to the school library, the teachers and student teachers supplied books from their personal collections. Children also brought books from home. The teachers asked me to supplement their books. Before each unit of study, I checked books out from the local public library as well as my personal collection. I selected books that related to the unit of study. For fictional stories, I tried to locate quality books: those with relatable characters, themes and topics that are relevant to children, and illustrations that support the written text (LynchBrown \& Tomlinson, 2005). I avoided texts that were cartoonish or had underdeveloped characters. For nonfiction books, I sought quality texts that adhered to the following guidelines: content is accurate and appropriate in scope and depth, written text and visuals support comprehension, and texts display a clear pattern of organization (Bamford, Kristo, \& Lyon, 2002). I avoided nonfiction books with long dense text and those in which the facts were obviously inaccurate. Teachers then chose books from these multiple sources to read aloud in small groups. They strove to read a balance of fiction and nonfiction for each unit of study.

Teacher interviews. I interviewed teachers individually at the research site in a quiet location (i.e., teacher's office, assessment room). Interviews were semi-structured with a preset protocol of questions (Merriam, 1998). They were also conversational, which enabled me to inquire into new ideas and topics as they emerged. During all interviews, I periodically summarized teachers' statements to confirm that my interpretations 
represented their meanings. Interviews lasted from 15-25 minutes each. There were three rounds of teacher interviews (Appendix F).

The first round took place during week two of the project. The purposes of initial interviews were to learn about teachers' educational and professional development backgrounds related to read aloud and gain a sense of teachers' perspectives of reading fiction and nonfiction with children (e.g., benefits and challenges). I also inquired into their curriculum design and text selection processes (e.g., planning, choosing texts, integrating texts into the classroom environment), how they read both fiction and nonfiction in small groups (e.g., reading style, involving children, classroom management).

The second round of teacher interviews occurred midpoint through the project (week four). The purposes of these interviews were to explore teachers' reflections on reading fiction and nonfiction during the first half of the study. I also inquired into teachers' plans for the new unit of study (i.e., choice of texts, activities, materials). The third round of teacher interviews occurred at the conclusion of the project (week six). The purposes were similar to the second round: to document teachers' reflections on small group reading events. I also inquired into ways teachers' perspectives about reading fiction and nonfiction might have changed and how they planned to read with children in the future.

Observation of small group reading sessions. Observations occurred in the classroom. I observed small group reading events four or five days per week (depending on the class schedule) for about 10 to 15 minutes per session. I audio and video recorded each classroom observation. I set a small voice recorder in the middle of the group during 
all reading sessions. I video recorded with a small handheld camcorder that could also be attached to a tabletop tripod. I held the camcorder when using the tripod was not feasible. I also scribed a few notes such as the title of the book. Observations and recordings of small group reading were ongoing throughout the duration of the study.

Observations of teacher planning sessions. Teachers planned in the classroom. I observed teachers' planning sessions three times for one half hour each session. I asked a few questions (for clarification) and scribed notes throughout each planning session (Appendix G).

Collection of teacher-created artifacts. The teachers created weekly lesson plans that provided detailed records of units of study and daily activities. Teachers also followed a daily schedule (Appendix H). The weekly plans and daily schedule were posted on a bulletin board for families to read.

Child interviews. I briefly and informally interviewed individual children about their reading experiences. I asked children if I could ask them a few questions and gained their consent so that no one was coerced. No children talked to me against their will. All child interviews took place in the classroom directly following response activities. Interviews were brief (one minute or less) and informal (conversational); they caused minimal disruption to children's play/work time and activities. They did not deviate from the a priori questions approved in my Institutional Review Board (IRB) application (Appendix I).

Logs: Analytic memos and reflections. After observing in the classroom and participating in planning sessions, I recorded events with as many details as I could recall as well as my initial reflections (i.e., thoughts/reactions, questions) (Appendix J). 


\section{Data Analysis}

I simultaneously collected and analyzed data; data collection and analysis were continuous and iterative throughout the project (Leavy, 2017; Lincoln \& Guba, 1985; Merriam, 1998). Merriam (1998) explains, "Data that have been analyzed while being collected are both parsimonious and illuminating" (p. 162). After each observation of a reading event, I immediately wrote my initial impressions as an analytic memo and reflection in the form of a double entry log (Glaser, 1978; Strauss \& Corbin, 1998). The left hand column served as a record of my observations. In the right hand column, I noted my initial interpretations that included noticings, questions, and thoughts about my observations. Saldaña (2016) indicates that the function of analytic memos is to unload thoughts about participants and the phenomenon under investigation. Through writing, the researcher thinks more deeply. Saldaña (2016) suggests that analytic memos function as a "conversation with ourselves about our data" (p. 44). The memo served as a permanent record of details from reading episodes and my initial reflections on those events.

All observations were audio and video recorded. For each observation, the recording device was placed in the middle of the group (usually on the table) and clearly recorded all voices. I first transcribed the audio recording. I then transcribed the video to double check for accuracy, determine who was talking, and note significant gestures. I also scribed field notes during teacher planning sessions and transcribed those as soon as possible for organization and clarity of ideas.

Inductive analysis. Inductive data analysis allowed me to maximize receptivity to what the data showed. Initial analysis included transcriptions of all observations and interviews followed by open coding. Using constant-comparative methods, I first 
conducted open coding (Glaser \& Strauss, 1967) across data sources. Saldaña (2016) indicates that open codes "break down data into discrete parts" (p. 115), which enabled me to closely inspect the data. I conducted open coding on teacher interview transcripts, log and reflections, and observations of reading sessions. Open coding entailed labeling data as I read with my research questions in mind. I described and labeled data with a single word, short phrase, or question. For example, a teacher read the passage from The Listening Walk (Showers \& Aliki, 1961/1993, p. 20), "My father and I walk down a shady path. I do not talk. I"- (points to ear and waits for children to fill in). A child replies, "Listen." In this example, the teacher gestured and used the cloze procedure so I wrote "gesture, cloze" in the margin next to it. My coding techniques were based on an “emergent conceptual framework" (Saldaña, 2016, p. 71) as I explored diverse thematic possibilities. I also recorded the number of the research question the data piece addressed. For example, when reading Whoever You Are (Fox \& Staub, 2006) the teacher thinks aloud to share her interpretation of a picture of children from different parts of the world, "These people are all— they're all children but they all have different skin tones." Since this example relates to research question three (which asks about teachers' modeling and scaffolding techniques), I wrote and circled a " 3 " in the margin next to it (Appendix K, Appendix L).

Iterative processes involve rereading transcriptions of interviews and observations, and reexamining artifacts in search of patterns in ideas, content, and events, that inform future data collection and analysis (Leavy, 2017). I then conducted axial coding (Strauss \& Corbin, 1998) to identify categories and subcategories. Saldaña (2016) describes the process of axial coding as reassembling the data that were broken down during open 
coding. After recording these codes (labels and numbers), I strove to ensure that I had enough examples from the data to form a category, so I listed examples from the data that fell into a category. For example, I identified "Teacher Scaffolding Fiction/Asking for Connections" as a category and then listed the examples from each fiction book. Saldaña (2016) refers to this technique as "pattern coding" (p. 235) and indicates the purposes are to organize data and to assign meaning to that organization. Pattern coding enabled me to conduct an exhaustive search through the data to determine if I had sufficient examples to establish a pattern of regularities.

I then combined categories across data sources (i.e., interviews, observations, teacher planning notes, weekly curricula) to form larger, more abstract themes. Saldaña (2016) indicates that themes have become sufficiently abstract if they no longer symbolize something physical. Instead, they are representative of a concept. Finally, I returned to my data to ensure that themes, subthemes, and parts were representative of, and had strong support from, the data.

Data reduction was used due to the large amount of data collected (Miles \& Huberman, 1994). I analyzed 10 read aloud events of both fiction and nonfiction books. I also analyzed all six teacher interviews and three planning activity notes. I also checked to ensure that no new themes (that could stand alone) emerged from the data. Since data were redundant, I present episodes that are representative of the larger data set. In my report, I analyzed read aloud sessions with two fictional stories and two nonfiction books to investigate the similarities and differences in teachers' modeling and scaffolding strategies, as well as teachers' and children's responses to both types of text. I then analyzed one teacher's readings of the same nonfiction text with two small groups of 
children to take a deeper look at the teacher's modeling and scaffolding techniques with this type of text. Regarding the two teachers, my focus of analysis was across the case. The nuanced differences in findings between the two teachers did not impact the larger findings.

\section{Data Triangulation}

Multiple methods of data collection and multiple data sources (data triangulation, Leavy, 2017; Merriam, 2009) enabled me to compile corroborating evidence to support findings. For example, I was able to determine if teachers' statements during interviews were supported by their words and actions when reading aloud. I could then compare these findings with teachers' curriculum plans and my own notes from planning sessions to establish consistencies across data sources. I was able to find corroborating evidence from my observations of children's words and actions as they participated in reading with child interviews, as well as photographs of children and their work (e.g., art pieces).

\section{Theory Triangulation}

Theory triangulation involves the use of multiple theories to interpret data (Denzin, 1970; Leavy, 2017). In this inquiry, I drew from sociocultural theory (Vygotsky,1930/1978), reader response theory (Rosenblatt, 1938/1983), and an emergent literacy perspective (Teale, 1986) to gain a more holistic view of the complex processes of curriculum design, teaching, and learning that took place during read aloud with fiction and nonfiction literature. Each theoretical lens contributed a different perspective of the phenomena under investigation.

\section{Ethics and Positionality}

\section{Research in Early Childhood Classrooms}


There are compelling reasons to conduct research in settings where young children are served. Early childhood teachers and researchers can deepen their understandings of young children's learning and development. They can critically examine teaching practices to determine how teachers might deliver the most benefits to children. Research in early childhood classrooms can illuminate ways to understand perplexing issues related to teaching and learning. Finally, it can contribute to the body of knowledge that becomes accessible to others who work with young children.

Research in early childhood classrooms carries a unique set of ethical issues, which can include the potential for coercion, lack of child assent, research that detracts from children's immediate needs, and lack of confidentiality (Castle, 2012; Mertler, 2009). Dewalt et al. (1998) indicate participant observation raises more ethical concerns than any other naturalistic method because the researcher gains close access to participants as they go about their daily lives. Participants might not be fully aware of the detail in which their activities are observed, recorded, and might ultimately be reported (i.e., actions, conversations, decisions, reactions, etc.). Dewalt and colleagues recommend the researcher make careful decisions on what to report (and omit) based on the impact that information will have on participants as well as how much it matters in the research agenda. I also followed their recommendations by taking notes publicly as a reminder that research was under way and ensuring anonymity by protecting participants' identities in field notes and transcriptions. I maintained positive relationships, yet understood the researcher-participant relationship was temporary and needed appropriate closure. Finally, I carefully monitored my level of participation to maintain the role of observer participant.

\section{Consent to Conduct Research}


The Institutional Review Board (IRB) at my institution approved the study. As part of the approval process, administrators at the research site provided a letter of support that granted me permission to conduct the study at their school. I also obtained signed consent from both teachers that granted me permission to audio record, video record, and photograph them, as well as collect photocopies of curriculum plans and materials. Nineteen of the 20 children participated in the study. Parents of 18 children granted consent for me to audio record, video record, photograph their child, and photograph their child's work. One parent granted consent to audio record the child and photograph the child's work; I did not have permission to video record or photograph the child. I also adhered to a short list of a priori questions (Appendix L) to use when interviewing children. Since children were age five or younger, I obtained verbal assent before speaking to them or taking their picture.

\section{Positionality}

Dewalt and colleagues (1998) remind researchers to become as aware as possible of their biases and to understand how those might shape the research process (e.g., attending to some events/situations, participants) and interpretations. Herr and Anderson (2005) suggest researchers critically examine their own perspectives and the choices they make at each phase of the inquiry process. I strove to acknowledge how my identity as a former early childhood teacher and researcher in early childhood education influenced data collection, interpretations, and conclusions (Creswell, 2013). I aimed to abstain from evaluating the quality of instruction (e.g., teachers' choices of materials and activities, inthe-moment decisions) or judging teachers based on their interview responses. 
The act of observation alters events, so it was important for me to acknowledge how my presence influenced activities and events. I remained reflexive throughout the study by staying aware of the ways my words and actions shaped the inquiry project. It was important that I displayed an ethic of caring that demonstrated respect for all members of the classroom, as well as routines, spaces, and norms. I strove to protect all members of the classroom's privacy and confidentiality. I only observed activities and collected data that pertained to my study (i.e., the teachers and children who participated small group read aloud). I collected data as unobtrusively as possible so that I did not disrupt the natural flow of classroom activities or draw unnecessary attention to myself. I arrived before the scheduled observation periods so that my recording equipment was ready. At times, the one child who was not in the study chose to participate in small group reading events. Therefore, I stepped out of the classroom and waited in the observation booth until the child had transitioned to another activity. I maintained confidentiality by securing digital data on passcode-protected devices and by securing data inside a locked location. I avoided all identifying information on transcripts and research reports; participants received pseudonyms and the research site and state in which the study took place were anonymous.

\section{Provisions for Trustworthiness}

Merriam (1998) explains issues of validity, reliability, and generalizability become complicated when researching participants living their everyday lives in real world settings due to the complexity of human behavior and the highly contextual setting in which data are collected. Qualitative researchers assume human experience is subjective and unfixed in real world situations. Reliability, validity, and generalizability are not the 
goals of qualitative research. Instead, qualitative researchers seek "to describe and explain the world as those in the world experience it" (Merriam, 2009. p. 220). They intend for their findings to make sense, considering the data they have collected (Lincoln \& Guba, 1985).

Qualitative researchers strive for trustworthiness, which requires careful research at every step from design, data collection, analysis, and reporting. Lincoln and Guba (1985) propose four criteria for establishing trustworthiness: credibility, dependability, confirmability, and transferability. I established credibility by familiarizing myself with participants, gaining knowledge of the school, and building relationships with the teachers through "persistent observation" (Lincoln \& Guba, 1985, p. 304) as they performed different functions of their work. Credibility was further established through triangulation of data (i.e., having multiple data sources) as well as data collection methods (e.g., interviews, observations, artifact collection). Multiple data sources and data collection methods enabled me to look for consistencies and redundancies across the data. Saldaña (2016) suggests that coding during transcription helps to ensure that the account of events is trustworthy. Merriam (2009) indicates that credibility is established through sufficient data collection so that findings become saturated. As I carried out the study, I began to hear ideas repeated in interviews and observe similar phenomena during reading sessions. At the same time, data collection seemed to produce fewer new ideas over time, an indication that I reached saturation.

Dependability, the extent to which the study could be replicated, was made possible as I described my research processes and findings in sufficient detail. I provided "thick description" (Geertz, 1973) so that, in the future, other researchers could carry out 
comparable studies. I established confirmability, the degree to which findings are based on participants' responses, by including participants' words and actions. I provided excerpts from teacher interviews as well as specific examples of teachers' and children's utterances and actions that I gleaned from the data.

Finally, transferability refers to the degree to which findings are applicable to similar contexts. Lincoln and Guba (1985) indicate that "the burden of proof lies less with the original investigator than with the person seeking to make an application elsewhere" (p. 298). Those reading my study might consider it transferable to their populations (i.e., early childhood teachers, young children), programs (i.e., preschool, kindergarten), settings (e.g., small groups, dyads, centers) and learning activities (e.g., read aloud, interactive reading).

\section{Limitations}

This study has several limitations. First, the researcher was the data collection instrument; no data collection instruments with established metrics were used. Data collection, analysis, and reporting were therefore susceptible to the researcher's biases. Although I am biased toward small groups for reading aloud in preschool, I explored the tensions that teachers encountered when working with children in this structure. I am also biased toward teachers composing their own curricula (as opposed to implementing a prepackaged curriculum with fidelity). I aimed to investigate the dilemmas and tensions teachers experienced when conducting the readings of their choice.

The study included purposive sampling (Bogdan \& Biklen, 1998; Lavrakas, 2008) of a small number of participants: two teachers and 19 children in one preschool classroom during small group read aloud. These limitations and the nature of case study 
methodology make it impossible to generalize to the larger populations of preschool teachers and students. There was also no member checking to ensure that findings accurately represented participants' views and experiences.

\section{Summary of Chapter Three}

This instrumental case study examined two preschool teachers and their students' responses to readings with fiction and nonfiction in small groups during choice time in one classroom. The children in this study ranged in age from two-and-a-half to five years. Several children spoke different languages at home and one child, who was mostly nonverbal, had been diagnosed with Down's syndrome. This study involved observing participants in the setting (classroom) in which read aloud took place rather than controlled laboratory conditions. This study took place over a six-week period. I gathered types of data that are consistent with qualitative research: interviews, observations, and participant-created artifacts (e.g., lesson plans, daily schedule). Data analysis consisted of open coding through labeling units of analysis (utterances) followed by axial coding to identify thematic categories and subcategories.

I took precautions to conduct an ethical study during each step of the inquiry. In compliance with the university's Institutional Review Board (IRB), I obtained the support of administrators at the site of the study, teacher consent, and parental consent. During data collection, I reflected on the impact of my presence in the classroom and strove to minimize disruptions to the natural functioning of the classroom by taking on the role of observer participant. I generally spoke when addressed and only as much as necessary. I took steps to protect the privacy of participants by only observing phenomena under investigation and then exiting the classroom. I avoided coercion by obtaining child assent 
to answer questions and take children's pictures. I protected participants' confidentiality by using pseudonyms and omitting identifying information relating to the site of the study and state in which the study took place. All data remain in a locked location or on a passcode protected device.

I acknowledge the limitations of the study, which are common limitations of qualitative research. Since the researcher was the single data collection instrument, data collection, analysis, and reporting are subject to researcher bias. The study design included purposive sampling of a small number of participants in a single location. The participants are not necessarily representative of the larger populations of preschool teachers and preschool-aged children. While the study had several limitations, I strove to maintain provisions of trustworthiness. I familiarized myself with the participants and the setting to better represent their lived experiences. I collected data through multiple sources utilizing different techniques. I included participants' actual words and actions to support the credibility of my findings. 


\section{CHAPTER FOUR: RESEARCH FINDINGS \\ Introduction}

This instrumental case study (Stake, 1995) focuses on the interactions among two preschool teachers and small groups of children in one classroom during small group read aloud of fictional and nonfiction texts. Specifically, this study addresses the following research question and sub-questions: What are teachers' roles and children's responses during small group read aloud with fiction and nonfiction texts for children ages two-anda-half to five years old in one preschool classroom?

1. How do children respond during small group read aloud?

2. How do teachers use modeling and scaffolding during small group read aloud to elicit children's responses?

In Section I, “The Classroom Context”, I provide background information about the teachers, children, and families. I also discuss teachers' curriculum design processes, their uses for fiction and nonfiction literature, and the role of small group read aloud in the curriculum. In Section II, “Small Group Read Aloud With Fictional and Nonfiction Literature", I explore small group read aloud with both types of books by closely examining four read aloud episodes: two with fiction and two with nonfiction books. A careful inspection of these episodes offers "thick description" (Geertz, 1973) of events. In Section III, "Scaffolding and Modeling Strategies With Nonfiction Literature”, I investigate the differentiation techniques, modeling, and scaffolding one teacher employed during two read aloud episodes of a nonfiction expository book. The findings from these events are representative of findings from small group read aloud sessions across the larger set of data. 


\section{Section I: The Classroom Context}

\section{The Teachers}

Kailee and Becky (all names are pseudonyms) were co-teaching partners in a laboratory school on a midwestern university campus. Kailee was the lead instructor; in addition to serving as a full-time teacher during the school's hours of operation (7:30 am to $5: 30 \mathrm{pm}$ ), she participated in meetings to coordinate programming between the school's directors and other lead instructors. Becky was the assistant instructor and remained in the classroom except during her planning periods. Kailee and Becky had both been teaching young children for over 20 years. Although they were both early childhood teachers, their educational backgrounds were different. Kailee held a bachelor's degree in elementary education and a master's in early childhood special education. Becky earned a bachelor's degree in child development.

Their formal educations and professional development experiences varied, as well. Kailee indicated that she has taken several courses about reading aloud to children. She learned many things, especially how important it is to repeat the same story (which she does at various times of the day, throughout the week). She explained, "When children keep requesting that I read the story again, they are getting something out of it and it is really important to read it as many times as they need" (Interview 1). She also revealed that she points to the words as she reads "so that children connect that that's where you're getting the story" (Interview 1). Becky disclosed that she had been to a couple of trainings, but they focused more on the importance of reading as opposed to read aloud techniques (Interview 1). During their 20 years of teaching, both teachers had become skilled at 
reading with children and they had developed a repertoire of strategies to engage their young students in relevant and enjoyable reading events.

While both teachers had taught at the school for several years, they had only begun teaching together in the past year as Kailee completed her master's and became the lead instructor. Since they taught in a laboratory school, preservice teachers majoring in child development took part in educational experiences in their classroom each semester. As a component of their coursework, these undergraduates supported Kailee and Becky by carrying out classroom routines (e.g., preparing the classroom for meals, naptime, activities) and working with children. In addition to teaching children, Kailee and Becky supervised the preservice teachers in their classroom by modeling teaching practices, reviewing their lesson plans, observing teaching, and providing constructive feedback.

Kailee and Becky formed a teaching partnership in which they shared power and worked in close collaboration. Each brought an accumulation of past teaching experiences (with books, materials, activities) that enabled them to pool their expertise, collaborate on ideas, and share resources. When discussing their curriculum design and teaching, they used "we", which suggested that they regarded each other as teaching partners. When I observed planning sessions, their strong teamwork was evident: They collaborated while completing their weekly curriculum sheet by incorporating both of their ideas into the plans.

Not only did they work together during planning, Kailee and Becky supported each other as they collaborated on classroom management issues to effectively manage children, time, space, materials, and clerical tasks. As teaching partners, they remained flexible in assuming complementary co-teaching roles as they shared responsibilities for 
the smooth functioning of the classroom. For example, one might greet a family while the other supervised children in the bathroom. If a child needed assistance, redirection, or a diaper change, one would attend to those needs while the other led a large group. At times, one teacher led the morning meeting while the other prepared materials for an upcoming activity. Importantly, while one taught small groups during choice time, the other effectively managed the rest of the class, which made small group time possible.

\section{The Children}

During the 2016-2017 school year, there were 20 preschoolers ranging from ages two-and-a-half to five years old in Kailee and Becky's multi-age class. Nineteen children participated in the study (nine boys, ten girls). Several children began school as infants or toddlers and transitioned into the class as two-and-a-half-year-olds, whereas others were new to the school. I conducted this study in the fall of 2016. The five-year-old children had recently turned five, but were ineligible for kindergarten. The average age among the 19 children who participated was 3.95 years.

Becky and Kailee took advantage of opportunities for children of different ages and developmental levels to learn from their peers. The teachers did not separate children into "levels" for specific skill instruction. Instead, children participated in various grouping structures each day (Appendix H). For example, the whole class assembled for morning meeting and large group read aloud. Children chose to participate in small groups during choice time, which occurred each morning and afternoon. In all of these groupings, children of different ages had chances to interact with peers. Cazden (2001) asserted that when children are grouped heterogeneously, they have more opportunities to interact and contribute in ways that work to equalize social status within the classroom. 
Table 2

Children's Personal Information

\begin{tabular}{llll}
\hline & & & \\
Child's Name & Sex & Age & Personal Information \\
\hline Madison & F & $2.6 \mathrm{y}$ & NES \\
Thanom & M & $2.6 \mathrm{y}$ & Native Thai speaker \\
Marie & F & $2.8 \mathrm{y}$ & $\begin{array}{l}\text { Native Hebrew, Catalan Spanish } \\
\text { speaker }\end{array}$ \\
Renée & & & NES \\
Tommy & F & $3.0 \mathrm{y}$ & Native Russian speaker, uses sign \\
& & $3.3 \mathrm{y}$ & language, diagnosed with Down's \\
& & & syndrome \\
James & M & $3.5 \mathrm{y}$ & NES \\
Michael & $\mathrm{M}$ & $3.6 \mathrm{y}$ & NES \\
Peter & $\mathrm{M}$ & $3.6 \mathrm{y}$ & NES \\
Caden & $\mathrm{M}$ & $4.0 \mathrm{y}$ & NES \\
Julia & $\mathrm{F}$ & $4.1 \mathrm{y}$ & NES \\
Amelia & $\mathrm{F}$ & $4.3 \mathrm{y}$ & NES \\
Alexandra & $\mathrm{F}$ & $4.3 \mathrm{y}$ & NES \\
Seth & $\mathrm{M}$ & $4.4 \mathrm{y}$ & NES \\
Grace & $\mathrm{F}$ & $4.6 \mathrm{y}$ & NES \\
Zeke & $\mathrm{M}$ & $4.6 \mathrm{y}$ & NES \\
Brandon & $\mathrm{M}$ & $4.8 \mathrm{y}$ & Native Mandarin speaker \\
Willow & $\mathrm{F}$ & $4.9 \mathrm{y}$ & NES \\
Ava & $\mathrm{F}$ & $5.0 \mathrm{y}$ & NES \\
Lucy & $\mathrm{F}$ & $5.1 \mathrm{y}$ & NES \\
\hline Note NES & &
\end{tabular}

Note. NES denotes native English speaker.

The laboratory school served several international families, making Kailee and Becky's class rich in cultural and linguistic diversity. Five children were emergent bilinguals; they were learning multiple languages simultaneously (i.e., at home and school; García, Kleifgen, \& Falchi, 2008). One bilingual child was diagnosed with Down's syndrome and used sign language to communicate. Kailee and Becky supported all children's linguistic development by immersing them in abundant language experiences each day rather than targeting their emergent bilingual children for interventions. 


\section{The Families}

Early childhood educators have an ethical responsibility to partner with families in support of young children's learning and development through ongoing "communication, cooperation, and collaboration" (National Association for the Education of Young Children [NAEYC], 2005/2011, p. 3). Kailee and Becky regarded families as essential partners in their children's education. They communicated regularly with families by engaging in informal conversations at drop-off and pick-up and posting weekly curriculum updates. The teachers created a welcoming environment and solicited family involvement by inviting them to participate in special classroom happenings (e.g., sock hop, celebrations, etc.) and supply items for activities. Each classroom had an observation booth and microphones throughout the room so families could observe at any time. Throughout the year, there were several school-wide family events and volunteer opportunities such as family literacy celebrations, playground improvement days, and book fairs (school website). Families enjoyed shared decision-making regarding their individual children and could also serve on an advisory council that reviewed programming policies.

\section{The Curriculum}

Each classroom in the school used a different curriculum to model for their preservice teachers; Kailee and Becky were assigned The Creative Curriculum ${ }^{\mathrm{TM}}$ (Appendix M). This commercial curriculum included detailed instructions for arranging the classroom, step-by-step directions for studying preplanned topics, scripted instructions for interacting with children that included book discussions, a preselected collection of songs and games, and a comprehensive assessment system. Kailee and Becky utilized a 
few, but not all, components of The Creative Curriculum ${ }^{\mathrm{TM}}$. They designed curriculum by units of study (although they did not necessarily use The Creative Curriculum ${ }^{\mathrm{TM}}$ topics), partitioned areas of the classroom (Appendix C), and followed a daily schedule according to the prepackaged curriculum. They asked children a question-of-the-day that tied to the unit of study. Kailee explained that they used the term "units of study" as opposed to "thematic units" because it was "more intentional" (Interview 1) and helped them and the preservice teachers develop more concrete objectives to determine what to teach and assess. Kailee said she found that it prevented the undergraduates from simply giving children thematic coloring sheets (Interview 1). Instead, they thoughtfully integrated small group reading and response activities into the unit of study.

Teachers designed curriculum. A prepackaged curriculum is not appropriate for every child in the class, so teachers must know how to tailor and design curriculum for their individual children (McAfee \& Leong, 2002). While Kailee and Becky utilized the basic structure of The Creative Curriculum ${ }^{\mathrm{TM}}$, they designed a more child-centered curriculum grounded in developmentally appropriate practice (DAP). NAEYC (2009) outlines essential principles of DAP. Early childhood teachers should possess knowledge and hold appropriate expectations according to children's age-related learning and development, seek to understand the unique characteristics of children in their care, and remain sensitive to the social and cultural contexts in which children live outside of school.

Goodman (1986) identified three elements of a curriculum that makes it relevant to children: the curriculum must relate to children's lives and experiences, they can take ownership of their learning, and children have autonomy to choose meaningful and 
interesting activities. During my six weeks in their classroom, Kailee and Becky implemented three units of study: music and sounds; animals; and families, cultures, and traditions. Since Kailee and Becky followed children's interests, children became deeply invested in exploring topics. Kailee was delighted, Just that the children really remember those things [...] It's spilling over into this unit. This week we're starting to talk about what animals $d o$. Last week we talked about where they live. This week we talk about what jobs they have. And it's spilling over. They're, they're talking about where they live and what they do. So [...] yes, it's building (Interview 2).

Children were able to form a more comprehensive understanding of animals as they explored different aspects to build knowledge over time within the unit of study.

In late fall, Kailee and Becky implemented the unit on families, cultures, and traditions because they wanted to honor children's cultures and knew that children would be celebrating holidays. Becky shared,

We are trying to plan something in the coming weeks around families and traditions that is topical and relevant, knowing that a lot of children come from different cultures $[\ldots]$ We are always in essence trying to do what the children are probably desiring to do (Interview 2).

They extended their study by concentrating on the languages children use at home by collecting books with different languages, including sign language, and displaying toys that feature various languages. Like the animal unit, they broke it into weekly subtopics that built over time. During my last week in the classroom, they focused on costumes. While they knew children would be thinking and talking about Halloween, the teachers 
didn't want the focus to be on Halloween, so they emphasized how people around the world wear costumes as part of their cultural traditions and celebrations.

Teachers chose books and activities. Kailee and Becky selected a book-of-theweek to read at large group time that supported their topic of study. They also displayed both fiction and nonfiction on children's bookshelves and placed nonfiction books throughout the different areas of the classroom. In addition, the classroom featured an array of environmental print, children's writing and artwork, and colorful posters. The teachers' practice of choosing books according to children's interests and literacy development aligns with the emergent literacy approach. From this perspective, children's understandings and skillfulness with language, print, and images unfold over time, in different trajectories, and at various paces, so young children will display a range of abilities and interests when interacting with text (Teale \& Sulzby, 1989).

Kailee explained why she chose nonfiction for the different areas of the classroom, "I try to stick to nonfiction books in areas to relate it to the real world." She wanted children to understand that "there are real world things that they are learning in these areas" (Interview 1). For example, in the home living nook of the dramatic play area, she displayed books with photographs featuring diverse families.

Teachers planned small group reading and response. During planning, Kailee and Becky chose books to read during small group read aloud time. "We always make sure we are trying to pinpoint the best books possible by analyzing them beforehand," Becky explained (Interview 1). Kailee shared how she chose books based on "relevance to the topic, information it has in it, and the length of the story" (Interview 1). The teachers strove to ensure that units of study were cohesive across lessons, texts, and response 
activities. Becky indicated that she first developed small group response activities to support the unit and the question-of-the-day, and then she chose her book, "I really like to plan [the response activity] first and find my books because I feel like it narrows my focus a bit more" (Interview 2). Kailee, on the other hand, first chose her book for small group reading and then thought of a response activity to pair with it (Interview 1).

Kailee and Becky both led small group read aloud sessions. In the study, Kailee led eight and Becky led twelve. These events took place during choice time in the classroom area related to the book and corresponding activity. Choice time occurred after the large group meeting each morning and afternoon (Appendix $\mathrm{H}$ ). While one teacher led the large group, the teacher conducting the small group reading and related response activity prepared the book and activity materials in the small group classroom area. Before children were dismissed from large group, the teacher leading small group made an announcement to the class; she described the book and activity, indicated the area of the classroom where it would take place, and how many children could participate at a time. For example, a teacher might announce, "I will be reading a book about music and we will play our drum in the science area. I can have four friends at a time." The teacher who led large group then dismissed the class by calling individual children's names and each child would announce the area of the classroom he or she chose. Since choice time lasted for an hour, the teacher leading the reading and response activity would often lead two small groups with different children. In my study, some sessions were observed twice for this reason. A few times in my study, a child chose a book and requested the teacher read it aloud. They would typically meet on a large comfortable couch in the large group/reading 
area; other children would notice the teacher reading to a child and gather around. In this case, the teacher and children usually held a brief discussion about the book afterward.

\section{Section II: Small Group Read Aloud With Fictional and Nonfiction Literature}

\section{Introduction}

Kailee and Becky implemented small group "literacy engagements" (Owocki, 2001) by reading aloud to children and leading small group activities one or two times per day. Owocki (2001) describes literacy engagements as "classroom experiences for supporting children's literacy growth" (p. 49) that encompass several literacy-related events (e.g., reading, discussion, assessment, response activities). These events were interactive as teachers and children became conversational partners.

The following four episodes take a closer look at teachers' modeling and scaffolding, as well as teachers' and children's responses, that took place during small group read aloud. I examine small group read aloud with two fictional stories, Dewey: There's a Cat in the Library! by Vicki Myron, Bret Witter, and Steve James (Illustrator) (2009) and Lucy's Picture, by Nikola Moon and Alex Ayliffe (Illustrator) (1994). I then investigate small group read aloud with two nonfiction texts. Patterns at the Museum, by Tracey Steffora (2011) is an expository text while One Tiny Turtle, by Nicola Davies and Jane Chapman (Illustrator) (2001) is a narrative nonfiction book. The findings from these read aloud episodes are representative of the findings across the fiction and nonfiction literature in the larger data set.

\section{Small Group Read Aloud with Fictional Literature}

Small group read aloud with Dewey: There's a Cat in the Library. Kailee and four-year-olds Julia and Alexandra, who have requested the story, settle on the couch in 
the large group/reading area for an impromptu reading of Dewey: There's a Cat in the Library! by Vicki Myron, Bret Witter, and Steve James (Illustrator) (2009). The book is 32 pages and contains computerized illustrations that resemble watercolors. It is a fictionalized account of the early life of a real cat, an orange tabby named Dewey, who lived in a library in Spencer, Iowa. The narrator frequently enters Dewey's inner world so that readers know what Dewey thinks and how he feels. As Kailee reads, four-and-a-halfyear-old Grace, three-and-a-half year old James, and four-year-old Amelia join the group. In the end, five children congregate, making this one of the larger groups in the study. Since this is a child-selected story, all of Kailee's questions and comments are improvised and there is no response activity. After reading, Kailee and Alexandra relate to the book by sharing personal stories about their own cats.

Kailee begins by asking the children if they think this is a "true" book (i.e., nonfiction) and Alexandra shakes her head. Kailee asks her to explain and Alexandra replies, "Because, because cats, because cats don't really live in the library." The notion that a cat lives in a library conflicts with her prior knowledge. Kailee responds, "Because cats don't really live in the library? Well, let's see if we can find out, okay?" Kailee has established a purpose for the reading.

In one rare example of attending to peritextual elements, Kailee draws children's attention to cat tracks inside the front and back covers, "Look at all the kitty prints!" The cat prints orient readers to the topic of the story. In the opening scene, Kailee reads how Dewey is discarded in the library book deposit on a bitterly cold winter night as a tiny kitten, "When Vicki the librarian found him the next morning, the kitten was cold and scared and very, very dirty" (p. 3). The narrator has revealed Dewey's emotions, which 
draws children's attention to the abandoned kitten's feelings and might support their capacities to empathize with him.

Four-and-a half year old Grace has joined the group and interjects, "I want to sit with Alexandra. What is that?" Grace points to a picture. Kailee stops reading to manage the group, “I don't know. Why don't you stand right here so you can see.” Kailee then continues to read how Vicki the librarian gives the dirty kitten a bath, names him "Dewey Readmore Books", and decides he will live at the library. The narrator then enters Dewey's mind again, "But Dewey had no idea what it meant to be a library cat" (p. 5) giving readers another glimpse into Dewey's inner world. Kailee then reads how Dewey becomes a friendly playful kitten who loves people. Grace interjects as she points to a picture, "I have a purple barrette that looks like that." She has personalized the story by relating an item in the picture to one of her possessions, which makes the story more relevant to her. No one responds to Grace's comment; they are attending to the story.

Kailee then reads how Dewey hates to be petted the wrong way and she prompts children to interpret Dewey's feelings by examining the pictures (p. 7), "Look, does the kitty look happy?' Grace seeks more information to make sense of Dewey's feelings by asking, "Where is he petting him?" Kailee explains, "Kitties like to be petted from the head to their tail, not from their tail to their ears. That messes their hair up. Would you like that very much?" Grace shakes her head. Kailee has prompted Grace to take an aesthetic stance by imagining how she would feel in the same situation.

Kailee then reads how Dewey meets a baby, “Dewey’s ears perked up. He looked around Waaa! Waaa!” (pp. 8-9). The illustration shows a baby carrier and a tiny fist clutching a rattle. Kailee asks, "What do you think it might be?" Kailee elicits a prediction 
from the children. Drawing from their background knowledge and clues from the picture, Alexandra and Julia predict it is a baby. Rather than confirm, Kailee reads on to verify, modeling how to confirm or disconfirm predictions. As she reads how Dewey thinks babies smell wonderful but they grab and pull (pp. 11-12), Kailee asks, "Is the baby being gentle? Does the kitty look happy?" Kailee prompts the children to interpret Dewey's feelings by studying the picture. Grace points to the picture of the baby grabbing Dewey's ear, "No." Grace has inferred his feelings by examining the picture.

Kailee then reads how Dewey discovers a crowd of children listening to a read aloud during story hour, is subsequently chased through the room, and then carried upside down by a little girl (pp. 13-17). Again, the narrator enters Dewey's inner world, "Oh my! Dewey thought, what should I do now?!” (p. 16). Grace giggles because the upside down cat looks silly.

Four-year-old Amelia joins the group and examines the pictures. In the next passage, the narrator personifies Dewey as the cat confides in his mouse toy; he is worried that he is not a very good library cat. He dislikes the rough treatment. He then decides to be the best library cat possible by helping people. From that point, he greets patrons at the door, reads with them, helps shelve the books, and turns around so children pet him in the correct direction (pp. 18-21). Amelia complains to Grace, who is blocking her view of the book, “I can't see, Grace! Kailee, I want to see but I can't!” Meanwhile, three-and-a-half year old James has joined the group. As he pushes in for a closer look, he bumps Julia's head. The group now consists of five children. Conflicts ensue as they vie for closer proximity to the book; Kailee must stop reading to reposition the children. She knows it is 
important for each child to have an unobstructed view of the illustrations because they hold children's attention and contain valuable information for making sense of the story.

In the next scene, Dewey squeezes into a tiny box to nap; his fur protrudes from the top (pp. 23-24). Kailee asks the children, "Is that a good box?" Grace and Alexandra observe that Dewey does not fit. This short exchange enables the children to evaluate Dewey's choice. Kailee reads a comment by a child in the story, “"There's an orange muffin in the library,"” (pp. 23-24). In this rare example, children are exposed to a metaphor. Kailee poses a question to the group, "Is he an orange muffin?" A child answers, "No," and Grace giggles. They realize the words are not to be taken literally and Grace discerns the humor in the analogy. Three-and-a-half year old James remains quiet as he observes how his slightly older classmates respond to the pictures.

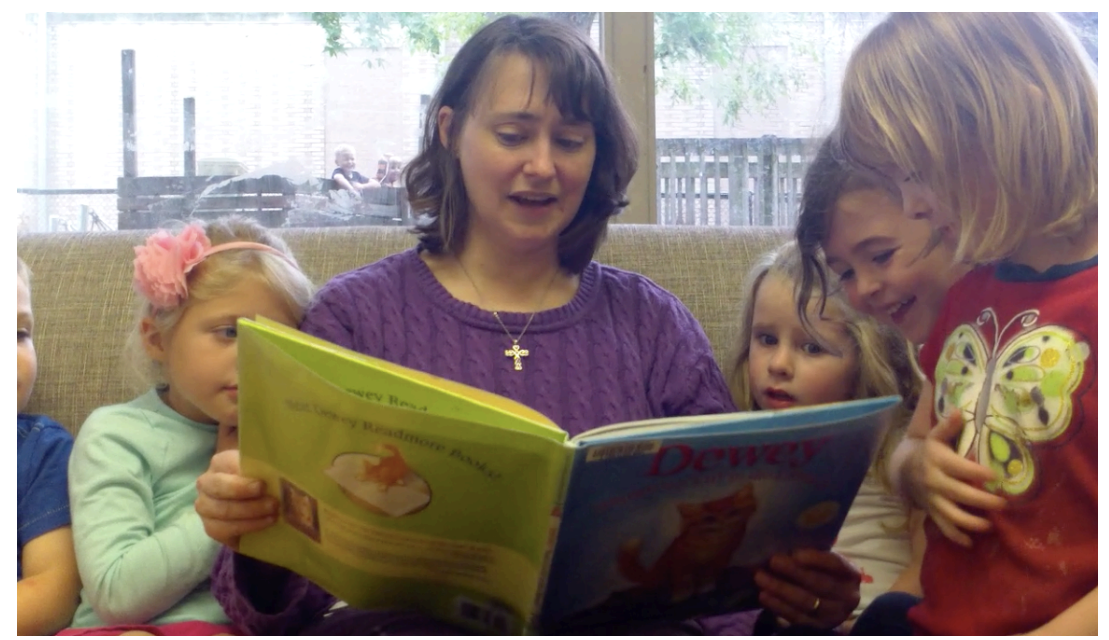

Figure 1. Grace laughs at Dewey's antics.

In the final scene, Dewey hears a sigh and spies a sad girl reading alone (pp. 2532). As Dewey seeks her attention, the girl looks away. Kailee quickly turns her head to mimic the girl's nonverbal communication. After many attempts to cheer her up, Dewey wiggles inside the girl's jacket lying nearby, "Silly always works. I'm a silly cat today" (p. 
29). The narrator voices Dewey's thoughts, revealing them to reader. The girl speaks to Dewey, "You look like a fuzzy hot dog in a purple bun" (p. 29). Grace perceives the humor in this unlikely simile and laughs aloud, displaying her appreciation of the figurative language. The girl then surprises Dewey by laughing, hugging, and telling him she loves him. In this final scene, the narrator personifies Dewey again as the cat settles on the girl's lap and purrs, pleased that he has become the best library cat he can be. Meanwhile, Grace is still savoring the humor in the simile, "A fuzzy hot dog!" she giggles.

As Kailee closes the book, Grace implores her to read it again. Kailee turns to the back cover with a photograph of Dewey. Four-year-old Julia, who has listened quietly for the entire reading, asks to see the cat, so Kailee holds the book closer to her. Grace requests that Kailee read it again. Alexandra, who has also listened quietly for most of the story, then announces, "I need to go to that library." She has become so immersed in the story world that she wishes to visit the actual place. She asks Kailee, "Can I go there sometime?" Kailee then explains it is a long trip to Iowa but they could tell her mom she wants to see the cat in the library. This possibility seems to satisfy Alexandra. Meanwhile, James leaves the group.

Kailee then asks children how Dewey got into the library; Julia and Alexandra were the only two who listened from the beginning. When no one can recall, Kailee states, "Somebody put the kitten in the book box. Have you seen the book box at the library where you're supposed to put books?" Kailee has invited them to personalize the story and a few children nod. "Are you supposed to put cats in there?" She asks a critical question that requires children to evaluate these actions, giving them a chance to exercise their 
judgment. "No, so was someone being nice or not very nice?" Alexandra replies, "Not very nice." Kailee affirms and concludes, "But a nice lady found him." She is careful to reassure the children that the kitten is fine. She then discloses her feelings, "I think it would be scary to be shoved in a box. Do you think it would be scary to be shoved in a box?" The children nod in agreement. They empathize as they imagine themselves in the same situation.

Grace interjects, "Can you read that again to me?" She is not ready to move on from the book. Kailee personalizes the story by asking children if they ever had a kitty at their house. Alexandra reveals that she has a cat while Grace implores Kailee to read the story again. Grace does not want the story to be over and she does not participate in the conversation. Kailee then shares how her kitty would crawl into her purse and asks Alexandra if her kitty crawls into things. Alexandra relates, "Guess what. When she is scared and hided in the thing, I couldn't reach her." Alexandra has interpreted her own cat's feelings much like Dewey's.

A child approaches the group with a drum in his hand, "Come listen to the band!" Kailee complies with his request as she thanks the children for listening and stands up. While she walks away, Grace pleads for the fifth time, "No! Read it again!" She and Amelia then settle onto the couch and read it together while the rest of the group disperses. They slowly pore over the pages as they point, chat, and giggle. Afterward, Amelia departs and five-year-old Ava joins Grace on the couch to explore the book. Grace has had such an intense aesthetic experience, she is compelled to immerse herself in the story long after Kailee and the other children have moved on. 
Analysis. This episode offers several examples of the ways Kailee supported children's comprehension. It also illustrates how children were becoming strategic readers as they integrated meaning making strategies. Finally, this episode provides evidence that children assumed stances along the efferent-aesthetic continuum at different points during the reading to make sense of the text.

Kailee scaffolded children's meaning making of the text in different ways. First, she prompted children to attend to pictures throughout the reading. She drew their attention to the cat paws in the end pages, which gave children a clue about the story. At other points, she prompted children to interpret Dewey's feelings by studying the pictures. On two separate occasions, she asked, "Look, does the kitty look happy?" Later, she posed an inferential question about Dewey squeezing into the box, "Is that a good box?" Children then inferred that Dewey did not fit. Kailee knew that children relied heavily on pictures to construct meaning and gave them practice with extracting information from illustrations to aid their comprehension.

Second, Kailee modeled various prediction strategies. Before she began reading, she prompted children to determine what type of text it was (fiction or nonfiction) by asking whether or not it was a "true" book. She then demonstrated how to establish a purpose for reading when she indicated the children would find out if cats really live in a library. Later, she elicited children's predictions and then modeled how to read on to confirm or disconfirm their predictions. When Dewey encountered a baby in a carrier, she asked, "What do you think it might be?" Rather than tell children, she continued reading to find the answer in the text. By modeling how to predict then read to confirm or 
disconfirm, Kailee demonstrated how to revise her thinking by integrating new information from the text (i.e., story events, pictures).

Third, Kailee personalized the reading. At one point, she invited children to recall if they had seen a book box at the library. She revealed her own feelings as she shared how she would be scared to be shoved in a book box and asked children how they would feel in that same situation. She shared, "I think it would be scary to be shoved in a box. Do you think it would be scary to be shoved in a box?" By personalizing, she helped children see how the text related to their lives. Kailee scaffolded children's uses of comprehension strategies in their zone of proximal development (ZPD) as she modeled her own strategy use and prompted children to be strategic to further their development as readers.

Children were becoming strategic readers by integrating information from pictures and their background knowledge. Children examined pictures throughout the reading. In two separate examples, Grace pointed to illustrations and inquired about them. She asked, "What is that?" as she pointed to a purple barrette. She then commented, "I have a purple barrette like that." Later, Kailee asked children to interpret Dewey's feelings from a picture. As a baby grabbed Dewey's ear, Kailee asked if the cat liked that. Grace pointed to the illustration and concluded, "No." Pictures acted as a springboard for children's meaning making. Children asked questions as they looked at pictures and related images to their own experiences. Like Grace, other children attended primarily to the pictures and became upset if they could not see the illustrations. In one instance, Amelia complained when Grace blocked her view, “I can’t see, Grace! Kailee, I want to see but I can't!" As children moved around, they bumped heads and a small argument ensued. The desire to see the images indicates how children relied heavily on pictures to 
experience the story. They were disrupted when they could not see the illustrations. The pictures contained information that helped children learn about socially and culturally relevant places and events as they learned about the library.

Children moved along the efferent-aesthetic continuum to make sense of new information in the text. For instance, Alexandra was initially skeptical of a real cat living in the library because this information was incongruent with her background knowledge. However, at the end of the book, when Kailee divulged that the story was based on the life of a real cat, Alexandra stated repeatedly that she wanted to visit the library to meet the cat. Alexandra took an efferent stance as she revised her thinking based on new information. Likewise, Grace moved along the efferent-aesthetic continuum. She shifted toward an efferent stance when she sought information about how the child in the story was petting Dewey. She posed an information-seeking question, "Where is he petting him?" She took an aesthetic stance by imagining how she would feel if someone messed up her hair. Both children transacted continuously with ideas in the text. They shifted their stances by considering how these ideas related to their background knowledge and experiences. Alexandra incorporated new information about where cats could live whereas Grace sought details from the story to help her respond aesthetically to what happened to Dewey.

This read aloud episode demonstrates the complexity in the interactions among Kailee and the children as they read together in a small group. Kailee scaffolded children's meaning making in multiple ways to help them comprehend the text more fully. Children were strategic readers as they integrated information to make sense of the text. Children 
moved across the efferent-aesthetic continuum as they remained sensitive to ideas in the text, sought information, and revised their thinking.

Small group read aloud with Lucy's Picture. In the following read aloud episode, Kailee, two-and-a-half-year-old Marie, along with four-year-olds Caden, Julia, and Alexandra settle around the art table to read Lucy's Picture, by Nikola Moon and Alex Ayliffe (Illustrator) (1994). In this fictional story, Lucy's teacher asks children to paint pictures, but Lucy creates a collage for her blind grandfather from craft materials and items gathered on the playground. At the end, Lucy's mother, grandfather, and his service dog pick Lucy up from school. Lucy gives her grandfather the collage, so he can feel it with his hands. The story is told in 24 pages with colorful collages in 12 full-page spreads. Each spread contains a several sentences in large font. The end papers display artwork from students in Lucy's class. Lucy's collage is not featured because she has given it to her grandfather. After the reading, the children created collages with craft supplies (e.g., construction paper, glue, beads, confetti, string, crinkled paper). Kailee read this story during the unit of study about animal jobs, so children could learn more about the work of service dogs.

Kailee begins by reading the title and first page, which introduces Lucy and her teacher, Miss Kelly. Caden immediately personalized the story by announcing, "I have a mom named Kelly." Kailee acknowledges his comment and continues reading. In the story, Lucy sits and thinks while her classmates are busy painting. Miss Kelly tries to help Lucy choose colors for her painting (pp. 3-4). Kailee then invites children to infer Lucy's feelings, "Look at Lucy. Do you think she likes any of these paint colors? It doesn't look like it, does it? Hmm, she's thinking." The children examined the picture. Although they 
do not yet know that Lucy wishes to create an art piece for her blind grandfather, Kailee has already begun to help them infer that Lucy has a different plan. As Kailee reads how Lucy plans to glue items onto her picture, she asks, "What is a collage?"

Alexandra, drawing from her background knowledge, replies, "A collage is something that you put things on."

Kailee elaborates on her answer, "Yes, it's where you put glue on paper and put lots of stuff on top."

Two-and-a half-year-old Marie, who speaks Catalan Spanish and Hebrew at home, then hands Kailee a fistful of collage materials, "Here you go." In this short exchange, Kailee introduces the concept of a collage and reveals a clue about Lucy's plan. She then reads how Lucy cuts and arranges different textures of cloth and objects she has found on the playground to glue onto her collage (pp. 5-16). Finally, Lucy has finished her collage and Miss Kelly sets it next to the paintings to dry (pp. 17-18). The classroom clock on the wall shows the passage of time.

On the next page, Lucy's grandfather and his service dog have joined her mother to pick her up from school. Kailee holds the book up close to each child to see the picture, "Do you see Grandpa? Do you notice something about Grandpa? What do we notice about Grandpa? Look at it Julia.”

Four-year-old Julia replies, "He got a dog."

"Look at that dog? Is that just a regular dog?" Kailee wants her to infer from the picture that Grandpa has a service dog.

Four-year-old Alexandra shakes her head, so Kailee probes for more information "No. What kind of dog is that? Do you remember?" 
"It's a working dog," Alexandra replies.

Kailee confirms, "It is a working dog. What do we think we know about Grandpa if he has a working dog? What might be going on with Grandpa, hmm?" She invites the children to infer that Grandpa is blind.

Alexandra speculates, "He might, he might, he might be blind."

Kailee and Alexandra both use tentative language (i.e., think, might) as they work on understanding (Barnes, 1975/1992). Kailee then draws the other children into the conversation "He might be blind. What do you think, Julia?"

Julia shrugs. Kailee continues, "What do you think, Marie?"

"Blind."

"Blind, what do you think, Caden?"

Four-year-old Caden takes a cue from his peers, "Blind."

Kailee summarizes their inferences, "You think he might be blind." She then reads how Lucy guides her blind grandfather's hand over the picture. Kailee asks the children to infer Lucy’s motives, "Why did she take his hand?"

After a short pause, Marie replies, "I don't know.” Rather than supply the answer, Kailee takes Alexandra's hand and touches the book with it, "Do you know? Why did she take Grandpa's hand and put it on her picture?"

Alexandra, who was the first to infer that Grandpa was blind, answers, "So he can, so he can feel it."

Kailee confirms, "So he can feel it. Because can he see it with his eyes?" Alexandra shakes her head and Kailee summarizes, "No, but he could feel it with his 
hands." She then reads the last page to bring closure to the story and immediately introduces the response activity: making collages.

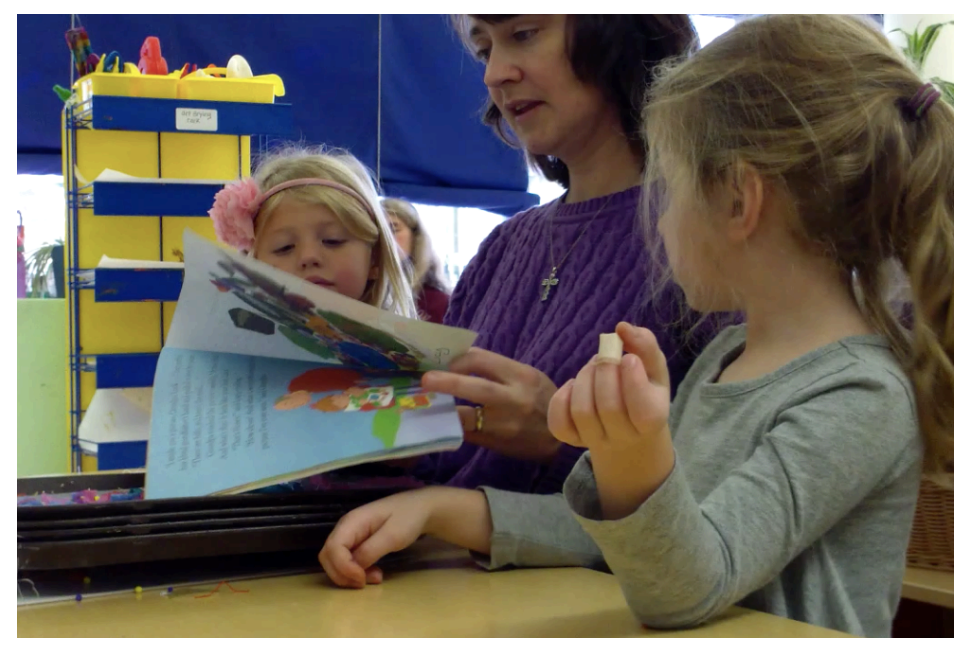

Figure 2. Julia and Alexandra inspect the illustrations.

Analysis. This read aloud episode illustrates the multiple ways that Kailee supported children's comprehension. She prompted children to draw from a variety of sources to make meaning. In addition, she supported their aesthetic stances by asking them to consider characters' feelings, motives, and perspectives. This episode also shows how older children served as peer models for their younger classmates as they shared their meaning making strategies with the group.

Kailee utilized various teaching moves that scaffolded children's meaning making. First, she encouraged children to examine particular aspects of pictures to focus and make inferences. Children then used information in the pictures to understand the story. For example, Kailee prompted children to study the picture of Lucy and notice her feelings about the paints, "Look at Lucy. Do you think she likes any of these paint colors? It doesn't look like it, does it? Hmm, she's thinking." As children considered that Lucy was not happy with the paints, they could better understand the character's actions as she later 
dug through the box of scrap materials and collected items at recess for her collage. Later, Kailee asked children to share what they noticed as they studied the picture of Grandpa with his service dog, "Do you see Grandpa? Do you notice something about Grandpa? Look at it Julia." Four-year-old Julia indicated that he had a dog. Kailee's invitations gave children experience with focusing on visual images and inferring information that was not explicitly stated in the written text.

In addition to eliciting children's interpretations of pictures, Kailee prompted them to draw from other sources to make meaning. She invited them to access their background knowledge about collages as well as their understandings of service dogs. After Julia noticed that Grandpa had a dog, four-year-old Alexandra provided a deeper response as she accessed her background knowledge, "It's a working dog." She likely knew this because the children had been studying animal jobs. Kailee then encouraged all children's participation by inviting everyone to share their speculations for why Grandpa had a working dog. Alexandra surmised, "He might, he might, he might be blind." She knew that some people are blind and use service dogs to help them navigate safely. In another example, Kailee asked children to describe a collage. Alexandra drew from her existing knowledge, "A collage is something that you put things on.” Kailee used multiple techniques to support children's comprehension in their ZPD. While children made meaning by integrating information from the pictures, they also drew from their knowledge of the larger social world. In doing so, they learned to integrate new information from the text with their existing knowledge to comprehend the story.

Kailee supported children's aesthetic stances. First, she asked children to consider Lucy's feelings as the character contemplated using the paints. To scaffold children's 
interpretations, Kailee described Lucy's feelings. Kailee also asked children to infer Lucy's motives for guiding Grandpa's hand over the collage, "Why did she take Grandpa's hand and put it on her picture?" Four-year-old Alexandra realized that Grandpa needed to touch the collage because he was blind and could not see it, "So he can, so he can feel it." Children not only gained experience understanding Lucy's motive for choosing a collage, Alexandra was able to take up Grandpa's perspective. Young children are learning that others have their own thoughts, feelings, motives, and perspectives that are distinct from their own. As they considered characters' perspectives, they gained experience understanding other points of view. This could increase their capacities to empathize and support their understandings of others in their social environments.

Older children served as peer models for their younger classmates. Alexandra and Julia, who were both four years old, answered Kailee's questions while two-and-a-halfyear-old Marie observed and imitated her older peers. Four-year-old Caden was mostly quiet. For example, when Kailee asked, "What is a collage?" Alexandra was the first to answer. After Kailee confirmed her response, Marie, who had been listening, grabbed a fistful of collage materials to show Kailee. Both children drew from their semiotic resources to answer the question. In another exchange, Kailee prompted children to examine a picture to notice something special about Grandpa. Four-year-old Julia responded, "He got a dog." Alexandra then inferred that it was a working dog and that Grandpa might be blind. When Kailee asked the other children, they either shrugged or offered the same response as Alexandra, whose idea had become available to the group. Marie and Caden both answered, "Blind." When Kailee asked why Lucy guided Grandpa's hand over the collage, two-and-a-half-year-old Marie replied, "I don't know." 
Kailee then touched Alexandra's hand to the book and Alexandra inferred that Grandpa needed to feel the collage. The other children observed as Alexandra demonstrated how to infer from story events, pictures, and her background knowledge. Two-and-a-half-year-old Marie had several opportunities to observe her slightly older peers who had more experience making sense of text. These experiences gave children chances to learn from each other and not just their teacher, which highlights the social processes involved in learning.

This reading episode shows how strategic readers flexibly integrate a range of strategies to make sense of the text. As Kailee scaffolded children's comprehension in different ways, she gave them experiences using different reading strategies. Children demonstrated that they were capable of drawing from various resources with appropriate scaffolds from their teacher. Younger children's observations and imitations of their older peers provide evidence that mixed ages in preschool can support children's emerging reading strategies.

\section{Small Group Read Aloud with Nonfiction Literature}

Small group read aloud with Patterns at the Museum. During the unit of study on music and sounds, Kailee and a small group of children examined visual patterns on objects in Patterns at the Museum, by Tracey Steffora (2011). This nonfiction book features photographs of different types of patterns found in the architecture and artifacts in museums. Each of the 24 pages contains a picture and one sentence in large font. Patterns at the Museum (2011) is an early nonfiction reader in the Math Around Us® series. It contains a table of contents, picture glossary (i.e., a photograph of an object beside the bolded term and definition), and index. 
Kailee, three-year-old Tommy, three-and-a-half-year-old Michael, four-year-old Alexandra, and four-and-a-half-year-old Willow gather at the math table to explore patterns together. Kailee begins by showing children the front cover and asking what the book is about. Each child examines the photograph of a spiral staircase and Willow touches it, "It's about patterns." Willow, who will turn five the next month, is the oldest child in the group and often participates in interactive read aloud. Kailee confirms Willow's observation, reads the title, and describes the topic, "The book is about pictures of patterns around us." Kailee has elaborated on Willow's response so that children understand that the purpose for reading is to look for patterns in the photographs.

After Kailee illustrates how colors can make a pattern, Willow imitates her by spontaneously reading and pointing to a color pattern, "Red-yellow, red-yellow, redyellow, red-yellow. Is that a pattern?" (p. 10). She is seeking confirmation because the concept is new and wants to assess for comprehension.

Kailee confirms and then reads, "The colors on this boat make a pattern" (p. 11). She invites four-year-old Alexandra, who is the second oldest in the group, to read a pattern. Like Kailee and Willow, Alexandra points as she reads, "White-blue, white-blue, white-blue, white-blue." Willow and Alexandra have both demonstrated their understanding of the concept as they read simple A-B, A-B alternating patterns. 


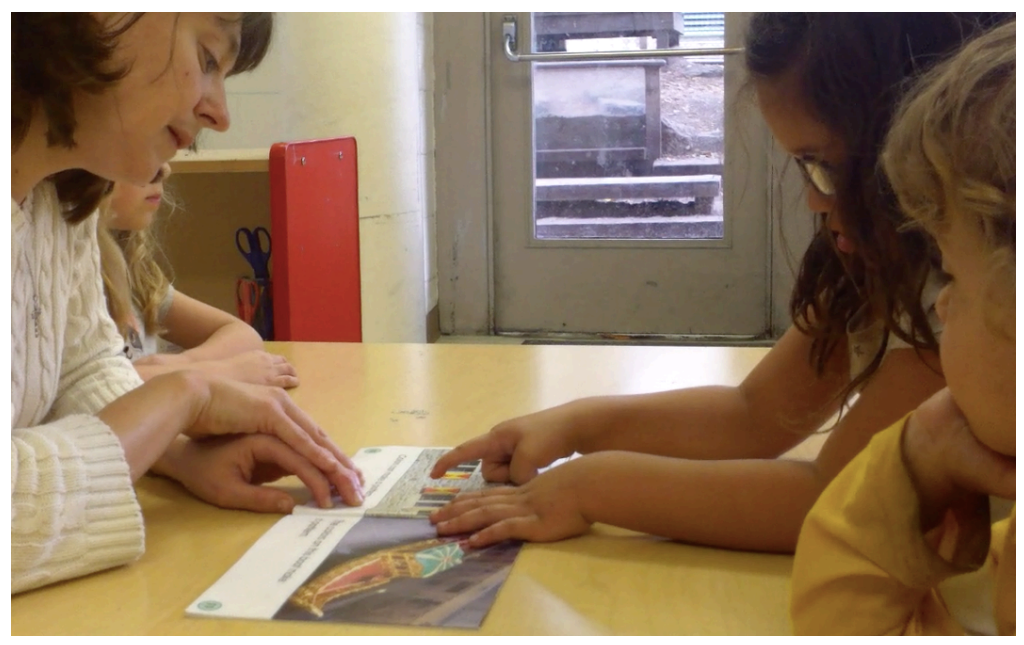

Figure 3. Willow points to a color pattern as Kailee and Michael observe.

The next page shows a series of orange triangles that increase in size from left-toright. Kailee reads, "A pattern can go from small to large" (p. 12). She points to a circular mosaic with triangles that increase in size further from the center (p. 13). Kailee points to the edge and inquires, "Would a bigger one be here or a smaller one be here?" Willow and Alexandra offer conflicting responses, so Kailee asks Alexandra, who has answered correctly (bigger), how she knows. Kailee is probing so that Alexandra can explain her thinking to the group. Willow now recognizes the pattern, points to the photograph, and reads, “Small, bigger, bigger, bigger, bigger, bigger, bigger, biggest!” In her exuberance, she reads the pattern before Alexandra has a chance to explain her thinking.

Meanwhile, the two younger children, Tommy and Michael, have been quietly observing their older peers. Kailee invites three-and-a-half year old Michael into the discussion by saying his name and asking if he sees a pattern. Michael examines a series of green bars that decrease in length from left-to-right and then nods (p. 14). As Willow points to the picture, Kailee prevents her from answering for Michael, "Let Michael find it." 
Willow persists, "This picture right here."

Kailee repeats, "Let Michael find it. You see it?" Michael nods again but does not speak, so Kailee provides the words, "Do they go from little-to-big or big-to-little?"

Michael responds, "Big-to-little." Willow then interrupts with her answer, which is incorrect, "Little-to-big."

Kailee clarifies and points to the photograph, "Big-to-little! Do you see, Willow, they're really, really big and they go to really, really little." In this episode, Michael, who is younger, has shown his older classmate how to read this pattern. Meanwhile, Willow has demonstrated that her grasp of the concept is tenuous.

As Kailee models how to read an alternating color pattern, Alexandra indicates, "I want to do it." Having read a pattern earlier, she now feels confident enough to volunteer. She and Willow both put their hands on the book so Kailee reminds Willow it is Alexandra's turn. Alexandra points and reads the color pattern in a series of shapes, "Blue-black, blue-black, blue-black" (p. 16). Alexandra has assumed a leadership role and demonstrates her understanding of the concept for the group, enabling the others to learn from her. Willow is also vying for this position in the group, so Kailee must intervene to ensure all children have the chance to demonstrate their knowledge of the concept.

Meanwhile, three-year-old Tommy has been quietly observing his older classmates. Tommy, who was diagnosed with Down's syndrome, hears Russian at home. He is primarily nonverbal and communicates through vocalizations, sign language, and other gestures. He receives special education services at another school and spends part of the day in Kailee and Becky's classroom where he interacts with typically developing peers and participates in an enriching, child-centered curriculum. Kailee invites him to 
look at a repeating shape pattern as she points and reads, "We have a circle-square, circlesquare, circle-square" (p. 17). Tommy imitates by vocalizing sounds and pointing. He has participated by using the modes of communication that he is able to utilize.

Kailee concludes the reading by involving all children in interpreting patterns. She prompts three-and-a-half year old Michael to notice how a pattern can match on the left and right (pp. 18-19) and by encouraging Willow and Alexandra to point out the patterns in a series of antique windows (p. 20). She then asks Tommy, "Is that what you think too? Tommy, which window do you think goes here?"

Tommy vocalizes, "Ah-doh!” and points to a window (p. 21).

Kailee interprets, "You think this one? Maybe." Although Tommy is primarily nonverbal, Kailee ensures he participates in the curriculum similarly to other children. At the conclusion of the book, she immediately transitions to a clapping activity in which she and the children clap and pat patterns with their hands.

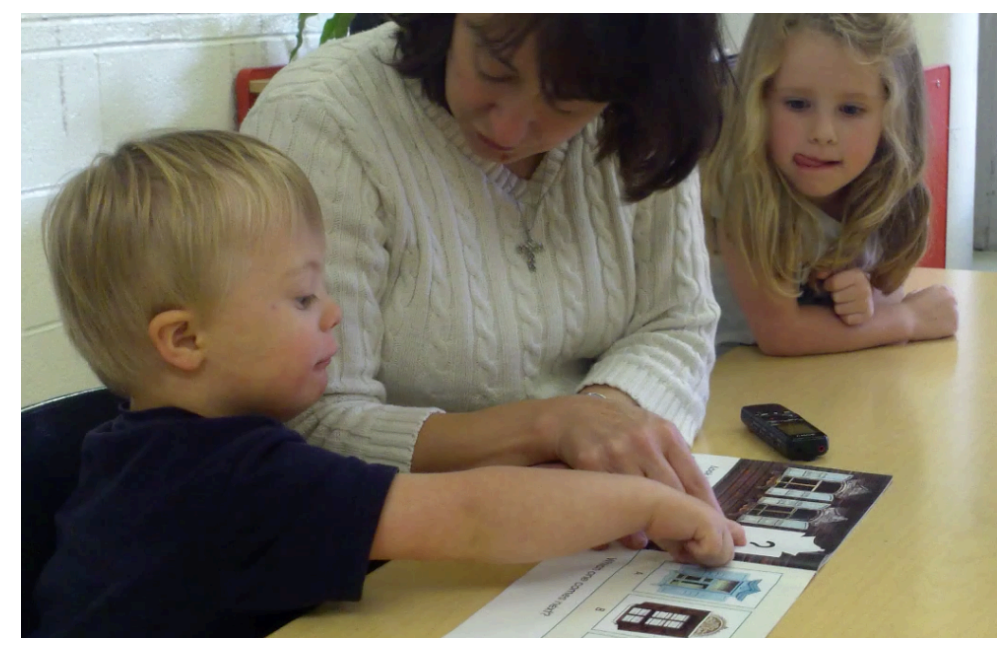

Figure 4. Tommy points to a window while Kailee and Alexandra observe.

Analysis. In this episode, Kailee modeled how to read patterns and provided guided practice as children read different types of patterns. Older children first displayed 
this new skill while the other children observed, which gave the younger peers multiple opportunities to learn from their slightly older classmates. Kailee and the children took an efferent stance toward the text as they read to recognize various visual patterns.

Kailee scaffolded children's interpretations of patterns. After showing children the front cover, she asked them what the book was about. Four-and-a half-year-old Willow announced the topic, "It's about patterns." After modeling how to read patterns, Kailee invited children to imitate her. Throughout the book, she asked them to read patterns involving colors and shapes, as well as seriating sizes. Kailee scaffolded children's readings of patterns in their ZPD as she first modeled the behaviors she wanted children to exhibit and then provided opportunities for guided practice. She then used gradual release of responsibility with the older children; she expected them to read different types of patterns with increased independence. Willow and Alexandra took responsibility for exhibiting this new reading and math skill as they demonstrated their competence.

Later in the book, Kailee elicited a response from three-and-a-half year-old Michael. To support his comprehension, she said his name, pointed to a series of bars, and narrowed his choices, "Do they go from little-to-big or big-to-little?" These were appropriate scaffolds as Michael correctly identified the pattern, "Big-to-little.” After observing his teacher and peers, it was three-year-old Tommy's turn to participate. Kailee first said his name, pointed to the pattern, and read it aloud, "We have a circle-square, circle-square, circle-square.” Tommy immediately imitated her actions and vocalized. Tommy successfully participated in the group as he attended to the pattern.

Toward the end of the book, Kailee invited Michael's response and encouraged the older children to recognize a more complex pattern. As Tommy vocalized and pointed, she 
provided the words, "You think this one? Maybe." Kailee heavily scaffolded the two younger children's readings and did not expect them to read patterns independently. This episode shows how scaffolding in children's ZPD enables them to display new skills they would otherwise not demonstrate. As an effective teacher, Kailee tailored instruction for each child to provide appropriate levels of support and challenge so that all children in the group were successful.

Older children served as peer models for their younger classmates. During this episode, the older children participated first as their younger peers observed. Immediately after Kailee modeled how to read a color pattern, four-and-a-half-year-old Willow, who was the oldest child in the group, spontaneously read another color pattern. She pointed as she read aloud, "Red-yellow, red-yellow, red-yellow, red-yellow. Is that a pattern?" She sought confirmation because this was an emerging skill. Kailee then invited four-year-old Alexandra to read a color pattern. The two older children also read patterns on subsequent pages while their two younger peers observed.

Willow was so eager to display her new skill that she interrupted other children when it was their turn. For example, when Kailee asked Alexandra to explain how she read a pattern, Willow read it aloud. When Kailee encouraged three-year-old Michael to recognize a pattern, Willow pointed to the picture and answered (albeit incorrectly). Later, she placed her hand on the book when Alexandra had volunteered to read a color pattern. Alexandra independently read the pattern while her peers observed, "Blue-black, blueblack, blue-black." In these instances, Kailee prevented Willow from answering for her peers. 
Finally, after multiple opportunities to listen and watch his older classmates, Kailee invited three-year-old Tommy to participate. In this episode, younger peers had multiple opportunities to observe their older classmates while they demonstrated an emerging reading and math skill. Moreover, Willow's actions suggest that she seemed to take pride in her role and sought opportunities to exhibit her new skill for the group. Teachers might consider ways to take advantage of children's various skill levels and willingness to serve as peer models by allowing them to demonstrate their skills for others.

Kailee and the children took a predominantly efferent stance toward the text. Their purpose was to read patterns. Kailee began by showing children the front cover and asking them to identify the topic. After Willow shared, Kailee reiterated, "The book is about pictures of patterns around us." She and the children ignored other aspects of the pictures (e.g., design, artistry, architecture, historic significance) and focused exclusively on recognizing patterns. Kailee pointed out each one to the children and prompted them to recognize patterns. For example, she read, "The colors on this boat make a pattern." In one of many examples of children reading aloud, Willow pointed to a series of triangles in a mosaic and exclaimed, "Small, bigger, bigger, bigger, bigger, bigger, biggest!" Readers choose their stance according to their purpose for reading. Neither Kailee nor the children displayed strong emotional responses or personalized the text, which are indications of aesthetic reading. Rather, their efferent stances remained fixed as they read to recognize patterns in visual images.

This episode exemplifies the ways children of different skill levels can learn together. Kailee made this possible as she differentiated instruction through scaffolding and guided practice in each child's ZPD. Children's varying skill development was 
potentially beneficial for the older and younger classmates in different ways. The older children took up leadership roles while their younger peers had more chances to observe before they displayed new skills. Children gained experience reading to learn new content, which is a vital reading behavior they will use in future educational settings and for real life purposes.

Small group read aloud with One Tiny Turtle. In this episode, Becky reads One Tiny Turtle, by Nicola Davies and Jane Chapman (Illustrator, 2001) in the art area with three-and-a-half year old Peter, four-and-a-half-year old Willow, as well as Ava and Lucy, who are five. It features 24 pages of realistic acrylic illustrations of scenes from the life of a female loggerhead sea turtle. The written text consists of short paragraphs in large font on each page. Several pages contain additional information in a smaller font. One Tiny Turtle (2001) is the single narrative nonfiction in the study. The narrative is told in present tense verbs that convey the timelessness of generations of sea turtles, similar to a wildlife documentary. After the reading, Becky facilitates an art activity in which children construct and paint turtles with paper plates, bottled paints, and other craft items. This reading and response activity are part of a larger unit on animals of our state.

Although this story is about the life of a sea turtle, which does not live in our state, Becky immediately personalizes the topic by asking children where they have seen turtles. Five-year-old Ava, who is one of the older children in the group, volunteers first, "I've seen a baby turtle. I've seen a turtle in my, at the backyard of my house. But it was on my trampoline!"

Becky acknowledges Ava's contribution before eliciting responses from the others. Five-year-old Lucy shares next, "I have seen one in a park. We found one in the water. It 
was a baby." Becky summarizes how turtles can live on land and in the water and invites Willow, who is four-and-a-half, to join the conversation.

Willow reveals, "I saw a turtle at the beach and I tried to get it in the water but it wouldn't stay in. It wouldn't go in.”

Becky then turns to three-and-a-half-year-old Peter, who has been quietly listening to his older classmates. Peter discloses, "I seen it at the pool so I don't want to go in the water." Becky then offers her own personal experience with turtles; she often sees them while driving. Becky and the children become conversational partners as each participates in the discussion and adds to their collective experiences with turtles.

Becky begins by reading background information about sea turtles and introduces the term "loggerhead." She makes an intertextual tie between the loggerhead in the book and the sea turtles in Finding Nemo® (Walters \& Stanton, 2003), which sparks a short exchange among the children about the names of the sea turtle characters in the movie. Becky's talk move gives children the opportunity to relate something familiar (i.e., the turtle characters in the movie) to new facts about the loggerhead sea turtle, which could help them make sense of unfamiliar content.

As Becky reads about the young turtle, Lucy spontaneously makes the hand sign for turtle (p. 8). She has made an intertextual tie to something she has learned from an earlier learning activity. The other children observe and imitate her. Lucy, who had just recently turned five, is the oldest child in the class and is often the first to answer questions and share her experiences. While Lucy enjoys a leadership role among her peers, her younger classmates have the chance to learn from a slightly older peer model. 
Becky stops reading to acknowledge their contributions, which honors children's multiple modes of learning and expression.

Four-and-a-half-year-old Willow makes multiple attempts to share her knowledge about turtles, "Hey Miss Becky, do you know what a turtle does? Turtle, a turtle..."

Becky interrupts, "Here, let's read our story and then you can tell me about it."

Willow continues, "A turtle hides in its shell to get to..."

Becky then repeats Willow's name and instructs her to listen.

Willow begins again, “Turtle...” After saying Willow’s name 11 times, Becky asks, "Did you listen to my words?" as she taps her ear. Becky then explains, "Let's finish our story and then we can talk about it, okay?" Becky is concerned children's interests will fade if she stops to let them talk too often.

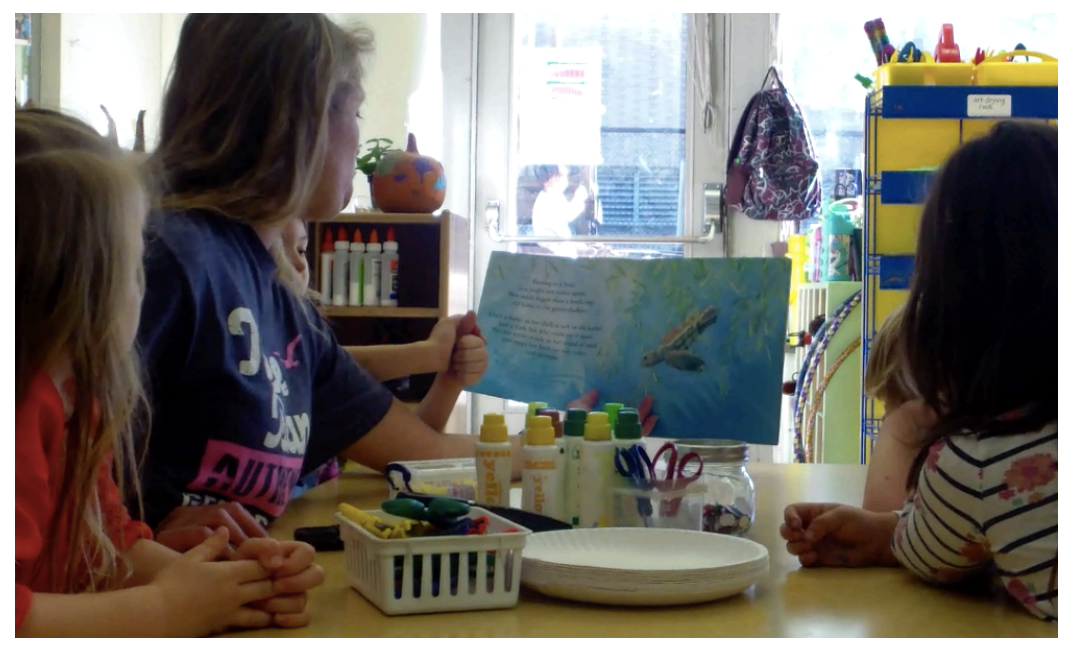

Figure 5. Lucy makes the sign for turtle while Becky reads.

Over the next several pages, Becky reads some passages, paraphrases entire pages, and omits passages to shorten the text so that it does not become too lengthy to hold children's attention (pp. 10-17). When she reads how the turtle has grown and its shell has become as hard as armor (p. 14), Becky knocks on the table, using multimodal 
communication to convey the shell's firmness. On one page, she simply shows children the picture without talking (p. 15). It is an illustration of the loggerhead chomping large crabs. The children examine the pictures while she holds the pages up. Pictures tell part of the story, which enabling her to skip over portions of written text. The children listen quietly as Becky reads how the loggerhead returns to the beach where she hatched to dig holes and lay her eggs in the sand (pp. 18-19).

Finally, Becky elicits more participation, "What will happen to the turtle's nest if she doesn't hide it?"

Willow, who has been eager to talk, offers an explanation, "Predators might find and take them." Willow has recalled a technical word not found in the book.

Becky then extends the conversation by adding ideas, "Or eat them. Do we want that to happen?"

Ava concludes, "So, we have to, we have to keep the eggs, we have to keep the turtle eggs away from the predators." Ava has personalized the content by using the inclusive pronoun, "we." She has become immersed in the story and taken a personal interest in protecting the turtle eggs. Ava's comment is marked by hesitation and repetition as she works on understanding (Barnes, 2008). She has also used the technical term "predators", which has become a shared word.

Becky closes the dialogue by expanding on their ideas, "We have to keep the turtle eggs away from the predators so they can hatch, right?" These are example of interthinking (Mercer, 2000), in which group members collaborate to build upon ideas. 


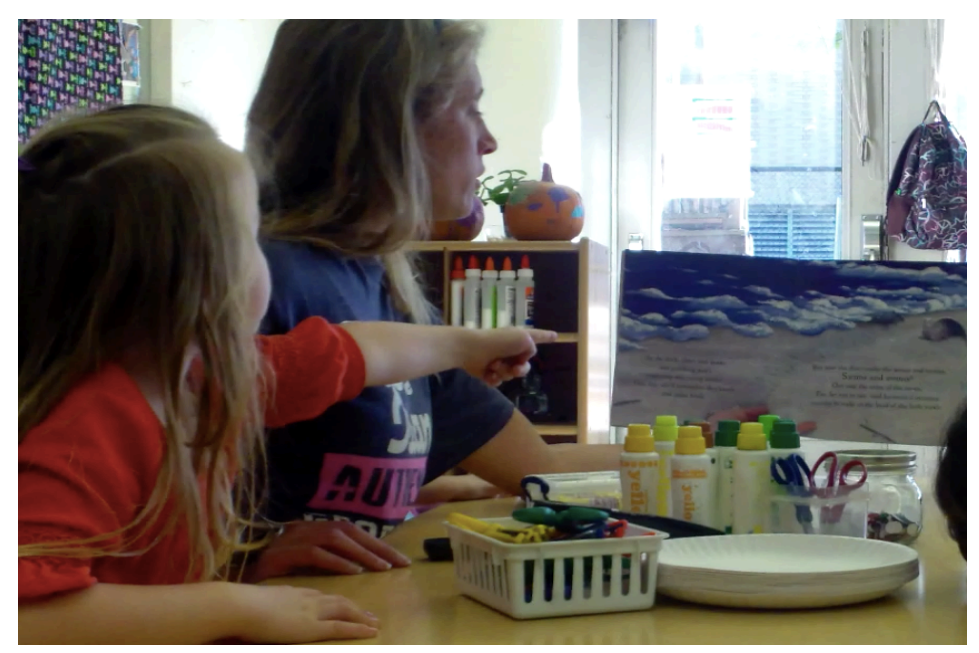

Figure 6. Ava points to a seashell on the last page of the story.

Becky finishes the story by reading about the tiny turtles hatching and scurrying toward the water while predators catch them (pp. 22-27). Suddenly, Ava interjects by drawing everyone's attention to a large seashell, "Look how big that seashell is!" (p. 29). The seashell is larger than the tiny turtle. Ava is gaining experience with interpreting information from the pictures. Becky acknowledges the large shell and then quickly transitions to the activity so that children's interests do not wane. Ava quietly whispers to herself, "Seashell, seashell, seashell," as she lingers over the final image.

Analysis. In this read aloud episode with the one narrative nonfiction text in the study, Becky took several actions to support children's comprehension. Children responded to Becky's talk moves and shifted stances along the efferent-aesthetic continuum to make meaning.

Becky utilized various talk moves to scaffold children's comprehension. She began by asking children to access their background knowledge of turtles. Children then shared their personal experiences with turtles, which prepared them to build on existing knowledge as they read. Becky elaborated upon children's ideas as they discussed what 
might happen to the turtle eggs if they were not hidden. She first posed the question, "What will happen to the turtle's nest if she doesn't hide it?" With this question, she asked children to contemplate cause and effect. Four-and-a-half-year-old Willow quickly ascertained that the eggs would be in danger. Cause and effect is a common text structure, so children's experience with this structure could potentially aid their comprehension. After children contributed ideas, Becky concluded, "We have to keep the turtle eggs away from the predators so they can hatch, right?" She and the children arrived at deeper understandings by elaborating upon ideas as conversational partners. Becky also demonstrated how to draw conclusions, which is another important reading strategy that supports meaning making. Through these teacher-learner interactions, children gained experience with making sense of this nonfiction text and to further their knowledge of the topic.

Children shifted along the efferent-aesthetic continuum. First, children responded efferently to the text. Willow took an efferent stance when she attempted to share turtle facts. She began, "Hey, Miss Becky, do you know what a turtle does? Turtle, a turtle, a turtle hides in its shell to get to...." Becky instructed her to listen while she continued reading. Willow's efferent responses continued as she discussed what would happen to the turtle eggs if they were not hidden. In addition to sharing facts, children also integrated discipline-specific language to increase their knowledge of subject matter. Willow first introduced the term "predators" as she described what might happen to the turtle eggs, "Predators might find and take them." "Predators" is not found in this text, which illustrates how Willow appropriately used academic vocabulary she had previously learned. 
In the same conversation, five-year-old Ava also used "predators" correctly. She shifted toward an aesthetic stance as she used the pronoun "we" when she indicated they would have to keep the turtle eggs safe, "So, we have to, we have to keep the eggs, we have to keep the turtle eggs away from the predators. Ava's language suggests that she had inserted herself into the story. Later, Ava moved toward an efferent stance as she pointed out the size of the seashell on the last page. She gathered information from the image to make meaning. Children read strategically as they shifted stances along the continuum in response to content in the written text and visual images. As children remained sensitive to ideas, as well as their own transactions, they gained experience interacting with the text in different ways to support meaning making.

In this read aloud episode, Becky's purpose was to read efferently as she employed multiple strategies to support children's comprehension. Children gained experience thinking scientifically as they considered cause and effect and used academic vocabulary. Children also demonstrated their own purposes for reading. Often, they took an efferent stance, but then shifted toward an aesthetic stance to personalize story events. This event illustrates that children assume stances independently of their teacher as they respond to the text.

\section{Integration of Episodic Analyses With Interview Data}

Introduction. A close examination of observational and interview data provided evidence for patterns in teachers' and children's reading behaviors with fiction and nonfiction texts. First, Kailee and Becky used two reading strategies with both types of text: they prompted children to interpret pictures and access their background knowledge about the book topic to better comprehend both fiction and nonfiction books. Teachers 
utilized one strategy that was unique to fictional stories as they elicited children's predictions and continued reading to confirm or disconfirm. When reading nonfiction books, teachers elaborated upon children's ideas and used gradual release of responsibility to support children's comprehension. Children exercised these same strategies in response to teacher's prompting. In addition, they explored characters' inner states while reading fiction and used academic language while reading nonfiction. Another pattern that emerged was that older children (four-and five-year-olds) consistently demonstrated reading strategies first while their younger peers (two-and-a-half-and three-year-olds) observed and imitated. Finally, teachers and children had distinct purposes for reading. Teachers took an aesthetic stance toward fictional stories and read nonfiction texts efferently. Children's responses were unfixed as they displayed flexible stances toward both types of text.

Teachers' strategies for both fictional and nonfiction texts. In these episodes, teachers utilized two teaching techniques to support children's comprehension when reading both fiction and nonfiction books. First, they prompted children to interpret pictures to make sense of the text. For example, when reading Dewey: There's a Cat in the Library! (Myron, Witter, \& James, 2009) Kailee encouraged children to examine the pictures to interpret story events and the cat's feelings. Similarly, she invited children to inspect the illustrations in Lucy's Picture (Moon \& Ayliffe, 1994) to consider characters' thoughts, feelings, and motives. As Kailee and the children read Patterns at the Museum (Steffora, 2011), she prompted children to read the patterns. While reading One Tiny Turtle (Davies \& Chapman, 2001), Becky and the children examined the image of the turtle laying her eggs in the nest as they discussed how the turtle needed to hide her eggs 
from predators. Both teachers indicated that children want to see the pictures, so they let them. Kailee commented, "We stop throughout and we talk about what we see. I do that in fiction and I do that in nonfiction" (Interview 1). Children's interpretations of pictures were so essential to their meaning making that teachers often prompted them to study the details to aid comprehension of fiction and nonfiction books.

Second, teachers invited children to access their background knowledge about the book topic. Kailee introduced Dewey: There's a Cat in the Library! (Myron, Witter, \& James, 2009) by asking children if cats lived in libraries. The children could then consider how the story changed their minds about cat homes. As they read Lucy's Picture (Moon \& Ayliffe, 1994), Kailee asked the children, “What's a collage?” so they could draw from their background knowledge to make sense of story events. Before reading One Tiny Turtle (Davies \& Chapman, 2001), Becky led a discussion in which children shared past experiences with turtles. This helped children think about their prior knowledge. Before Kailee read Patterns at the Museum (Steffora, 2011), she oriented children to the topic.

Kailee and Becky indicated that they strove to build on children's background knowledge and experiences. Becky discussed how children connect ideas in the text to content they had previously learned, "They're relating it to a book that we even read earlier during our story time, making all kinds of connections" (Interview 2). Likewise, Kailee revealed,

Well, I'm trying to keep building on prior knowledge because that's a nice way to do it. So, we've been doing this three-week unit on animals. We started with animal homes, we're doing animal jobs, and we're concluding with animals of (our state) (Interview 2). 
Both teachers used this technique to support children's integration of new information into their prior knowledge about the topic.

Children's abilities to analyze pictures and access their background knowledge of book topics were so essential to their comprehension that both teachers elicited these reading behaviors with fiction and nonfiction texts. Kailee and Becky scaffolded these reading behaviors in children's ZPD so that children could successfully engage with the text, which shows that these are appropriate expectations when reading with preschoolers.

Teachers' strategies unique to fictional and nonfiction texts. Despite the two common strategies, teachers employed different strategies when reading fiction and nonfiction books. First, for fictional stories, they used prediction. In both episodes, Kailee continued reading to confirm or disconfirm children's predictions. While reading Lucy's Picture (Moon \& Ayliffe, 1994), Kailee and the children read how Lucy gathered collage items. Kailee asked, "What do you think she's going to do with all that stuff?" When fouryear-old Alexandra shrugged, Kailee queried, "You don't know?" She then turned to fouryear-old Julia, "What do you think?" Julia also shrugged, so Kailee responded, "You don't know, either?" Julia shook her head as Kailee continued reading how Lucy constructed her collage. Later, Kailee asked why Grandpa might have a service dog. After each child had a chance to speculate, Kailee responded, "You think he might be blind." She then continued reading the passage in which Lucy greets her grandfather, “'I made you a picture, Grandpa!"' Kailee prompted children to view the picture, "Look!" She read on to confirm that Grandpa was blind, "Lucy grabbed her blind grandfather's hand." She then asked, "Were we right? He's blind. He can't see.” She finished the passage, "And guided it over her picture." Kailee first prompted children to predict whether or not Grandpa was 
blind and then drew their attention to the answer in the text. Kailee also elicited children's predictions while reading Dewey: There's a Cat in the Library! (Myron, Witter, \& James, 2009). In the passage where Dewey heard a baby cry, Kailee asked, "What do you think it might be?" Four-year-old Alexandra replied, "Baby." Rather than confirm, Kailee answered, "A baby?" Four-year-old Julia then shared her prediction, “A baby.” Kailee followed, "You think it might be a baby?" Julia asserted, "I think it is too." Kailee and the children then read about Dewey's encounter with the baby. Prediction and reading on are important reading strategies because they require readers to integrate new information into existing knowledge to make sense of the story. Readers must continuously refine their understandings as they make new predictions and read on to confirm or disconfirm as the narrative continues.

For nonfiction, Kailee and Becky scaffolded children's comprehension by elaborating upon ideas and employing gradual release of responsibility. Becky extended children's ideas as they read the passage in One Tiny Turtle (Davies \& Chapman, 2001) about the female loggerhead sea turtle hiding her nest. After the children had discussed how predators might take the eggs, Becky elaborated, "We have to keep the turtle eggs from the predators so they can hatch, right?" She then continued reading how the turtle made several nests before returning to the sea, "Left behind under the sand her eggs stay deep and safe." By elaborating, Becky alluded to the next event in the story, which might help children connect story events.

While reading Patterns at the Museum (Steffora, 2011), Kailee employed gradual release of responsibility as she provided children opportunities to read patterns with increased independence. She began by modeling how to read patterns and then observed 
as children imitated. While the two older children quickly acquired the skill, she provided additional support for the two younger peers. When it was three-year-old Michael's turn, she pointed to a picture, "Do you see a pattern in there?" Michael nodded but did not name it, so she asked a more direct question, "Where's the pattern, Michael?" She provided flexible scaffolding according to the child's response. Three-year-old Tommy needed the most support, so Kailee provided additional direct instruction. As they determined the next item in a pattern of differently shaped windows, she touched the picture, "What do you think this last window is going to look like?" She used both verbal and nonverbal cues to guide his thinking. Toward the end of the book, the two older children read patterns independently, so Kailee faded her supports. Throughout the reading, Kailee demonstrated her responsiveness to children's skill level by adjusting her scaffolding in each child's ZPD by employing gradual release of responsibility as children displayed their competencies.

Kailee and Becky both expressed that they took additional actions to support children as they read nonfiction. Kailee shared, "I tend to be more involved in nonfiction than fiction because a fiction book doesn't need the extra. The story is told purely through the book" (Interview 2). Becky was concerned that children became disengaged when reading nonfiction, so she utilized teaching techniques to support their engagement, "I feel like they're not always as interested in the nonfiction books as the fiction. So, just trying to ask questions and keep them engaged with the nonfiction books" (Interview 2). Later, she elaborated, "I'm always trying to check to make sure that children are engaged. I might ask the one child a question to get them drawn back into the book. So yeah, I have to use different strategies when I read those books" (Interview 2). Teacher-learner 
interactions were vital as teachers stimulated children's involvement with nonfiction books to aid their comprehension.

Summary. Kailee and Becky realized that they needed to scaffold children's comprehension of fiction and nonfiction books in diverse ways as they addressed the challenges and affordances of texts. In these four episodes, they employed strategies and prompted children's uses of strategies so that children could better comprehend each unique book. This required teachers to consider reading strategies that were best suited for each book and that children could demonstrate with supports.

In all four episodes, they prompted children to interpret pictures and access background knowledge of the topic because these general reading strategies had wide application and were appropriate for the young children in their class. The narrative structure of the fictional stories required readers to predict future story events and then read on to confirm or disconfirm. The nonfiction book, One Tiny Turtle (Davies \& Chapman, 2001), was unique because it was written in narrative form but described facts about the life of the female loggerhead sea turtle. Becky made the instructional decision to emphasize the information rather than the unfolding of the story. Therefore, she focused the conversation on facts rather than story events. The nonfiction book, Patterns at the Museum (Steffora, 2011), was expository (i.e., it explained facts and lacked a cohesive narrative structure). Kailee provided direct instruction (e.g., modeling, prompting) to read patterns. The similarities and differences in these episodes show that preschool teachers should employ a range of reading strategies when reading fiction and nonfiction books with their young students. In addition, they must provide flexible scaffolding (e.g., direct 
instruction, gradual release of responsibility) as children need more or less support in using reading strategies.

Children's reading strategies. Children displayed some of the same reading strategies with fiction and nonfiction texts. First, they relied heavily on pictures for making meaning and frequently commented on the images. As four-year-old Grace read Dewey: There's a Cat in the Library! (Myron, Witter, \& James, 2009), she pointed to a picture and inquired, "What's that?" She then personalized the text by sharing how she had a purple barrette like the one in the picture. At one point, children argued when they could not see the pictures. Children were also able to answer Kailee's questions about the character's feelings and story events by interpreting the illustrations. Children's attention to pictures continued during Lucy's Picture (Moon \& Ayliffe, 1994) as they interpreted Lucy's thoughts and feelings, and noticed Grandpa's service dog. These interpretations enabled children to make inferences about Lucy's motives for creating the collage.

Children's dependence on pictures was evident during nonfiction readings, as well. They relied nearly exclusively on images as they read patterns with colors, shapes, and sizes in Patterns at the Museum (Steffora, 2011). When Becky read One Tiny Turtle (Davies \& Chapman, 2001), children examined the illustrations. On the last page, fiveyear-old Ava drew everyone's attention to the picture of a large seashell on the beach. For children, illustrations played an essential role in meaning making while reading both fiction and nonfiction. Sometimes, children interpreted pictures as their teachers elicited this response. The use of this strategy was in their ZPD. At other times, they attended to pictures independently, which provides evidence that some children were becoming independently strategic readers. 
Second, children accessed their background knowledge in response to teachers' prompting. Before reading Dewey: There's a Cat in the Library! (Myron, Witter, \& James, 2009), they considered whether or not a cat might live in a library. While reading Lucy's Picture (Moon \& Ayliffe, 1994), Kailee prompted them to recollect their knowledge about collages and service dogs. Children's uses of background knowledge were evident during One Tiny Turtle (Davies \& Chapman, 2001) as they each shared their experiences with turtles before Becky read the book. Since these were unique to each child, everyone heard diverse stories about turtles. They could then draw upon these ideas as they read the book. While reading Patterns at the Museum (Steffora, 2011), children utilized their preexisting knowledge of shapes, colors, and size order (i.e., big-to-little; big, bigger, biggest) to interpret the patterns. Children did not display this reading behavior independently. It was necessary for teachers to provide explicit instruction (i.e., prompting, modeling, eliciting children's responses) for children to utilize this effective strategy.

Children employed one additional reading strategy while reading fiction and one while reading nonfiction. First, when reading fiction, they interpreted characters' thoughts, feelings, and motives. They also explored how characters' actions affected others. In Lucy's Picture (Moon \& Ayliffe, 1994), they considered story events from Lucy and her grandfather's perspectives and the ways that Lucy's decisions and actions (making a collage instead of a painting) changed the outcome of the story. In Dewey: There's a Cat in the Library! (Myron, Witter, \& James, 2009), the cat was anthropomorphized. The children witnessed the different ways Dewey adapted to his new social environment as he aimed to be the best library cat he could be (e.g., greeted patrons, helped others, cheered 
people up). Becky wanted children to realize that stories are not just for entertainment but could also teach children about their social worlds. She explained,

Sometimes you know if there are things that are funny or silly, they will react. You know, kind of continuing, being able to continue to read through all those reactions. And still get through it and have a, have a moral with it. You know, you always, even though you're reading the silly story, you know, sometimes they have to remember 'Oh! There's a purpose still to the story besides just being a silly story to read' (Interview 1).

Reading fictional stories provided opportunities for lived through experiences that children did not always have with the nonfiction books. These reading experiences could help children better understand their social interactions: how people's thoughts, feelings, and perspectives relate to their behaviors, as well as how people's behaviors affect others.

Conversely, when reading nonfiction books, children used academic language and explored subject matter content, which was not evident when reading the fictional stories. They shared their scientific knowledge and used content-specific language while reading One Tiny Turtle (Davies \& Chapman, 2001) as they discussed how the eggs had to be buried to be safe from predators. They integrated reading and science content to comprehend the book. During Patterns at the Museum (Steffora, 2011), children used reading strategies as they learned math concepts (interpreting patterns). Kailee noted that children remembered content they explored in books,

And they really like having facts that, that are true. They tell their parents what they've read. They will tell other friends on the playground, 'We read...that's a 
caterpillar...and caterpillars...'. They like to share information that they've

learned from the true books (Interview 1)

Children realized that nonfiction books served as resources for learning about the physical world. Through nonfiction reading, children were gaining the background knowledge needed for future learning in specific content areas.

Children exhibited complex reading behaviors during these episodes that demonstrate how they can utilize a range of strategies to meet the demands of both types of text. Children employed these strategies with various competencies. They used some independently and other strategies required teacher prompting. This indicates that teacherlearner interactions are central to fostering young children's strategy use when reading. Children also read for different reasons: to learn about their social worlds and the physical environment. As children explore these pertinent topics, they might apply their new knowledge to their lives and future academic learning.

Older children served as peer models for younger children. The small groups in Kailee and Becky's class usually consisted of children of different ages who exhibited a range of emergent reading behaviors. Typically, the older peers displayed their reading strategies with both fiction and nonfiction texts while their younger classmates observed. First, older children were often the first to share their background knowledge, answer teachers' questions, and explain their thinking strategies. For example, when Kailee asked children to describe a collage while reading Lucy's Picture (Moon \& Ayliffe, 1994), fouryear-old Alexandra, who was one of the older children in the group, responded.

Throughout the story, the older peers were the first to answer questions as they inferred from pictures. As Kailee read Dewey: There's a Cat in the Library! (Myron, Witter, \& 
James, 2009), four-and-a half-year-old Grace, who was the oldest child in the group, frequently interjected. She pointed to pictures, asked questions, and personalized the text. Grace also moved along the efferent-aesthetic continuum as she sought information at times and responded emotionally during funny or sad moments in the story. Grace also displayed her appreciation of figurative language.

Second, the older classmates were also the first to demonstrate reading strategies during nonfiction read aloud episodes. While reading Patterns at the Museum (Steffora, 2011), the two older peers read multiple patterns while their younger classmates observed. As Becky facilitated the conversation about children's past experiences with turtles before reading One Tiny Turtle (Davies \& Chapman, 2001), the three older peers first shared their stories. Throughout the reading, they responded in various ways (e.g., sign language, sharing facts, answering questions, elaborating on each other's ideas, sharing details in pictures) while the youngest child, three-and-a-half-year-old Peter, listened.

The younger children observed and took cues from their classmates. While reading Lucy's Picture (Moon \& Ayliffe, 1994), two-and-a-half-year-old Marie answered Kailee's question about the collage immediately after Alexandra responded. Later, she gave the same reply to Kailee's question as her older classmates. It is possible that Marie was learning to respond to teachers by taking cues from her older peer. Toward the end of Patterns at the Museum (Steffora, 2011), the two younger children participated. As they read patterns, they responded similarly to the older children (i.e., pointing and naming). When Peter participated in the conversation about his past experiences with turtles, his reply was comparable to the older children's answers. Like the others, he shared where he had seen a turtle. 
Older children displayed reading strategies more quickly and independently than their younger peers. As older children demonstrated for the group, younger peers might be learning how to answer questions and employ strategies by observing and imitating their older classmates. These episodes provide evidence that preschoolers do not need to be placed in ability groups for reading instruction. Rather, children's mixed ages and abilities might be advantageous because children can learn from each other.

\section{There were differences between teachers' and children's transactions with}

texts. Kailee and Becky maintained established purposes for reading fiction and nonfiction texts, which were evident in their fixed stances toward both types of text. They read fictional texts aesthetically, for the purpose of living vicariously through characters, and nonfiction books efferently, to take away information. Conversely, children assumed flexible stances toward fiction and nonfiction as their responses shifted along the efferentaesthetic continuum throughout the readings.

First, Kailee and Becky took preconceived stances according to the type of text. In the four episodes, Kailee read fictional stories aesthetically so that children could use their imaginations to vicariously experience the stories through characters. First, she provided children abundant opportunities to enter characters' inner worlds to contemplate their feelings, thoughts, and motives while reading both fictional stories. She encouraged children's aesthetic responses through questions and by prompting children to study the pictures to interpret characters' feelings. For example, in Dewey: There's a Cat in the Library! (Myron, Witter, \& James, 2009), she inquired, "Look, does the kitty look happy?" Later, she shared her own feelings as she empathized with the cat, "I think it would be scary to be shoved in a box. Do you think it would be scary to be shoved in a 
box?" Moreover, she invited children to consider how they would feel if they were in the same situation. Kailee's focus on aesthetic responses continued as she read Lucy's Picture (Moon \& Ayliffe, 1994) as she encouraged children to interpret Lucy's feelings as she pondered over the paints, "Look at Lucy thinking. Do you think she likes any of the paint colors? It doesn't look like it, does it? Hmm, she's thinking". Later, she asked children to infer Lucy's motives for touching Grandpa's hand to the collage, "Why did she take Grandpa's hand and put it on her picture?" She touched Alexandra's hand to the book to demonstrate Lucy's actions. Alexandra guessed, "Um, so he can, so he can feel it." Kailee confirmed, "So he can feel it. Because can he see it with his eyes?" Alexandra shook her head no. Kailee concluded, "But he could feel it with his hands." In this exchange, Alexandra contemplated Lucy and her grandfather's perspectives.

Both teachers shared that their purpose for reading fictional stories was to stimulate children's imaginations and enable them to have vicarious experiences through characters. Becky stressed that she read fictional books because they fostered children's imaginative responses, "Imagination, because, you know, imagination, dramatic play purposes, anything that they can just kind of step out and think and be silly and you know, fun" (Interview 1). She also added that she read fiction with strong emotion in her voice, "When you're reading fiction it's a story that, you know, has the steps and components of the story so you can have different emotion" (Interview 1). Kailee explained,

Fiction is a great way for the kids to explore emotions and things that might be a little scary. If you read a book about a little girl that gets lost in a grocery store they can process how they might feel if they were lost without actually being lost. 
That's one benefit of reading fiction. Another benefit is you know, you know, it improves your imagination (Interview 1).

She realized that, as children read about characters in intensely emotional situations, they could simultaneously feel those same emotions yet manage their feelings by distancing themselves from the story world.

While teachers took a predominantly aesthetic stance toward fiction, they read nonfiction efferently: to teach facts about the book topic. For example, Kailee's purpose for reading Patterns at the Museum (Steffora, 2011) was to teach children to recognize visual patterns. She established her purpose at the beginning when she asked children to identify the topic. She did not deviate throughout the reading as she continually prompted children to attend to different patterns. Becky also took an efferent stance as she and the children read One Tiny Turtle (Davies \& Chapman, 2001). She facilitated conversations that emphasized facts about the female sea turtle.

When discussing the reasons they read nonfiction, Kailee and Becky offered similar responses: to read about facts. Kailee disclosed, "Well that's great because that actually gives you information about something” (Interview 1). Similarly, Becky shared, “Teaching them facts $[\ldots]$ it's so important also because to learn something from it as opposed to just the imaginary" (Interview 1). She also revealed that she read nonfiction differently than fictional stories. She explained, "When you're reading nonfiction $[\ldots]$ it's a lot of facts $[\ldots]$ you're almost discovering as you read it" (Interview 1). She read as if she was surprised at the amazing facts in the book. As Kailee and Becky communicated their distinct purposes for reading fiction and nonfiction, they showed children that people read different texts for different reasons. Setting a purpose for reading is a necessary 
strategy that children will need to develop to become increasingly skilled readers. As Kailee and Becky modeled this reading behavior, they demonstrated an action that strategic readers take.

While teachers took fixed stances toward fiction and nonfiction books, children moved more fluidly across the efferent-aesthetic continuum with both types of text. While reading Dewey: There's a Cat in the Library! (Myron, Witter, \& James, 2009), four-anda-half-year-old Grace read efferently as she sought information and displayed an aesthetic stance as she responded emotionally to Dewey's various experiences. She and Alexandra also responded aesthetically by considering Dewey's feelings at different points in the story. Children's movement along the efferent-aesthetic continuum was also evident as they read Lucy's Picture (Moon \& Ayliffe, 1994). Several times, children read aesthetically as they considered characters' thoughts, feelings, motives, and perspectives. They shifted toward an efferent stance as they accessed their background knowledge about different topics in the story (e.g., collages, working dogs, blindness).

Like Kailee, children took an efferent stance to the text as they read Patterns at the Museum (Steffora, 2011) but shifted their responses while reading the other nonfiction text, One Tiny Turtle (Davies \& Chapman, 2001). They read efferently to access their background knowledge of the topic, share facts, use academic language, and notice details in the illustrations. However, five-year-old Ava offered an aesthetic response as she inserted herself into the story when she announced that they needed to keep the turtle eggs away from the predators.

While teachers believed it was important to model how to read texts for specific purposes, this practice narrowed their range of responses. Children remained more 
receptive to fuller possibilities as their stances shifted in-the-moment while they encountered pictures, story events, and information that ignited their thoughts and feelings. These episodes provide evidence that preschool-aged children are capable of reading with autonomy as they establish and continually revise their own purposes for reading, stay sensitive to content in the text throughout the reading, and independently exhibit a wide range of responses to more fully interact with the text. In these ways, children were becoming increasingly strategic and independent readers.

\section{Section III: Scaffolding and Modeling Strategies With Nonfiction Literature}

\section{Introduction}

When reading both fiction and nonfiction, Kailee and Becky differentiated instruction to scaffold children's meaning making and emerging reading strategies in their zone of proximal development (ZPD) and to model more sophisticated reading strategies that are just beyond children's ZPD (Appendix N). They used interactional scaffolding, which is contingent upon the learner's responses (Hsin \& Hsin-Kai, 2011; Reynolds, 2017). Kailee described how small group reading is conducive to differentiation "by paying attention to the areas where children need more support and what areas they are really strong in" (Interview 1). Teachers differentiated instruction by modifying aspects of their teaching to meet the learning needs of individual children by providing support according to children's various emergent literacy behaviors. Kailee and Becky elicited responses from children (Zurek et al., 2014), gave feedback according to children's responses (La Joie, 2005), and modeled strategic reading. They employed a variety of interactional scaffolding strategies (Reynolds, 2017) to help children make sense of both fiction and nonfiction. Pentimonti et al. (2017) point out that scaffolding can look different 
in a preschool setting than with older students due to the prevalence of naturalistic approaches to teaching and learning in preschool (i.e., teaching and assessment are more conversational as preschool teachers generally use fewer scripted lessons and standardized tests).

The following two small group read aloud episodes took place during the unit of study on music and sounds. They include Becky reading the same nonfiction expository text, A Listen to World Music, by Jennifer Reed (2014) to two small groups in the science area. This 24-page nonfiction expository text is part of the Rourke Educational Media Art and Music ${ }^{\circledR}$ series. This contemporary book contains large brightly colored photographs of instruments and people from many continents and cultures playing music and dancing in traditional costumes. The text contains several nonfiction organizational features such as table of contents, subheadings, index, and glossary. The subsections include: "Music of the World", "Sounds of Africa", "Latin Music", "Celtic Sounds", "Music of Asia and the Pacific", and "Australian Songs". The first page of each subsection displays a world map (in gray) with the featured area in orange. Other nonfiction visual features include captions and labels. The reading is followed by a teacher-led activity in which children count drumbeats. Becky has brought a drum and sticks for the activity; these items lay on the table while she reads. Each small group consists of an older and younger child who chose to participate in small group read aloud, making them some of the smallest groups in the study.

\section{Reading I: A Listen to World Music}

In this read aloud episode, three-and-a-half-year-old Michael and five-year-old Lucy join Becky in the science area to read A Listen to World Music (2014). Becky begins 
by having children identify the objects they will be using in the activity; Lucy identifies the sticks and drum while Michael observes. Lucy picks up a stick and beats the drum, "I know what it did." As usual, the older child in the group is the first to participate. Becky then turns their attention to the book, "We have a drum, we have some sticks, and I have this lovely book about instruments from around the world." Becky's actions help children connect the reading and activity and might motivate them to stay for the entire reading and response event. She has also modeled how to establish a purpose for reading. Next, Becky poses a geography question, "Do you know where we live in the world?" and Lucy gives the name of our state. Becky is preparing children to learn about places around the world and she starts with their location. As Becky reads the title, Lucy voluntarily identifies the W in "World." So far, five-year-old Lucy is the only child who has participated. She is older than three-and-a-half-year-old Michael and might have more world knowledge and letter recognition. Michael is afforded the chance to observe his older classmate and is not just learning from a teacher but also a peer model.

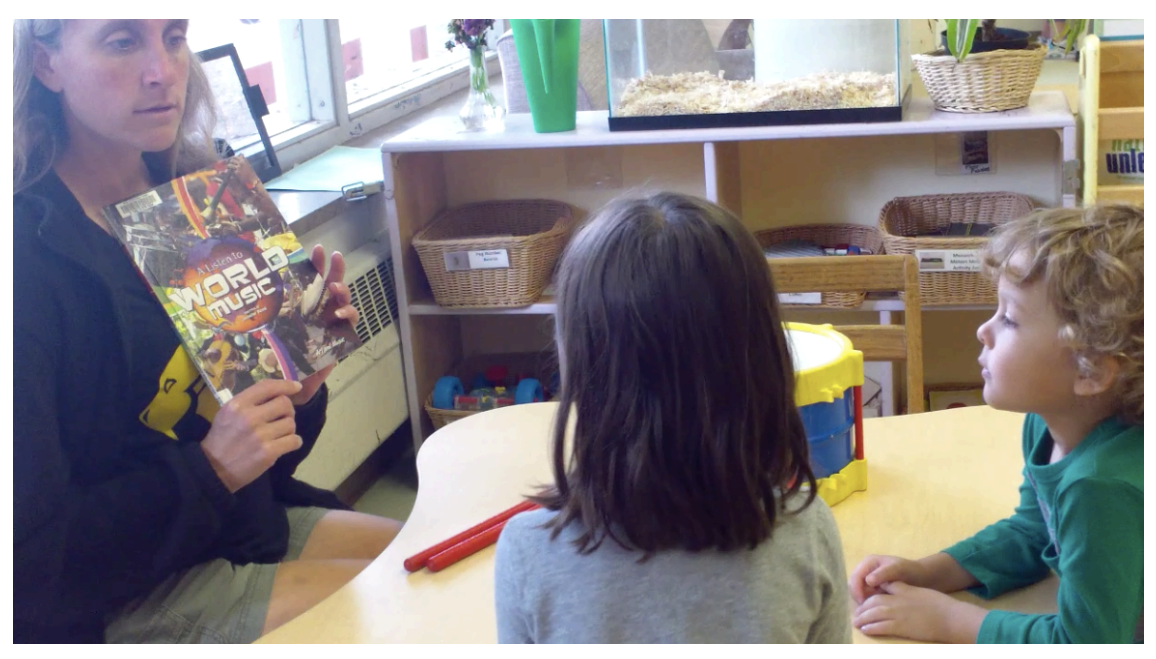

Figure 7. Becky shows Lucy and Michael the book title. 
As Becky begins to read, she draws children's attention to a photograph of drums and asks if they look like their drum (p. 4). This explicit connection between the book and activity helps children see how they are related. Becky then contrasts the instruments in the photograph with their drums and sticks, "They have drums. Do they look the same as our drums? They don't do they. They look a little different. And they even have drum sticks but they look like they're wood." Becky points to the picture, "They're just straight from a tree." She models how to compare and contrast similar objects. Becky then points to an unfamiliar vocabulary word in bold letters, "ethnomusicology" (p. 5), and reads the definition: the study of world music. She is modeling how to interact with a common nonfiction text feature: vocabulary words in bold letters.

On page 5, Becky invites children to compare an instrument in the photograph to a recognizable instrument (i.e., guitar), “This item looks kind of like...” Becky waits for children to answer. The traditional African stringed instrument is not named in the book. This is an example of contextualization, in which the teacher draws comparisons to something familiar to help children understand an unknown object (Zurek et al., 2014).

Five-year-old Lucy guesses that the instrument in the photograph is similar to a violin and Becky acknowledges, "It has strings like a violin. What else does it look like?" Lucy replies, "A drum."

Rather than telling her she is wrong, Becky dignifies her answer by asking, "Does it look like a drum?" She points to a part of the instrument, "This part here looks kind of like a drum." Becky is scaffolding Lucy's ability to interpret information from pictures. She has found something they can agree upon, lending credibility to Lucy's meaning making. 
When teachers dignify children's responses, children could feel more confident to share their thoughts with the group.

Becky enthusiastically announces a new subheading: "Sounds of Africa" (p. 6).

The excitement in her voice conveys her curiosity about the new subtopic as she strives to pique children's interests. She points to Africa on the world map while she reads about the regions and cultures of Africa. She is modeling how to attend to this common nonfiction feature by showing how it corresponds to the printed text. Becky then points out North America and the United States; she tells children this is where we are as she points to the US. This might help children understand that Africa is far away and very different from our country. Lucy and Michael inspect the world map and then Lucy queries, "Where's St. Louis?" As Becky points to the center of the US, Lucy announces, "Two hours." Lucy personalizes the information in the text by relating it to a familiar experience: driving to St. Louis. Lucy is using this reading strategy (personalizing) independently. Meanwhile, Becky has taken the time to digress from the reading to address a topic of interest to Lucy, which shows Lucy that her interests matter to her teacher.

Becky continues to read about the instruments of Ethiopia and points out a picture of a shepherd blowing a horn (p. 7). She then personalizes by sharing how her son has a friend who is adopted from Ethiopia, "Did you know that my son who has a friend who is adopted? He is from Ethiopia."

Lucy then states, "You know, just, people don't have to be born, they could be founded."

Becky takes a moment to briefly explain why people get adopted. In this example of "point of need" (Sharpe, 2001, p. 33) scaffolding, Becky recognizes Lucy's 
misconception. Becky's personal anecdote has sparked a short exchange that reveals Lucy's misunderstanding and leads to Becky giving the children insight into something Lucy has misunderstood. While Michael has not yet spoken during this read aloud, he has observed the reading and conversation, enabling him to process a range of new information.

As Becky continues to read about Ethiopian music (p. 8), she spots an error: The text says this type of music only has five notes but lists six. Becky reads, "Ethiopians love their traditional music, which itself has only five notes: do, re, me, fa, so, and la" (p. 8). Becky then invites the children to count so they notice the discrepancy too. She puts the book down because she needs two hands to count. She sings, "Do, re, me, fa, so, la." Lucy counts with her and Michael remains silent.

Lucy replies, "That's six."

Becky summarizes, "That's six! And the book says what? The book's telling me five. Hmm, did someone not know how to count? That's wrong." Becky scaffolds Lucy's use of vital nonfiction reading skills: checking the accuracy of texts by using metacognition to monitor for comprehension and recognizing when information doesn't make sense.

Becky then reads a new subheading: "Latin Music" (p. 10). She addresses Michael by saying his name, pointing to a picture, and commenting, "Michael, Look at these guys playing guitars. They have on sombreros!” She speaks directly to him, instructs him to examine the photograph, and tells him what is happening in the picture. She is supporting his abilities to make meaning. Much of this information might have been a challenge for three-and-a-half year old Michael to understand, so Becky attempts to bridge this new 
information with something familiar: a guitar. Although Michael still does not speak, he attends to important information in the pictures and is exposed to new words and ideas.

When Becky reads about the regions, cultures, and music of Latin America (p. 10), she points to that area on the world map. Lucy and Michael attend to the map, enabling Becky to scaffold their attention to this visual feature. Becky then directs them to look at various pictures. As they focus on the photograph of a man playing a pan flute, Becky supplies additional information and prompts children to imitate, "He blows to the top. Can you pretend to do that?" She then demonstrates how to blow over the top of her hand and the children mimic her. Although her actions do not elicit dialogue, Becky models and scaffolds children's nonverbal responses through gesture.

As Becky reads about Caribbean music (pp. 12-13), she points to a photograph of a couple dancing, "They're dancing to the Caribbean music." She models how to integrate information from written and visual texts. She sings and sways, "La-la-la-la-la! Think salsa? We did salsa painting the other day when we did our painting, didn't we? I think we did." Becky models how to connect ideas in the text to a previous learning activity. She makes intertextual ties and connects ideas from the book to the topic of their unit of study to help children understand the relevance of the content of the book.

When Becky reads about Celtic music (pp. 14-15), she points out Ireland on a map and again tries to hold Michael's attention by having him look at a picture. She attempts to help Michael relate the reading to his own life by asking him if he ever dances and if his baby sister will dance (his mother is pregnant). Michael quietly observes but is not ready to share aloud. Becky exposes both children to an essential reading skill as she encourages Michael to think about ways the text might relate to his life. Although Becky is 
unsuccessful in eliciting a verbal response, Michael continues to attend to the reading and she models how to personalize ideas from the book.

As Becky turns the page (p. 16), she points to a photograph of bagpipers, "Look at these bagpipes! Oh, do you see the bagpipes?” Rather than react to Becky’s prompt, Lucy imitates Becky's reading behavior by pointing to a photograph of dancers on a stage, "Look at these girls" (p. 17). Lucy spontaneously demonstrates the use of this strategy as she independently attends to another photograph to gather information. Becky extends Lucy's response, “They're dancing." She models how to verbalize an interpretation by labeling the girls' actions.

By this time, Michael's attention has started to wane, and he has turned around in his seat to scan the classroom. Becky notices and quickly draws him back by saying, "Michael, do you see that harp that Kailee has talked about?" She personalizes the information in the photograph in an attempt to regain his interest. "Remember the bagpipes we've talked about?" Becky moves beyond the book by recalling an earlier learning activity. Michael looks at the photograph but does not speak. Lucy has also become quiet. Becky realizes she must quickly finish the book or Michael will lose interest and walk away.

Becky reads the final subheading: "Asia and the Pacific" (pp. 18-19), points out a sitar, and spells the word. She mentions Japanese folk musicians (p. 19) but does not discuss the photographs in detail. She also does not attend to the map of Asia. Becky omits these features to shorten her reading time and bring quick closure to the reading. She then realizes there is one more page featuring Australian music. She immediately labels the didgeridoo in the photograph, shares how it was played at the world cup soccer 
games, and gives a quick demonstration by making a low drone with her voice. Once, again, she models how to gather information from a photograph, label the object, and respond nonverbally. Before she loses children's attention, she quickly switches to the activity by inviting them to play the drum.

Analysis. Becky supported children's comprehension by scaffolding and modeling reading strategies. First, she scaffolded children's comprehension by prompting them to interpret visual images and eliciting their multimodal responses. Second, Becky differentiated instruction as she scaffolded individual children's reading strategies in their ZPD. Third, Becky modeled other reading behaviors that she did not expect children to exhibit. These included reading nonfiction text features such as subheadings and defining terms.

Scaffolding techniques with both children. Becky scaffolded both children's uses of two comprehension strategies: interpreting visual images and displaying multimodal responses. Becky prompted children to interpret visual images as she encouraged them to notice details in pictures by naming instruments, describing people's actions in the photographs, and labeling parts of the world map. First, she drew children's attention to photographs of various instruments. At the beginning, she requested, "Look at all these, what do they have?"

Lucy responded, "Drums."

Becky encouraged children to notice and name objects (Johnston, 2003) to draw their attention to the most salient aspects of the photographs.

Later, she urged children to notice details in a photograph of a mariachi band, "Look at these guys playing guitars. They have on sombreros!" The children peered at the 
picture. In this example, Becky noticed and named the instruments and other details to guide children's attention (Johnston, 2003). On one page, she pointed to bagpipes, “Look at these bagpipes! Oh, do you see the bagpipes?" Later, she pointed to an Indian musician while the children examined the photograph, "And it shows this guy playing this instrument here, which is called, let me remember the name of it...the sitar, S-I-T-A-R.” Children were exposed to new content-specific vocabulary and corresponding images as Becky explicitly named and pointed to various instruments throughout the book. Becky displayed an important nonfiction reading strategy: reading labels and captions.

At times, Becky moved beyond labeling objects to describe people's actions in the photographs. For example, as they viewed a picture of shepherd boys blowing horns, Becky commented on the boys' actions, "Like this flute played by shepherd boys." She pointed to different details in the photograph, which might help children notice them. Later, she pointed to a picture of a couple dancing, "They're dancing to the Caribbean music." In one instance, she pointed to a photograph of Celtic dancers, "This is Celtic music that comes from Ireland and Scotland. Look, they're going to dance to Celtic music." Becky's comments might help children realize that photographs, unlike many illustrations, depict real world objects and events. Moreover, Becky's descriptions could help children visualize how a photograph captures a single moment in a stream of action.

In multiple instances, Becky drew children's attention to places (in orange) on the world map (in gray) that could be found at the bottom of several pages. For example, she pointed to Africa and North America, "Here's Africa. Here we are in the United States." This action might help children understand that Africa is far away. Later, she drew children's attention to the different parts of Latin America, "Four regions make up Latin 
America. They include Mexico, Central America, the Caribbean Islands, and South America." These areas were labeled on the map, so Becky showed them how to read labels. Toward the end, she commented, "And this is the last one. It's in Asia in the Pacific." The children inspected the map as she pointed. Children gained experience with interpreting maps as Becky exposed them to the names of different parts of the world and located specific areas on the world map. Maps are important texts in our culture that display geographic information in two dimensions. Interpreting maps is an important reading skill that children will use in school and life.

At several points in the reading, Becky utilized multiple modes of communication (e.g., sound, gesture) and prompted children to imitate. In one example, she blew over the top of her hand as she demonstrated how a man played the pan flute, "Look at this thing he's playing, the pan flute. Look at that. He blows to the top. Can you pretend to do that? Do you think that would be hard?" She blew over the top of her hand and the children mimicked her actions, which might help them better understand what was happening in the photograph. Soon after, Becky sang and swayed to imaginary music, "La-la-la-la-la! Think salsa?" as she and the children examined a photograph of a couple dancing to Caribbean music. Although the children did not imitate her, they were exposed to different forms of response. On the last page, she imitated the deep drone of the didgeridoo as she and the children inspected the photograph of people playing the instrument, "This, here, is called a didgeridoo. When they had the last soccer World Cup, when all the people played soccer, there were a lot of people in the stands going 'Duuuuuuuuu' [hand to mouth in a low drone] playing their didgeridoo." Lucy imitated the deep hum of the instrument. Becky employed multimodal techniques so that children could interpret information 
through various senses to help them better comprehend the content and consider various forms of response.

The two reading strategies that both children displayed in response to Becky's prompting were interpreting pictures and displaying multimodal responses (e.g., gesture, sound). As Becky communicated through multiple modes, both children were able to use their senses and different modes to attend to the text and imitate her actions. Reading with young children should be multimodal and multisensory because it enables teachers to communicate through a range of modes and children to respond by drawing upon various semiotic resources. As teachers and children utilize multiple modes of communication, they might be better able to convey meaning. When children employ reading behaviors that engage their senses, it could enhance their reading comprehension.

Scaffolding for individual children. Becky scaffolded individual children's reading strategies in their ZPD. This was necessary because three-and-a-half-year-old Michael's and five-year-old Lucy's reading behavior were unique.

Michael. Michael, who seemed reserved, exhibited few reading strategies independently, so Becky stimulated his participation by cueing him to attend to pictures as she noticed and named important parts (Johnston, 2003). Roughly half way through the book, Becky pointed, “Okay, so Michael, look. There’s this big drum. It kind of looks like our drum, doesn't it? A little bit?" Michael leaned over the photograph of a man a beating drum with his hands and silently nodded. It was important for Becky elicit his nonverbal responses because Michael did not respond verbally. On the page with the Celtic dancers, Becky urged, “And Michael, look. They're going to dance to Celtic music.” Michael silently inspected the photograph. Becky then personalized the content, "Do you ever 
dance? Yeah? Do you think your baby sister will dance when she comes out of mommy's tummy? You think so?" Michael observed his teacher but did not demonstrate that he could connect ideas in the text to his life. Looking at pictures was in Michael's ZPD but personalizing the text was beyond his ability, even with teacher support. Toward the end, Becky pointed, “This is a harp. Kailee has talked about the harp hasn't she? Michael, do you see that harp that Kailee has talked about?" Michael turned around in his seat and scanned the classroom, so Becky quickly finished the reading and switched to the activity.

One of the few reading behaviors Michael displayed was looking at pictures, which suggests that it might be one of the first strategies very young children exhibit. Becky prompted him multiple times to scrutinize the pictures, which points to the central role adults play in eliciting young children's uses of reading strategies. Her frequent cues to examine specific parts of the pictures might have persuaded Michael to remain at the table for the duration of the reading. As a result, he practiced building his reading stamina, was exposed to additional content, and participated in the response activity that immediately followed (i.e., counting drumbeats). Becky's success in engaging Michael with the text by prompting him to look at pictures likely led to additional learning opportunities.

Lucy. Becky scaffolded five-year-old Lucy's use of several reading strategies: accessing background knowledge, personalizing the text, comparing and contrasting objects, and identifying a factual error. While Becky encouraged both children to utilize these strategies, Lucy displayed these behaviors as her younger classmate observed. First, Becky scaffolded Lucy's ability to access her background knowledge when Becky discussed the objects that they would be using in the activity (i.e., drum and stick). 
She began, "So what I have today is I have a..."

Lucy spoke up, “Drum.”

Becky continued, "I have a drum and I have some..." Becky used the cloze

technique to encourage Lucy to use her background knowledge (Taylor, 1953).

Lucy stated, "Sticks."

Becky concluded, "We have a drum, we have some sticks, and I have this lovely book about instruments from around the world." As Becky read with the intent to learn about different instruments, she oriented children to the book topic and corresponding response activity and showed them how to be strategic in setting a purpose for reading.

Later, Becky prompted the children to access their background knowledge by naming where they lived. She asked, "Do you know where we live in the world?"

Lucy answered, "We live in (our state)."

Becky confirmed, "We live in (our state)." Lucy recalled their location, which might have helped her realize that the places in the book were far away and she would be learning about people and places she had never encountered.

Second, Becky personalized the text as she modeled her past connections and invited children's personal connections. When they read about Ethiopian music, she shared, "Did you know that my son who has a friend who is adopted? He is from Ethiopia." Becky modeled how the content from the book sparked her own personal connection. Toward the end of the text, Becky and the children studied a picture of two people dancing to Caribbean music. She discussed how they might be dancing to salsa music like they had done in class, "We did salsa music the other day when we did our painting, didn't we? I think we did." Children might then consider how they participated 
in an activity similar to people in the photograph. As Becky personalized the text, she demonstrated multiple ways to realize the commonalities between content in the book and their lives, which might show children how to seek out those connections.

Lucy seemed to respond to Becky's invitations to make personal connections. After Becky pointed out North America and the United States, Lucy asked, "Where's St. Louis?"

Becky scrutinized the map, "St. Louis would be not too far from us." She pointed to the center of the US, "Let me see where it is...okay, here. St Louis..."

Lucy announced, "Two hours."

Becky continued, "Is right there so with my, my finger pointing it's really hard to see the difference because there is just a little bit of difference there between the two. There's just this much difference on the map." She pinched her thumb and index finger closely together. Lucy personalized the content as she wondered about the location of a familiar city. She might have also gained a sense of scale as she knew it took two hours to drive to St. Louis, yet it was close to her town on the map.

Third, Becky encouraged children to compare and contrast instruments in pictures with familiar instruments. At the beginning, she prompted them to notice the drum in the picture and asked if it looked similar to the drum on the table in front of them, "They have drums. Do they look the same as our drums? They don't do they. They look a little different. And they even have drumsticks but they look like they're wood. They're just straight from a tree." Lucy shook her head. She contrasted the two items by scrutinizing the details. Next, Becky pointed to an exotic stringed instrument, "Look, what does it look like? This item looks kind of like..." 
Lucy replied, "A violin.”

Becky elaborated, "It has strings like a violin. What else does it look like?"

Lucy responded, "A drum."

Becky pointed to the instrument's individual features, "Does it look like a drum? This part here looks kind of like a drum. I agree with that." This technique could support Lucy's comprehension as she noticed details in visual images and distinguished the similarities and differences.

Finally, Becky invited children to notice a factual error as she read how Ethiopian music had six notes but the text indicated that it had five, "Ethiopians love their traditional music, which itself has only five notes: do-re-mi-fa-so and la!" She asked, "How many notes is that? That's what the book says." She then put down the book and sang as she counted on her fingers, "Do-re-mi-fa-so-la! Is that five?"

Lucy asserted, "That's six."

Becky added, "That's six! And the book says what? The book's telling me five. Hmm. Did someone not know how to count? That's wrong." Lucy gained experience analyzing the text for accuracy, recognizing when content did not make sense, and figuring out how to handle information that was not factual. She could potentially apply these skills as she encounters misinformation in various media.

Becky elicited several reading strategies in Lucy's ZPD. Lucy's reading behaviors provide evidence that young children are capable of responding to text in complex ways when supported by their teacher. This is important because Lucy's repertoire of responses is expanding, which might enable her to more fully interact with text and support her comprehension. As Lucy practices utilizing various strategies to make sense of text with 
Becky's help, she might begin to display these reading behaviors independently, becoming a more strategic reader.

Modeling reading strategies. In addition to scaffolding multiple reading strategies, Becky also modeled reading behaviors that she did not expect children to demonstrate. She read the title, A Listen to World Music, as well as subheadings, and introduced content-specific vocabulary. First, she read subheadings. As Becky read about different area of the world, she read the corresponding subheading. She read with excitement, "Sounds of Africa: There are many regions in Africa. Each region has its own culture. Each culture has its own type of music." Becky enthusiastically read the subheading, which signaled a shift to a new place. She used voice tone to demonstrate a shift as she read about the music of Latin America, Scotland and Ireland, and Asia and the Pacific. In each instance, Becky aimed to communicate that they were reading about a different area of the world. This could support children's comprehension as they realized they were moving to new subtopics.

Second, Becky introduced children to discipline-specific vocabulary words. She pointed as she read a bolded term and its definition, "Ethnomusicology” is the study of world music. Let's learn about world music.” Throughout, she read other bolded vocabulary words (e.g., sing, dance, music, culture, instruments, festivals, Aborigines) Becky showed children how to notice this feature, which is an important nonfiction reading skill because bolded vocabulary words are common to this type of text. Becky also read several names of unfamiliar instruments. For example, she read, "Some instruments found in Ethiopia are the krar, the begenna, the masenko, and drums." Children could then consider how instruments are unique to different cultures. She also 
read about Caribbean music, "Types of music that come from the islands include, calypso, kompa, merengue, salsa, reggae, and steel band." Unlike "ethnomusicology", these terms were not bolded. This shows children that they will need to listen for unfamiliar terms that might not be bolded. As children were exposed to content-specific vocabulary, these words might become part of their receptive vocabularies and eventually their expressive vocabularies. Children's knowledge of discipline-specific terms might increase their knowledge of the topic and aid their content area comprehension. These terms are uncommon in everyday conversations, which points to the potential for reading nonfiction as a way to introduce children to rare words.

Becky introduced children to common nonfiction text features that they will need to be able to read in the future. She modeled reading behaviors that she did not expect children to display; these reading strategies were still beyond children's ZPD. Becky's use of this technique suggests that children might need multiple exposures to reading strategies before they are ready to use them, even with teacher support.

Summary. Becky scaffolded children's comprehension in their ZPD and modeled reading strategies that were beyond their ZPD. Two reading strategies, interpreting pictures and using multimodal response, were in three-and-a-half-year-old Michael's and five-year-old Lucy's ZPD since both children exhibited these behaviors with support from their teacher. Becky provided additional scaffolding for Michael to attend to specifics in pictures and scaffolded multiple reading strategies for Lucy. She modeled other reading behaviors that were outside both children's ZPD. Becky's utilization of multiple reading strategies highlights the complexity of reading; strategic readers need to be able to quickly employ a range of strategies. Second, Becky's scaffolding techniques suggest that young 
children who are learning different reading behaviors can read together, as long as their teacher differentiates to meet individual children's learning needs. Third, Becky’s modeling of reading strategies that were beyond children's ZPD lends support for introducing children to these behaviors long before children are expected to exhibit them.

\section{Reading II: A Listen to World Music}

The second reading of A Listen to World Music (Reed, 2014) takes place during the same choice time immediately following the first read aloud and response activity. Two-and-a-half-year-old Thanom and four-year-old Amelia join Becky at the science table to read the book and count drumbeats. Like the first reading, it only involved two children, making it one of the smallest groups in the study. Becky begins by introducing the instrument, "Okay, friends, so today I have my /st/, my sticks. And what else do I have, Thanom?" She beats on the drum to gain his attention. Thanom answers, "Drum" as he places his hands on the drum. Thanom speaks Thai at home and, at two-and-a half, is one of the youngest children in the class. He is learning to label objects in the classroom and in books. Becky scaffolds his English language development by sounding out the beginning blend, /st/, and prompting him to label the objects in front of him.

Becky then reads the book title and tells the children, "It has music and instruments from around the world. It has pictures." She prepares children for the reading by orienting them to the topic and cuing them to expect pictures of musicians and instruments. While Amelia has begun to recognize letters and words, Thanom attends almost exclusively to pictures. Repeated from the first group, Becky reads the first subheading, written text, the term "Ethnomusicology", and the definition (p. 4). Then, she shifts her focus to the photographs as she points to people in costumes and their drums. 
She tells, "These people are playing music. It looks like they have special outfits on, don't they? And they have their drumsticks and their drums." She explicitly draws the children's attention to the drums because the instruments are similar to their drum and she wants children to make connections between the reading and activity.

Another picture features a stringed instrument and she asks them to think of a familiar instrument it resembles (contextualizing, Zurek et al., 2014), “They have something that looks kind of like a...what?" The children inspect the picture and Amelia replies, "A guitar." During this unit of study on music and sounds, Amelia has frequently mentioned that her dad plays guitar, so Becky knows Amelia will be able to recognize the similarities between the instruments. Since Amelia has a guitar at home, Becky gives her the opportunity to reason and make comparisons. Like other readings, the older child has participated first while the younger child observes.

Becky reads the next subheading, "Sounds of Africa" (p. 6), and points to Africa on the world map at the bottom of the page. She asks Thanom if he can see to make sure he looks at the map. Amelia then points to Africa (in orange on a gray world map) and Becky responds, "Oh, that's very nice, Amelia, you're helping." Thanom follows her cue and looks at Africa. Amelia has taken an active role in showing her younger classmate the visual feature. Becky points to photographs as she reads about traditional African instruments. She then poses a question about a shepherd blowing a horn, "What animal do you think it's from?" She wants them to infer from the pictures that it is a horn from one of the cattle the shepherd tends, but Amelia replies, "An elephant." Amelia is drawing from her background knowledge because she knows elephants have tusks; she might also know that elephants are from Africa. Rather than correct her, Becky replies, "You think 
it's from an elephant? You think it's a tusk?" She dignifies Amelia's response and supplies the scientific term. Becky does not correct her because the fact is not essential.

As she reads about traditional Ethiopian music (p. 8), Becky points out the error in the number of notes that she discovered during the previous reading. She explains, "We discovered in our story that there is a flaw or mistake in our book." She points to the words, "Look, so it says that this traditional music usually has five notes: do, re, mi, fa, so, la" (p. 8). She continues, "So if I say (singing up the scale) do, re, mi, fa, so, la. Oh, goodness. How many notes is that?" Becky holds up six fingers.

Amelia counts Becky's fingers, "One, two, three...one, two, three, four, five, six." Becky asks, "Is that five?"

Amelia counts her fingers and realizes the difference, "No." They engage in a short exchange about the discrepancy in the book. Becky asks, "That's what the book says. Is the book wrong? Right or wrong?"

Amelia replies, "Right."

Becky probes, "Is the book right if that said it was five? Is the book right if they say there's five notes and it told me six?"

Amelia understands, "No."

Becky reiterates, "Nooo! That's silly." Becky must have thought this was an important point to make, so she guides Amelia to detect the mistake in the book. She is scaffolding an important reading skill: to notice when the text does not make sense.

Becky then reads the next subheading, "Latin America", and points to the area (in orange) on the world map. Similar, to the previous reading, she models how to integrate written and visual information. She then circles the area and addresses Thanom, "Look at 
all this, the orange part. Do you see that, Thanom? The orange part?" Thanom fixates on that area of the world map. Four-year-old Amelia then points to the same area and Becky asks, “Are you pointing to it for Thanom?” Amelia nods. Becky takes explicit action to help two-an-a-half-year-old Thanom notice important visual information and Amelia imitates her teacher's actions as she becomes a peer tutor for one of the youngest children in the class.

Becky then points out the picture of the men in the sombreros playing guitars ( $\mathrm{p}$. 10). Amelia connects, "Uh-huh, my dad plays guitar." Amelia personalizes the reading independently. She also serves as a model for her younger classmate who does not yet use this strategy. Becky responds, "Does your dad wear a sombrero when he plays his guitar?" She scaffolds Amelia's ability to contrast her dad and his guitar from the men in the photograph. Amelia then describes how her dad uses a guitar strap and Becky adds an idea, "Because he doesn't want to have to hold the guitar." They are "working on understanding” (Barnes, 1975/1992) together while Thanom listens.

As Becky reads on, Amelia asks her to go back. Becky turns back to the page of the men playing guitars with sombreros (the mariachi band). Amelia points, "There used to be something like that in the Elena [of Avalor ${ }^{\circledR}$, an animated television show] (Gerber, Bour, \& Chew, 2016) that did that." Becky is confused, "There used to what?" Amelia elaborates, "Sometimes I watch Elena and on one show, on Elena that they did that." She points to the men in sombreros playing guitars. Becky replies, "Oh! Is that what it looked like when you watched?" Amelia nods. Amelia is independently making intertextual ties. Thanom does not speak but observes how Amelia goes beyond the book to tie the reading to the show. 
As Becky reads a passage about the different types of Caribbean music (pp. 1213), she and Amelia sway back and forth and Amelia dances in her seat. She giggles as Becky asks her if she likes to dance. Thanom does not move as he observes his teacher and slightly older peer pretend they are swaying to Caribbean music. As a two-and-half year old, his capacities to engage in pretense are emerging. He watches as his teacher older classmate model how to respond imaginatively and playfully to ideas and pictures in the book.

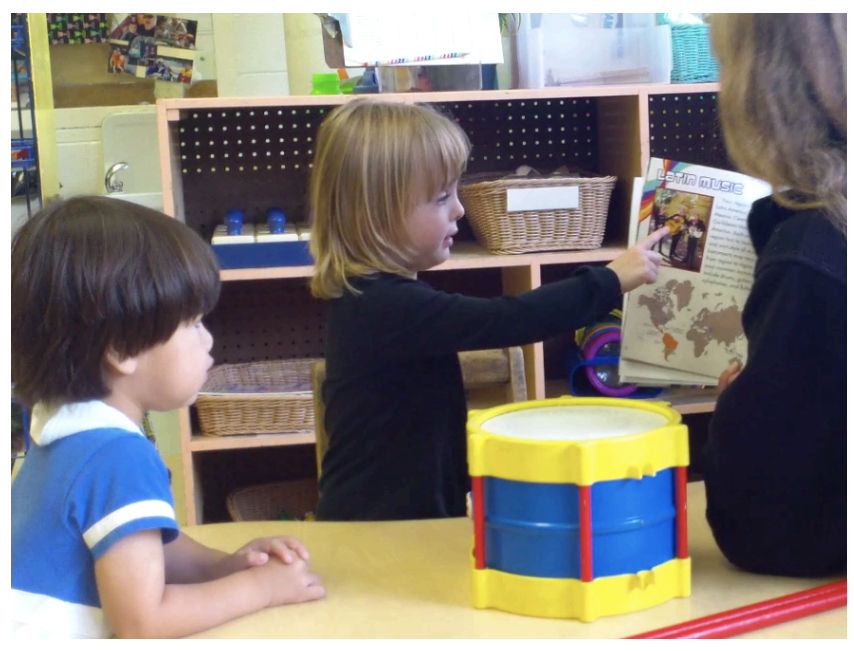

Figure 8. Amelia points to the mariachi band while Thanom observes.

Becky does not lose momentum as she reads the next subheading, "Celtic Sounds", and points to Ireland on the world map (p. 14). She invites the children to look, and Amelia leans in close to inspect the tiny island. As Becky reads about music from this region, she says Thanom's name, instructs him to look at the photographs, and labels the instruments in the pictures. She asks, "Remember when Kailee talked about bagpipes and harps?" (p. 16). She focuses his attention to pictures and models how to personalize the reading by connecting objects in the picture to an earlier classroom discussion (contextualization, Zurek et al., 2014). 
When Becky reads the next subheading, "Music of Asia and the Pacific", she points to Asia and the Pacific Ocean on the world map (p. 18). As she reads about the sitar, she once again prompts children to study the photograph, "Indian classical music is most often played on a sitar, which is this thing" (p. 18) Becky points to the picture. She then makes a comparison to the guitar, "It is a plucked instrument like a what? What else is a plucked instrument? Like a...guitar, only much more difficult to play" (p. 18). She is modeling how to compare two similar instruments and learn more about an unfamiliar instrument by highlighting its similarity to an instrument they have already viewed and discussed on previous pages.

Becky skips the final subheading and immediately points to pictures of Aboriginal Australian dancers and Australia on the world map (p. 20). Like the previous reading, she mentions that the didgeridoo was played at the world cup soccer games. Then, she and the two children make the low drone sound of the instrument. Like earlier, she shares a connection to the larger world and prompts children to imitate the didgeridoo with her. Amelia pretends to blow on an imaginary instrument while Thanom observes. Becky is modeling this type of connection and scaffolding Amelia's multimodal responses. Becky compliments their listening and switches to the activity. She seems eager to finish the reading before Thanom's attention wanders. She has skipped nearly all the written text, especially over the last few pages so she can finish the book and start the activity.

Analysis. Becky read with two-and-a-half-year-old Thanom and four-year-old Amelia immediately following the episode with three-and-a-half-year-old Michael and five-year-old Lucy. In both reading events, Becky scaffolded all children's attention to specifics in the pictures. She directed children's attention to visual elements as she labeled 
objects in photographs, described people's actions, and located places on the world maps. Similar to her interactions with Lucy, Becky solicited Amelia's help in noticing the factual error about the Ethiopian scale. One unique aspect of the second episode was the way in which Becky encouraged Amelia as she took up a peer-tutoring role to support Thanom as he viewed places on the map. Like the previous episode, Becky differentiated for Thanom and Amelia to teach reading strategies in each child's ZPD. In addition, she modeled the same two behaviors: reading subheadings and content-specific vocabulary. Similarly, Becky did not expect Thanom and Amelia to display these behaviors because they were beyond children's ZPD.

Scaffolding for both children. Becky scaffolded two-and-a-half-year-old Thanom's and four-year-old Amelia's abilities to focus and notice details in pictures. Throughout the reading, Becky prompted children to pay attention to the photographs as she noticed and named instruments (Johnston, 2003). She began by reading the title and showing children the front cover, "So, this is called A Listen to World Music. It has music and instruments from around the world. It has pictures." Becky made the book topic more explicit, which might have prepared children to become engaged as they looked for people playing instruments. In several instances, she named the instruments in the pictures. For example, she pointed to a photograph of a man playing the pan flute, "Peru is a country in South America where they play this music. It's called the pan flute.” The children peered at the photograph. Later, Becky labeled the bagpipes and harp. Becky showed children how to integrate visual and verbal information as they learned about instruments that were likely unfamiliar to them. Her actions could aid children's comprehension of new information and content-specific vocabulary. Becky also demonstrated another reading 
strategy, determining importance of information, as she drew children's attention to the most salient information (i.e., photographs, the names of instruments). She also brought attention to the way nonfiction texts function as she read labels and captions. Readers can expect to encounter these common features, which provide crucial information that might not be found in the larger written portions of text.

Second, Becky described people's actions in the photographs. At the beginning, she pointed to a group of musicians, "These people are playing music.” Thanom and Amelia viewed the picture. Becky paired her verbal input with visual information as she noticed and named people's actions, which provided children with additional information to make sense of the photographs (Johnston, 2003). At the end of the book, Becky discussed how Aboriginal Australians played the didgeridoo, "And then finally we have Australian instruments that are played by Aborigines who are native Australian people who live in tribes. In the outback over here in the, in the land, in the bush." Becky introduced children to a word that is specific to Australia, then put it in more familiar language, and repeated another form of the word to help children understand the term in context. She pointed to various places in the pictures of an Aboriginal man playing the didgeridoo and several men dancing around a fire in their native clothes and body paints. Both photographs were taken outside. Becky's use of this technique might help children integrate information from different visual sources with her verbal input to acquire some knowledge of Aboriginal culture. Becky demonstrated how to notice details in visual images and describe people's actions, which could help children visualize what was happening in the scene. Visualization might help them gain a more comprehensive understanding as they form their own mental representations of events. 
Similar to the previous reading episode, Becky gave children experience with locating places (in orange) on the world maps (in gray) at the bottom of several pages. In one instance, she pointed to Asia and the Pacific Ocean on the world map, "So here's Asia. Ah! And here's the Pacific Ocean out here.” Both children studied the map as Becky pointed out the large land mass and body of water, which are important geographic features. When Becky pointed out Australia, Amelia asserted, "That's farther than, that's farther than, that's farther than where we live." As Becky showed children how to interpret the various world maps, they might gain an understanding of how this visual feature functions. Amelia engaged in abstract thinking as she realized that the map was a two-dimensional representation of the larger three-dimensional world. Moreover, she was beginning to grasp a sense of scale as she understood Australia was far from her current location.

Becky encouraged peer tutoring. Becky encouraged Amelia, who volunteered to assist in supporting Thanom's comprehension by pointing to two locations on the world map. First, Becky pointed to Africa and read, "There are many regions of Africa. Here's Africa right here. Thanom, can you see? There are many regions of Africa. Each region has its own culture." Amelia then imitated Becky by pointing to the continent while Thanom observed. Becky commented, "Oh, that's very nice, Amelia. You're helping." Amelia became more engaged with the text and demonstrated her comprehension as she pointed to Africa. Later, Becky read about the music of Latin America and circled the area on the map with her finger, "Four regions make up Latin America. They include Mexico, Central America, the Caribbean Islands, and South America. Look at all this, the orange part. Do you see that, Thanom? The orange part?" Again, Amelia pointed to the area on 
the world map. Becky acknowledged, “Are you pointing to it for Thanom?” Amelia gave Thanom two opportunities to learn from a slightly older classmate. Her nonverbal communication was effective, yet unobtrusive, as she oriented him to specific areas of the map without disrupting the reading. Amelia's actions suggest that the child who displays a greater range of reading behaviors could take up a peer-tutoring role to support the other child's strategy use. Becky recognized the potential for a peer to scaffold Thanom's use of this reading strategy and she gave Amelia positive feedback, which seemed to reinforce her behavior. This scenario helps build the case for mixed ability reading instruction in preschool as children who demonstrate fewer reading strategies might attend to the actions of their peers who model the desired reading behaviors.

Scaffolding for individual children. Becky scaffolded individual children's uses of reading strategies because Thanom exhibited few reading behaviors, whereas Amelia used multiple strategies.

Thanom. Becky repeatedly gave Thanom directions to look at specifics in the pictures. In addition to previous examples, Becky sought his attention as she pointed to Celtic musicians, "Look at what they're playing, Thanom. They're playing a banjo it looks like. I know it's called something else but it looks like a banjo.” Becky noticed and named the instrument (Johnston, 2003). She first cued Thanom to view the photograph then compared it to an instrument that could be more familiar so that Thanom might connect this new information to his existing knowledge. Becky then pointed back and forth between the photograph of the bagpipes and a harp, "It shows there are bagpipes. Oh, and here's a harp. Remember when Kailee talked about bagpipes and harps?" In this example, Becky used multiple techniques in her efforts to aid Thanom's comprehension and 
increase his vocabulary: She pointed and labeled the objects twice then attempted to trigger his memory of an earlier learning event. Two-and-a-half-year-old Thanom consistently demonstrated that he could attend to pictures with teacher prompting, which suggests that this scaffolding strategy might be effective with very young children.

Amelia. With Becky's support, Amelia displayed a wider range of reading behaviors. She accessed her background knowledge, made connections, and responded in multiple modes. First, Becky supported Amelia as she related her background knowledge to content in the book. At the beginning, Becky posed a question about a photograph of a stringed instrument, "They have something that looks kind of like a...what?" Becky used the cloze technique to prompt Amelia to access her background knowledge (Taylor, 1953).

Amelia studied the picture, "Um, a guitar."

Becky confirmed, "Like a guitar." Becky knew that Amelia's dad played the guitar so she solicited this connection. Becky prompted Amelia to make this connection so that she might recognize how to make sense of new information by comparing it to something familiar.

Becky also elicited Amelia's personal connections to the book's content. Becky commented about a mariachi band, "There are these men in sombreros with their guitars." Amelia added, "Uh-huh. My dad plays guitar."

Becky probed for more information, "Does your dad wear the guitar when he plays? Does your dad wear a sombrero when he plays his guitar?"

Amelia then moved her hands in a circle around her neck and described how her dad wore a guitar strap. The men in the photograph reminded Amelia of her dad playing his guitar. 
This personal connection might have helped her to better understand what was happening in the photograph by connecting to her personal experience.

Becky's description of the photograph of the men playing their guitars sparked an intertextual connection for Amelia. After Becky had turned the page and continued reading, Amelia requested, "Can you go back a little bit?"

Becky wondered, "Can I go back? Like here?" She turned back to the page with the mariachi band.

Amelia pointed to the men, "Yeah. There used to be something like that in the Elena” [of Avalor ${ }^{\circledR}$, an animated television show about a Latina teen princess] (Gerber, Bour, \& Chew, 2016). As Amelia moved beyond a personal tie to make an intertextual connection to the photograph, she related to the picture in multiple ways. She possessed firsthand knowledge about playing the guitar from observing her dad and had been exposed to mariachi bands from the show. Amelia might have integrated her knowledge from these two sources to better understand how the men in the photograph looked and sounded as they sang and played their guitars.

Becky also encouraged multimodal responses from Amelia. Becky swayed in her seat as she read about Caribbean music, "Types of music that come from the islands include calypso, kompa, merengue, salsa, reggae, and steel band.” Amelia imitated Becky by dancing in her seat. Becky acknowledged, "Are you dancing like?" She continued, "The music often echoes the carefree lifestyle of the Caribbean. Music for this area often features drums and singing and they dance!” Amelia danced in her seat again. Becky then asked, "Do you like to dance?" Amelia giggled as she continued to move back and forth. Becky's positive reaction might have encouraged Amelia to display this response. Toward 
of the end of the book, Becky commented on the dancers from Ireland and Scotland, "And they're doing Celtic dancing. They're dancing." Again, Amelia danced in her seat. Becky's descriptions might have supported Amelia's abilities to visualize the people's movements and imagine being there in real life.

At the end of the book, Becky discussed how people at the World Cup soccer games played the didgeridoo and she sounded the deep hum of the instrument. Amelia put her hand to her mouth and imitated the deep drone, which might have helped her imagine what the instruments at the games sounded like. Becky provided additional sensory information as she danced (visual) and droned like the didgeridoo (sound). She encouraged Amelia's multimodal responses (kinesthetic, sound), which provided Amelia with additional means of self-expression and communication as she engaged with the text. These exchanges highlight the importance of facilitating children's multisensory and multimodal responses during reading as they might demonstrate their understandings of the content through a range of nonverbal behaviors.

Summary. Becky scaffolded the same reading strategy for two-and-a-half-yearold Thanom and four-year-old Amelia as she did for three-and-a-half-year-old Michael and five-year-old Lucy: viewing visual images. Becky's use of this strategy provides evidence that it is important for engaging young children with the text and facilitating their reading comprehension. Moreover, children gained experience with focusing on the specifics of common visual features found in nonfiction texts: photographs, labels, captions, and maps. Amelia's actions to direct Thanom's attention to locations on the world map suggest that it might be advantageous for preschoolers who exhibit different emergent reading behaviors to participate in read alouds together since some children 
might support others' strategy use. Becky scaffolded various reading strategies in Thanom and Amelia's ZPD. The differences in the two children's emerging reading behaviors highlight the essential role of differentiation during read aloud in preschool. Similar to the first reading event, Becky modeled other behaviors she did not expect children to demonstrate: reading subheadings and content-specific vocabulary. Her actions exposed children to these common nonfiction text features that they will need to read in the future. Becky's scaffolding and modeling of reading strategies might have helped them learn more about reading nonfiction (e.g., how it is structured, how different features function) and aid their comprehension of this complex type of text.

\section{Integration of Episodic Analyses With Interview Data}

Introduction. A close inspection of the two reading episodes revealed patterns in Becky's scaffolding techniques. First, Becky scaffolded two reading strategies during both events: she prompted children to interpret visual images and to display multimodal

responses. Second, Becky modeled two reading behaviors: reading subheadings and technical vocabulary. Third, Becky scaffolded limited reading strategies for the two younger children (two-and-a-half-year-old Thanom and three-and-a-half-year-old Michael) and a wider range of strategies with the two older children (four-year-old Amelia and five-year-old Lucy) in each child's ZPD.

\section{Becky's scaffolding of strategies across both reading episodes. Becky}

scaffolded two reading strategies across both events for all children. First, she prompted children to focus on visual elements as she labeled instruments, described people's actions in the photographs, and located places on the world map. In both episodes, Becky labeled drums and sticks, the bagpipes, harp, sitar, and didgeridoo. She called children's attention 
to the shepherd boys playing their horns, men playing the guitar in the mariachi band, and the couple dancing to the Caribbean music in both reading events. Becky also pointed out places around the world on the map: Africa, Latin American, Ireland, as well as Asia and the Pacific. Her verbal input (e.g., labels, descriptions, instructions) as well as nonverbal signals (i.e., pointing to objects and places) might have enhanced children's interpretations of these various forms of visual information. Children could potentially integrate information from these multiple sources for increased comprehension.

Both teachers indicated that the pictures seemed to captivate children's attention when reading nonfiction texts. Kailee shared, "With the nonfiction you have to, as the adult, show them and get them interested or they - they won't stay involved" (Kailee, Interview 2). She knew that pictures held children's attention. Similarly, Becky discussed, They seem very interested in the complex topics, even though you don't know if children are going to, how they're going to respond. Sometimes if it's something really new and really different and very factual, if they're going to sit and listen to it or if they're going to walk away. But they seem to be very interested in it, and want to see the pictures about what I was talking about (Interview 3).

For these teachers, children's attention to visual elements was so important that it was the difference between children staying engaged with the text versus losing interest and leaving the reading event.

Children's abilities to focus on visual elements were so essential that Becky frequently elicited this reading behavior from all children. Moreover, she scaffolded this strategy throughout both reading events and did not utilize fading nor gradual release of responsibility for children to display this behavior independently (although Lucy and 
Amelia did spontaneously interpret some pictures). Becky's actions support the notion that viewing and interpreting visual elements are developmentally appropriate expectations for young children and that preschool teachers could utilize this strategy more than any other for supporting children's engagement and comprehension of nonfiction texts.

Second, Becky encouraged children to display multimodal responses. In both reading events, she invited them to imitate her by dancing to the Caribbean music and hum the low drone of the didgeridoo. Children potentially had a wider range of response modes available to them, so they were not solely dependent on language to communicate. Kailee also encouraged multiple modes of expression,

I usually let kids pick how much they want to move because not everybody is the same in needs of movement [...] If they choose to wiggle, stand up and jump, I don't care. It doesn't matter. And I definitely encourage talking. I encourage them to be themselves. So, I think that's important (Interview 1).

Kailee recognized that different children reacted to ideas in the text in various ways and respected their autonomy in choosing their modes of response. Children might then have the chance to broaden the ways they could communicate their understandings and ideas.

The teachers' uses of these two strategies highlight the value of providing children opportunities to communicate nonverbally. Young children's first reading responses could be largely nonverbal since their limited vocabularies might prohibit them from expressing themselves primarily through language. This might have been especially important for two-and-a-half-year-old Thanom, who was a native Thai speaker. The teachers' abilities to notice and interpret children's nonverbal behaviors were important so that they could tune 
in to children's varied modes of response and better assess how they were making sense of text.

Becky's modeling of strategies across both reading episodes. Becky read subheadings and discipline-specific vocabulary in both reading events but did not solicit responses from children. First, she read several of the same subheadings in both episodes: "Music of the World," "Sounds of Africa," "Latin Music," and "Music of Asia and the Pacific." Subheadings are important nonfiction features that signal a shift in subtopic and help readers recognize how the text is organized. Becky explained that she believed it was necessary to read nonfiction books with children because they needed exposure to this type of text to read successfully in the future,

Since nonfiction is more difficult to read down the road [...] having had that experience $[\ldots]$ will make them more comfortable continuing later in life to read those texts and to learn and to know that those are books you can read and enjoy reading (Interview 1).

As children were exposed to subheadings, they might come to understand how this organizational feature functions, which could support their abilities to read this complicated type of text.

Second, Becky read several of the same discipline-specific vocabulary words across both episodes (i.e., names of instruments, dances, types of music, places on the world map). Some of these terms were bolded. Becky did not show children how bolded words functioned in the glossary, which might have been beyond children's ZPD. Children are unlikely to encounter discipline-specific vocabulary words in everyday conversations but these terms are important for gaining content area knowledge. 
Both teachers indicated that they encountered more discipline-specific terms when reading nonfiction than fiction. Kailee acknowledged, "And in the nonfiction, there's a lot of technical terms" (Interview 3). Becky stated, "I'd say there's vocabulary several times probably on a page sometimes" (Interview 1). Becky realized the potential to teach new vocabulary when reading nonfiction books in small groups, "You can give one-on-one, like as you read through the book with a smaller group, you're better able to pinpoint words as you go through, have a better discussion with the kids" (Interview 1). Since she introduced children to discipline-specific words while pointing to photographs and places

on the map, children might then associate these new terms with visual images. As children are exposed to these words in context, they could incorporate them into their receptive and expressive vocabularies, enabling them to comprehend and share their knowledge about world music.

\section{Becky scaffolded a limited repertoire of strategies for the younger children.}

First, Becky prompted two-and-a-half-year-old Thanom and three-and-a-half-year-old Michael to focus on visual images as she repeatedly called their names and directed them to look at the pictures. She then drew their attention to specific aspects of the pictures as she noticed and named particular instruments, people's actions, and places on the world maps (Johnston, 2003). Becky discerned that the pictures seemed to hold the youngest children's attention and they relied heavily on visual information to make sense of the text. She scaffolded this reading behavior in their ZPD as they were able to demonstrate that they could focus on visual images with support. Becky did not fade her scaffolding nor use gradual release of responsibility with either child because their attention to visual images was critical for their engagement with the text. 
Kailee also recognized that the younger children attended nearly exclusively to pictures. She commented,

I watch to see what the children are doing as we read. If they're looking at the picture then I'm pretty sure they - they're not, they may not know where the words are $[\ldots]$ Our children who are just looking at pictures, I see if they can identify the picture. If they can tell me what they think is happening on that page $[\ldots]$ We try really hard to make certain that we've picked books that have lots of pictures for our beginners and some words that are easy to read for our ones that are at the other end of the spectrum (Interview 1).

Kailee knew that read aloud was a prime opportunity for assessing children's reading development and observed that children first attended to pictures and later to letters and words in their reading development. She used this knowledge to support the youngest children's comprehension,

And it's easier to understand where each child is. You can ask an individual child to 'point to the tow truck' to see if they understood what you were talking about. You can ask the children who are beginning to be a little more literate to point to the words or tell you where the story begins (Interview 1).

To Kailee, this type of differentiation was essential because she could observe that some children were not ready to attend to print. Instead, they needed more experiences examining pictures to make sense of the content. Some of the older children recognized print, so she encouraged them to name letters and words. The youngest children also did not give verbal responses, so it was especially important for her to attend to their nonverbal reading behaviors. Kailee and Becky's practice of noticing and naming 
provided children with abundant opportunities to integrate verbal and visual information that likely helped them focus on the text and aided their comprehension (Johnston, 2003). They strove to meet their two-and-a-half to five-year-olds learning needs in their ZPD.

Second, Becky attempted to elicit three-year-old Michael's multimodal responses as she prompted him to imitate her gestures and sounds. Michael's use of this strategy was inconsistent as he briefly blew over his fingers like the man playing the pan flute but did not mimic other gestures. Becky did not insist that he imitate her nonverbal responses because she might have detected that his abilities to display this behavior were just emerging.

Kailee and Becky were attuned to their youngest children's reading development and they scaffolded strategies (i.e., interpreting visual images, and, for Michael, displaying some multimodal responses) in their ZPD rather than push them toward more advanced reading behaviors that were beyond their ZPD. The youngest children could then participate in the read aloud events in developmentally appropriate ways. Two-and-a-halfyear-old Thanom and three-and-a-half-year-old Michael did not speak during these reading episodes, which highlights the role that nonverbal responses play.

\section{Becky scaffolded a wider range of strategies for the older children. Becky} supported three of the same reading strategies for four-year-old Amelia and five-year-old Lucy: accessing background knowledge, personalizing the content, and identifying a factual error. First, in both reading episodes, Becky prompted children to remember familiar instruments (e.g., drums, guitar). As Amelia and Lucy focused on the visual information and considered their background knowledge, they might have made sense of new content by drawing comparisons between new and familiar instruments. Becky's use 
of this technique highlights the importance of guiding children's attention toward visual information to trigger their recollections.

Becky described how she strove to help children access their prior knowledge by asking what they already knew about the topic,

You read the word, you know, 'penguin' and it's like an Emperor Penguin. You can describe, 'Oh, have you guys ever heard of an Emperor Penguin?' You know, 'Where would you see it? What type of penguin is it?' And just get more in-depth with them (Interview 1).

She directed children to focus on content she deemed important and prompted them to reflect on their prior knowledge to aid their comprehension. As children shared, their knowledge became available to the group, which is a potential benefit to other children who might be exposed to new ideas from their peers.

Second, as Becky noticed and named details from a photograph and map (e.g., men playing guitars, map of North America), both Lucy and Amelia inspected the visual images and then related that information to their past experiences (Johnston, 2003). They personalized the content in different ways. Amelia visualized her dad playing his guitar as she viewed the musicians, whereas Lucy sought information about a familiar location while examining the map. In both reading events, Becky diverged from the reading to extend the dialogue; she asked Amelia for details about her dad and his guitar and analyzed the map to answer Lucy's question. Becky's technique of noticing and naming details in visual images furthered children's thinking in diverse ways and her interest in their personal connections showed that their past experiences were important to her. 
Becky's encouraging responses to these connections might have reinforced this strategic reading behavior.

Both teachers strove to show children how to relate ideas in the text to their own lives. Kailee revealed, "Kind of extend it to, you know, relate it to their lives or relate it to something they're doing in the classroom" (Interview 1). She wanted children to realize that the content in books could be relevant to their lived experiences and the subject matter they learned in the classroom. Becky shared, "I try to relate it to them because of course they'll be more likely to stay and listen to my story longer (laughs)" (Interview 1). She understood that children were more engaged with the text when it was personally relevant, so she encouraged children's connections.

Third, Becky scaffolded Amelia and Lucy's abilities to notice a factual error about the Ethiopian scale. She guided them through the process of evaluating information to consider whether or not it made sense. Amelia and Lucy could not rely on their background knowledge, experiences, nor visual cues to check the accuracy of this information. Instead, Becky scaffolded each step of this process because it was unlikely they would have noticed that the information in the text was incongruent. Becky made the misinformation explicit: She repeated the passage, counted on her fingers, and asked children to count with her. Becky did not continue reading until Lucy and Amelia could both tell her how the information was wrong. She did not fade her supports or expect children to check the accuracy of information independently. Lucy and Amelia gained experience with this vital nonfiction reading behavior that requires readers to employ metacognition to realize when the text does not make sense (i.e., when they are confused) and to utilize fix up strategies by rereading and finding the error. 
Summary. Becky employed multiple techniques to scaffold children's comprehension of this nonfiction text. She realized that children's attention to pictures and their nonverbal responses were essential to their engagement with the text. Becky differentiated her scaffolding techniques as she strove to support each child's reading strategy development in their ZPD. Her scaffolding of various reading behaviors illustrates that during the preschool years, children can develop a repertoire of reading strategies with support. Becky's multifaceted approach also shows that comprehension is complex, as it requires readers to integrate verbal and visual information with their background knowledge and experiences. Young children can be capable of using multiple reading strategies quickly and flexibly (as needed) to make sense of information in texts and to express themselves verbally and through other modes when they have developmentally appropriate support. Becky gave more time and attention to the reading strategies she expected children to display as opposed to the reading behaviors she modeled but did not expect children to use. Her actions point out the need to provide children with abundant exposure to reading strategies before they can demonstrate them, as well as scaffold children's emerging reading behaviors.

\section{Summary of Chapter Four}

Analysis of reading episodes with two fictional stories, Dewey: There's a Cat in the Library! by Vicki Myron, Bret Witter, and Steve James (Illustrator) (2009) and Lucy's Picture, by Nikola Moon and Alex Ayliffe (Illustrator) (1994), as well as two nonfiction texts, Patterns at the Museum, by Tracey Steffora (2011) and One Tiny Turtle, by Nicola Davies and Jane Chapman (Illustrator) (2001), established patterns in teachers' and children's reading strategies, as well as their transactions with texts. Specifically, Kailee 
and Becky utilized two reading strategies when reading fiction and nonfiction: They prompted children to interpret pictures to make sense of story events and new information. They also invited children to access their background knowledge about book topics so they could better integrate new information and their existing knowledge.

While there were similarities in Kailee and Becky's reading strategies across both types of text, there were also differences. Teachers employed one strategy that was exclusive to fictional stories and two that were unique to nonfiction texts. When reading fiction, Kailee elicited children's predictions by asking questions about pictures and story events then reading to find out. When reading nonfiction texts, teachers elaborated upon children's ideas and employed gradual release of responsibility. Becky extended children's ideas by adding her own thoughts that referred to the next event in the narrative nonfiction, One Tiny Turtle (Davies \& Chapman, 2001). When reading Patterns at the Museum (Steffora, 2011), Kailee employed gradual release of responsibility for children to read patterns. She modeled the desired behaviors and prompted children to imitate, then allowed them to read patterns independently as they demonstrated their competencies.

Inspection of children's reading strategies across fiction and nonfiction texts revealed that children displayed two of the same reading strategies that their teachers promoted: They interpreted pictures and accessed their background knowledge to make sense of story events and information. Children also employed reading strategies that were unique to the two types of books. When reading fictional stories, they interpreted characters' thoughts, feelings, and motives as they sought to understand characters' inner worlds. Children also considered the ways that characters' actions affected others. When reading fictional stories, children had chances to gain insight into their social experiences. 
When reading nonfiction, children used academic language and discussed subject matter content that was not evident during their readings of fictional texts. Reading nonfiction also provided children opportunities to integrate reading with science and math.

Another pattern that emerged across both readings was that older children served as peer models for their younger classmates. The four- and five-year-old preschoolers were often the first to display reading strategies, share their background knowledge, respond to images and ideas in the text, answer teachers' questions, and describe their thinking strategies. Meanwhile, their younger peers observed quietly and then imitated their older classmates' responses.

Analysis of teachers' and children's stances toward fictional and nonfiction texts showed differences in their responses. Kailee and Becky took predetermined stances toward fiction and nonfiction books. They took a predominantly aesthetic stance toward fictional stories to promote children's vicarious experiences. Both teachers responded efferently to nonfiction since their purpose was to expose children to information. Conversely, children assumed flexible stances across the aesthetic-efferent continuum with both types of text. These findings suggest that children were engaged readers who established their own purposes for reading and shifted their stances in response to different aspects of the text (e.g., images, ideas, events).

Analysis of Becky's scaffolding strategies during two read aloud episodes with the same nonfiction text, A Listen to World Music, by Jennifer Reed (2014), showed patterns in her strategies as she supported children's comprehension. Becky scaffolded two reading strategies across both episodes: she directed children to interpret visual images as she labeled instruments, noticed and named people's actions in the photographs, and located 
places on the world maps. Becky also invited children's multimodal responses.

Subsequently, children focused on pictures and expressed themselves nonverbally as they imitated her gestures and movement. Becky also modeled reading strategies across both events that she did not expect children to imitate. She read discipline-specific vocabulary words that exposed children to terms they would likely not encounter in everyday conversations. She also read subheadings that signaled transitions to new subtopics. These reading strategies were likely beyond children's ZPD, so Becky exposed children to these features rather than teach them explicitly.

Analysis also revealed the ways Becky differentiated instruction to teach reading strategies in each child's ZPD. First, she scaffolded a limited range of strategies for the two younger children. She repeatedly stated their names and directed them to attend to visual images as she noticed and named objects, people's actions, and places. She attempted to elicit nonverbal responses from three-and-a-half-year-old Michael, but his use of this strategy was just emerging and inconsistent. Two-year-old Thanom did not display this response. Second, Becky scaffolded a wider array of reading strategies for the two older children, four-year-old Amelia and five-year-old Lucy: accessing their background knowledge, personalizing the content, and identifying a factual error. With support, the older children moved beyond the text to consider ways in which the content related to their prior knowledge and experiences and gained experience analyzing the information to recognize when it did not make sense.

In Chapter Five, I summarize the purpose of the study and methodological procedures. Next, I provide an analysis of the findings according to theories utilized in the 
study. I then offer implications for research and practice. Finally, I conclude with my reflections. 


\section{CHAPTER FIVE: PURPOSE, SUMMARY OF PROCEDURES, ANALYSIS OF FINDINGS, IMPLICATIONS, AND FINAL REFLECTIONS}

The following chapter provides an overview of the research project, including the purpose of the study, summary of procedures, and analysis of the findings. I conclude the chapter by discussing the implications of these findings for future research, practitioners, and teacher educators as well as my final reflections on the research enterprise.

\section{Purpose of the Study}

The purpose of this instrumental case study (Stake, 1995) was to investigate preschool teachers' read aloud practices with fiction and nonfiction literature with small groups of children, ages two-and-a-half to five years. The study examined teacher and children's responses during read aloud of fiction and nonfiction literature that immediately followed the morning whole group read aloud and afternoon meeting. These small group read aloud sessions took place during choice time. This inquiry was guided by the following research question: What are teachers' roles and children's responses during small group read aloud with fiction and nonfiction texts for children ages two-and-a-half to five years old in one preschool classroom? For a deeper exploration of this question, the following sub-questions were investigated:

1. How do children respond during read aloud?

2. How do teachers use modeling and scaffolding during small group read aloud to support children's meaning making?

These questions guided my investigation into preschool teachers' and children's talk, as well as teachers' modeling and scaffolding of reading strategies.

\section{Summary of Procedures}


This qualitative study drew from constructivism/interpretivism (Denzin \& Lincoln, 2011) and instrumental case study (Stake, 1995). Purposive sampling (Bogdan \& Biklen, 1998; Lavrakas, 2008) was utilized in one preschool classroom in a laboratory school at a midwestern institution. I collected data from two teachers and 19 preschoolers for six weeks (four to five times per week). I conducted interviews, observed small group reading events, and collected relevant artifacts. I recorded analytic memos and reflections in a double entry journal (Glaser, 1978; Strauss \& Corbin, 1998). I conducted constantcomparative analysis (Glaser \& Strauss, 1967; White \& Marsh, 2006), which entailed ongoing and iterative data collection and analysis. I analyzed transcripts of small group read aloud, teacher interviews, and children's interviews. Constant-comparative analysis ensured data reached saturation (Glaser \& Strauss, 1967).

\section{Analysis of Findings}

Findings suggest that children were responsive to Kailee and Becky's strategies and efforts at scaffolding in the ways in which they interacted with both fiction and nonfiction texts. For example, teachers stressed two main strategies (i.e., interpreting pictures, accessing prior knowledge), which the children utilized in their own reading practices. However, teachers drew on other processes to support children's engagements with fiction and nonfiction texts. For fiction, teachers elicited children's predictions of story events and read aesthetically. When reading nonfiction, they encouraged children's multimodal responses, elaborated upon children's input, employed gradual release of responsibility, and read efferently. 
Table 3

Teachers' and Children's Reading Strategies

\begin{tabular}{|c|c|c|c|}
\hline & $\begin{array}{l}\text { For Both Fiction and } \\
\text { Nonfiction }\end{array}$ & For Fiction Only & For Nonfiction Only \\
\hline $\begin{array}{l}\text { Teachers' } \\
\text { Strategies } \\
\text { for } \\
\text { Teaching } \\
\text { Texts }\end{array}$ & $\begin{array}{l}\text { Prompting Children } \\
\text { to Interpret Pictures } \\
\text { Prompting Children } \\
\text { to Access } \\
\text { Background } \\
\text { Knowledge }\end{array}$ & $\begin{array}{l}\text { Eliciting Predictions } \\
\text { Aesthetic Reading }\end{array}$ & $\begin{array}{l}\text { Encouraging } \\
\text { Children's } \\
\text { Multimodal } \\
\text { Responses } \\
\text { Elaborating on } \\
\text { Children's Input } \\
\text { Employing Gradual } \\
\text { Release of } \\
\text { Responsibility } \\
\text { Efferent Reading }\end{array}$ \\
\hline $\begin{array}{l}\text { Children's } \\
\text { Strategies } \\
\text { for } \\
\text { Engaging } \\
\text { With } \\
\text { Texts }\end{array}$ & $\begin{array}{l}\text { Interpreting Pictures } \\
\text { Drawing on } \\
\text { Background } \\
\text { Knowledge } \\
\text { Serving/Relying on } \\
\text { Peer Models } \\
\text { Responding Along } \\
\text { the Efferent- } \\
\text { Aesthetic } \\
\text { Continuum }\end{array}$ & $\begin{array}{l}\text { Considering } \\
\text { Character's } \\
\text { Actions and Inner } \\
\text { Worlds }\end{array}$ & $\begin{array}{l}\text { Utilizing Academic } \\
\text { Language }\end{array}$ \\
\hline
\end{tabular}

Children displayed a range of reading behaviors when reading fiction and nonfiction. In addition to interpreting pictures and accessing their background knowledge, some of their responses were unique to each type of text. When reading fiction, children considered character's actions and inner worlds (i.e., thoughts, feelings, motives). During nonfiction readings, they utilized academic language (i.e., vocabulary words, disciplinespecific content). Older children served as peer models while younger classmates relied on 
them for cues. Children also responded along the efferent-aesthetic continuum with both types of text. These teacher moves and student responses demonstrate the application of various theoretical approaches that define the reading process. Table 3 provides an overview of these findings. Below, I explore how these findings relate to the theories that shaped this study: sociocultural theory, transactional theory of reader response, and the emergent literacy perspective.

\section{Sociocultural Analysis of Findings}

One theory utilized in this study is sociocultural theory, which proposes that social interactions drive children's learning and development (Green \& Piel, 2010; Vygotsky, 1978). Children's language use is central to their development because it is the primary tool by which individuals communicate. Sociocultural theory also foregrounds the essential role of teacher-learner interactions in children's learning and development (Green \& Piel, 2010; Vygotsky, 1978). Ideally, these occur in the child's zone of proximal development (ZPD), the distance between the learner's independent functioning and performance with support from more capable others (e.g., peers, adults; Green \& Piel, 2010; Vygotsky, 1978). This assistance, scaffolding (Wood, Bruner, \& Ross, 1976), is contingent upon the learner's abilities, entails fading of support as the learner demonstrates competency, and gradual release of responsibility as the learner exhibits independent performance (Green \& Piel, 2010).

Sociocultural theory informs key findings from this study. First, Kailee and Becky elicited a range of reading strategies in children's ZPD across both types of text. They promoted a few general reading behaviors across fiction and nonfiction and prompted strategies unique to each. They seemed to realize that some reading strategies were more 
appropriate for certain types of text. For example, using prediction and then reading to find out fit with the narrative structure of fictional stories, whereas more intensive communication was needed with nonfiction literature (e.g., multiple modes of response, elaboration of ideas). Children were responsive to teachers' prompting as they took up the reading behaviors their teachers promoted. These exchanges highlight the key role of teacher-learner interactions for eliciting children's appropriate uses of reading strategies in their ZPD. It was unlikely that children would have demonstrated these behaviors if their teachers had not explicitly promoted them.

Second, Kailee and Becky adjusted their scaffolding in children's ZPD according to children's performance. The teachers seemed to understand that many of their children's reading behaviors were just emerging and provided intensive support so that children could employ particular strategies (e.g., noticing details in pictures, accessing prior knowledge, making predictions, imitating nonverbal actions, etc.). As children demonstrated their abilities to use these strategies independently, teachers faded their supports. For example, as children read patterns, Kailee offered less modeling and fewer cues. The teachers in this study recognized when children successfully employed reading strategies and allowed them to take responsibility for their own reading behaviors as they were able. The children in this study were capable of learning and demonstrating reading strategies with support and, in some cases, more independently as teachers faded their scaffolding. Importantly, teachers recognized that children displayed a range of early reading behaviors and differentiated according to children's ages and early reading development. The findings from this study help build the case for the value of teaching 
reading strategies in young learners' ZPD and providing flexible support that is contingent upon children's competencies.

In addition to relying on teachers to guide their strategy use, children participated in social learning events as they took cues from each other. Specifically, older children typically shared their thinking, demonstrated strategic reading behaviors, and sometimes explicitly provided cues for their younger classmates. As younger children deferred to their older peers, they had chances to observe reading behaviors that might have been in or just beyond their ZPD. Older children had opportunities to assume leadership roles as they made their thinking available to the group. These scenarios lend credibility to the notion that social learning opportunities do not always lie in adult-child interactions, but also in observations and exchanges between and among children as peers can serve as more knowledgeable, experienced, and capable others.

These findings reiterate the vital role of texts as cultural tools. The young readers in this study were exposed to language, academic content, and visual images that could potentially support their literacy development in our culture. Children might have acquired knowledge through exposure to the content in these texts and as they interacted with more experienced others (i.e., adults, peers). The young children in this study had opportunities to learn how to think while using texts as teachers (and peers) provided modeling and scaffolding of reading strategies.

\section{Transactional Reader Response Analysis of Findings}

Another theory that informed this study was Rosenblatt's transactional theory of reader response (1938/1983). According to this theory, meaning does not reside solely in the text or the mind of the reader $(1938 / 1983 ; 1978)$. Rather, readers make meaning as 
they transact with the text. Texts can be read aesthetically and efferently (1978), according to the reader's purposes. Aesthetic reading is a personal vicarious experience in which the reader becomes emotionally invested in text, whereas efferent reading involves taking away information $(1978 ; 1993)$. Aesthetic and efferent stances lay at polar ends of a continuum. Readers assume their stances on this continuum as they read for particular purposes. Readers should read sensitively and flexibly by shifting their stances in response to their transactions and the demands of the text (1978). Young children are capable of a range of reading responses as they communicate through talk, connect ideas in the text to their own lives, take up dramatic play, and engage in storytelling (Hungerford, 1993), as well as respond through artistic expression (Arizpe \& Styles, 2016).

This theoretical lens provides insights into teachers' and children's purposes for reading both fiction and nonfiction books. Kailee and Becky seemed to hold preconceived notions about the purposes for reading both types of text as well as the need to convey those purposes to children. They read nonfiction efferently with the aim of exposing children to facts and took a predominantly aesthetic stance to fiction as they read for the vicarious experience. Children, on the other hand, established their own reading agendas. Sometimes they took the same stances as their teachers, and at other times, responded across the efferent-aesthetic continuum with both types of text. As this study shows, it is important for teachers to guide children's interactions with texts but also allow them the freedom to respond according to their own shifting purposes. The children in this study were capable and strategic as they continually negotiated their cognitive and emotional responses to ideas in both fiction and nonfiction books. Importantly, their teachers afforded them the autonomy to respond in unique and flexible ways to make sense of the 
ideas they encountered. As children responded aesthetically and efferently to people, places, objects, and events they discovered in books, they might have ascertained that reading is relevant and valuable, as it helps them better understand their own lives and the larger physical and social worlds.

While sociocultural theory emphasizes the role of texts as cultural tools and the necessity of teacher-learner interactions for learning and development, transactional theory brings attention to the potential for reading to be both an individual and social

phenomenon. First, individual readers respond cognitively and emotionally to ideas in the text. Then, social interactions within the group (thinking aloud, building understanding together) can shape and refine readers' initial evocations so they might arrive at more nuanced understandings of ideas presented in the text (Rosenblatt, 1978).

\section{Emergent Literacy Analysis of Findings}

Emergent literacy refers to young children's experiences with texts that take place before conventional reading and writing. From this perspective, these early interactions are important because they lay the foundation for future literate behaviors such as utilizing a range of reading strategies (e.g., accessing background knowledge, personalizing the text, making predictions, etc.), as well as encountering text structures and interpreting text features (Harste, Woodward, \& Burke, 1984; Owocki, 2001). Literacy is a social and cultural practice in which children use texts that are relevant to their personal and social experiences and children need abundant engagements with various texts to learn how they function (Owocki, 2001).

Data analysis from the emergent literacy perspective could raise awareness into the ways Kailee and Becky provided children experiences with fiction and nonfiction books. 
In this study, the teachers helped children navigate both types of text, which were ensembles of words and images (e.g., illustrations, photographs with labels and captions, maps) that required readers to integrate verbal and visual information (e.g., interpreting pictures, using academic vocabulary, giving exposure to organizational features that signal a shift in topic, etc.). The nonfiction texts conveyed information about the physical environment and larger world as children were introduced to discipline-specific content (i.e., terms, ideas), read visual patterns, and examined images of people, places, and objects around the world. The fictional books told stories that could provide children with insights into their social worlds as children interpreted pictures of places in our culture (e.g., the library, school), contemplated social events, and considered characters' inner worlds (i.e., their thoughts, feelings, motives).

Sociocultural theory emphasizes the social nature of learning as well as the central role of texts in transmitting culturally salient information, whereas transactional theory draws attention to the personal and social nature of response. The emergent literacy perspective offers insights into young children's literacy development as it highlights how children who are not yet reading conventionally need experiences with different types of texts to learn how they function. The teachers in this study showed how adults can facilitate this exposure in developmentally appropriate ways as they built on children's tendencies to communicate through oral language, focus on visual images, and express themselves in multiple modalities (e.g., language, gesture, sound, etc.). As children engaged with fictional stories and nonfiction books, they might have been learning how to use these important texts found in our society. It is essential that children understand how these books function and how to use them, since reading these types of texts are 
fundamental literate behaviors in our culture. The young children in this study will likely read fictional stories and nonfiction books in school and the workplace, and possibly as a leisurely activity for entertainment and to pursue topics of interest.

\section{Summary}

All three theoretical orientations underscore the social nature of reading and work in tandem to provide a multifaceted view of reading and response. The teachers and children in this study illustrated how reading is a social practice in which individuals use cultural tools (e.g., language, text) to make meaning. Teachers capitalized on the potential of social learning through teacher-learner interactions as they scaffolded and modeled reading behaviors in children's ZPD. Moreover, children had opportunities to learn with and from peers. The young readers in this study navigated ideas individually as they felt emotions and drew from their personal knowledge and experience when transacting with ideas in texts. They also responded socially as they took cues from more experienced others (i.e., adults, peers) as they observed and practiced reading strategies. Importantly, these events took place before children received formal reading instruction, so that they might apply their knowledge of reading processes to future reading endeavors.

\section{Implications}

These findings offer important implications about read aloud of fiction and nonfiction literature with preschoolers.

\section{Implications for Future Research}

Read aloud of fictional and nonfiction texts with different populations. This study took place in one preschool classroom at a laboratory school at a midwestern institution with two teachers and 19 children. To gain a broader understanding of the 
phenomena under investigation, future studies would need to include participants in various preschool programs and in different geographic areas. The two teachers in this study had been working with young children for over 20 years each. They were highly educated and had multiple professional development experiences relating to early literacy. Future studies should inquire into read aloud of fiction and nonfiction books with novice teachers, those who have not earned advanced degrees, and early childhood teachers who have not had a lot of professional development about reading to children. Other populations could include teachers and children in schools with different missions and philosophies, programs that serve predominantly low-income children, caregivers and children in more informal settings such as home daycares, and family members who read with young children.

Repeated readings of nonfiction literature. Since read aloud took place during choice time and different children participated in each reading, it was impossible to observe repeated readings of the same book with the same teacher and children. While several studies investigate teacher's instruction and children's reading behaviors with repeated readings of fictional stories (Bus, 2003; Loizou et al., 2011; Morrow, 2007; Purcell-Gates, 1988), more research is needed to investigate how teachers and children's readings of nonfiction change or remain the same during repeated readings.

Large versus small group reading. Several studies have inquired into large group read aloud of literature in early childhood educational settings (see Dambur, 2015; Heisey \& Kucan, 2010; Maloch, 2008; Moschovaki \& Meadows, 2005; Pentimonti et al., 2011; Price et al., 2012; Richgels, 2002; Smolkin \& Donovan, 2001; Suggate et al., 2013; Webster, 2009; Wiseman, 2011; Zucker et al., 2013; Zucker et al., 2010). Other studies 
have examined small group read aloud (see Pollard-Durodola et al., 2016; Shine \& Roser, 1999; Tower, 2002). However, little is known about the explicit differences between reading with young children in large and small groups. Future research should investigate the similarities and differences of reading aloud in these two grouping structures to learn more about the affordances and challenges of each and the role both grouping structures plays in the curriculum.

\section{Implications for Practitioners}

The findings from this study have several implications for inservice preschool teachers and preschool administrators.

\section{Implications for preschool teachers.}

Choose fictional and nonfiction literature for the preschool classroom. Preschool teachers should be intentional when selecting both fiction and nonfiction books for their classrooms. To maximize the affordances of texts, they should examine the book's physical characteristics and content. The physical characteristics include peritextual elements (e.g., cover, endpapers, copyright and informational pages) as well as the written portion. Considerations include the length of text, visual elements, font, and complexity of organizational features. Preschool teachers must reflect on the scope and depth of the content to determine how it aligns with the curriculum and the book's appropriateness for the children in their class.

To balance the number of fiction and nonfiction texts and strengthen intertextual ties, preschool teachers might consider pairing a fictional story with a nonfiction book on the same subject in two closely timed read aloud events. They could then explicitly reference the first text while reading the second book. This technique, using twin texts 
(Camp, 2000), gives children exposure to books on the same topic that present content in different ways (e.g., narrative, expository) and for various purposes (e.g., to inform, entertain, persuade).

Some early childhood teachers overwhelmingly prefer to read fiction to their young students and many texts in early childhood classrooms are fictional stories (Duke, 2000; Yopp \& Yopp, 2006, 2012). However, young children are curious about the real world and often choose nonfiction books when these texts are available (Correia, 2011; Duke, 2000; Kraemer et al., 2012). Teachers need to be responsive to their students' interests and realize that many young children enjoy nonfiction because reading these types of texts is a way to explore topics of interest. Preschool teachers need to learn about their students' various preferences so they can stock the classroom and read aloud the books that will interest their children.

Teachers can take steps to make read aloud of nonfiction books more successful. When considering a nonfiction text, the teacher should preview the book to determine if the subject matter is relevant to the curriculum, addresses children's interests, and is developmentally appropriate for the children in their class. If teachers choose lengthy nonfiction texts, they must be prepared to omit passages and content to adapt to their young audience. Nonfiction books should have detailed and realistic pictures (i.e., illustrations, photographs) that support children's meaning making and lend themselves to dialogue. These elements should support the reader's understanding (e.g., pictures with captions, pictures clearly relate to the words) (Bamford et al., 2002).

During planning, teachers need to study nonfiction books to familiarize themselves with the subject matter and text features. They must educate themselves on topics so that 
they can give children accurate information in case a child asks a question that extends the book. If nonfiction books contain organizational and visual features (e.g., table of contents, index, glossary, maps, captions, labels, diagrams), teachers need to consider which features to read or omit. They should consider what content and terms might be challenging for preschoolers and plan how to describe or exclude certain subject matter (Calo, 2011; Pappas, 2006). These actions might alleviate some of the difficulty in making in-the-moment decisions about reading or skipping text. Teachers can also prepare some questions and conversation starters by considering ways to personalize the topic, tie the book to other media, assess children's knowledge of the topic, and engage children in discussions about the content.

Read nonfiction with preschoolers. Preschool teachers have reported they must provide more intensive instruction as they read nonfiction and feel less confident, which might explain why this type of text is less prevalent in early childhood classrooms (Price et al., 2012). The preschool teachers in my study utilized some common strategies when reading fiction and nonfiction books aloud. Reading nonfiction aloud did not require an entirely unique set of reading strategies. Rather, teachers were able to incorporate additional strategies into their preexisting repertoires such as introducing children to some nonfiction organizational and visual features, as well as describing pictures, content, and technical vocabulary terms. They also compared and contrasted objects in pictures to items familiar to children. In addition, they monitored the accuracy of information. The teachers in this study did not read every word of the nonfiction texts, including the narrative nonfiction book. They strategically omitted passages to adjust to children's attention spans and learning needs. They also made decisions about their use of 
organizational and visual features and how these elements might support or detract from their purposes for reading. These findings illuminate the ways preschool teachers can successfully read nonfiction with both younger and older preschoolers. They do not need to read every word, all the information, each visual element, organizational feature, nor every page. Strategic readers use nonfiction text as a resource; they are selective about the content they read and target the text that contains the information they seek. Preschool teachers can also be judicious about the techniques they use depending on the interests and development of the individual children in the group.

Differentiate instruction for younger and older preschoolers. The reading groups in this study had mixed ages of children (two-and-a-half to five years). The older children (four-and five-year-olds) were typically the first to display reading strategies, while their younger peers (two-and-a-half and three-and-a-half-year-olds) observed. Children's reading behaviors correlated with their ages, so teachers differentiated instruction to optimize children's learning in their ZPD. The younger children's strategies were limited to examining pictures and exhibiting some multimodal responses in reaction to teachers' encouragement. In several instances, teachers prompted them to become engaged with the text and participate in conversations. The older preschoolers demonstrated a wider range of reading behaviors (e.g., accessing background knowledge, personalizing, inferring, predicting, interpreting patterns, noticing factual errors, etc.). At times, teachers prompted their responses. In other instances, they volunteered to participate. Based on these findings, preschool teachers can expect to differentiate reading instruction because children will likely exhibit various behaviors according to their reading development. Teachers will need to observe their young students and provide strategy instruction in 
children's varying ZPD. Teachers' scaffolding should remain flexible as they offer and fade supports contingent upon children's competencies.

Read on the efferent-aesthetic continuum. The preschool teachers in this study took mostly fixed stances toward fiction and nonfiction literature. While strategic readers establish a purpose for reading, they also respond sensitively to ideas and content they encounter. As teachers preview a text, they might reconsider their purposes to realize the various potentials of the text to be read efferently and/or aesthetically. They can scaffold and model for their young students how readers move across the efferent-aesthetic continuum as they consider their knowledge, experiences, feelings, and beliefs that relate to the text and share their responses with children.

Implications for preschool administrators. As school directors, preschool administrators can influence their school's literacy programming. They should permit teachers to exercise autonomy in choosing books and other instructional materials, as well as implementing a relevant curriculum based on developmentally appropriate practice. Since state licensing agencies require preschool teachers to complete professional development clock hours each year, directors can also promote teachers' literacy-related professional development by seeking out those opportunities. Administrators also have some influence on school budgets and can prioritize ordering books and other learning materials that support their mission of providing children with high quality fiction and nonfiction texts.

\section{Implications for Early Childhood Teacher Education Faculty}


Early childhood teacher education faculty must support preservice teachers' capacities to choose and read fiction and nonfiction literature. Faculty should take steps to build these opportunities into their courses. They should:

- familiarize preservice teachers with young children's emergent literacy behaviors and how to create relevant and developmentally appropriate learning experiences for their students;

- support preservice teachers as they learn to select, preview, and read both fiction and nonfiction texts aloud;

- give preservice teachers experience reading to young children so they can practice interacting with them while reading, modeling and scaffolding strategies. This practice would also give them experience making in-the-moment decisions as they encounter long passages, conceptually difficult content, technical vocabulary, and various nonfiction organizational and visual features (e.g., subheadings, table of contents, bolded vocabulary words, maps, diagrams, labels/captions).

\section{Final Reflections}

I have learned many things through this research project. My experiences interviewing Kailee and Becky and observing them read with children have deepened my knowledge of the ways preschool teachers support children's engagements with fiction and nonfiction literature. I have learned that there is no right way to read a book. It is more important for teachers to make instructional decisions that enable children to interact with the text than it is to read every word, read without stopping, or read the entire book frontto-back. Instead, it is vital that adults and children engage in generative discussions as they think deeply while reading together. Small groups are an ideal setting for these rich 
conversations because everyone can engage with the book and with each other. In this intimate setting, children are both novices and experts as they learn from others and demonstrate their meaning making capabilities.

I have learned that young children enjoy learning about the real world and that nonfiction books can further their knowledge of familiar topics. Nonfiction literature has the potential to enlarge children's worlds and introduce them to new things they would not otherwise encounter. These early experiences with nonfiction books help build children's content knowledge and meaning making strategies that form the foundation for future learning in many disciplines. Nonfiction literature does not just expose children to scientific phenomena but to people, places, and events that are beyond their immediate lives. They might gain an appreciation for the lived experiences of people who are both similar and different to them.

The findings from this study have made me reconsider what it means to learn to read. I knew that the emergent literacy perspective considers the many interactions young children have with texts as essential to their literacy development. I knew that preschoolers needed abundant opportunities to talk about ideas in books, interpret pictures, and recognize letters and words. I did not realize the value of children learning to think while reading or that young children could demonstrate the many ways they make meaning for their peers. Children must have plenty of opportunities to make sense of ideas and events in texts with adult support and peer interactions through talk. If they have had these rich early literacy experiences, they might then apply their sense making strategies to the written code during formal reading instruction. Children's small group read aloud experiences lay the foundation for a lifetime of literacy and learning. 


\section{Children's Literature}

${ }^{*}$ Ajmera, M., Hofer Derstine, E., \& Pon, C. (2012). What we wear: Dressing up around the world. Washington, DC: The Global Fund for Children.

${ }^{*}$ Ajmera, M., Hofer Derstine, E., \& Pon, C. (2014). Music everywhere! Washington, DC: The Global Fund for Children.

${ }^{\mathrm{F}}$ Berenstain, S., \& Berenstain, J. (1978). The Berenstain bears and the spooky old tree. New York, NY: Random House.

${ }^{*}$ B Berger, M., \& Berger, G. (2002). Bears. New York, NY: Scholastic.

${ }^{\mathrm{F}}$ Cole, J., \& Degen, B. (Illustrator). (1992). The magic school bus: On the ocean floor. New York, NY: Scholastic.

${ }^{\mathrm{F}}$ Cole, J., \& Degen, B. (Illustrator). (1996). The magic school bus: Inside a beehive. New York, NY: Scholastic.

${ }^{\mathrm{N}}$ Davies, N., \& Chapman, J. (Illustrator). (2001). One tiny turtle. New York, NY: Scholastic.

${ }^{*}$ Fox, M., \& Staub, L. (Illustrator). (2006). Whoever you are. Boston, MA: Houghton Mifflin Harcourt Books for Young Readers.

${ }^{\mathrm{N}}$ Golden Books. (1999). Frogs. New York, NY: Golden Books.

${ }^{\text {F} M o o n, ~ N ., ~ \& ~ A y l i f f e, ~ A . ~(I l l u s t r a t o r) . ~(1994) . ~ L u c y ' s ~ p i c t u r e . ~ N e w ~ Y o r k, ~ N Y: ~ S c h o l a s t i c . ~}$

${ }^{*}$ Myron, V., Witter, B., \& James, S. (Illustrator). (2009). Dewey: There's a cat in the library! New York, NY: Little, Brown and Company.

${ }^{\mathrm{N}}$ Nicholas, C., \& Maydak, M. (Illustrator). (1999). Spiders! New York, NY: McClanahan.

${ }^{\mathrm{N}}$ Reed, J. (2014). A listen to world music. Vero Beach, FL: Rourke Educational Media. 
${ }^{\mathrm{F}}$ Relf, P., \& Stevenson, N. (Illustrator). (1995). The magic school bus: Hops home. New York, NY: Scholastic.

${ }^{\mathrm{F}}$ Showers, P., \& Aliki. (Illustrator). (1961/1991). The listening walk. New York, NY: HarperCollins.

${ }^{\mathrm{N}}$ Steffora, T., (2011). Patterns at the museum. Chicago, IL: Heinemann Library.

${ }^{\mathrm{F}}$ Thompson, L., \& Erdogan, B. (Illustrator). (2003). Mouse loves school. New York, NY: Scholastic.

Note. $*$ denotes a book that I supplied, ${ }^{\mathrm{F}}$ denotes fiction, ${ }^{\mathrm{N}}$ denotes nonfiction 


\section{References}

Adomat, D. S. (2009). Actively engaging with stories through drama: Portraits of two struggling readers. The Reading Teacher, 62(8), 628-636.

Adomat, D. S. (2010). Dramatic interpretations: Performative responses of young children to picturebook read-alouds. Children's Literature in Education, 41(3), 207-221. doi: $10.1007 / \mathrm{s} 10583-010-9105-0$

Aldemir, O., \& Gursel, O. (2014). The effectiveness of the constant time delay procedure in teaching pre-school academic skills to children with developmental disabilities in a small group teaching arrangement. Educational Sciences: Theory \& Practice, 14(2), 733-740.

Anderson, R. C., Hiebert, E. H., Scott, J. A., \& Wilkinson, I. A. G. (1985). Becoming a nation of readers: The report of the commission on reading. Urbana, IL: The National Academy of Education Center on the Study of Reading.

Applebee, A. N., \& Langer, J. A. (1983). Instructional scaffolding: Reading and writing as natural language activities. Language Arts, 60(2), 168-175.

Arizpe, E., \& Styles, M. (2016). Children reading picturebooks: Interpreting visual texts. London, England: Routledge.

Athanases, S. Z., \& de Oliveira, L. C. (2014). Scaffolding versus routine support for Latina/o youth in an urban school: Tensions in building toward disciplinary literacy. Journal of Literacy Research, 46(2), 263-299.

Azevedo, R., \& Hadwin, A. F. (2005). Scaffolding self-regulated learning and metacognition-Implications for the design of computer-based scaffolds. Instructional Science, 33(5), 367-379. 
Bakhtin, M. M. (1990). Art and answerability: Early philosophical essays by M. M. Bakhtin. Austin, TX: University of Texas Press.

Bamford, R. A., Kristo, J. V., \& Lyon, A. (2002). Facing facts: Nonfiction in the primary classroom. The New England Reading Association, 38(2), 8-15.

Bandura, A. (1986). Social foundations of thought and action. Englewood Cliffs, NJ: Prentice Hall.

Barnes, D. (1975/1992). From communication to curriculum (2nd ed.). Portsmouth, NH: Heinemann.

Barnes, D. (2008). Exploratory talk for learning. In N. Mercer \& S. Hodgkinson (Eds.), Exploring talk in school (pp. 1-15). Los Angeles, CA: SAGE.

Barnett, W. S., Hustedt, J. T., Robin, K. B., \& Schulman, K. L. (2004). The state of preschool: 2004 state preschool yearbook. New Brunswick, NJ: National Institute for Early Education Research, Rutgers University.

Barnett, W. S., Hustedt, J. T., Robin, K. B., \& Schulman, K. L. (2005). The state of preschool: 2005 state preschool yearbook. New Brunswick, NJ: National Institute for Early Education Research, Rutgers University.

Barone, D. M. (2011). Children's literature in the classroom: Engaging lifelong readers. New York, NY: The Guilford Press.

Barton, D., \& Hamilton, M. (2000). Literacy practices. In D. Barton, M. Hamilton, \& R. Ivanic (Eds.), Situated literacies: Reading and writing in context (pp. 7-15). London, England: Routledge.

Beaulieu-Jones, L., \& Proctor, C. P. (2016). Implementing small-group collaborative discussions. The Reading Teacher, 69(6), 677-682. 
Beck, I. L., \& McKeown, M. G. (2001). Text talk: Capturing the benefits of read-aloud experiences for young children. The Reading Teacher, 55(1), 10-20.

Belland, B. R. (2014). Scaffolding: Definition, current debates, and future directions. In M. Spector, M. D. Merrill, J. Elen, \& M. J. Bishop (Eds.), Handbook of research on educational communications and technology (pp. 505-518). New York, NY: Springer.

Blewitt, P., \& Langan, R. (2016). Learning words during shared book reading: The role of extratextual talk designed to increase child engagement. Journal of Experimental Child Psychology, 150, 404-410.

Bloom, P. (May 30, 2010). The pleasures of imagination. The Chronicle of Higher Education. Retrieved from http://www.chronicle.com/article/The-Pleasures-ofImagination/65678

Boat, M. B., Dinnebiel, L. A., \& Bae, Y. (2010). Individualizing instruction in preschool classrooms. Dimensions of Early Childhood, 38(1), 3-11.

Bodrova, E., \& Leong, D. J. (2003). Learning and development of preschool children from the Vygotskian perspective. In A. Kozulin, B. Gindis, V. S. Ageyev, \& S. M. Miller (Eds.), Vygotsky's educational theory in cultural context (pp. 156-176). Cambridge, England: Cambridge University Press.

Bogdan, R. C., \& Biklen, S. K. (1998). Qualitative research for education: An introduction to theory and methods (3rd ed.). Boston, MA: Allyn \& Bacon.

Bransford, J., Darling-Hammond, L., \& LePage, P. (2005). Introduction. In L. DarlingHammond \& J. Bransford (Eds.), Preparing teachers for a changing world: What 
teachers should learn and be able to do (pp. 1-39). San Francisco, CA: JosseyBass.

Brassell, D. (2006). Inspiring young scientists with great books. The Reading Teacher, 60(4), 336-342.

Bruner, J. (1986). Actual minds: Possible worlds. Cambridge, MA: Harvard University Press.

Brush, T., \& Saye, J. W. (2002). Scaffolding critical reasoning about history and social issues in multimedia-supported learning environments. Educational Technology Research and Development, 50(3), 77-96.

Buli-Holmburg, J., \& Jeyaprathaban, S. (2016). Effective practice in inclusive and special needs education. International Journal of Special Education, 31(1), 119-134.

Bus, A. G. (2003). Social-emotional requisites for learning to read. In A. van Kleek, S. A. Stahl, \& E. B. Bauer (Eds.), On reading books to children: Parents and teachers (pp. 3-15). Mahwah, NJ: Lawrence Erlbaum.

Butts, D. P., Hofman, H. M., \& Anderson, M. (1993). Is hands-on experience enough? A study of young children's views of sinking and floating. Journal of Elementary Science Education, 5(1), 50-64.

Calo, K. M. (2011). Incorporating informational texts in the primary grades: A researchbased rationale, practical strategies, and two teachers' experiences. Early Childhood Education Journal, 39, 291-295. doi: 10.1007/s10643-011-0470-0

Camp, D. (2000). It takes two: Teaching with twin texts of fact and fiction. The Reading Teacher, 53(5), 400-408. 
Castle, K. (2012). Early childhood teacher research: From questions to results. New York, NY: Routledge.

Caswell, L. J., \& Duke, N. K. (1998). Non-narrative as a catalyst for literacy development. Language Arts, 75, 108-117.

Cazden, C. (1979). Peekaboo as an instructional model: Discourse development at home and at school. Stanford Papers and Reports in Child Language Development, 17, 1-19.

Cazden, C. (2001). Classroom discourse: The language of teaching and learning (2nd ed.). Portsmouth, NH: Heinemann.

Chall, J. S. (1983). Stages of reading development. New York, NY: McGraw-Hill.

Chambers, A. (2011). Tell me: Children, reading and talk with the reading environment. Stroud, England: Thimble Press.

Clark, K. F., \& Graves, M. F. (2005). Scaffolding students' comprehension of text. The Reading Teacher, 58(6), 570-580.

Clark, S. K., Jones, C. D., \& Reutzel, D. R. (2013). Using the text structures of informational books to teach writing in the primary grades. Early Childhood Education Journal, 41, 265-271. doi: 10.1007/s10643-012-0547-4

Cochran-Smith, M. (1984). The making of a reader. Norwood, NJ: Ablex.

Cole, A. D. (2006). Scaffolding beginning readers: Micro and macro cues teachers use during student oral reading. The Reading Teacher, 59(5), 450-459.

Collins, M. F. (2010). ELL preschoolers' English vocabulary acquisition from storybook reading. Early Childhood Research Quarterly, 25(1), 84-97. 
Connor, C., Morrison, F., \& Slominski, L. (2006). Preschool instruction and children's emergent literacy growth. Journal of Educational Psychology, 98(4), 665-689.

Cooper, D. H., \& Farran, D. C. (1991). The Cooper-Farran behavioral rating scales. Brandon, VT: Clinical Psychology Publishing.

Cooper, J. L., MacGregor, J., Smith, K. A., \& Robinson, P. (2000). Implementing smallgroup instruction: Insights from successful practitioners. New Directions for Teaching and Learning, 81, 63-76.

Correia, M. P. (2011). Fiction vs. informational texts: Which will kindergarteners choose? Young Children, 66(6), 100-104.

Corsaro, W. A. (2003). “We're friends, right?”: Inside kids' cultures. Washington, DC: Joseph Henry Press.

The Creative Curriculum ${ }^{\mathrm{TM}}$. (2011). The Creative Curriculum ${ }^{\mathrm{TM}}$ for preschool. Bethesda, MD: Teaching Strategies.

Creswell, J. W. (2013). Qualitative inquiry and research design: Choosing among five approaches (3rd ed.). Los Angeles, CA: SAGE.

Curby, T. W., Brock, L. L., \& Hamre, B. K. (2009). Teachers' emotional support consistency predicts children's achievement gains and social skills. Early Education and Development, 24(3), 292-309.

Curby, T. W., LoCasale-Crouch, J., Konold, T. R., Pianta, R. C., Howes, C., Burchinal, M.,... Barbarin, O. (2009). The relations of observed pre-k classroom quality profiles to children's achievement and social competence. Early Education \& Development, 20(2), 346-372.doi:10.1080/10409280802581284.

Curby, T. W., Rimm-Kaufman, S. E., \& Cameron Ponitz, C. (2009). Teacher-child 
interactions and children's achievement trajectories across kindergarten and first grade. Journal of Educational Psychology, 101(4), 912-925.

Damber, U. (2015). Read-alouds in preschool: A matter of discipline? Journal of Early Childhood Literacy, 15(2), 256-280.

Daniels, H. A. (1990). Young readers and writers reach out: Developing a sense of audience. In T. Shanahan (Ed.), Reading and writing together: New perspectives for the classroom, (pp. 99-124). Norwood, MA: Christopher-Gordon.

Danis, A., Bernard, J., \& Leproux, C. (2000). Shared picture-book reading: A sequential analysis of adult-child verbal interactions. British Journal of Developmental Psychology, 18, 369-388.

Denzin, N. K. (1970). The research act: A theoretical introduction to sociological methods. Chicago, IL: Aldine.

Denzin, N. K., \& Lincoln, Y. S. (2011). The SAGE handbook of qualitative research (4th ed.). Los Angeles, CA: SAGE.

Dewalt, K. M., Dewalt, B. R., \& Wayland, C. B. (1998). Participant observation. In H. R. Bernard (Ed.), Handbook of methods in cultural anthropology (pp. 259-299). Walnut Creek, CA: Altamira.

Dickinson, D. K., \& Smith, M. W. (1994). Long-term effects of preschool teachers' book readings on low-income children's vocabulary and story comprehension. Reading Research Quarterly, 29(2), 104-122.

Dockett, S., Einarsdottir, J., \& Perry, B. (2012). Young children's decisions about research participation: Opting out. International Journal of Early Years Education, 20(3), 244-256. 
Dodici, B. J., Draper, D. C., \& Peterson, C. A. (2003). Early parent-child interactions and early literacy development. Topics in Early Childhood Special Education, 23(3), 124-136.

Donovan, C. A., \& Smolkin, L. B. (2002). Considering genre, content, and visual features in the selection of trade books for science instruction: Analyses of different aspects of stories and informational books can help teachers make informed decisions to enhance science instruction. The Reading Teacher, 55(6), 502-520.

Dorl, J, (2007). Think aloud! Increase your teaching power! Young Children, 62(4), 101105.

Dougherty Stahl, K. A. (2014). Inference generation with emergent and novice readers. The Reading Teacher, 67(5), 384-388.

Duke, N. K. (2000). 3.6 minutes per day: The scarcity of informational texts in first grade. Reading Research Quarterly, 35(2), 202-224.

Duke, N. K. (2003). Reading to learn from the very beginning: Information books in early childhood. Young Child, 58, 14-20.

Duke, N. K. (2013). Starting out: Practices to use in K-3. Educational Leadership, 71(3), $40-44$.

Duke, N. K., \& Bennett-Armistead, V. S. (2003). Reading and writing informational texts in the primary grades. New York, NY: Scholastic.

Duke, N. K., \& Block, M. K. (2012). Improving reading in the primary grades. The Future of Children, 22(2), 55-72.

Duke, N. K., \& Kays, J. (1998). “Can I say 'Once upon a time'?”: Kindergarten children developing knowledge of information book language. Early Childhood Research Quarterly, 13(2), 295-318.doi: 10.1016/S0885-2006(99)80041-6 
Durkin, D. (1978). What classroom observations reveal about reading comprehension instruction. Reading Research Quarterly, 14(4), 481-533.

Dust, P. H. (1981). Literature and vicarious experience: The imagination as trickster and midwife. Journal of Mental Imagery, 5, 143-156.

Dyson, A. H., \& Genishi, C. (2005). On the case: Approaches to language and literacy research. New York, NY: Teachers College Press.

Edwards, S., Blaise, M., \& Hammer, M. (2009). Beyond developmentalism? Early childhood teachers' understandings of multiage grouping in early childhood education and care. Australasian Journal of Early Childhood, 34(4), 55-63.

Elley, W. B. (1989). Vocabulary acquisition from listening to stories. Reading Research Quarterly, 24(2), 174-187.

Farrant, B. M., \& Zubrick, S. R. (2012). Early vocabulary development: The importance of joint attention and parent-child book reading. First Language, 32(3), 343-364.

Fisher, D., Flood, J., Lapp, D., \& Frey, N. (2004). Interactive read-alouds: Is there a common set of implementation practices? The Reading Teacher, 58(1), 8-17.

Forman, E. A., \& Cazden, C. B. (1985). Exploring Vygotskian perspectives in education: The cognitive value of peer interaction. In J. V. Wertsch (Ed.), Culture, communication, and cognition (pp. 323-347). New York, NY: Cambridge University Press.

Fountas, I. C., \& Pinnell, G. S. (2006). Teaching for comprehending and fluency: Thinking, talking, and writing about reading, $K-8$. Portsmouth, NH: Heinemann.

Freebody, P., \& Luke, A. (2003). Literacy as engaging with new forms of life: The 'four roles' model. In G. Bull \& M. Anstey (Eds.), The literacy lexicon ( $2^{\text {nd }}$ ed.) (pp. 5257). Sydney, Australia: Prentice Hall. 
Gee, J. P. (2012). Social linguistics and literacies: Ideologies in discourses $\left(4^{\text {th }}\right.$ ed.). London, UK: Routledge.

García, O., Kleifgen, J., \& Falchi, L. (2008). From English language learners to emergent bilinguals. Equity Matters, Research Review No. 1. Initiative of the Campaign for Educational Equity. New York, NY: Teachers College Press.

Geertz, C. (1973). Thick description: Toward an interpretive theory of culture. In C. Geertz (Ed.), The interpretation of cultures (pp. 3-30). New York, NY: Basic Books.

Gerber, C. (Creator), Bour, E. M., \& Chew, N. (Directors). (2016). Elena of Avalor [Television series]. USA: Disney Enterprises.

Gibbons, P. (2002). Scaffolding language, scaffolding learning: Teaching second language learners in the mainstream classroom. Portsmouth, NH: Heinemann.

Gibbons, P. (2003). Mediating language learning: Teacher interactions with ESL students in a content-based classroom. TESOL Quarterly, 37(2), 247-273.

Girolametto, L., Hoaken, L., Weitzman, E., \& van Lieshout, R. (2000). Patterns of adultchild linguistic interaction in integrated day care groups. Language, Speech, and Hearing Services in Schools, 31(2), 155-168.

Girolametto, L., \& Weitzman, E. (2002). Responsiveness of childcare providers in interactions with toddlers and preschoolers. Language, Speech, and Hearing Services in Schools, 33, 268-281.

Glaser, B. G. (1978). Theoretical sensitivity: Advances in the methodology of grounded theory. Mill Valley, CA: Sociology Press. 
Glaser, B. G., \& Strauss, A. L. (1967). The discovery of grounded theory: Strategies for qualitative research. Chicago, IL: Aldine.

González, N., Moll, L. C., \& Amanti, C. (2005). Funds of knowledge: Theorizing, practices in households, communities, and classrooms. Mahwah, NJ: Lawrence Erlbaum.

Goodman, K. (1986). What's whole in whole language? Portsmouth, NH: Heinemann.

Graesser, A., Wiemer-Hastings, K., Wiemer-Hastings, P., Kruez, R., The Tutoring Research Group. (2000). AutoTutor: A simulation of a human tutor. Journal of Cognitive Systems Research, 1, 35-51.

Green, M., \& Piel, J. A. (2010). Theories of human development: A comparative approach (2nd ed.). Boston, MA: Allyn \& Bacon.

Hall, K. (2013). Effective literacy teaching in the early years of school. In J. Larson \& J. Marsh (Eds.), the SAGE handbook of early childhood literacy ( $2^{\text {nd }}$ ed.) (pp. 523541). Thousand Oaks, CA: SAGE.

Hammond, J., \& Gibbons, P. (2005). Putting scaffolding to work: The contribution of scaffolding in articulating ESL education. Prospect, 20(1), 6-30.

Hamre, B. K., \& Pianta, R. C. (2005). Can instructional and emotional support in the firstgrade classroom make a difference for children at risk of school failure? Child Development, 76(5), 949-967.

Hargrave, A. C., \& Senechal, M. (2000). Book reading interventions with languagedelayed preschool children: The benefits of regular reading and dialogic reading. Early Childhood Research Quarterly, 15(1), 75-90. 
Harms, T., Clifford, R. M., \& Cryer, D. (1998). The early childhood environment rating scale (Rev. ed.). New York, NY: Teachers College Press. Retrieved from http://ers.fp.unc.edu/early-childhood-environment-rating-scale-ecers-r

Harste, J. C., Woodward, V. A., \& Burke, C. L. (1984). Language stories and literacy lessons. Portsmouth, NH: Heinemann.

Harvey, S., \& Goudvis, A. (2007). Strategies that work: Teaching comprehension for understanding and engagement. Portland, ME: Stenhouse.

Hasan, R. (1992). Rationality in everyday talk: From process to system. In J. Svartvik Ed.), Directions in corpus linguistics: Proceedings of Nobel symposium 82 Stockholm (pp. 257-310). Berlin, Germany: De Gruyter Mouton.

Heflebower, T., Hoegh, J. K., \& Warrick, P. (2014). A school leader's guide to standardsbased grading. Blomington, IN: Marzano Research.

Heisey, N., \& Kucan, L. (2010). Introducing science concepts to primary students through read-alouds: Interactions and multiple texts make the difference. The Reading Teacher, 63(8), 666-676.

Herr, K., \& Anderson, G. L. (2005). The action research dissertation: A guide for students and faculty. Thousand Oaks, CA: SAGE.

Hindman, A. H., Connor, C. M., Jewkes, A. M., \& Morrison, F. J. (2008). Untangling the effects of shared book reading: Multiple factors and their associations with preschool literacy outcomes. Early Childhood Research Quarterly, 23, 330-350.

Hirsch, E. D. (2003). Reading comprehension required knowledge—of words and the world: Scientific insights into the fourth-grade slump and the nation's stagnant 
comprehension scores. Retrieved from http://www.aft.org/ae/authorindex\#quicktabs-authors $=1$

Hoffman, J. L., Collins, M. F., \& Schickedanz, J. A. (2015). Instructional challenges in developing young children's science concepts: Using informational text readalouds. The Reading Teacher, 68(5), 363-372. doi: 10.1002/trtr.1325

Holquist, M. (1990). Dialogism: Bakhtin and his world. New York, NY: Routledge.

Hopkins, E. J., \& Skolnick Weisberg, D. (2016). The youngest readers' dilemma: A review of children's learning from fictional sources. Developmental Review, 43, 48-70.

Hosan, N. E., \& Hoglund, W. (2017). Do teacher-child relationship and friendship quality matter for children's school engagement and academic skills? School Psychology Review, 46(2), 201-218.

Hovland, M. R., Gapp, S. C., \& Theis, B. L. (2011). Look: Examining the concept of learning to look at print. Reading Improvement, 48(3), 128-138.

Howes, C., Burchinal, M., Pianta, R., Bryant, D., Early, D., Clifford, R., \& Barbarin, O. (2008). Ready to learn? Children's pre-academic achievement in pre-kindergarten programs. Early Childhood Research Quarterly, 23(1), 27-50.

Hoyt, L. (2007). Interactive read-alouds grades 2-3: Linking standards, fluency, and comprehension. Portsmouth, NH: Heinemann.

Hsieh, H., \& Shannon, S. E. (2005). Three approaches to qualitative content analysis. Qualitative Health Research, 15(9), 1277-1288. doi: 10.1177/1049732305276687 
Hsin, C-T., \& Hsin-Kai, W. (2011). Using scaffolding strategies to promote young children's scientific understandings of floating and sinking. Journal of Science Education and Technology, 20(5), 656-666.

Huck, C. S. (1990/1998). The power of children's literature in the classroom. In K. G. Short \& K. M. Pierce (Eds.), Talking about books, (pp. 3-15). Portsmouth, NH: Heinemann.

Hungerford, R. A. (1993). Star Wars and the world beyond. In K. E. Holland, R. A. Hungerford, \& S. B. Ernst (Eds.), Journeying: Children responding to literature (pp. 27-42). Portsmouth, NH: Heinemann.

Ioney, J., \& Carter, T. S. (2007). Questioning and informational texts: Scaffolding students comprehension of content areas. Forum on Public Policy, 2007(3), 1-13.

Joffe, V. L. (2009). Explicit print referencing enhances early literacy in preschoolers. Evidence Based Communication, Assessment, and Intervention, 3(3), 145-150. doi:10.1080/17489530903198307

Johnston, P. H. (2003). Choice words: How our language affects children's learning. Portland, ME: Stenhouse.

Jones, C. D., \& Henriksen, B. M. (2013). Skills-focused small group literacy instruction in the first grade: an inquiry and insights. Journal of Reading Education, 38(2), 2530.

Justice, L. M., \& Ezell, H. K. (2004). Print referencing: An emergent literacy enhancement strategy and its clinical applications. Language, Speech \& Hearing Services in Schools, 35(2), 185-193.

Justice, L. M., Kaderavek, J. N., Fan, X., Safka, A., \& Hunt, A. (2009). Accelerating 
preschoolers' early literacy development through classroom-based teacher-child storybook reading and explicit print referencing. Language, Speech, and Hearing Services in Schools, 40(1), 67-85.

Kamberelis, G. (1999). Genre development and learning: Children writing stories, science reports, and poems. Research in the Teaching of English, 33(4), 403-460.

Karpov, Y. V. (2003). Vygotsky's doctrine of scientific concepts: Its role for contemporary education. In A. Kozulin, B. Gindis, V. S. Ageyev, \& S. M. Miller (Eds.), Vygotsky's educational theory in cultural context (pp. 65-82). Cambridge, England: Cambridge University Press.

Katz, L. G., \& Chard, S. C. (2001). Engaging children's minds: The project approach. Norwood, NJ: Ablex.

Keene, E. O., \& Zimmerman, S. (1997). Mosaic of thought: Teaching comprehension in a reader's workshop. Portsmouth, NH: Heinemann.

Kendeou, P., Bohn-Gettler, C., White, M. J., \& van den Broek, P. (2008). Children's inference generation across different media. Journal of Research in Reading, $31(3), 259-272$.

Kimmel, M. M., \& Segel, E. (1988). For reading out loud! New York, NY: Delacorte.

Klein, A., Starkey, P., \& Wakeley, A. (2004). Enhancing prekindergarten children's readiness for school mathematics. Early Childhood Research Quarterly, 19, 99120.

Klesius, J. P., \& Griffith, P. L. (1996). Interactive storybook reading for at-risk learners. The Reading Teacher, 49, 552-560. 
Koss, M. D. (2015). Diversity in contemporary picturebooks: A content analysis. Journal of Children's Literature, 41(4), 32-42.

Kozulin, A. (2003). Psychological tools and mediated learning. In A. Kozulin, B. Gindis, V. S. Ageyev, \& S. M. Miller (Eds.), Vygotsky's educational theory in cultural context (pp. 15-38). Cambridge, England: Cambridge University Press.

Kraemer, L., McCabe, P., \& Sinatra, R. (2012). The effects of read-alouds of expository text on first graders' listening comprehension and book choice. Literacy Research and Instruction, 51(2), 165-178. doi: 10.1080/19388071.2011.557471

Kress, G. (1994). Learning to write, ( $2^{\text {nd }}$ ed.). London, England: Routledge and Kegan Paul.

Krippendorff, K. (2004). Content analysis: An introduction to its methodology (2nd ed.). Thousands Oaks, CA: SAGE.

Kristeva, J. (1980). Desire in language: A semiotic approach to literature and art. New York, NY: Columbia University Press.

La Joie, S. P. (2005). Extending the scaffolding metaphor. Instructional Science, 33, 541557.

Lavrakas, P. J. (2008). Encyclopedia of survey research methods. Thousand Oaks, CA: SAGE.

Leavy, P. (2017). Research design: Quantitative, qualitative, mixed methods, arts-based, and community-based participatory research approaches. New York, NY: The Guilford Press.

Ledford, J. R., \& Wolery, M. (2015). Academic and social behaviors during small-group direct instruction. Exceptional Children, 81(3), 272-291. 
Lincoln, Y. S., \& Guba, E. G. (1985). Naturalistic inquiry. Newbury Park, CA: SAGE.

Logue, M. E. (2006). Teachers observe to learn: Differences in social behavior of toddlers and preschoolers in same-age and multiage groupings. Young Children, 61(3), 7076.

Loizou, E., Kyriakides, E., \& Hadjicharalambous, M. (2011). Constructing stories in kindergarten: Children's knowledge of genre. European Early Childhood Education Research Journal, 19(1), 63-77.

Lovelace, S., \& Stewart, S. R., (2007). Increasing print awareness in preschoolers with language impairment using non-evocative print-referencing. Language, Speech and Hearing Services in Schools, 38(1), 16-30.

Lynch-Brown, C., \& Tomlinson, C. M. (2005). Essentials of children's literature (5th ed.). Boston, MA: Pearson Education.

Mackey, J., O-Reilly, N., Fletcher, J., \& Jansen, C. (2017). What do teachers and leaders have to say about co-teaching in flexible learning spaces? Journal of Educational Leadership, Policy \& Practice, 32(1), 97-110.

Macrine, S. L., \& Sabbatino, E. D. (2008). Dynamic assessment and remediation approach: Using the DARA approach to assist struggling readers. Reading and Writing Responsibly, 24(1), 52-76.

Magruder, E. S., Hayslip, W. W., Espinoza, L. M., \& Matera, C. (2013). Many languages, one teacher: Supporting language and literacy development for preschool dual language learners. Young Children, 68(1), 8-15. 
Mahn, H. (2003). Periods in child development: Vygotsky's perspective. In A. Kozulin, B. Gindis, V. S. Ageyev, \& S. M. Miller (Eds.), Vygotsky's educational theory in cultural context (pp. 119-137). Cambridge, England: Cambridge University Press.

Maloch, B. (2002). Scaffolding student talk: One teacher's role in literature discussion groups. Reading Research Quarterly, 37(1), 94-112.

Maloch, B. (2008). Beyond exposure: The uses of informational texts in a second grade classroom. Research in the Teaching of English, 42(3), 315-362.

Mantzicopoulos, P., \& Patrick, H. (2010). "The seesaw is a machine that goes up and down": Young children's narrative responses to science-related informational text. Early Education and Development, 21(3), 412-444.

Mariani, L. (1997). Teacher support and teacher challenge in promoting learner autonomy. Retrieved from http://www.learningpaths.org/papers/papersupport.htm

Martinez, M., \& Harmon, J. M. (2012). Picture/text relationships: An investigation of literary elements in picturebooks. Literacy Research and Instruction, 51(4), 323343.

Martins, M. A., Salvador, L., Albuquerque, A., \& Silva, C. (2016). Invented spelling activities in small groups and early spelling and reading. Educational Psychology, 36(4), 738-751. doi: 10.1080/014433410.2014.950947

Mashburn, A. J., Pianta, R. C., Hamre, B. K., Downer, J. T., Barbarin, O. A., Bryant, D. ... \& Howes, C. (2008). Measures of classroom quality in prekindergarten and children's development of academic, language, and social skills. Child Development, 79(3), 732-749. 
May, L. (2011). Animating talk and texts: Culturally relevant teacher read-alouds of informational texts. Journal of Literacy Research, 43(1), 3-38.

McAfee, O., \& Leong, D. J. (2002). Assessing and guiding young children's development and learning. Boston, MA: Allyn \& Bacon.

McGee, L. M., \& Richgels, D. J. (2012). Literacy's beginnings: Supporting young readers and writers (6th ed.). Boston, MA: Pearson.

McGee, L. M., \& Richgels, D. J. (2014). Designing early literacy programs: Differentiated instruction in preschool and kindergarten. New York, NY: The Guilford Press.

McGee, L. M., \& Schickedanz, J. A. (2007). Repeated interactive read-alouds in preschool and kindergarten. The Reading Teacher, 60(8), 742-751.

Mehan, H. (1979). Learning lessons: Social organization in the classroom. Cambridge, MA: Harvard University Press.

Mercer, N. (1994). Neo-Vygotskian theory and classroom education. In V. Steiner \& J. Maybin (Eds.). Language, literacy, and learning in educational practice (pp. 92109). Clevedon, England: Multilingual Matters.

Mercer, N. (2000). Words and minds: How we use language to think together. London, England, Routledge.

Mertler, C. A. (2009). Action research: Teachers as researchers in the classroom (2nd ed.). Thousand Oaks, CA: SAGE.

Merriam, S. B. (1998). Qualitative research and case study applications in education. San Francisco, CA: Jossey-Bass. 
Merriam, S. B. (2009). Qualitative research: A guide to design and implementation. San Francisco, CA: Jossey-Bass.

Meyer, L. A., Wardrop, J. L., Stahl, S. A., \& Linn, R. L. (1994). Effects of reading storybooks to children. The Journal of Educational Research, 88(2), 69-85.

Milburn, T. R., Girolametto, L., Weitzman, E., \& Greenberg, J. (2014). Enhancing preschool educators' ability to facilitate conversations during shared book reading. Journal of Early Childhood Literacy, 14(1), 105-140.

Miles, M. B., \& Huberman, A. M. (1994). Qualitative data analysis: An expanded sourcebook (2nd ed.). Thousand Oaks, CA: SAGE.

Mohr, K. A. J. (2006). Children's choices for recreational reading: A three-part investigation of selection preferences, rationales, and processes. Journal of Literacy Research, 38(1), 81-104. doi: 10.1207/s15548430j1r3801_4

Moller, A. C., Forbes-Jones, E., \& Hightower, A. D. (2008). Classroom age composition and developmental change in 70 urban preschool classrooms. Journal of Educational Psychology, 100(4), 741-753.

Morrow, L. M. (1997). Literacy development in the early years (3rd ed.). Boston, MA: Allyn \& Bacon.

Morrow, L. M. (2003). Motivating lifelong voluntary readers. In J. Flood, D. Lapp, J. Squire, \& J. Jensen (Eds.), Handbook of research on teaching the English language arts (2nd ed., pp. 857-867). Mahwah, N J: Erlbaum.

Morrow, L. M. (2007). Developing literacy in preschool. New York, NY: The Gilford Press.

Morrow, L. M., \& Smith, J. K. (1990). The effects of group size on interactive storybook 
reading. Reading Research Quarterly, 25, 213-231.

Moschovaki, E., \& Meadows, S. (2005). Young children's cognitive engagement during classroom book reading: Differences according to book, text genre, and story format. Early Childhood Research and Practice, 7(2), 51-65.

Mulyani, P. K. (2011). The effects of interactive read alouds on reading comprehension in a second-grade classroom. International Journal of Arts and Sciences, 4(21), 175199.

Nagy, W., \& Townsend, D. (2012). Words as tools: Learning academic vocabulary as language acquisition. Reading Research Quarterly, 47(1), 91-108.

National Association for the Education of Young Children. (2005/2011). Code of ethical conduct and statement of commitment: A position statement of the National Association for the Education of Young Children. Washington, DC: Authors.

National Association for the Education of Young Children. (2009). Developmentally appropriate practice in early childhood programs serving children from birth through age 8: A position statement of the National Association for the Education of Young Children. Washington, DC: Authors.

Nix, R. L., Bierman, K. L., Domitrovich, C. E., \& Sukhdeep, G. (2013). Promoting children's social-emotional skills in preschool can enhance academic and behavioral functioning in kindergarten: Findings from Head Start REDI. Early Education and Development, 24, 1000-1019.

Oakhill, J. V., Cain, K., \& Bryant, P. E. (2003). The dissociation of word reading and text comprehension: Evidence from component skills. Language and Cognitive Processes, 18(4), 443-468. 
Owocki, G. (2001). Make way for literacy!: Teaching the way young children learn. Portsmouth, NH: Heinemann.

Owocki, G., \& Goodman, Y. (2002). Kidwatching: Documenting children's literacy development. Portsmouth, NH: Heinemann.

Pantaleo, S. (2007). Interthinking: Young children using language to think collectively during interactive read-alouds. Early Childhood Education Journal, 34(6), 429447.

Pappas, C. C. (1991). Young children's strategies in learning the "book language" of information books. Discourse Processes, 14(2), 203-225.

Pappas, C. C. (1993). Is narrative "primary"? Some insights from kindergarteners' pretend readings of stories and information books. Journal of Reading Behaviour, 25, 97129.

Pappas, C. C. (2006). The information book genre: Its role in integrated science literacy research and practice. Reading Research Quarterly, 41(2), 226-250.

Pea, R. D. (2004). The social and technological dimensions of scaffolding and related theoretical concepts for learning, education, and human activity. The Journal of the Learning Sciences, 13(3), 423-451.

Pentimonti, J. M., Justice, L. M., Yeomans-Maldonado, G., McGinty, A. S., Slocum, L., \& O'Connell, A. (2017). Teachers' use of high- and low-support scaffolding strategies to differentiate language instruction in high-risk/economically disadvantaged settings. Journal of Early Intervention, 39(2), 125-146.

Pentimonti, J. M., Zucker, T. A., \& Justice, L. (2011). What are preschool teachers reading in their classrooms? Reading Psychology, 32(3), 197-236. 
Pentimonti, J. M., Zucker, T. A., Justice, L., \& Kaderavek, J. N. (2010). Information text use in preschool classroom read-alouds. The Reading Teacher, 63, 656-665.

Pianta, R. C., Burchinal, M., Jamil, F. M., Sabol, T., Grimm, K., Hamre, B. K., ... \& Howes, C. (2014). A cross-lag analysis of longitudinal associations between preschool teachers' instructional support identification skills and observed behavior. Early Childhood Research Quarterly, 29(2), 144-154.

Pianta, R. C., \& Stuhlman, M. W. (2004). Teacher-child relationships and children's success in the first years of school. School Psychology Review, 33(3), 444-458.

Piasta, S. B., \& Wagner, R. K. (2010). Developing early literacy skills: A meta-analysis of alphabet learning and instruction. Reading Research Quarterly, 45(1), 8-38.

Pollard-Durodola, S. D., Gonzalez, J. E., Simmons, D. C., Davis, M. J., Simmons, L., \& Nava-Walichowski, M. (2011). Using knowledge networks to develop preschoolers' content vocabulary. The Reading Teacher, 65(4), 265-274. http://dx.doi.org/10.1002/TRTR.01035

Pollard-Durodola, S. D., Gonzalez, J. E., Saenz, L., Soares, D., Resendez, N., Kwok, O., ...\& Zhu, L. (2016). The effects of content-related shared book reading on the language development of preschool dual language learners. Early Childhood Research Quarterly, 36(3), 106-121.

Price, L. H., Bradley, B. A., \& Smith, J. M. (2012). A comparison of preschool teachers' talk during storybook and information book read-alouds. Early Childhood Research Quarterly, 27(3), 426-440. 
Price, L. H., van Kleek, A., \& Huberty, C. J. (2009). Talk during book sharing between parents and preschool children: A comparison between storybook and expository book conditions. Reading Research Quarterly, 44(2), 171-194.

Purcell-Gates, V. (1988). Lexical and syntactic knowledge of written narrative held by well-read-to kindergarteners and second graders. Research in the Teaching of English, 22, 128-160.

Ramani, G. B. (2012). Influence of a playful, child-directed context on preschool children's peer cooperation. Merrill-Palmer Quarterly, 58(2), 159-190.

Read, S., Reutzel, D. R., \& Fawson, P. C. (2008). Do you want to know what I learned? Using informational trade books as models to teach text structure. Early Childhood Education Journal, 36(3), 213-219. doi: 10.1007/s10643-008-0273-0

Reese, D., \& Harris, V. J. (1997). "Look at this nest!”: The beauty and power of using informational books with young children. Early Child Development and Care, $127(1), 217-231$.

Reiser, B. J. (2004). Scaffolding complex learning: The mechanisms of structuring and problematizing student work. The Journal of the Learning Sciences, 13(3), 273304.

Reynolds, D. (2017). Interactional scaffolding for reading comprehension: A systematic review. Literacy Research: Theory, Method, and Practice, 66(1), 135-156.

Richardson, J. S. (2000). Read it aloud! Using literature in the secondary content classroom. Newark, DE: International Reading Association.

Richgels, D. J. (2002). Informational texts in kindergarten. The Reading Teacher, 55(6), 586-595. 
Roberts, T., \& Neal, H. (2004). Relationship among preschool English language learners’ oral proficiency in English, instructional experience, and literacy development. Contemporary Educational Psychology, 29(3), 283-311.

Rogoff, B. (1995). Observing sociocultural activity on three planes: Participatory appropriation, guided participation, and apprenticeship In J. V. Wertsch, P. del Rio, \& A. Alvarez (Eds.), Sociocultural studies of mind (pp. 139164). Cambridge, England: Cambridge University Press.

Rosenblatt, L. M. (1938/1983). Literature as Exploration $\left(4^{\text {th }}\right.$ ed.). New York, NY: Modern Language Association.

Rosenblatt, L. M. (1978). The reader the text the poem: The transactional theory of the literary work. Carbondale, IL: Southern Illinois Press.

Rosenblatt, L. M. (1993). Evocation and response. In K. E. Holland, R. A. Hungerford, \& S. B. Ernst (Eds.), Journeying: Children responding to literature (pp. 1-23). Portsmouth, NH: Heinemann.

Rosenblatt, L. M. (1998). Readers, texts, authors. Transactions of the Charles S. Peirce Society, 34(4), 885-921.

Saldaña, J. (2016). The coding manual for qualitative researchers. Los Angeles, CA: SAGE.

Sanacore, J., \& Palumbo, A. (2009). Understanding the fourth-grade slump: Our point of view. The Educational Forum, 73(1), 67-74.

Schlechter, C. R., Rosenkranz, R. R., Fees, B. S., \& Dzewaltowski, D. A. (2017). Preschool daily patterns of physical activity driven by location and social context. Journal of School Health, 87(3), 194-199. 
Schreiber, L. M., \& Valle, B. E. (2013). Social constructivist teaching strategies in the small group classroom. Small Group Research, 44(4), 395-411.

Serafini, F. (2014). Reading the visual: An introduction to teaching multimodal literacy. New York, NY: Teachers College Press.

Sharpe, T. (2001). Scaffolding in action: Snapshots from the classroom. In J. Hammond (Ed.). Scaffolding: Teaching and learning in language and literacy education. Newtown, NSW, Australia: Primary English Teaching Association.

Shaw, C., Louca-Mai, B., \& Davey, C. (2011). Guidelines for research with children and young people. London, England: National Children's Bureau Research Centre.

Shepard, L. A. (2005). Linking formative assessment to scaffolding. Educational Leadership, 63(3), 66-70.

Shine, S., \& Roser, N. L. (1999). The role of genre in preschoolers' response to picture books. Research in the Teaching of English, 34(2), 197-254.

Simonsen, S. (2004). Identifying and teaching text structures in content area classrooms. In D. Lapp, J. Flood, \& N. Farnan (Eds.), Content area reading and learning: Instructional strategies. Mahwah, NJ: Erlbaum.

Sin Goh, S., Yamauchi, L. A., \& Ratliffe, K. T. (2012). Educators' perspectives on instructional conversations in preschool settings. Early Childhood Education Journal, 40, 305-314.

Sipe, L. R. (2008). Storytime: Young children's literary understanding in the classroom. New York, NY: Teacher's College Press.

Smidt, S. (2012). Reading the world: What young children learn from literature. Stoke on Trent, England: Trentham. 
Smith, F. (1978). Reading without nonsense. New York, NY: Teachers College Press.

Smolkin, L., \& Donovan, C. (2001). The context of comprehension: The information book read aloud, comprehension acquisition, and comprehension instruction in a firstgrade classroom. The Elementary School Journal, 102(2), 97-122.

Stake, R. E. (1995). The art of case study. Thousand Oaks, CA: SAGE.

Stipek, D., \& Byler, P. (2004). The early childhood classroom observation measure. Early Childhood Research Quarterly, 19, 375-397.

Strauss A. L., \& Corbin, J. M. (1998). Basics of qualitative research: Techniques and procedures for developing grounded theory (2nd ed.). Thousand Oaks, CA: SAGE.

Streb, J., Keis, O., Lau, M., Hille, K., Spitzer, M., \& Sosic-Vasic, Z. (2015). Emotional engagement in kindergarten and school children: A self-determination theory perspective. Trends in Neuroscience and Education, 4, 102-107.

Suggate, S. P., Lenhard, W., Neudecker, E., \& Schneider, W. (2013). Incidental vocabulary acquisition from stories: Second and fourth graders learn more from listening than reading. First Language, 33(6), 551-571.

Tarim, K. (2009). The effects of cooperative learning on preschoolers' mathematics problem-solving. Educational Studies in Mathematics, 72(3), 325-340.

Tarim, K. (2015). Effects of cooperative group work activities on pre-school children's pattern recognition skills. Educational Sciences: Theory \& Practice, 15(6), 15971604.

Taylor, W. L. (1953). Cloze procedure: A new tool for measuring readability. Journalism Quarterly, 30, 415-433. 
Teale, W. H. (1986). Home background and literacy development. In W. H. Teale \& E. Sulzby (Eds.), Emergent literacy: Writing and reading (pp. 173-202). Westport, CT: Ablex.

Teale, W. H., \& Sulzby, E. (1989). Emergent literacy: New perspectives. In D. S. Strickland \& L. M. Morrow (Eds.), Emerging literacy: Young children learn to read and write (pp. 1-15). Newark, DE: International Reading Association.

Thiel, J. J. (2015). Vibrant matter: The intra-active role of objects in the construction of young children's literacies. Literacy Research: Theory, Method, and Practice, 64(1), 112-131.

Tomlinson, C. A., \& Imbeau, M. B. (2010). Leading and managing a differentiated classroom. Alexandria, VA: ASCD.

Tompkins, G. E. (2009). Language arts: Patterns of practice (7th ed.). Upper Saddle River, NJ: Pearson.

Tompkins, V., Guo, Y., \& Justice, L. M. (2012). Inference generation, story comprehension, and language skills in the preschool years. Reading and Writing, 26, 403-429.

Tompkins, V., Zucker, T. A., Justice, L. M., \& Binici, S. (2013). Inferential talk during teacher-child interactions in small-group play. Early Childhood Research Quarterly, 28(2), 424-436.

Torr, J., \& Clugston, L. (1999). A comparison between informational and narrative picture books as a context for reasoning between caregivers and 4-year-old children. Early Child Development and Care, 159(1), 25-41. doi: 10.1080/0300443991590104 
Tower, C. (2002). "It's a snake, you guys!”: The power of text characteristics on children's responses to information books. Research in the Teaching of English, 37(1), 55-88. Trelease, J. (1979). The read-aloud handbook. New York, NY: Penguin.

Turnbull, K. P., Anthony, A. B., Justice, L., \& Bowles, R. (2009). Preschoolers' exposure to language stimulation in classrooms serving at-risk children: The contribution of group size and activity context. Early Education and Development, 20(1), 53-79.

Tyson, L. (2006). Critical theory today: A user-friendly guide (2nd ed.). New York, NY: Routledge.

Urlacher, S., Wolery, M., \& Ledford, J. R. (2016). Peer modeling of commenting during small group direct instruction for academic behaviors. Journal of Early Intervention, 38(1), 24-40.

van de Pol, J., Volman, M., \& Beishuizen, J. (2010). Scaffolding in student-teacher interaction: A decade of research. Educational Psychology Review, 22(3), 271-296.

van der Veen, C., de Mey, L., van Kruistum, C., \& van Oers, B. (2016). The effect of productive classroom talk and metacommunication on young children's oral communicative competence and subject matter knowledge: An intervention study in early childhood education. Learning and Instruction, 48, 14-22.

van Kleek, A. (2008). Providing preschool foundations for later reading comprehension: The importance of and ideas for targeting inferencing and storybook-sharing interventions. Psychology in the Schools, 45(7), 627-643.

van Lier, L. (1996). Interaction in the language curriculum: Awareness, autonomy, and authenticity. London, England: Longman. 
Van Maanan, J. (1988). Tales of the field: On writing ethnography. Chicago, IL: University of Chicago Press.

Venezky, R. L. (2000). The origins of the present-day chasm between adult literacy needs and school literacy instruction. Scientific Studies of Reading, 4(1), 19-39.

Vygotsky, L. S. (1930/1978). Mind in society. Cambridge, MA: Harvard University Press. Vygotsky, L. S. (1981). The genesis of higher mental functions. In J. Wertsch (Ed.), The concept of activity in Soviet psychology (pp. 144-188). White Plains, NY: Sharpe.

Vygotsky, L. S. (1986). Thought and language. In A. Kozulin (Ed.). Cambridge, MA: The MIT Press.

Vygotsky, L. S. (1998). The problem of age. (M. Hall, Trans.). In R. W. Rieber (Ed.), The collected works of L. S. Vygotsky: Child psychology (Vol. 5, pp. 187-205). New York, NY: Plenum Press.

Walters, G. (Producer), \& Stanton, A. (Director). (2003). Finding Nemo [Motion picture]. USA: Pixar Animation Studios.

Wasik, B. (2008). When fewer is more: Small groups in early childhood classrooms. Early Childhood Education Journal, 35, 515-521.

Webster, P. S. (2009). Exploring the literature of fact. The Reading Teacher, 62(8), 662671. doi: 10.1598/RT.62.8.4

Wells, G. (1986). The meaning makers: Children learning language and using language to learn. London, England: Hodder \& Stoughton.

Wells, G. (1990). Talk about text: Where literacy is learned and taught. Curriculum Inquiry, 20(4), 369-405. 
Wells, G. (1999). Dialogic inquiry: Towards a sociocultural practice and theory of education. Cambridge, MA: Cambridge University Press.

Whaley, K. L., \& Kantor, R. (1992). Mixed-age groupings in infant/toddler childcare: Enhancing developmental processes. Child and Youth Care Forum, 21, 369-384.

White, M. D., \& Marsh, E. E. (2006). Content analysis: A flexible methodology. Library Trends, 55(1), 22-45.

Whitehurst, G. J., \& Lonigan, C. J. (1998). Child development and emergent literacy. Child Development, 69, 848-872.

Wilson, H. K., Pianta, R. C., \& Stuhlman, M. (2007). Typical classroom experiences in first grade: The role of classroom climate and functional risk in the development of social competencies. The Elementary School Journal, 108(2), 81-96.

Wiseman, A. (2011). Interactive read-alouds: Teachers and students constructing knowledge and literacy together. Early Childhood Education Journal, 38, 431-438.

Wolf, S. A., Carey, A. A., \& Mieras, E. L. (1996). "'What is this literachurch stuff anyway?', Preservice teachers' growth in understanding children's literary response. Reading Research Quarterly, 31(2), 130-157.

Wood, D., Bruner, J. S., \& Ross, G. (1976). The role of tutoring in problem solving. Journal of Child Psychology and Psychiatry, 17, 89-100.

Wright, T. S. (2014). From potential to reality: Content-rich vocabulary and informational text. The Reading Teacher, 67(5), 359-367.

Wyatt, T., \& Chapman-DeSousa, B. (2017). Teaching as interaction: Challenges in transitioning teachers' instruction to small groups. Early Childhood Education Journal, 45, 61-70. doi: 10.1007/s10643-015-0758-6 
Yamauchi, L. A., Im, S., \& Mark, L. (2013). The influence of professional development on educators' instructional conversations in preschool classrooms. Journal of Early Childhood Teacher Education, 34(2), 140-153. doi:10.1080/10901027.2013.787476

Yopp, R. H., \& Yopp, H. K. (2006). Informational texts as read-alouds at school and home. Journal of Literacy Research, 38(1), 37-51

Yopp, R. H., \& Yopp, H. K. (2012). Young children's limited and narrow exposure to informational text. The Reading Teacher, 65(7), 480-490.

Youdale, L. (2010). Planning, teaching and assessing mathematics learning for real! Australian Primary Mathematics Classroom, 15(4), 29-32.

Young, T. A., Moss, B., \& Cornwell, L. (2007). The classroom library: A place for nonfiction, nonfiction in its place. Reading Horizons, 48(1), 1-18.

Zhang, Y., \& Wildemuth, B. M. (2005). Qualitative analysis of content. In B. Wildemuth (Ed.), Applications of social research methods to questions in information and library science (pp.308-319). Westport, CT: Libraries Unlimited.

Zimmerman, F. J., Gilkerson, J., Richards, J. A., Christakis, D. A., Xu, D., Gray, S., \& Yapanel, U. (2009). Teaching by listening: The importance of adult-child conversations to language development. Pediatrics, 124, 342-349.

Zucker, T. A., Cabell, S. Q., Justice, L. M., Pentimonti, J. M., \& Kaderavek, J. N. (2013). The role of frequent, interactive prekindergarten shared reading in the longitudinal development of language and literacy skills. Developmental Psychology, 49(8), 1425-1439. 
Zucker, T. A., Justice, L. M., Piasta, S. B., \& Kaderavek, J. N. (2010). Preschool teachers' literal and inferential questions and children's responses during whole-class shared reading. Early Childhood Research Quarterly, 25(1), 65-83.

Zurek, A., Torquati, J., \& Acar, I. (2014). Scaffolding as a tool for environmental education in early childhood. International Journal of Early Childhood Environmental Education, 2(1), 27-57. 


\section{Appendix A}

\section{Letter of Support From the Laboratory School}

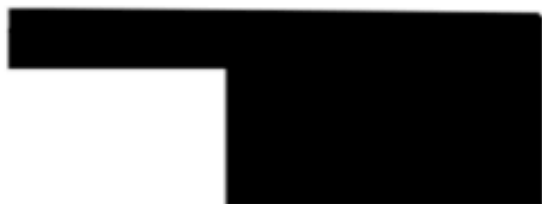

Ariel Robinson

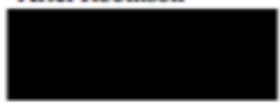

Ms. Robinson:

We are pleased to provide a letter of support for your research proposal exploring the ways in which teachers and preschoolers read fiction and nonfiction stories together in small groups in the preschool classroom. We approve your request to both recruit participants from the and to collect data onsite, through discussions and interactions with both teachers and children. Your goal of learning more about how nonfiction is included in the early childhood classroom is consistent with the mission of the lab and we are excited you have selected our program to conduct your research.

The

includes three preschool classrooms with 60 preschool-aged children. The staff of the lab will be happy to work with you to facilitate the recruitment of participants and provide any assistance we can with conducting your research project. Depending on your research needs, we have specialized equipment, observation booths, and an assessment room that we can offer to support your research program. Be certain that your IRB-approved parental consent form contains all details of the project procedures, including intent to audio or video record data collection sessions with children and information about how you will interact with the children (e.g., interview topies and questions). Please also provide the verbal assent process and procedures for incentives, should you use them, ahead of time. We will work with you to make sure these things align with our policies prior to commencement of data collection.

We are excited about this project and that you have selected the lab as a place to conduct your research!

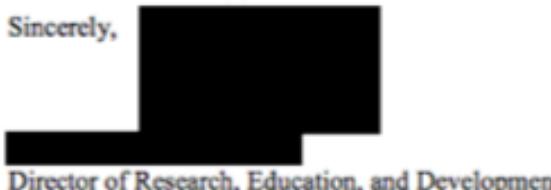

Director of Research, Education, and Development

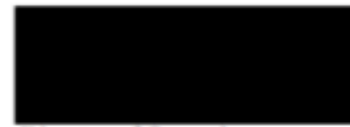

Director of Operations 
Appendix B

Parent Informed Consent Letter

Dear Parents/Guardians:

My name is Ariel Robinson and I am a doctoral student in the College of Education at the University of Missouri-Columbia. I study young children's literacy development. This fall, I am inquiring into ways preschool teachers and children read books together. The purpose of this study is to learn about preschool teachers' professional experiences with reading fiction and nonfiction to their students, how preschool teachers plan curriculum with fiction and nonfiction books, how preschool teachers and children read fiction and nonfiction books together in small groups, and ways they participate in book-related activities. The title of the study is "Reading and Responding to High Quality Fiction and Nonfiction in Preschool."

Data collection will take place in the classroom one to two hours per day, four to five days per week, for seven weeks during small group reading and reading-related activities. I will be an observer in the classroom as teachers and children participate in small group reading and activities. Children will remain in the classroom with their teachers and classmates as they participate in normal classroom activities. This study could potentially benefit children because they might be exposed to new stories, content, and vocabulary. They might enjoy reading and participating in activities with their teachers and classmates. There is minimal risk to the children because there will be little disruption to their regular daily activities.

Data collection will include audio recording, video recording, and photography. I will audio record and video record small group reading and reading-related activities. At times, I will briefly interview children about these reading experiences and activities and photograph them and their work. To protect your child's privacy, I will not use participants' names or the site of the study in any reports of the research; I will use fictitious names only. Your child's part in the research is voluntary and if you choose not to have your child participate, he/she will not be penalized in any way. Children whose parents/guardians choose to not have them participate will still engage in normal classroom activities with their teachers and classmates; I will not use their information in my study. Participants may withdraw from the study any time they wish.

I would appreciate your signing the consent form below so that I may use the information that I learn from my research to share with educators and scholars. If you have questions or concerns about the study, please contact me. You may also contact my advisor, If you have questions about your child's rights as a human subject research participant, please contact the Institutional Review Board at

Sincerely, Ariel Robinson

Please check the appropriate line to indicate that you have read and understand this letter: I give my permission to use audio recordings of my child in the research project. I give my permission to use video recordings of my child in the research project. I give my permission to use photographs of my child in the research project. I give my permission to use photographs of my child's work in the research project. I would like more information before giving consent. Please call me at I do not give consent for my child to participate.

Child's Name:

Signed:

(
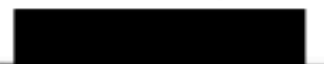
Appendix C

Classroom Configuration

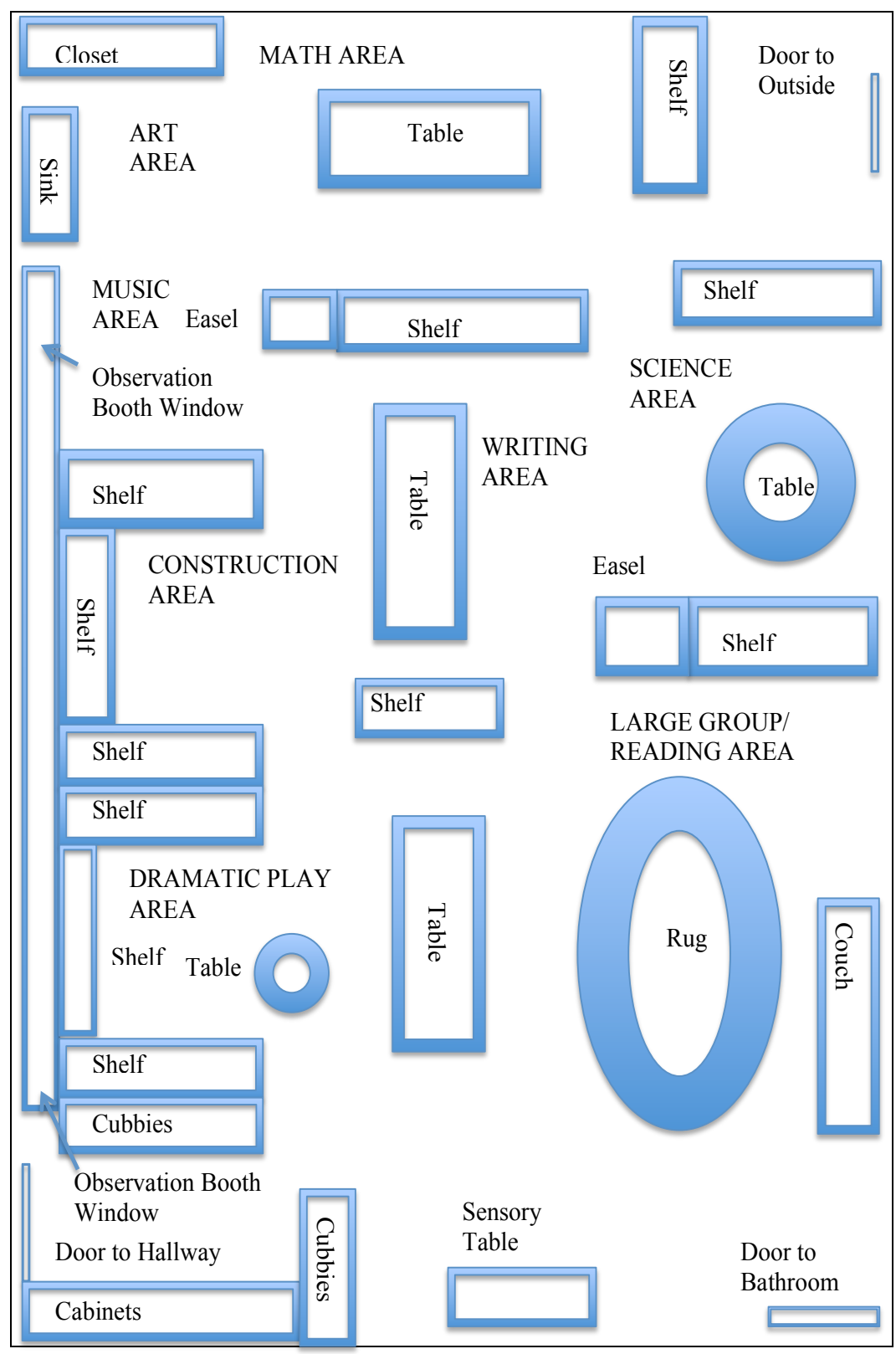


Appendix D

Teacher Read Aloud Books

Read Aloud Books

Read Aloud Book

The Listening Walk, by Paul Showers, illustrated by Aliki $\mathrm{F} / \mathrm{N}$

${ }^{C}$ The Magic School Bus: Hops Home, by Patricia Relf, illustrated by Nancy Stevenson

Mouse Loves School, by Lauren Thompson, illustrated by Buket Erdogan

The Magic School Bus: Inside a Beehive, by Joanna Cole, illustrated by Bruce F Degen

${ }^{C}$ Dewey: There's a Cat in the Library, by Vicki Myron and Bret Witter, illustrated by Steve James

*Magic School Bus: On the Ocean Floor, by Joanna Cole, illustrated by

Bruce Degen

${ }^{C}$ The Berenstain Bears and the Spooky Old Tree, by Stan and Jan Berenstain F

Whoever You Are, by Mem Fox, illustrated by Leslie Staub F

Lucy's Picture, by Nicola Moon, illustrated by Alex Ayliffe F

Music Everywhere!, by Maya Ajmera, Elise Hofer Derstine, and Cynthia Pon N

*A Listen to World Music, by Jennifer Reed N N

Patterns at the Museum, by Tracey Steffora N N

Spiders!, by Christopher Nicholas, illustrated by Mike Maydak N N

One Tiny Turtle, by Nicola Davies, illustrated by Jane Chapman N

Frogs, by Little Golden Books $\quad$ N

*Bears, by Melvin and Gilda Berger $\quad \mathrm{N}$

What We Wear: Dressing Up Around the World, by Maya Ajmera, Elise N Hofer Derstine, and Cynthia Pon

Note. ${ }^{C}$ Denotes that a child selected the book. * Denotes the story was read twice. $\mathrm{F}=$ Fiction, $\mathrm{N}=$ Nonfiction. 
Appendix E

Data Sources Table

\section{Data Sources}

\begin{tabular}{|c|c|c|c|c|c|c|}
\hline $\begin{array}{l}\text { Data } \\
\text { Sources }\end{array}$ & Week 1 & Week 2 & Week 3 & Week 4 & Week 5 & Week 6 \\
\hline $\begin{array}{l}\text { Teacher } \\
\text { Interviews }\end{array}$ & & $X$ & & $X$ & & $\mathrm{X}$ \\
\hline $\begin{array}{l}\text { Observations } \\
\text { of Read } \\
\text { Aloud } \\
\text { Sessions }\end{array}$ & $X$ & $X$ & $X$ & $X$ & $X$ & $X$ \\
\hline $\begin{array}{l}\text { Observation } \\
\text { of Teacher } \\
\text { Planning } \\
\text { Sessions }\end{array}$ & $\mathrm{X}$ & $X$ & & & $X$ & \\
\hline $\begin{array}{l}\text { Child } \\
\text { Interviews }\end{array}$ & $X$ & $X$ & $X$ & $X$ & $\mathrm{X}$ & $X$ \\
\hline $\begin{array}{l}\text { Photos of } \\
\text { Child- } \\
\text { Created } \\
\text { Artifacts }\end{array}$ & $X$ & $\mathrm{X}$ & $X$ & $X$ & $X$ & $X$ \\
\hline $\begin{array}{l}\text { Photocopies } \\
\text { of Teachers' } \\
\text { Weekly } \\
\text { Lessons }\end{array}$ & $X$ & X & $X$ & $X$ & $X$ & $X$ \\
\hline $\begin{array}{l}\text { Logs: } \\
\text { Analytic } \\
\text { Memos and } \\
\text { Reflections }\end{array}$ & $X$ & $\mathrm{X}$ & $X$ & $X$ & $X$ & $X$ \\
\hline
\end{tabular}




\title{
Teacher Interview 1:
}

\author{
Appendix F \\ Sample of Teacher Interview Protocols
}

1. In your professional experiences, what, if any, are the benefits of reading to children in small groups? Challenges?

2. In your professional experiences, what, if any, are the benefits of reading fiction to children? Nonfiction?

3. In your professional experiences, what, if any, are the challenges of reading fiction to children? Nonfiction?

4. Have you ever had any professional development on reading to children? If yes, please describe it.

5. How would you describe your reading style when reading aloud to your students? Do you think it is different or the same when reading fiction and nonfiction? How is it different? The same?

6. Does your reading style differ or stay the same according to group size (one-onone, small group, whole group)? If yes, how?

7. What instructional strategies, if any, do you use when reading fiction to children in small groups?

8. What instructional strategies, if any, do you use when reading nonfiction to children in small groups?

9. Do you involve children while you read (i.e., encourage participation)? If yes, how?

10. What, if any, are the benefits of involving children as you read? Challenges?

11. Can you think of a time a child/children gave a remarkable or memorable response to fiction during reading? If yes, what made it remarkable or memorable?

12. Can you think of a time a child/children gave a remarkable or memorable response to nonfiction during reading? If yes, what made it remarkable or memorable?

13. Do you respond to children's participation during reading (e.g., questions, comments, nonverbal response)? If yes, how?

14. How do you manage your group during small group reading (i.e., seating/physical arrangement, talk, movement, etc.)? What are your reasons?

15. Do you assess children as you read with them in small groups? If yes, how? What do you learn about the child? Does it influence your curriculum design? If yes, how?

16. What, if anything, do you look for in a book when choosing it for small group read-aloud? Classroom library? Other places in the classroom?

17. How do you plan response activities (i.e., responsive plans)?

18. What instructional strategies, if any, do you use during response activities?

19. Do you encourage children's participation in response activities? If yes, how?

20. Do you assess children's work during response activities (i.e., observe their processes, evaluate things they produce)? If yes, how? What do you learn about the child? Does it influence your curriculum design? If yes, how?

21. Is there anything else you think I should know at this time? 
Appendix G

Sample of Weekly Lesson Plans

C Animal Jobs (kenes wint

Weekly Curriculum Plan Week of October 17-21

\begin{tabular}{|c|c|c|c|c|c|}
\hline & Monday 17 & Tuesday & Wednesday 19 & Thursday 20 & Friday \\
\hline $\begin{array}{l}\text { Large groin } \\
\text { Morning Meeting } \\
\text { Queation of } \\
\text { the day }\end{array}$ & $\begin{array}{l}\text { Do animals } \\
\text { learn? How? }\end{array}$ & $\begin{array}{c}\text { How can } \\
\text { animals help } \\
\text { peaple? }\end{array}$ & $\begin{array}{l}\text { What jobs } \\
\text { do animal: } \\
\text { help with? }\end{array}$ & $\begin{array}{l}\text { How do } \\
\text { onimals help } \\
\text { if thore is on } \\
\text { orergena? }\end{array}$ & $\begin{array}{l}\text { What animals } \\
\text { will you see } \\
\text { in the parade? }\end{array}$ \\
\hline $\begin{array}{c}\text { Garden } \\
\text { Time/Gross Motor }\end{array}$ & $\begin{array}{l}\text { Look for ants, } \\
\text { see if can get } \\
\text { ant to maxe thraing } \\
\text { a stick maze }\end{array}$ & $\begin{array}{l}\text { Loole for onirnds } \\
\text { that relp in } \\
\text { the gorden } \\
\text { cmalle }\end{array}$ & $\begin{array}{l}\text { Find animal doing } \\
\text { a jib-drow } \\
\text { picture }\end{array}$ & $\begin{array}{c}\text { Practice fice. } \\
\text { Drill, tornads } \\
\text { drill }\end{array}$ & $\begin{array}{l}\text { Jim Day } \\
\text { (gaiden) }\end{array}$ \\
\hline $\begin{array}{l}\text { Small Group } \\
(A M)\end{array}$ & $\begin{array}{l}\text { The children show } \\
\text { what they have } \\
\text { learned about senvice } \\
\text { doass by drowing. }\end{array}$ & $\begin{array}{l}\text { The chibra will } \\
\text { dis cuss bees } t \\
\text { the job bees do as } \\
\text { they mate a herey } \\
\text { (d) cake }\end{array}$ & 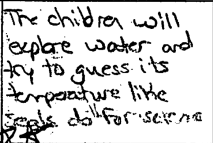 & $\begin{array}{l}\text { The children will } \\
\text { learn abeut circus } \\
\text { animals and deeorate } \\
\text { their own. }\end{array}$ & $\begin{array}{l}\text { The chidred is ill } \\
\text { ask a puppy traines } \\
\text { about how her puppies } \\
\text { leosn to help people. }\end{array}$ \\
\hline Music/Movement & & $\begin{array}{l}\text { mave like an } \\
\text { animal }\end{array}$ & (D) & $\begin{array}{l}\text { preterd to be } \\
\text { orergency dogt } \\
\text { Find doll }\end{array}$ & \\
\hline $\begin{array}{l}\text { Small Group Q } \\
(P M)\end{array}$ & $\begin{array}{l}\text { The chibren will } \\
\text { explore has mice } \\
\text { con learn by crootis } \\
\text { block masies for } \\
\text { the Classrom mice }\end{array}$ & $\begin{array}{l}\text { The children will } \\
\text { pretad to be } \\
\text { seeing eye mogs to } \\
\text { gride iheir frods } \\
\text { trragh a maze. }\end{array}$ & $\begin{array}{l}\text { CLOSE } \\
\text { Early }\end{array}$ & $\begin{array}{l}\text { The children will } \\
\text { kern about dogs } \\
\text { whohelp in } \\
\text { energensics }\end{array}$ & $\begin{array}{l}\text { (school) } \\
\text { parade! }\end{array}$ \\
\hline $\begin{array}{l}\text { Family } \\
\text { Involvement }\end{array}$ & & & 4 prn & & $($ cihcol) \\
\hline
\end{tabular}

study: Animals (Jobs) 
Appendix $\mathrm{H}$

Daily Schedule

\section{- DALY SCHEDULE \\ 2016-2017}

\begin{tabular}{|c|c|c|}
\hline $7: 30-8: 45 a m$ & Arrival / Free Play / Outside & \\
\hline $8: 45-9: 00 \mathrm{am}$ & Morning Meeting & \\
\hline $9: 00-9: 30 \mathrm{am}$ & Breakfast & \\
\hline $9: 30-10: 30 \mathrm{am}$ & Garden /Outside Gross Motor & \\
\hline $10: 30-10: 45$ am & Read Aloud & \\
\hline $10: 45-11: 45 \mathrm{am}$ & Choice Time / Small Grou & \\
\hline $11: 45-12: 00 \mathrm{pm}$ & Outside & \\
\hline $12: 00-12: 30 \mathrm{pm}$ & Lunch & \\
\hline $12: 30-1: 00 \mathrm{pm}$ & Bathroom, Stories, Transition to Nap & $\begin{array}{l}\text { teachess } \\
\text { do thic } \\
\text { actisitics }\end{array}$ \\
\hline $1: 00-2: 30 \mathrm{pm}$ & Nap / Quiet Time & \\
\hline $2: 30-3: 30 \mathrm{pm}$ & Outside & \\
\hline $3: 30-4: 00 \mathrm{pm}$ & Open Snack & \\
\hline $4: 00-4: 15 \mathrm{pm}$ & Afternoon Meeting & \\
\hline $4: 15-5: 15 p m$ & Choice Time & \\
\hline $5: 15-5: 30 p m$ & Read Aloud & \\
\hline
\end{tabular}




\section{Appendix I \\ List of A Priori Child Interview Questions}

\section{After Reading in Small Groups:}

Script: May I ask you a few questions about the book you just read?

Tell me about the book you read.

What did you like about it?

After Participating in Reading-Related Response Activities:

Script: May I ask you a few questions about your work?

Tell me about your work.

What is it?

What does it do?

How do you know about that?

How did you learn about that?

What do you like about it?

\section{Statements I will say:}

That is interesting.

Thank you for sharing. 


\section{Appendix J}

Sample of Coded Log: Analytic Memo and Reflection

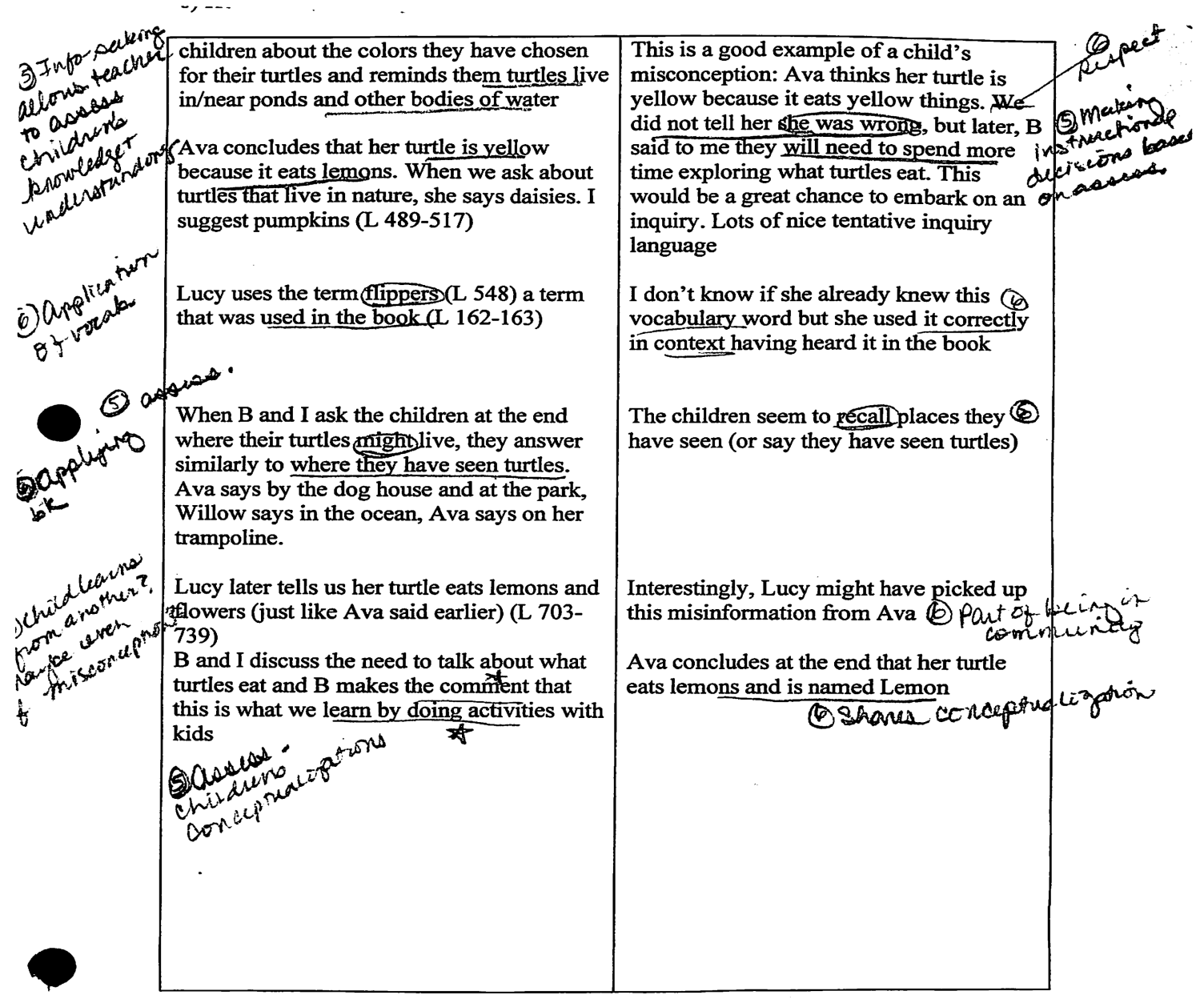




\section{Appendix K \\ Sample of Coded Teacher Interview}

Me: Does it influence your curriculum design?

M: Yes

Me: How?

M: Well we try to make certain that..with our curr-with our curriculum design, we use Creative Curriculam, when we pick a topic of study we watch what the children are interested-in And for that, we pick books that are based around that and we try really hard to make certain that we've picked books that have lots of pictures for our beginners and some words that are easy to read for our ones that are at the other end of the spectrum.

Me: So it helps you differentiate to for the different learning needsin your-

M: Yes

Me: Room. Thank you. Well you, you might have already alluded to this too. What, if anything, do you look for in a book when choosing it for small group reading aloud, in your classroom library, and other places in the classroom?

M: I try to make sure we have books. Nonfiction and fiction books. Both

Me: Mm-hmm

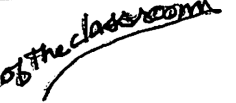

M (14:40): On thame-on the topic of study. Not every book is going to be on the topic of study but I try to have several on the topic of study. I try to make sure there are books in each areag Um, some topics are easier than others to come up with a book for say block play. Sometimes the block area books just have to be on an area of construction whether or not you're talking about construction. Again, there's not a struggy lot of choice. The books I put in the areas I try to stick true.

Me: That's interesting. Very interesting. So you choose nonfiction for those different parts of your classroom.

$$
\text { pequerples }
$$

M: Yes. Because I want to give them an idea of Why What we're doing nose areas. Those areas are not just for pretend play. Except for dramatic play I guess. And block to some extent. But I want them to understand that there are real world things that they're learning in these areas.

Me: Hmm.

M: And I'm sorry I stick with the rue That's what I use-that's the language I use-

Me: No, that's fine. That's absolutely fine. And I think that's um, that's important because it's something they can understand. child-friendly langurage 


\section{Appendix L \\ Sample of Coded Read Aloud Session}

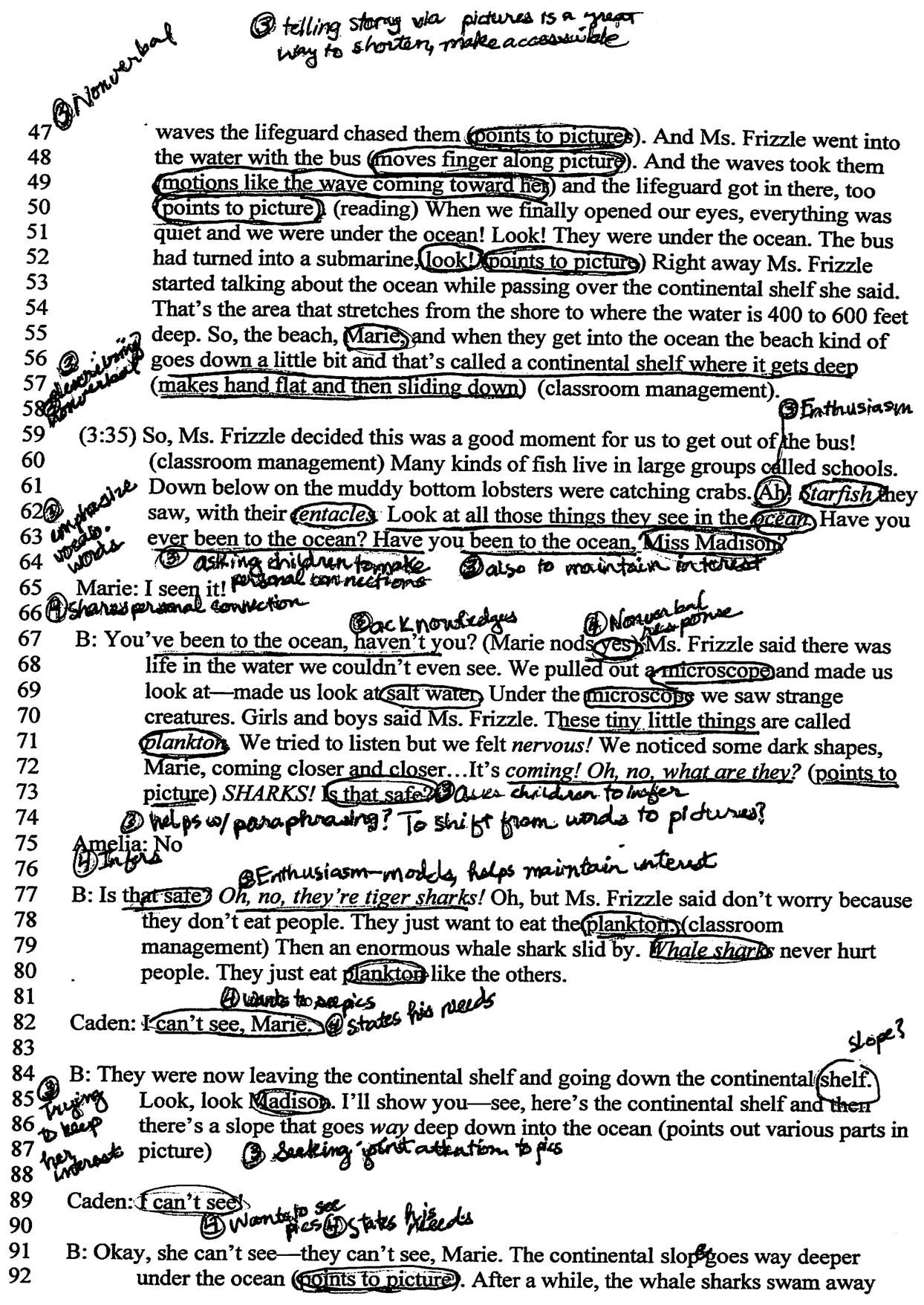


Appendix M

The Creative Curriculum ${ }^{\mathrm{TM}}$ Overview

- Research-based curriculum

- Comprehensive Curriculum

$\circ$ Guide to The Creative Curriculum ${ }^{\mathrm{TM}}$

- Six-volume Foundation ${ }^{\mathrm{TM}}$ set to establish a high-quality preschool program

- Six Teaching Guides ${ }^{\mathrm{TM}}$ for daily support

$\circ$ Daily Intentional Teaching Cards ${ }^{\mathrm{TM}}$ with scripted directions for interacting with children throughout the day

- Children's Book Collection' ${ }^{\mathrm{TM}}$

- Book Discussion Cards ${ }^{\mathrm{TM}}$

- Mighty Minutes ${ }^{\mathrm{TM}}$ cards (songs and games)

- Resources and guidance for making connections with families

- Resources and guidance for supporting English and dual-language learners

- Expanded Daily Resources ${ }^{\mathrm{TM}}$ for project-based learning

- Supplemental Teaching Guides ${ }^{\mathrm{TM}}$

- Digital Curriculum Resources ${ }^{\mathrm{TM}}$

- GOLD ${ }^{\mathrm{TM}}$ assessment system

- In-person educator training for The Creative Curriculum ${ }^{\mathrm{TM}}$ and GOLD ${ }^{\mathrm{TM}}$

- Online professional development courses

- Professional development books

- Coaching solutions to implement The Creative Curriculum ${ }^{\mathrm{TM}}$ and GOLD ${ }^{\mathrm{TM}}$ with fidelity

- Online Child Development Associate credentialing preparation (eCDA ${ }^{\mathrm{TM}}$ )

- Professional Development Network ${ }^{\mathrm{TM}}$ for contracted trainers

For details, visit The Creative Curriculum ${ }^{\mathrm{TM}}$ website at https://teachingstrategies.com 


\begin{tabular}{|c|c|c|}
\hline $\begin{array}{l}\text { Type(s) of } \\
\text { Scaffolding }\end{array}$ & Citation(s) & $\begin{array}{l}\text { Example(s) From Reading } \\
\text { Episodes }\end{array}$ \\
\hline $\begin{array}{l}\text { Prompting/ } \\
\text { Eliciting/ } \\
\text { Drawing } \\
\text { attention to } \\
\text { important } \\
\text { information } \\
\text { (look, label) }\end{array}$ & $\begin{array}{l}\text { Clark \& Graves, 2005; Cole, } \\
\text { 2006; Zurek, Torquati, \& } \\
\text { Acar, } 2014\end{array}$ & $\begin{array}{l}\text { Prompting children to attend to } \\
\text { objects, pictures, visual features } \\
\text { (maps) }\end{array}$ \\
\hline $\begin{array}{l}\text { Using } \\
\text { metacognition }\end{array}$ & Azevedo \& Hadwin, 2005 & $\begin{array}{l}\text { Prompting children to monitor for } \\
\text { comprehension, check the } \\
\text { accuracy of information }\end{array}$ \\
\hline $\begin{array}{l}\text { Making } \\
\text { meaning from } \\
\text { text (direct } \\
\text { teaching of } \\
\text { comprehension } \\
\text { strategies) }\end{array}$ & $\begin{array}{l}\text { Clark \& Graves, 2005; } \\
\text { Maloch, } 2008\end{array}$ & $\begin{array}{l}\text { Prompting children to personalize, } \\
\text { make intertextual times }\end{array}$ \\
\hline Using gesture & Cole, 2006 & $\begin{array}{l}\text { Prompting children to look at } \\
\text { picture by pointing }\end{array}$ \\
\hline $\begin{array}{l}\text { Using } \\
\text { reasoning/ } \\
\text { evaluation }\end{array}$ & $\begin{array}{l}\text { Zurek, Torquati, \& Acar, } \\
2014\end{array}$ & $\begin{array}{l}\text { Prompting children to recognize } \\
\text { similarities and differences }\end{array}$ \\
\hline Questioning & $\begin{array}{l}\text { Clark \& Graves, 2005; Ioney } \\
\text { \& Carter, 2007; Zurek, } \\
\text { Torquati, \& Acar, } 2014\end{array}$ & Asking questions about the text \\
\hline $\begin{array}{l}\text { Vocabulary } \\
\text { development/ } \\
\text { Denomination }\end{array}$ & $\begin{array}{l}\text { Clark \& Graves, 2005; Zurek, } \\
\text { Torquati, \& Acar, } 2014\end{array}$ & $\begin{array}{l}\text { Introducing and/or defining } \\
\text { technical terms }\end{array}$ \\
\hline $\begin{array}{l}\text { Contingent on } \\
\text { children's } \\
\text { learning and } \\
\text { developmental } \\
\text { needs }\end{array}$ & Hsin \& Hsin-Kai, 2011 & $\begin{array}{l}\text { Differentiating for individual } \\
\text { children }\end{array}$ \\
\hline
\end{tabular}




\begin{tabular}{|c|c|c|}
\hline $\begin{array}{l}\text { Clarifying } \\
\text { misconceptions/ } \\
\text { Corrective } \\
\text { feedback }\end{array}$ & $\begin{array}{l}\text { Zurek, Torquati, \& Acar, } \\
2014\end{array}$ & $\begin{array}{l}\text { Clarifying children's } \\
\text { misconceptions }\end{array}$ \\
\hline $\begin{array}{l}\text { Adjusting } \\
\text { feedback } \\
\text { according to } \\
\text { performance }\end{array}$ & La Joie, 2005 & $\begin{array}{l}\text { Responding to children's ability to } \\
\text { interpret pictures }\end{array}$ \\
\hline $\begin{array}{l}\text { Prompting } \\
\text { predictions }\end{array}$ & $\begin{array}{l}\text { Pentimonti et al., 2017; } \\
\text { Zurek, Torquati, \& Acar, } \\
2014\end{array}$ & $\begin{array}{l}\text { Prompting children to predict what } \\
\text { would happen next in the story }\end{array}$ \\
\hline $\begin{array}{l}\text { Narrowing } \\
\text { choices }\end{array}$ & Pentimonti et al., 2017 & Providing choice of answers \\
\hline $\begin{array}{l}\text { Validation } \\
\text { feedback }\end{array}$ & $\begin{array}{l}\text { Zurek, Torquati, \& Acar, } \\
2014\end{array}$ & $\begin{array}{l}\text { Acknowledging, praising } \\
\text { children's responses }\end{array}$ \\
\hline $\begin{array}{l}\text { Expansion/ } \\
\text { Teacher adds } \\
\text { information }\end{array}$ & $\begin{array}{l}\text { Zurek, Torquati, \& Acar, } \\
2014\end{array}$ & Adding ideas to the discussion \\
\hline $\begin{array}{l}\text { Co- } \\
\text { Participation }\end{array}$ & $\begin{array}{l}\text { Zurek, Torquati, \& Acar, } \\
2014\end{array}$ & Counting together \\
\hline $\begin{array}{l}\text { Attending to } \\
\text { print, picture } \\
\text { cues (concepts } \\
\text { of print) }\end{array}$ & Cole, 2006 & $\begin{array}{l}\text { Prompting children to notice } \\
\text { pictures, letters, words }\end{array}$ \\
\hline $\begin{array}{l}\text { Accessing prior } \\
\text { knowledge }\end{array}$ & Clark \& Graves, 2005 & Recalling earlier learning events \\
\hline
\end{tabular}




\section{VITA}

Germaine Ariel Robinson loves to confuse everyone by going by her middle name. Ariel was born in the Oklahoma Ozarks and is the girl part of a set of boy-girl twins. She grew up out west where she swam in the Pacific Ocean and learned to ski. She has loved to read since she was little and cried over the death of Charlotte the spider in Charlotte's Web many times as a child.

Ariel graduated from Torrey Pines High School in San Diego, California where some of her classrooms had an ocean view! She has been married to her husband, Christian, for 26 years and is the proud mother of two grown children, Hans and Rosie. She is also the happy owner of Jack, her Pomeranian-Chihuahua mix (so she was told by the Humane Society). Ariel earned a bachelor's in elementary education and master's with an endorsement in special reading from Columbia College in Columbia, Missouri. She holds teaching certifications in elementary and early childhood education. She was an early childhood teacher before pursuing her doctorate, in which she combined her love of literacy and early childhood education. She is now learning to quilt, grow better tomatoes, and perfect her baking skills. Ariel teaches at Stephens College in Columbia, Missouri. 